\title{
Ciliate Micrograzer Dynamics of the New England Shelf
}

\author{
by \\ Emily Fay Brownlee \\ B.A., Hood College, 2010 \\ Submitted in partial fulfillment of the requirements for the degree of \\ Doctor of Philosophy \\ at the \\ MASSACHUSETTS INSTITUTE OF TECHNOLOGY \\ and the \\ WOODS HOLE OCEANOGRAPHIC INSTITUTION
}

June 2017

(c) 2017 Emily F. Brownlee. All rights reserved.

The author hereby grants to MIT and WHOI permission to reproduce and to distribute publicly paper and electronic copies of this thesis document in whole or in part in any medium now known or hereafter created.

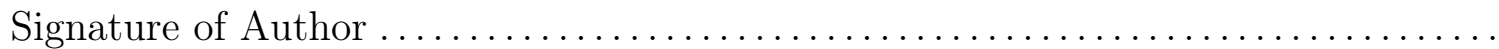

Joint Program in Oceanography / Applied Ocean Science and Engineering Massachusetts Institute of Technology and Woods Hole Oceanographic Institution

March 24, 2017

Certified by

Dr. Heidi M. Sosik

Senior Scientist, Woods Hole Oceanographic Institution

Thesis Supervisor

Accepted by

Dr. Ann Tarrant

Chair, Joint Committee for Biological Oceanography

Woods Hole Oceanographic Institution 


\title{
Ciliate Micrograzer Dynamics of the New England Shelf
}

\author{
by Emily Fay Brownlee
}

\begin{abstract}
Submitted to the MIT/WHOI Joint Program in Oceanography/Applied Ocean
Science and Engineering on March 24, 2017 in partial fulfillment of the requirements for the degree of Doctor of Philosophy in Biological Oceanography
\end{abstract}

\begin{abstract}
Protists play important roles in grazing and nutrient recycling, but quantifying these roles has been hindered by difficulties in collecting, culturing, and observing these often-delicate cells. During long-term deployments at the Martha's Vineyard Coastal Observatory (MVCO) (Massachusetts, USA), Imaging FlowCytobot (IFCB) made it possible to study live cells in situ without the need to culture or preserve. IFCB records images of cells with chlorophyll fluorescence above a trigger threshold, so taxonomically resolved analysis of protists is limited to mixotrophs and herbivores, which have eaten recently. To overcome this limitation, I coupled a broad-application 'live cell' fluorescent stain with a modified IFCB so that protists which do not contain chlorophyll (such as consumers of unpigmented bacteria and other heterotrophs) can also be recorded. Staining IFCB (IFCB-S) revealed higher abundances of grazers than the original IFCB, as well as some cell types not previously detected. To analyze a 10-year time series of herbivorous ciliates at MVCO and address broad patterns of seasonality of major ciliate classes and their components, I employed a statistical model that estimates a seasonal density pattern and simultaneously accounts for and separates any annual-scale effects. I describe the seasonality of three functional groups: a phototrophic ciliate, a mixotroph, and a group of strict heterotrophs, and comment on potential drivers of these patterns. DNA sequencing has also contributed to the study of protist communities, providing new insight into diversity, predator-prey interactions, and discrepancies between morphologically defined species and genotype. To explore how well IFCB images can be used to detect seasonal community change of the class Spirotrichea, an important and numerous group, I used high-throughput sequencing (HTS), which does not discriminate between chlorophyll-containing cells and the rest of the community. I report on species and genera of ciliates for which morphotype and genotype displayed high congruency. In comparing how well temporal aspects of genotypes and morphotypes correspond, I found that HTS was critical to detect and identify certain ciliates occupying a niche associated with warmer temperatures. I further showed that when these types of analyses are combined with IFCB results, they can provide hypotheses about food preferences.
\end{abstract}

Thesis Supervisor:

Dr. Heidi M. Sosik

Title: Senior Scientist, Woods Hole Oceanographic Institution 


\section{Acknowledgments}

This research was supported in part by NSF (grants OCE-1130140, OCE-1434440), NASA (grants NNX11AF07G and NNX13AC98G), the Gordon and Betty Moore Foundation (grants 934 and 2649), the Woods Hole Oceanographic Institution's Innovative Technology Program, student awards from the WHOI Ocean Ventures Fund and Hill Foundation Fund.

These last six and a half years have been full of scientific and self-discovery. I could not have pursued this adventure without a village of support. I'd like to thank all of these people.

To my advisor, Heidi, your guidance, patience, and belief in me is something I will always cherish and never forget. Apart from being an amazing advisor in a academic way (opening my eyes to diverse questions, guiding my writing, etc.), you also helped me with many life obstacles and stimulated me during my difficult moments. I am forever grateful I had you as role model throughout these years and for that I am a better scientist.

To Rob, thank you for taking a student who didn't even know how to use a drill under your wing. You taught me how to think about a problem and logically work out the steps to fix it. There was never an issue too large to handle and you were always there to tell me it was ok to spill water, as long as it was fresh.

To Becky, thank you for teaching me the ways of genetics and trusting me not to contaminate the stocks. Our conversations about the data and working together to figure out new types of analyses were invaluable.

Matt, I am so grateful for the discussions we had about ciliates and the lessons on picking cells. Thank you for showing me what a live Laboea strobila looks like and helping to contribute invaluable data to my thesis about Mesodinium spp.

Susanne, thank you for your insights and comments about my data. Your thoughts have given a new perspective for publication and discussion.

Penny, thank you for your interesting comments and views. Your advice about observational ecology helped to boost my confidence and direct my thoughts.

To Alexi, once again, no problem was ever too large for you to tackle. You were always there for both logistical help and insightful discussion. I am so grateful for all of the amazing work you do on the instruments.

Andy, thank you so much for your conversations about statistics with a student who feared models. Your invaluable help in creating the model allowed me to quantitatively assess seasonality, something that has been bothering me for a long time.

To Sam, thank you for chairing my defense and for all of the great and down to earth conversations we had. Allowing me to come along to the Arctic with you was an experience I will never forget and showed me the magic of bio-optical science. 
To past and current members of the Sosik Lab: Kristen, thank you for all of the 'check-ins' we had together. I would not have had such an enriching experience without your support, advice, and friendship. To Emily and Taylor, the lab cannot run without you as such I would not have been able to do my work without you. You both were there for great conversation, help with data and instrumentation, and tons of support. Joe, without you, we simply could not use our own data with the ease we have now. I will always cherish what you have brought to this lab and my experience with data management.

To the captains and crews of the R/V Tioga and the various NOAA ships that hosted IFCB14 and me, thank you for all of your hard work helping scientists reach their study sites with ease and making sure the science goes smoothly. Also to the MVCO Operations Team as our research endeavors at the tower would not be possible without you.

To my cohort, Katie, Harriet, Jeanette, Esther, Nicholas, Oscar, and Ellie, we started as a large class and finished together as a large class. From working on P-sets to dressing up on Halloween, our experiences have shaped my journey in more ways than I can describe.

To those in WHOI security and those working on the WHOI dock, in particular Norman and Linda, thank you for always having a smiling face during those late nights and long weekends on the dock. I always looked forward to coming in because I knew you would be there.

To the staff of Coffee O, thank you providing me with caffeine and fueling my work.

Members of APO, especially Julia, Meg, and Lea. We students cannot get through this program without the advice and support you provide.

To IFCB-14, its been a long ride my friend, keep enjoying your days at the dock and don't be too hard on Emily and Taylor. I look forward to hearing more about your adventures at sea.

To Rachel, your listening and advice were particularly valuable during some of the toughest times.

To my friends back home, in particular my Wifeys, Sammy, Alanna, Britt, and Ho-Ching. You guys keep me grounded and feeling loved. No matter how far apart, our friendship will always keep us together. Zach, thank you for the visits and the calls. You are my oldest friend and were always a listening ear when I needed it.

To Tony, my super awesome brother-in-law. You have been such a great source of humor, support, and family.

Dad and Melanie, your advice, kind words, and never-ending love are the kinds of things a grad student needs to do what they do. Dad, you taught me how to be a decent person, voice my thoughts, and appreciate the natural world. I will be forever thanking you for all that you have done and continue to do. I would not be here without you.

Mom and Kevin, how do I describe the mentorship, encouragement, and love you have given me over all these years? You have always showed me how proud you are and provided me 
with some of the greatest conversations about science, about life, and about how to properly clean things like a test tube or a kitchen sink. From a young age, you immersed me in the magic of science and I could not have done this without you.

Sarah, you are the best sister one could ask for. From sending me flowers around deadlines, listening to every idea in my head no matter how crazy, to making sure I never felt down, I could not have imagined tackling such a journey without you. We may be far apart, but you never let it feel that way. You have moved mountains to make sure that I got through this adventure and I can only dream to one day do as half as much as you have done for me.

To my animals, Maddie, Jaffe, and Banjo, you kept me grounded and your cuddles were more than I could have ever asked for.

And last but not least, my husband, Mark, we started this journey together on a ferry to the Vineyard. You asked me what I wanted in life and I said 'a Ph.D.'. You never let me forget that no matter how tough it got. You kept me fed, drove me to my instrument on the dock at midnight during a blizzard, and filled my life with art. It has been a long journey, but you never faltered and never stopped being there when I needed it. You have been the best companion, the best friend, and the best husband. You walked out on a limb with me six and a half years ago and for that I will be forever grateful. 


\section{Contents}

1 Introduction $\quad 17$

1.0.1 Evolution of methods to observe ciliates . . . . . . . . . . . . 18

1.0 .2 Time series . . . . . . . . . . . . . . . . . . . 21

1.0.3 Modern advancements in ciliate methods . . . . . . . . . . . . . . . 22

2 Microzooplankton community structure investigated with imaging flow $\begin{array}{ll}\text { cytometry and automated live-cell staining } & 25\end{array}$

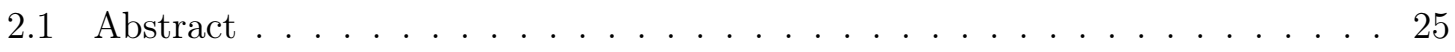

2.2 Introduction . . . . . . . . . . . . . . . . . 26

2.3 Materials and Methods . . . . . . . . . . . . . . . . . 28

2.3 .1 Instrument design $\ldots \ldots \ldots \ldots \ldots \ldots$

2.3.2 Staining validation . . . . . . . . . . . . . . . 29

$2.3 .3 \quad$ IFCB-S stain protocol . . . . . . . . . . . . . . . . . . . . . . . 29

2.3.4 Stain comparison . . . . . . . . . . . . . . . . . . . 29

2.3.5 Comparison with conventional microscopy . . . . . . . . . . 30

2.3.6 Comparison of detection between IFCB and IFCB-S . . . . . . . . 30

2.3.7 Automated classification of a time series . . . . . . . . . . . . . 31

2.4 Results . . . . . . . . . . . . . . . . . . . . . . 32

2.4 .1 Imaging of protozoa . . . . . . . . . . . . . . . . 32

2.4 .2 Performance of IFCB-S . . . . . . . . . . . . . . . . . . . 32

2.4 .3 Comparison of stains . . . . . . . . . . . . . . . 33

2.4.4 Determining stain protocols . . . . . . . . . . . . . . 33

2.4.5 Comparison of IFCB-S and manual microscopy . . . . . . . . . . . 34

2.4 .6 IFCB-S field application . . . . . . . . . . . . . . . 34 
2.4 .7 Automated classification . . . . . . . . . . . . . . 35

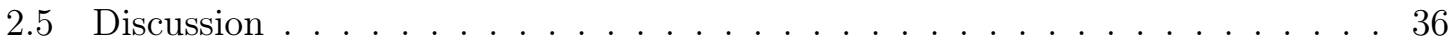

3 Seasonal dynamics of herbivorous ciliates from a 10-year time series 57

3.1 Introduction . . . . . . . . . . . . . . . . . 57

3.2 Materials and Methods . . . . . . . . . . . . . . . . . 60

3.2.1 Observations and study site . . . . . . . . . . . . 60

3.2.2 Manual image classification . . . . . . . . . . . . . . . . . . 62

3.2.3 Automated image classification . . . . . . . . . . . . . . . . . 62

3.2 .4 Data analysis . . . . . . . . . . . . . . . . . . . 64

3.2 .5 Time series model . . . . . . . . . . . . . . . . . . 64

3.3 Results . . . . . . . . . . . . . . . . . . . 67

3.3.1 Total ciliate concentration and biomass . . . . . . . . . . . 67

3.3 .2 Ciliate class seasonality . . . . . . . . . . . . 67

3.3.3 Ciliate size classes f . . . . . . . . . . . . . . . . . . . . . 68

3.3.4 Dominant known oligotrich: Laboea strobila . . . . . . . . . . . . . . . 68

3.3.5 Dominant known choreotrichs: tintinnids . . . . . . . . . . . . . . . 69

3.3.6 Dominant haptorid: Mesodinium spp. . . . . . . . . . . . 70

3.3.7 Environmental and prey conditions . . . . . . . . . . . 71

3.4 Discussion . . . . . . . . . . . . . . . . . . . . . 71

3.4.1 Herbivorous ciliate structure . . . . . . . . . . . . . . . . . 71

3.4 .2 Laboea strobila . . . . . . . . . . . . . . . . . . . . . 73

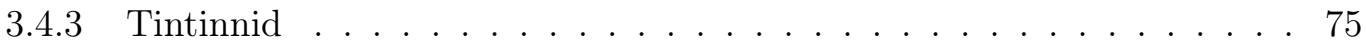

3.4.4 Mesodinium spp. ................... 76

3.4.5 Conclusions . . . . . . . . . . . . . . . . . . . . . 79

4 Seasonality in ciliate communities characterized by morphotype and geno$\begin{array}{ll}\text { type } & 113\end{array}$

4.1 Introduction . . . . . . . . . . . . . . . . . . . . 113

4.2 Materials and Methods . . . . . . . . . . . . . . . . 115

4.2 .1 Sample collection . . . . . . . . . . . . . . . . . . 115

4.2 .2 Manual image classification . . . . . . . . . . . . . . . . . 116

4.2 .3 DNA extraction . . . . . . . . . . . . . . . . . . 117 
4.2 .4 DNA amplification . . . . . . . . . . . . . . . . . 117

4.2 .5 Data preparation . . . . . . . . . . . . . . . . 118

4.2 .6 Multivariate analyses . . . . . . . . . . . . . . . . . 118

4.2.7 Mesodinium spp. amplification and sequencing . . . . . . . . . . 120

4.3 Results . . . . . . . . . . . . . . . . . . . . 120

4.3.1 Spirotrich composition . . . . . . . . . . . . . . . 120

4.3.2 Spirotrich relationship with temperature . . . . . . . . . . . . . . 121

4.3.3 Genotype and morphotype comparisons . . . . . . . . . . . . . 123

4.3.4 Mesodinium spp. subclades . . . . . . . . . . . . . . . . . . . 124

4.4 Discussion . . . . . . . . . . . . . . . . . . . . . . . 125

4.4.1 Beta diversity between temperature regimes . . . . . . . . . . . . 126

4.4.2 Genotype and morphotype comparisons . . . . . . . . . . . . 127

4.4.3 Mesodinium spp. genetic and morphological variations . . . . . . . . 130

4.4 .4 Conclusions . . . . . . . . . . . . . . . . . . . . . . . 131

5 Conclusions and future directions $\quad 151$

5.1 Thesis summary . . . . . . . . . . . . . . . . . . 151

5.2 Conclusions and future directions . . . . . . . . . . . . . . 155

$\begin{array}{ll}\text { A Appendix } & 157\end{array}$

A.1 Appendix for Chapter $3 \ldots \ldots \ldots \ldots \ldots$

A.2 Appendix for Chapter $4 \ldots \ldots \ldots \ldots$. . . . . . . . . . . . . . . . . . . . 


\section{List of Figures}

2-1 Schema of fluidics for IFCB-S . . . . . . . . . . . . . . . . 44

2-2 Schema of optical layouts for IFCB-S . . . . . . . . . . . . . . . 45

2-3 Example images of ciliates with IFCB $\ldots \ldots \ldots$

2-4 Example images of heterotrophic dinoflagellates with IFCB . . . . . . . . 47

$2-5 \quad$ FDA staining validation $\ldots \ldots \ldots \ldots \ldots$

2-6 Comparison between FDA and LTG . . . . . . . . . . . . . . . . . . 49

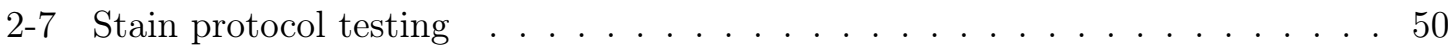

2-8 Seasonal comparisons between manual microscopy and IFCB-S . . . . . . . . 51

2-9 OKEX cruise comparison between staining and non-staining on IFCB-S . . . 52

2-10 Tintinnid abundances observed on OKEX cruise between IFCB-S and a standard IFCB . . . . . . . . . . . . . . . . . . . . . 53

2-11 Indicators for optimal threshold use in automated classification for Laboea

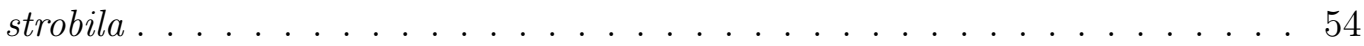

2-12 Comparison between automated and manual classification for Laboea strobila 55

2-13 Multiyear records of Laboea strobila concentrations . . . . . . . . . . . . . . . 56

3-1 Example images of all ciliate categories . . . . . . . . . . . . . . . . 82

$3-2$ Total ciliate abundance and biomass . . . . . . . . . . . . . . 83

3-3 Total ciliate expected seasonal cell concentration and annual multipliers . . . 84

3-4 Ciliate group expected seasonal cell concentrations and annual multipliers . . 85

3-5 Mean annual pattern of size class contribution to total ciliate abundance and

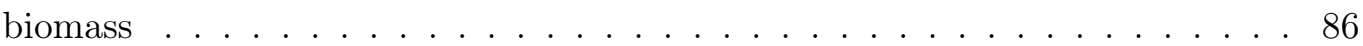

3-6 Time series of size classes contribution to total ciliate abundance and biomass 87

$3-7$ Ciliate class size histogram . . . . . . . . . . . . . . . . . 88

3-8 Size distributions of selected ciliate groups by season . . . . . . . . . . . . 89 
3-9 Comparison between automated and manual classification for Laboea strobila 90

3-10 Laboea strobila expected seasonal cell concentration and annual multipliers . . 91

3-11 Laboea strobila concentration by year . . . . . . . . . . . . . . . . . . 92

3-12 Comparison between automated and manual classification for total Tintinnids 93

3-13 Total tintinnid expected seasonal cell concentration and annual multipliers . . 94

3-14 Total tintinnid concentration by year . . . . . . . . . . . . . 95

3-15 Tintinnid group expected seasonal cell concentration . . . . . . . . . . 9 96

3-16 Multiyear records of tintinnid group concentrations . . . . . . . . . . . 97

3-17 Comparison between automated and manual classification for Mesodinium spp. 98

3-18 Mesodinium spp. expected seasonal cell concentration and annual multipliers 99

3-19 Total Mesodinium spp. concentration by year . . . . . . . . . . . . 100

3-20 Time series of Mesodinium spp. cell sizes . . . . . . . . . . . . . . . . 101

3-21 Mesodinium spp. size class expected seasonal cell concentration and annual multipliers . . . . . . . . . . . . . . . . . . . . . 102

3-22 Mesodinium spp. daily size mode versus temperature . . . . . . . . . . 103

3-23 Mean seasonal pattern of temperature and daily solar radiation . . . . . . . 104

3-24 Plankton group expected seasonal cell concentrations . . . . . . . . . . . . 105

3-25 Springtime Laboea strobila and 2-10 $\mu \mathrm{m}$ eukaryote cell concentrations . . . . . 107

3-26 Relationship between total tintinnid concentration and picophytoplankton concentration . . . . . . . . . . . . . . . . . 108

3-27 Relationship between total tintinnid concentration and 2-10 $\mu \mathrm{m}$ eukaryotic phytoplankton concentration . . . . . . . . . . . . . . . 109

3-28 Proportion of large Mesodinium spp. $(>20 \mu \mathrm{m})$ in response to nitrate and nitrite concentrations $(\mu \mathrm{M}) \ldots \ldots \ldots$

3-29 Proportion of large Mesodinium spp. $(>20 \mu \mathrm{m})$ in response to the temperature cycle . . . . . . . . . . . . . . . . . . . . . . 111

3-30 Mean seasonal pattern of water temperature and Mesodinium spp. size class contribution to total abundance. . . . . . . . . . . . . . . . 112

$4-1 \quad$ Example images of Spirotrich ciliates . . . . . . . . . . . . . . . 134

4-2 Tintinnopsis size class example images . . . . . . . . . . . . . . . 135

4-3 'Miscellaneous spirotrichs' size class example images . . . . . . . . . . . . 136 
4-4 NMDS of ciliate OTUs based on Bray-Curtis similarity matrices . . . . . . . 137

4-5 NMDS of ciliate cell concentrations based on Bray-Curtis similarity matrices . 138

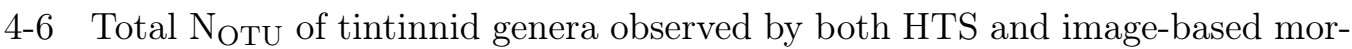
phology . . . . . . . . . . . . . . . . . . . . 139

4-7 Time series comparing $\mathrm{C}_{\mathrm{IFCB}}$ and $\mathrm{N}_{\mathrm{OTU}}$ of tintinnid genera . . . . . . . 140

4-8 Time series of $\mathrm{N}_{\mathrm{OTU}}$ for tintinnid genera not resolved in IFCB sampling $\ldots 141$

4-9 Time series comparing $\mathrm{N}_{\mathrm{OTU}}$ and $\mathrm{C}_{\mathrm{IFCB}}$ for the genus Eutintinnus . . . . . 142

4-10 Time series comparing $\mathrm{C}_{\mathrm{IFCB}}$ and $\mathrm{N}_{\mathrm{OTU}}$ of commonly defined species detected by both HTS and image-based morphology . . . . . . . . . . . . . . . . 143

4-11 Time series comparing $\mathrm{C}_{\mathrm{IFCB}}$ and $\mathrm{N}_{\mathrm{OTU}}$ of Tintinnopsis species detected from HTS and Tintinnopsis size classes from image-based morphology . . . . . . . 144

4-12 Mesodinium spp. subclade relationship to size and water temperature . . . . 145

A-1 Indicators for optimal threshold use in automated image classification for total tintinnids f . . . . . . . . . . . . . . . . . . . . 159

A-2 Indicators for optimal threshold use in automated image classification for Mesodinium spp. . . . . . . . . . . . . . . . . . . . . 160

A-3 Two-week resolved Laboea strobila anomalies by year . . . . . . . . . . . . . . 162

A-4 Two-week resolved total tintinnid anomalies by year . . . . . . . . . . . 163

A-5 Two-week resolved Mesodinium spp. anomalies by year . . . . . . . . . . . . 164

A-6 Weekly resolved temperature anomalies by year . . . . . . . . . . . . 165

A-7 Zoomed in NMDS of ciliate cell concentrations based on Bray-Curtis similarity matrices . . . . . . . . . . . . . . . . . . 167

A-8 Water temperature record from 2013-2016. . . . . . . . . . . . 168 


\section{List of Tables}

3.1 Biomass and abundance ranges and average temperature for ciliate groups . . 106

4.1 List of ciliates identified from IFCB images in the subclasses Oligotrichia and Choreotrichia . . . . . . . . . . . . . . . . . 146

4.2 ANOSIM results for HTS and image-based morphology . . . . . . . . . . . 147

4.3 SIMPER results for HTS . . . . . . . . . . . . . . . . . . . . . . . 148

4.4 SIMPER results for image-based morphology . . . . . . . . . . . . . . . . 149 


\section{Chapter 1}

\section{Introduction}

In marine ecosystems, the flow of energy is a complex and integral part of aquatic life. The classic marine food chain describes the flow of carbon as a linear system, transferring directly from smaller to larger organisms through consumption. In contrast, the microbial loop represents a more circuitous path, in which dissolved organic matter (DOM) is a major energy source moving through multiple trophic levels. DOM, which originates from a large pool of organisms from many trophic levels is consumed by heterotrophic bacteria. This DOM is transformed into bacterial biomass, then consumed by heterotrophic protists, which then continue contributing to the original pool of DOM. The heterotrophic protists also participate in the traditional marine food web when zooplankton graze upon them.

A major component of both pathways are ciliate micrograzers. Belonging to the microzooplankton, ciliates are protists between 20 and $200 \mu \mathrm{m}$ in size with organelles called cilia, used for feeding, small scale locomotion, attachment, and sensory processes. This important group of protists are common in both freshwater and marine ecosystems. When ciliates first made their way onto the aquatic research stage, taxonomy was most emphasized, and their ecological importance was not heavily studied. Eventually, when Pomeroy (1974) and Azam et al. (1983) challenged the typical view of the marine food web and described the microbial loop, ciliates were found to play a pivotal position in nutrient regeneration (Finlay and Fenchel 1996) and how it effects bacterial communities. They are top predators in the microbial loop, creating links between bacteria, smaller autotrophs, and higher order predators such as copepods, transferring carbon up the food web (Berk et al. 1977, Perez et al. 1997). 
Ciliates exhibit a wide variety of functionalities ranging from strict heterotrophs to essentially phototrophs with an array in between. This complexity is extended because various functional types can occur within the same size class and confound the use of size as proxy for function. On one end of the spectrum, strictly heterotrophic ciliates receive their nutrition solely through phagotrophy on a wide variety of prey: autotrophs, bacteria, and even other ciliates (Dolan, 1991a). Heterotrophy can also be combined with photosynthetic capabilities when food conditions are poor, a functional mode called mixotrophy. These ciliates ingest algal cells and retain functional chloroplasts for photosynthesis (Stoecker et al., 1987, 1988, 1989a). The mixotrophic middle ground represents a flexible means for acquiring energy in which many ciliates exhibit. This has major implications for food webs as mixotrophs contribute to both secondary and primary production. Mixotrophs can represent a competitive advantage over heterotrophs in oligotrophic environments. This functional group may also be responsible for decreasing the number of trophic transfers in planktonic food chains especially if they are large-celled taxa (i.e. Laboea strobila) (Blackbourn et al., 1973; McManus \& Fuhrman, 1986). On the opposite end of the spectrum, the ciliate, Mesodinium spp. is essentially a phototroph that only acquires its energy through photosynthesis by sequestering chloroplasts and retaining transcriptively active nuclei from cryptophyte prey (Gustafson et al., 2000; Johnson et al., 2007). In high enough numbers, Mesodinium spp. can cause red tides and be a dominant source of chlorophyll (McAlice, 1968; White et al., 1977; Lindholm, 1978; Smith \& Barber, 1979). Understanding these functional groups is important for study of the traditional food web and microbial loop.

\subsubsection{Evolution of methods to observe ciliates}

The historical perspective on ciliate studies provides insight into the evolution of modern techniques. Dolan et al. (2012) provides an excellent history of ciliate studies with particular emphasis on tintinnids, and references pertaining to ciliate history up until the late 20th century can be found therein. In the 18th and early 19th centuries, taxonomy of ciliates was most heavily explored, but once ciliates were maintained in culture, initial observations of life history and feeding were advanced (Faure-Fremiet 1908 provided the first detailed report of a tintinnid in culture). Culturing, though, is notoriously difficult as ciliates have complex needs and often prove challenging to isolate and maintain (Gifford, 1985).

During the late 19th and early 20th centuries, studies began to focus on the open ocean, 
a previously unexplored new environment for planktonic ciliates. Though their importance at the base of the food chain was suggested, it was not until the late 20th century that focus turned toward ecological studies and the role ciliates play in marine food webs. Issues arose, however, because net sampling typically used to study zooplankton missed the microzooplankton community (Banse, 1962). Eventually field studies along the California coast, with size-fractionated sampling, provided quantitative evidence of the importance of microzooplankton to total plankton biomass (Beers \& Stewart, 1967, 1969), though even these observations suffer from limitations. While-size fractionated counts can provide insight into the contributions of size classes to overall biomass, they can underestimate the importance of microzooplankton to the grazing community (especially aloricate ciliates). For example, Smetacek (1981) observed that tintinnids only dominated when samples were concentrated with $20 \mu \mathrm{m}$ gauze, indicating that aloricated ciliates were slipping through the mesh.

Since the 1960's, preferred sampling changed to analyzing whole water samples, but still the conventional approaches of staining and preservation added more complexities to quantifying ciliates. While Lugol's iodine is useful for long-term preservation and counting and allowed researchers to estimate the numerical contribution of ciliates, it can distort and damage cells. This may lead to underestimation of abundance and biomass and interfere with taxonomic identification (Stoecker et al., 1994). Lugol's iodine can also make it difficult to detect chlorophyll fluorescence, thus not allowing for identification of herbivorous or mixotrophic ciliates separate from carnivorous or bacterivorous ones. Even glutaraldehyde and formalin, which allow for the identification of chlorophyll fluorescence, caused shrinkage and swelling of ciliate cells (Wiackowski et al., 1994).

Once the importance of ciliates in the microbial loop was established, intricate studies on grazing and growth were more heavily emphasized than those quantifying and identifying ciliates. Advanced methods were developed to provide perspective on protistan grazing rates and trophic interactions through observations of natural populations, tracer techniques, and large-scale community manipulations. In situ grazing was estimated through the frequency of dividing cells (FDC) technique introduced by Sherr \& Sherr (1983), which incorporated fluorescent staining. With this technique, bacterial cells were stained and consumed by protists, allowing for quantification of grazing. This revolutionized the study of protists grazing on pico-sized cells, but certain assumptions about the prey community could at times lead to biased results (Neuer, 1992). In situ observations of food vacuole contents were 
also used to estimate ingestion by phagotrophic ciliates (Bernard \& Rassoulzadegan, 1990; Dolan \& Coats, 1991). This method only works if there can be an accurate assessment of average number of prey consumed by each predator (i.e., no loss of vacuole contents through preservation) (Sieracki et al., 1987) and if the rate of prey digestion can be determined experimentally (Sherr et al., 1988; Bernard \& Rassoulzadegan, 1990; Dolan \& Coats, 1991). Though they present certain limitations, these in situ experiments provided much insight into the potential effects microzooplankton grazing can have on the phytoplankton and bacterial communities.

Radioisotope labeling of potential prey allowed for sensitive detection of significant grazing by microzooplankton (Lessard \& Swift, 1985). Uptake of tracers specific to different prey could be measured in predator communities. Though this is a powerful technique for studying differential grazing, limitations in the form of tracer cycling throughout the predator and prey communities complicates interpretations (Caron et al., 1993). With the use of fluorescently labeled prey (FLP), Sherr \& Sherr (1987) proved previous studies were underestimating the rates of bacterivory by pelagic ciliates by 10-100 times. The advantages of using the FLP technique were widespread and allowed for visual confirmation of phagotrophic activity by a wide variety of microzooplankton types (Sanders et al., 1989), confirmation of size-dependency of prey selection (Gonzalez et al., 1990), and evidence of mixotrophy (Porter, 1988).

One of the most important techniques for studying community impacts of grazing is dilution studies (Landry \& Hassett, 1982). This technique allowed researchers to measure growth and mortality rates of photoautotrophic populations through a series of incubated diluted seawater samples. While these dilution studies remain an important approach, bottle effects and other growth uncertainties associated with dilution can occur as the studies are not in situ (Dolan et al., 2000; Calbet \& Landry, 2004; Calbet et al., 2011; Calbet \& Saiz, 2013). Inherent problems also arise with studying cultures, as organisms may behave differently when not in situ. Landry (1994) suggested 'hybrid' techniques, which combine many of these historical methods, are needed to overcome some of the inherent limitations and to control for critical assumptions. 


\subsubsection{Time series}

Ciliates, due to their fast generation times, can be tightly coupled with the dynamics of their prey and graze as quickly as their prey grow (hours to days) (Sherr \& Sherr, 1994; Strom et al., 2007). Evans and Parslow (1985), used a nutrient-phytoplankton-zooplankton (NPZ) model to show that protist grazing (when coupled with phytoplankton growth) could be powerful enough to suppress the spring bloom. Similarly, Behrenfeld (2010) suggested interruptions in grazing pressure could initiate the North Atlantic spring bloom. Not only is grazing on phytoplankton important, but ciliates are also known to graze on smaller heterotrophs, such as nanoflagellates and bacteria. Ciliates can also exhibit mixotrophy and at times can contribute significant amounts to total primary production (Smith \& Barber, 1979; Putt, 1990a; Stoecker \& Michaels, 1991; Sanders, 1995). Their ability to be either heterotrophic or mixotrophic allows for an interesting system to be studied in response to environmental conditions as well as biological ones. As ciliates can fill different niches and contribute to both the classic food web and the microbial loop, the ability to study these organisms quantitatively in nature over time is imperative.

As the transfer of carbon may be affected by warming climates, the study of this key trophic level in changing environments is essential. Time series are powerful ways to understand these effects. Time series, while increasing in number, have just recently been emphasized. They serve as an essential baseline to compare the effects of a changing climate. But, for time series, there are typically tradeoffs between resolution and length of sampling.

Limited sampling resolution can present many challenges for studying plankton populations because these communities have been observed to fluctuate rapidly. Pierce \& Turner (1994) found high fluctuations in tintinnid abundance in Buzzards Bay, MA both spatially and temporally; communities could change an order of magnitude between stations (a few kilometers) and over 2-week periods. Ciliates, with their short generation times, are quick to respond to optimal environmental conditions and couple their abundance with that of their prey. Because ciliates exhibit rapid regeneration times, ciliates can display several successional patterns of dominant genera in a short period of time. For these reasons, following their dynamics with high resolution is important. These short, successional patterns have also been captured in other regions (Morales, 1976; Montagnes et al., 1988; Graziano, 1989), 
where large fluctuations of abundance suggested that substantial patchiness is superimposed on seasonal signals. Furthermore, many time series have had to be pieced together with different methodologies (Moe et al., 2008; Olli et al., 2013), which can introduce inconsistencies in the data synthesis and interpretation.

\subsubsection{Modern advancements in ciliate methods}

Recent advances in DNA-based assessments now make it possible to study which ciliates are present in the environment with taxonomic detail. With the introduction of high throughput sequencing, we can study ciliate genetic diversity and dynamics in natural communities. Ciliates are unique in that they exhibit nuclear dualism, containing a macronucleus and micronucleus. This allows for an abundance of nuclear material to be sequenced and studied. Ciliates are also one of the most diverse protist clades in aquatic ecoysystems (de Vargas et al., 2015; Hu et al., 2016), making them an important target for understanding community dynamics and ecosystem functioning. Recently, Gimmler et al. (2016), during the Tara Oceans voyage, documented large diversity of ciliates in the world's oceans. Notably, more than half of the ciliate OTUs documented shared less than $90 \%$ sequence similarity to reference sequences, indicating a vast amount of unknown diversity. Similarly, Agatha (2011) suggested that more than $83-89 \%$ of the morphospecies of aloricate Oligotrichia (a dominant planktonic ciliate group) are unknown. It is therefore important to combine information about genetic and morphological diversity to investigate these uncertainties. This is further supported by Katz et al. (2005) who reported high levels of cryptic diversity in certain species, but low genetic diversity in other morphospecies (i.e., Laboea strobila).

Ciliates provide a unique opportunity for studying genetic versus morphological patterns, though to date this has only rarely been attempted and never done for extended (multi-year) time series. Tintinnids, in particular, because of their distinct, but diverse morphology, are a model group for these 'hybrid' studies (Santoferrara et al., 2012, 2016). Mesodinium spp., the autotrophic ciliate, presents cryptic diversity (Garcia-Cuetos et al., 2012a; Johnson et al., 2016) through a species complex of 8 different subclades, but contrastingly also presents various morphologies.

In addition to sequencing approaches, other recent advances make this an opportune time to undertake such studies. The Imaging FlowCytobot, developed at the Woods Hole Oceanographic Institution, is an automated underwater cytometer that can study microplankton 
in situ without the need to culture or preserve. It can also sample with high temporal resolution, as well as over a long period of time. The goal of my thesis is to observe ciliate communities over time through automated imaging and molecular analyses to provide insights into seasonality and how various groups of ciliates respond to environmental and ecological conditions. To do this, I have focused on the ciliate communities of the New England shelf at the Martha's Vineyard Coastal Observatory (MVCO).

In Chapter 2, I describe an updated Imaging FlowCytobot with automated staining capabilities (IFCB-S) that allows us to observe live ciliates, whether or not they exhibit chlorophyll fluorescence. I show applications of this instrument in various laboratory and field settings. In Chapter 3, I apply a statistical model to a ten-year time series (at a resolution of two weeks) of herbivorous ciliates at MVCO to investigate seasonality and multi-year trends. I focus on a subset of functional groups (an obligate mixotroph, a phototrophic ciliate, and a group of strict heterotrophs). In Chapter 4, I explore seasonality in taxonomic information from high throughput sequencing over three years and compare patterns between genotypes and morphotypes. In Chapter 5, I summarize my findings, provide hypotheses drawn from them, and comment on future studies. 


\section{Chapter 2}

\section{Microzooplankton community}

\section{structure investigated with imaging}

\section{flow cytometry and automated}

\section{live-cell staining}

Emily F. Brownlee ${ }^{1,2}$, Robert J. Olson ${ }^{2}$, Heidi M. Sosik ${ }^{2}$

${ }^{1}$ MIT-WHOI Joint Program in Oceanography/Applied Ocean Science and Engineering, Cambridge, MA 02142, USA

${ }^{2}$ Biology Department, Woods Hole Oceanographic Institution, Woods Hole, MA 02543, USA

Available online: Brownlee, E.F., R.J. Olson, H.M. Sosik. 2016. Microzooplankton community structure investigated with imaging flow cytometry and automated live-cell staining. Marine Ecology Progress Series. 550:65-81. doi:10.3354/meps11687

\section{$2.1 \quad$ Abstract}

Protozoa play important roles in grazing and nutrient recycling, but quantifying these roles has been hindered by difficulties in collecting, culturing, and observing these often-delicate cells. During long-term deployments at the Martha's Vineyard Coastal Observatory (Massachusetts, USA), Imaging FlowCytobot (IFCB) has been shown to be useful for studying 
live cells in situ without the need to culture or preserve. IFCB records images of cells with chlorophyll fluorescence above a trigger threshold, so to date taxonomically resolved analysis of protozoa has presumably been limited to mixotrophs and herbivores which have eaten recently. To overcome this limitation, we have coupled a broad-application 'live cell' fluorescent stain with a modified IFCB so that protozoa which do not contain chlorophyll (such as consumers of unpigmented bacteria and other heterotrophs) can also be recorded. Staining IFCB (IFCB-S) revealed higher abundances of grazers than the original IFCB, as well as some cell types not previously detected. Feeding habits of certain morphotypes could be inferred from their fluorescence properties: grazers with stain fluorescence but without chlorophyll cannot be mixotrophs, but could be either starving or feeding on heterotrophs. Comparisons between cell counts for IFCB-S and manual light microscopy of Lugol's stained samples showed consistently similar or higher counts from IFCB-S. We show how automated classification through the extraction of image features and application of a machine-learning algorithm can be used to evaluate the large high-resolution data sets collected by IFCBs; the results reveal varying seasonal patterns in abundance among groups of protists.

\subsection{Introduction}

Heterotrophic protists are significant in marine ecosystems; they mediate top-down control of primary producers, as well as playing central roles in the microbial loop and food web (Heinbokel \& Beers, 1979; Lessard \& Swift, 1985; Jacobson, 1987; Verity, 1985; Stoecker \& Capuzzo, 1990; Bjørnsen \& Kuparinen, 1991; Hansen, 1991; Verity, 1991). These microzooplankton have not been studied as extensively as other plankton, however, because it is typically time-consuming and difficult to enumerate and identify them. Many are fragile and net collection can be harmful to their structure. Furthermore, their soft bodies make preservation difficult due to shrinkage and distortion or disintegration (Stoecker et al., 1994). Certain types of preservation can also lead to lysis and egestion of food vacuole contents Sieracki et al. (1987). Protozoa are challenging to culture due to their complex nutritional needs. Because of these difficulties, long-term, high-resolution data sets are rare. This limits our ability to characterize how their abundance and community structure respond to natural variations such as seasonality and longer-term trends associated with environmental and climate change. 
New technology that combines microscopy and flow cytometry promises to overcome some of these observational challenges by enabling high temporal resolution sampling for long periods of time. Imaging FlowCytobot (IFCB), which uses laser-induced fluorescence to trigger capture of images of individual plankton, is one such system (Olson \& Sosik, 2007). While IFCB was originally designed to characterize phytoplankton, it can also be used to study herbivorous and mixotrophic protozoa in situ without the need to culture or preserve. Herbivorous protozoa ingest phytoplankton that can continue to fluoresce inside food vacuoles. Kleptoplastidic and mixotrophic protozoa are also fluorescent because they retain functional chloroplasts to supplement their nutrition.

Complete protozoan assemblages are traditionally counted and identified by epifluorescence microscopy of samples stained with protein or nucleic acid stains. These traditional methods quantify not only herbivorous microzooplankton, but also those grazing on non-chlorophyll-containing cells. To observe the complete heterotroph community, imaging methods must employ triggering on a property common to all grazers. Such triggering can be provided by 'live cell' fluorescent stains such as LysoTracker ${ }^{\circledR}$ Green (LTG) (Molecular Probes) or fluorescein diacetate (FDA) (Sigma-Aldrich). FDA permeates the cell to fluoresce in the presence of enzymatic activity. LTG accumulates within acidic food vacuoles so actively grazing protists can be distinguished. These stains accumulate within living cells to provide high signal-to-noise. Phototrophs can take up stain, but in cytometric analyses they can be differentiated from heterotrophs by their relatively high levels of red auto fluorescence from chlorophyll. Heterotrophs with chloroplasts in their food vacuoles may also express red autofluorescence, but typically at lower levels than autotrophs of similar size. Since IFCB is normally limited to detecting herbivorous or mixotrophic protozoa, the use of a stain to view a more complete community represents a powerful advance for this observational technique.

Here we use ciliate cultures and environmental samples to demonstrate the capabilities and performance of an IFCB modified for automated staining (IFCB-S). We also demonstrate the use of automated classification to analyze the resulting large data sets. We find automated imaging with the addition of staining allows for detection of a greater number and diversity of grazers and may also provide insight into feeding habits. 


\subsection{Materials and Methods}

\subsubsection{Instrument design}

We modified a standard IFCB to carry out automated staining and incorporated optical components that enable it to detect either orange (as from phycoerythrin, PE) or green (stain) fluorescence, in addition to chlorophyll fluorescence. The optical and fluidic design for IFCB has been described in detail in Olson \& Sosik (2007). A sample (typically $5 \mathrm{ml}$ ) is drawn into the instrument by a programmable syringe pump. The sample water is injected into the center of a particle-free sheath flow in the cone above a rectangular quartz flow cell. In the standard IFCB, seawater is drawn into a sample syringe and then injected directly into the cone through a needle; after the flow cell, particles are removed by passage through cartridge filters to regenerate sheath fluid. For IFCB-S, we added new fluidics control features utilizing IFCB's distribution valve and new solenoid valves (100T2NC24$62-4 \mathrm{E}$, Bio-Chem Valve) to allow for automated addition of stain, as well as for discarding sheath fluid during stained sample analysis (to prevent accumulation ofstain in the system). Staining is carried out in a mixing chamber (a $50 \mathrm{ml}$ Falcon tube fitted with plumbing) connected to an extra port on the valve. First, a microinjector (120SP2420-4EE, Bio-Chem Valve) adds $20 \mu \mathrm{l}$ of concentrated stain to the empty chamber. Then the seawater sample is pushed through the distribution valve into the mixing chamber, where it mixes with the stain and incubates (typically for $30 \mathrm{~s}$ ) before being pulled back into the sample syringe and sent through the flow cell for analysis (Fig. 2-1).

Standard IFCB excites chlorophyll fluorescence with a $635 \mathrm{~nm}$ diode laser (details in Olson \& Sosik 2007). As a particle passes through the focused laser, laser light is scattered and chlorophyll-containing cells emit red fluorescence $(680 \mathrm{~nm})$. One (or more) of these signals, usually chlorophyll fluorescence, is used to trigger a $1 \mu$ s pulse from a xenon flash lamp. The green component of the lamplight is isolated by a bandpass filter and used for the camera exposure. Dichroic mirrors separate the wavelengths used to detect chlorophyll fluorescence and side scattering (680 nm and $635 \mathrm{~nm}$, respectively). In the modified optics for IFCB-S (Fig. 2-2), the $635 \mathrm{~nm}$ laser is replaced by a $508 \mathrm{~nm}$ diode laser (Power Technology, model PM20(510-50)G4, $20 \mathrm{~mW}$ ) that can excite fluorescence from the stain (530 nm), as well as from chlorophyll $(680 \mathrm{~nm})$ and phycoerythrin $(575 \mathrm{~nm})$. A $488 \mathrm{~nm}$ laser can also be used for this set-up, though it utilizes more power than the $508 \mathrm{~nm}$ laser. In this case, a 
$570 \mathrm{~nm}$ shortpass filter is inserted before the photomultiplier tube that detects PE because $488 \mathrm{~nm}$ excitation causes Raman scattering from water at $\sim 590 \mathrm{~nm}$. We incorporated an automated optical filter slider making it possible to detect either orange (PE) fluorescence for unstained samples or green (stain) fluorescence for stained samples. To detect stain fluorescence, IFCB-S uses a 'double dichroic' (Omega Optical, 595 DMSP), which transmits light between 560 and $595 \mathrm{~nm}$ to the camera and reflects light below and above this band to the photomultiplier tubes. To detect PE fluorescence (when samples are not stained), IFCB-S uses a 555 DMSP, which transmits 530 to $570 \mathrm{~nm}$ and reflects longer wavelengths.

\subsubsection{Staining validation}

We used a cultured marine bacterivorous scuticociliate (Uronema marinum, isolated from Buzzards Bay, MA, in 1986; D. Caron pers. comm.) to evaluate initial IFCB-S performance. Cultures were maintained at $15^{\circ} \mathrm{C}$ on a $14: 10 \mathrm{~h}$ light:dark cycle and transferred weekly into $40 \mathrm{ml}$ sterile filtered seawater with 1 drop yeast extract and 2 rice grains. As a control, scuticociliate cells were imaged with IFCB-S triggering on scattering to ensure detection of all cells. To evaluate stain detection, cells were then analyzed with IFCB-S triggering only on stain fluorescence with and without stain added.

\subsubsection{IFCB-S stain protocol}

To select an appropriate stain concentration, various stock stain concentrations $(0,0.01$, 0.05, 0.1, 1, $2 \mathrm{mg} \mathrm{FDA} \mathrm{ml} \mathrm{ml}^{-1}$ acetone) were tested on a scuticociliate culture analyzed with IFCB-S triggering on stain fluorescence. As a control, an unstained sample (stock stain concentration of $0 \mathrm{mg} F D A \mathrm{ml}^{-1}$ acetone) was triggered on scattering. For each stock concentration, we added $8 \mu \mathrm{l}$ of stain to a $2 \mathrm{ml}$ sample prior to analysis on IFCB-S. This resulted in final stain concentrations of $0,0.04,0.2,0.4,4$, and $8 \mu \mathrm{g} \mathrm{FDA} \mathrm{ml}{ }^{-1}$. Once a final stain concentration was chosen, an additional $5 \mathrm{ml}$ sample of scuticociliate culture was stained and analyzed with triggering on stain fluorescence to determine if stain fluorescence values are stable over the time course of analysis (20 min).

\subsubsection{Stain comparison}

To compare detection efficiency between LTG and FDA, scuticociliate cultures were sampled daily during batch growth, and cell counts were determined with a FACSCalibur $^{T M}$ flow 
cytometer. Each day the scuticociliate culture was analyzed 3 ways; unstained and triggering on side scattering, stained with LTG and triggered on stain fluorescence, and stained with FDA and triggered on stain fluorescence. We withdrew $2 \mathrm{ml}$ subsamples of the culture and added either $8 \mu \mathrm{l}$ of FDA solution $\left(1 \mathrm{mg} \mathrm{ml}{ }^{-1}\right.$ stock solution in acetone for a final concentration of $4 \mu \mathrm{g} \mathrm{m}^{-1}$ ) or $1.25 \mu \mathrm{l}$ of LTG solution ( $1 \mathrm{mM}$ stock diluted to $12 \mu \mathrm{M}$ working stock for a final stain concentration of $75 \mathrm{nM}$ ). For each run through the FACSCalibur, 120 $\mu \mathrm{l}$ was analyzed over 2 min.

\subsubsection{Comparison with conventional microscopy}

Seawater samples were collected from Woods Hole Harbor (Massachusetts, USA). Samples were kept at in situ temperature for approximately $6 \mathrm{~h}$ while aliquots were taken for analysis on IFCB-S in staining and non-staining modes $(50 \mathrm{ml}$ were analyzed in total by pooling results from ten $5 \mathrm{ml}$ subsamples). For manual microscopic counts, $200 \mathrm{ml}$ of the sample was fixed with $10 \mathrm{ml}$ acid Lugol's solution (final concentration 5\%, modified from Throndsen (1978)). Acid Lugol's-fixed samples (50 ml) were settled for $24 \mathrm{~h}$ in Utermohl chambers and cells were subsequently enumerated under a Zeiss Axiovert S100 inverted microscope at 40X magnification.

Microzooplankton counts from manual light microscopy were compared to those from IFCB-S in staining mode (triggering on chlorophyll and stain fluorescence) and IFCB-S in non-staining mode (triggering on chlorophyll and PE fluorescence). For these comparisons, ciliates were grouped into 4 taxonomic categories: tintinnids, Mesodinium spp., Laboea strobila, and 'other ciliate taxa'. The heterotrophic dinoflagellates, Gyrodinium spp. and Protoperidinium spp. were also considered for comparison. Analyses were performed during all 4 seasons; winter, spring, summer, and fall (with the winter and fall sample lacking manual light microscopy). Poisson distribution statistics were used to calculate $95 \%$ confidence intervals for counts. The E-Test statistic described by Krishnamoorthy \& Thomson (2004) was used to test for significant differences.

\subsubsection{Comparison of detection between IFCB and IFCB-S}

For field assessment, IFCB-S was used during the National Marine Fisheries Service Ecosystem Monitoring survey (ECOMON, EX-13-05) aboard the NOAA Ship 'Okeanos Explorer' from August 24 to September 5, 2013. The cruise track covered the continental shelf from 
southern New England waters northward through Georges Bank and the Gulf of Maine to Nova Scotia shelf waters. IFCB-S was used side-by-side with a standard IFCB for continuous sampling of water from the ship's underway system (3 $\mathrm{m}$ sample depth). The standard IFCB triggered on chlorophyll fluorescence, while IFCB-S was configured to alternate between staining (triggering on chlorophyll and/or stain fluorescence) and nonstaining (triggering on chlorophyll and/or PE fluorescence) modes.

\subsubsection{Automated classification of a time series}

Since 2006, standard IFCB has been deployed underwater ( $\sim 4 \mathrm{~m} \mathrm{depth})$ at the offshore tower of the Martha's Vineyard Coastal Observatory (MVCO), located $3 \mathrm{~km}$ south of Martha's Vineyard, Massachusetts, USA. At MVCO, IFCB has provided near continuous long-term observations (2006 to present) of phytoplankton ranging from $\sim 10$ to $400 \mu \mathrm{m}$ in length, as well as herbivorous and mixotrophic ciliates that exhibit chlorophyll fluorescence. Routine analysis of IFCB data includes image processing, feature extraction, and supervised automated classification as described by Sosik \& Olson (2007) except that instead of the original support vector machine, we used a random forest classification algorithm after Breiman (2001). We applied a classifier with 50 categories, including L. strobila, mixed tintinnids, and mixed other ciliates. For each unknown image, results from the classification algorithm (Tree-Bagger function in MATLAB, The Mathworks) provide an affiliation score for each category (scores sum to 1 across all categories). By selecting a score threshold above which classifications are accepted, it is possible to reduce the incidence of false positives, albeit typically at the expense of lower probability of detection for true positives. The efficacy of this approach is demonstrated here by comparing intermittent manual image identification with a high-resolution multi year time series of cell abundance from the automated classifier for the ciliate species L. strobila at MVCO. L. strobila was chosen as a target because it has distinct morphology, it is typically among the top 5 contributors to micrograzer biomass on an annual basis at MVCO, and it exhibits seasonal patterns that we want to characterize with high resolution. Linear regression analyses between manual and automated counts for various score thresholds were performed and values of $\mathrm{R}^{2}$, $\mathrm{y}$-intercept, and slopes were used to select a threshold score. An ideal threshold would be one where the $\mathrm{R}^{2}$ is maximized, the y-intercept is near zero, and the slope approaches 1. Once a threshold score is selected, abundance estimates are determined by counting targets with scores above that cut-off, and 
an average correction efficiency is applied by dividing the total by the regression slope for the chosen threshold.

\subsection{Results}

\subsubsection{Imaging of protozoa}

The level of taxonomic identification allowed by IFCB images varies, but some distinctive taxa, such as Laboea strobila, can be identified to the species level. At MVCO, the predominant ciliates detected by the standard IFCB come from the Spirotrichea subclasses Oligotrichia and Choreotrichia (Fig. 2-3). The photosynthetic ciliate Mesodinium spp. is also readily detected due to its mixotrophic nature. More rare ciliate taxa include the haptorid Didinium spp. and the prostomatid Tiarina fusus.

Heterotrophic dinoflagellates are also detected if they are consuming phytoplankton (Fig. 2-4). These are predominantly gyrodinoid and gymnoid forms. Occasionally Protoperidinium spp. and Amphidinium spp. are observed.

The instrument can capture images of cells or chains up to at least $400 \mu \mathrm{m}$, though sampling is limited to cells $<150 \mu \mathrm{m}$ in width.

All images from the MVCO data set can be viewed and accessed through the IFCB Data Dashboard (Sosik \& Futrelle (2012); http://ifcb-data.whoi.edu/mvco). All annotated ciliate and dinoflagellate images (organized by year and taxonomic group) are available from the published WHOI-Plankton data set (Sosik et al., 2015). Heterotrophic dinoflagellates are also detected if they are consuming phytoplankton (Fig. 2-4).

\subsubsection{Performance of IFCB-S}

To evaluate the ability of IFCB-S to stain and detect ciliates lacking chlorophyll fluorescence, we used a bacterivorous scuticociliate culture. On a standard IFCB triggering on chlorophyll fluorescence, these ciliates do not trigger image capture, so initially we used a side-scattering trigger to detect all particles (Fig. 2-5A). In this case, both detrital particles and ciliates were imaged, with detrital particles dominating but ciliates readily detectable. When a non-stained cell culture was analyzed on IFCB-S configured to trigger on stain fluorescence, no scuticociliates were detected, as expected, since these cells do not exhibit detectable

autofluorescence (Fig. 2-5B). Once cells were stained, they were readily detected with a 
stain fluorescence trigger (Fig. 2-5C). Triggering on stain fluorescence rather than scattering increases the time spent imaging ciliates as opposed to detritus ( $75 \%$ of the fluorescencetriggered images contained ciliates compared to only $41 \%$ of scattering-triggered images).

\subsubsection{Comparison of stains}

To compare the performance of LTG and FDA, scuticociliate cell counts were determined by conventional flow cytometry triggering on stain fluorescence. Detection efficiency was similar between the 2 stains (Fig. 2-6), allowing for further considerations to be used in selecting the optimal stain for use in IFCB-S. We selected further application of FDA due to its stability in solution for up to 6 mo at room temperature (pers. obs.), as well as its lower cost. Recommended storage for LTG is -5 to $-30^{\circ} \mathrm{C}$, which presents challenges for long-term in situ deployments.

\subsubsection{Determining stain protocols}

We found the average stain fluorescence levels of scuticociliates measured by IFCB-S increased until leveling off at a final stain concentration of $4 \mu \mathrm{g} \mathrm{FDA} \mathrm{ml}{ }^{-1}$ (Fig. 2-7A). The unstained sample displayed low levels of stain fluorescence, representing instrument noise. We chose the final concentration of $4 \mu \mathrm{g} \mathrm{FDA} \mathrm{ml}{ }^{-1}$ for use in the IFCB-S system to maximize sensitivity without introducing excess stain that could contaminate the instrument's fluidic system and require extra rinsing to remove.

The time course of cell stain fluorescence during the $20 \mathrm{~min}$ analysis of a $5 \mathrm{ml}$ scuticociliate culture sample showed a slight increase of average stain fluorescence over the first 6 min of the sample and a slight decrease over the last 6 min (Fig. 2-7B). All cells stained, though, were above the detection level and whole cell counts per $30 \mathrm{~s}$ bin remained constant until a small increase in the last 2 min of the sample. That increase may partially be due to cells concentrating near the top of the syringe and being analyzed later in the time course. The counts from the first $30 \mathrm{~s}$ bin are low due to small amounts of particle-free sheath fluid from previous rinses remaining in the needle. Ultimately, this verifies $30 \mathrm{~s}$ is adequate for staining all cells prior to analysis, though highest staining occurs several minutes later. 


\subsubsection{Comparison of IFCB-S and manual microscopy}

We evaluated performance of IFCB-S on environmental samples by comparison with the conventional mode of counting protozoa: settling and using manual microscopy to count cells in acid Lugol's stained samples. We also compared IFCB-S counts with staining (chlorophyll and stain fluorescence trigger) and without staining (chlorophyll fluorescence trigger only). We specifically compared abundances for Mesodinium spp., L. strobila, mixed tintinnids, Protoperidinium spp., and mixed gyrodinoid dinoflagellates. During a comparison of wintertime samples, no significant differences were found between ciliate morphotypes detected by IFCB-S with and without staining (Fig. 2-8A). In stained samples, however, more gyrodinoid dinoflagellates were detected, indicating these organisms are likely consuming heterotrophs and thus often missed by standard IFCB with a chlorophyll trigger (Fig. 2-8A). During a springtime comparison, IFCB-S detected approximately $25 \%$ more mixed ciliates than microscopic analysis (Fig. 2-8B). At that time, there were no significant differences in abundances for other micrograzer morphotypes between the methods. There were also no differences in detection between staining and non-staining modes (Fig. 2-8B), consistent with most protists containing chlorophyll either in their guts or in retained plastids. A summertime sample allowed only for comparison in the ciliate mix and tintinnid groups as other types were not observed (Fig. 2-8C). For the detected ciliate types, both stained and unstained sample concentrations were significantly higher than manual microscopy. A fall comparison did not show any significant differences between staining and non-staining modes (Fig. 2-8D).

\subsubsection{IFCB-S field application}

IFCB-S was configured for automated underway sampling of surface waters during a cruise over the northeast US continental shelf (August 2013). We examined ciliate and gyrodinoid dinoflagellate abundance and compared morphotypes that did and did not ingest algae. Two populations of organisms were observed in the stained samples: one with high chlorophyll fluorescence and one with little to no chlorophyll fluorescence; both showed a range of stain fluorescence that roughly corresponded to cell size. Ciliates and dinoflagellates were present in both of these groups, so it was possible to detect a greater number of total grazers in stained samples. This was due to taxa present in the low red / high stain fluorescence 
population (Fig. 2-9).

Observations of tintinnids during the cruise provided a notable example of the advantages of IFCB-S. We found 2 morphologically different groups of tintinnids in the stained samples: one with high chlorophyll fluorescence and one with little to no chlorophyll fluorescence; as expected, both groups exhibited stain fluorescence. Only chlorophyll fluorescent tintinnids were detected by the standard IFCB, with maximum concentrations reaching approximately 0.4 cells $\mathrm{ml}^{-1}$ (Fig. 2-10A). This population was captured by IFCB-S in similar concentrations, but the second population with little chlorophyll fluorescence was detected only by this instrument, with resulting higher total tintinnid maximum abundances determined by IFCB-S compared to IFCB ( 1.1 cell ml$\left.^{-1}\right)$ (Fig. $\left.2-10 B\right)$. The staining of samples consistently allowed for detection of a group of tintinnids that otherwise would not have been observed.

\subsubsection{Automated classification}

Automated classification is essential for analyzing the large data sets produced by IFCB and IFCB-S. We explored the automated approach for ciliates by comparing manual and automated identification of images for times series data from 2006 to 2015 for L. strobila. Regression analysis between manual and automated classification results (Fig. 2-11) suggested an optimal classifier score threshold of 0.7 (i.e. an image is classified as L. strobila only if the score associated with the class is $>0.7)$ : the $\mathrm{R}^{2}$ value was high, the $\mathrm{y}$-intercept was not significantly different from 0 , and the slope was relatively close to 1 . This 0.7 threshold produced an acceptable tradeoff between detection efficiency and occurrence of false positives. This tradeoff is reflected in the performance statistics of the classifier, which for the case of the random forest method we used can be determined from the unbiased internal error rates (out-of-bag estimates that do not require a separate test set; Breiman 2001). From this approach, our classifier has a probability of detection $=0.97$ and precision $=0.90$ for the L. strobila class before application of any score threshold. With the selected score threshold of 0.7 , the corresponding probability of detection drops to 0.79 (19\% unclassified and $2 \%$ misclassified), while the precision increases to 0.99 . These rates are consistent with performance on the full set of manually labeled images, where the intercept between automated and manual counts is $\sim 0$ and the slope is 0.75 (Fig. 2-11A).

Automated and manual classification of the MVCO images provided similar patterns of 
variability with both showing distinct seasonal patterns in L. strobila abundance (Fig. 212). At finer scales, there can be discrepancies between automated and manual identification. Some of these discrepancies may be caused by patchiness at MVCO interacting with sampling differences: in some cases, manual classification was only completed for a few hours within a given day, while the daily estimate for automated classification reflects sampling over the entire day. If different water masses were moving by the MVCO offshore tower throughout the day, high frequency variability in cell concentration might lead to mis-matches with the resulting daily average values. For event- to seasonal-scales, fully automated abundance estimates provide robust patterns, with blooms of L. strobila occurring during April-May in most years, and some evidence for fall blooms that are smaller and more variable.

\subsection{Discussion}

Protist micrograzers are key players in aquatic ecosystems yet they are difficult to study due to methodological challenges. The standard IFCB is a powerful tool for studying these organisms in situ. Because IFCB can be deployed long-term, it is effective for characterizing protozoan community structure with high temporal resolution. It can image a wide variety of grazers and provide insight into which organisms are present (e.g. Figs. 2-3 \& 2-4), as well as their seasonal dynamics (Fig. 2-12). There are limitations, though, because the reliance on chlorophyll fluorescence for image triggering means standard IFCB is only able to quantify patterns of herbivores and mixotrophs. The addition of broad-application live cell staining is appropriate to take this observational technique forward to view a more complete community.

In typical cytometric analyses, there can be difficulty when discriminating a phototroph with concentrated stain from an herbivorous or mixotrophic protozoan because both can have high levels of chlorophyll fluorescence. Imaging technology allows us to differentiate the two from the images associated with each cell. On the other hand, some grazers may have undetectable levels of chlorophyll fluorescence or none at all (for instance, those grazing on heterotrophs) and the addition of stain is necessary for efficient detection. There are a number of possible fluorescent stains that can be used to label protists for flow cytometry. We considered several factors in selecting a stain for use with IFCB-S, including whether the stain fluorescence can be differentiated from chlorophyll and can remain stable at am- 
bient temperatures (important for long-term in situ deployments). Most importantly, the wavelength of the laser must be able to induce fluorescence by the stain, but limit overlap of emitted wavelengths with scattered laser light. This criterion led us to focus on LTG and FDA as candidates. While suggested final FDA concentrations vary (Dorsey et al., 1989; Jochem, 1999; Onji et al., 2000; Peperzak \& Brussaard, 2011), 0.06-500 $\mu \mathrm{g} \mathrm{FDA} \mathrm{ml}^{-1}$ ), we recommend use of FDA for extended in situ staining application at a final concentration of $4 \mu \mathrm{g}$ FDA ml${ }^{-1}$. Though $30 \mathrm{~s}$ of staining is adequate to stain all cells (so appropriate for most analyses), if maximum stain accumulation is desired, stained samples should be incubated for 2-6 min before analysis and sample analysis time should be limited to 10-15 min. FDA's effectiveness is comparable to that of LTG (Fig. 2-6), while its ability to remain stable at ambient temperatures (Boyd et al. (2008) and pers. obs.) and its affordability make it preferable. Because LTG stains the acid vacuoles created during digestion (Rose et al., 2004), it might be useful to distinguish those protists that are actively grazing, but our observations showed general staining of all cells including pure autotrophs (likely because chloroplasts can be acidic) and not in relation to levels of grazing. With controlled analysis of a bacterivorous scuticociliate culture, we have shown that automated staining can be used to readily detect and image grazers previously undetectable with IFCB (Fig. 2-5). While the degree of staining may be variable for different grazers, our results suggest that widespread detection of grazers without chlorophyll fluorescence is possible.

To test the effectiveness of protozoa detection by automated imaging in mixed assemblage natural samples, we compared results to those from manual light microscopy. For samples collected from Woods Hole Harbor in spring and summer, significantly higher abundances of mixed ciliates were detected with IFCB-S compared to manual microscopy (Fig. 2$8 \mathrm{~B}, \mathrm{C})$. This suggests traditional counting methods involving preservation and settling may be so detrimental to the cells that they become undetectable. This is consistent with the conclusions of Stoecker et al. (1994) that no single method of fixation is ideal for all purposes, so taxon- and fixation-specific correction factors may need to be applied for methods that involve preservation. Because the IFCB is used to image ciliates in situ without fixation steps, loss of delicate cells may be minimized. In no cases did we observe significantly lower concentrations of any organisms with the IFCB or IFCB-S compared to manual microscopy. This is consistent with previous findings for various types of phytoplankton (Olson \& Sosik, 2007; Campbell et al., 2010; Brosnahan et al., 2015). The instrument was not found to be 
biased towards certain morphotypes over others, as the range of microzooplankton detected with the IFCB-S did not differ from those observed with manual microscopy.

Comparisons between staining and non-staining modes with IFCB-S emphasize the value added by combining automated staining with imaging. During summertime sampling in Woods Hole Harbor, significantly higher counts of tintinnids and mixed other ciliates were observed in stained samples (Fig. 2-8C). These higher counts indicate that many ciliates exhibited no chlorophyll fluorescence (or too little to measure with IFCB-S), so staining was required to detect them. This comparison also provides insight into aspects of feeding strategy: the ciliates only detected after staining are presumably not mixotrophs and were either not actively grazing or were grazing on heterotrophs. Various types of tintinnids are known to graze on other heterotrophs (Sherr et al., 1989) so this result is not surprising for that group. Interestingly, we found no difference for mixed ciliates during the summer and, for a spring sample comparison, we found no significant differences between staining and non-staining modes of the IFCB-S for any category. This likely indicates chlorophyllcontaining micrograzers dominated, presumably a combination of mixotrophs and organisms actively feeding on autotrophs. Also working in waters near Woods Hole, Stoecker et al. (1989b) similarly found that, during summer seasons, when there is low phytoplankton biomass, autotrophic and mixotrophic ciliates can contribute high amounts of production, becoming important food sources for higher trophic levels. During winter sampling, we found similar abundance for ciliates with and without staining, but a heterotrophic gyrodinoid dinoflagellate was much more abundant in stained samples (Fig. 2-8A). While taxon-specific differential feeding has been observed in both ciliates and dinoflagellates (Lessard \& Swift, 1985; Verity, 1991), seasonal patterns of this have not been explored in detail. Our results suggest there could be taxon-specific differences in feeding strategies that vary with season.

Preliminary field applications of IFCB-S during the summer ECOMON survey further demonstrate and support expanded capabilities to detect heterotrophic protists. We found the use of stain allowed for imaging of greater numbers of ciliates on the cruise by IFCBS compared with a standard IFCB (Fig. 2-9). The additional cells detected by IFCB-S exhibited high ratios of stain fluorescence to chlorophyll fluorescence, indicating these grazers were unlikely to have been ingesting phytoplankton. Some ciliate morphotypes were similar in abundance during staining and non-staining modes and exhibited a range of chlorophyll fluorescence. This could indicate that some morphotypes without measurable chlorophyll 
fluorescence still have an autotrophic component of their diet, but with levels so low that they were only imaged when stained.

The use of stain also made it possible to detect additional ciliates during underway sampling on the cruise (Fig. 2-10). We found significantly higher numbers of the tintinnid Eutintinnus spp. than captured by the standard IFCB. Most of this population did not have chlorophyll fluorescence above the trigger threshold so they were not reliably counted without stain. At the same time, a different group of tintinnids with agglomerated loricas, Tintinnopsis spp., were observed with both the standard IFCB and IFCB-S at similar abundances due to their consistently high chlorophyll fluorescence.

Taken together, these comparisons not only support the efficacy of automated staining, they also provide insight into the diet of micrograzers. With observations such as these, we can start to hypothesize about the various diets and how they are distributed across taxa. If similar morphotypes exhibit a range of high and low chlorophyll fluorescence, we can infer that all feed on autotrophs, but that those with consistently low levels of chlorophyll fluorescence relative to their size and stain fluorescence supplement their diets with heterotrophs. While we cannot discern whether a grazer is herbivorous or mixotrophic (both exhibiting chlorophyll fluorescence along with FDA fluorescence), we can take into account a priori knowledge based on morphotypes from our images to gain further insights into possible feeding habits. For example, the primarily phototrophic dinoflagellate Gymnodinium sanguineum has been found to feed on oligotrich ciliates during times of nitrogen limitation (Bockstahler \& Coats, 1993). Our analyses would observe varying levels of chlorophyll fluorescence indicative of either herbivory or mixotrophy, but previous knowledge suggests the mixotrophic nature of this protist. Morphotypes that consistently exhibit undetectable chlorophyll fluorescence are likely to be grazing predominantly on other heterotrophs. A single morphotype could be comprised of genetically distinct populations, possibly exhibiting different feeding strategies, in which case this would be reflected in a range of chlorophyll relative to stain fluorescence. To further explore diet, a potential experimental application for our system includes feeding fluorescently stained prey items to grazers in environmental samples. Those grazers exhibiting stain fluorescence would indicate feeding on this prey item. Martinez et al. (2014) worked to optimize the use of live, fluorescently labeled algae in the field to determine grazing rates and explore trophic interactions during long incubations. Combining this method with the abilities of our system would further our understanding of 
grazer diet preferences.

These kinds of analyses also prompt questions about whether certain morphotypes exhibit different diets through time (perhaps depending on prey availability). For example, we detected similar gyrodinoid dinoflagellate morphotypes throughout the year in Woods Hole Harbor, but whether they were dominantly chlorophyll-containing or not differed with time (Fig. 2-8). This observation is consistent with certain feeding strategies being more favorable than others at different times of the year, but more extensive observations are needed to determine if recurrent patterns occur seasonally. Heterotrophic dinoflagellates, such as Gyrodinium spp., have been observed to feed on a wide range of prey types, from pure autotrophs to other heterotrophic organisms such as bacteria and small flagellates (Gaines \& Elbrachter, 1987; Jacobson, 1987; Hansen, 1992; Saito et al., 2006; Jeong et al., 2008). Though dinoflagellates have been observed to be dominant grazers on diatoms (Sherr \& Sherr, 2007), this may not always be the case in waters near Woods Hole. During the winter, when chainforming diatoms dominate the autotroph biomass, most gyrodinoid dinoflagellates were not chlorophyll containing (Fig. 2-8A), indicating it may be more favorable for them to feed on smaller heterotrophs. Hansen (1992) noted that heterotrophic dinoflagellates may at times outcompete other grazers by being able to efficiently maintain metabolism at low prey concentrations. One interpretation of our results is that these dinoflagellates are feeding less in the winter. During the spring and summer, when the gyrodinoid morphotype was predominantly chlorophyll-containing, it may have been feeding on small autotrophs. Certain species of gyrodinoids, such as Gyrodinium dominans, have been found to respond quickly to increases in cryptophytes (Schmoker et al., 2011), which can be important at that time of year.

Interestingly, we observed a contrasting pattern for ciliates compared to the gyrodinoid dinoflagellates; ciliates appear to be predominantly herbivorous or mixotrophic during the winter when gyrodinoid dinoflagellates were not (Fig. 2-8A). This is perhaps surprising since the ability of the two to ingest autotrophs has been shown to be comparable (Neuer \& Cowles, 1995). This difference could reflect ciliates having the potential to grow faster than their heterotrophic dinoflagellate competitors (Banse, 1982; Hansen, 1992; Strom \& Morello, 1998). In winter the dinoflagellates may be occupying a different niche associated with sustaining low growth rate via consumption of small heterotrophs. Though these analyses are only snapshots in time, they provide interesting insights that argue for studies 
of longer time periods to address questions of seasonality in a more quantitative manner.

Addressing these types of questions with large image data sets that include this more complete community of micrograzers raises immediate data analysis challenges, and automated image analysis and classification will be imperative. We can build from the approaches used for phytoplankton (Sosik \& Olson, 2007) to develop automated classification for these new populations. While work remains to extend automated classification to a wide range of protist morphotypes, we have shown efficacy for selected ciliates. For Laboea strobila, in particular, we can detect recurrent blooms and seasonal patterns with automated classification, as verified by intermittent manual identification of images. Our analysis emphasizes a recurrent spring bloom (Fig. 2-12), which is consistent with seasonal trends previously documented for L. strobila in the Gulf of Maine (Sanders, 1995). Modigh (2001) also observed a spring peak in the abundance of this species during a 3 yr study in the Mediterranean Sea. It remains to be determined what factors drive the similar spring increase between both New England and other temperate waters. Interestingly, our high-resolution time series has uncovered an additional more variable and smaller amplitude fall increase in L. strobila abundance (Fig. 2-13). Whether this is a feature in other systems is not known.

We have demonstrated that the expanded observational capabilities of IFCB-S make it possible to use live cell stains such as FDA to uncover a more complete micrograzer community in natural waters. When coupled with automated image analysis and classification this allows us to explore the diversity, dynamics, and ecosystem roles of protistan grazers in new ways. Not only are we now able to detect populations grazing on heterotrophs (those with undetectable chlorophyll fluorescence), but also we can detect some taxa at higher abundances than observed with traditional manual light microscopy coupled with settling of preserved cells. Because IFCB-S requires little sample handling and no preservation, it likely has reduced loss of delicate cells.

Furthermore, continuous, high temporal resolution sampling has important advantages. Long-duration time series permit detection of more rare species of grazers likely to be missed in intermittent small volume samples. Spatially resolved sampling, such as the underway cruise sampling described here, emphasize that both standard IFCB and IFCB-S can detect ciliate 'hot spots'. Station-based sampling on the same cruise provided far lower spatial resolution, with the result that patches would have been difficult to detect and characterize. We also have the power to resolve feeding habit and its possible plasticity, for instance as 
seen in seasonal changes in whether certain morphotypes exhibit chlorophyll fluorescence from retained chloroplasts or undigested autotrophic prey.

Along with optical information from the images, we also derive morphological characteristics, which have previously been used to gain insight into predator-prey dynamics. Most notably, cell size has been used to understand these relationships (Hansen et al., 1994), and has proved to be quite useful. Previous studies have shown size distributions of ciliate micrograzers and their prey throughout the year can help infer trophic transfer efficiency (i.e. a prey biomass which is high compared to the biomass of the predator points to a low efficiency and vice versa, (Gaedke \& Straile, 1994), as well as how and if this changes year to year. Banas (2011) exploited these types of allometric relationships between grazer and prey size in developing a size-spectral model that they used to study the predictability of phytoplankton bloom timescales in relation to food-web complexity (i.e. selective or generalist grazers). Though using grazer cell size as a proxy for diversity and diet has been advantageous, certain problems can arise in making these kinds of conclusions. Some grazers must be lumped into functional groups before size-relationships can be exploited; for example, filter feeders prefer relatively smaller prey than raptorial-interception feeders of the same size. With IFCB-S, we can not only determine the size of an organism (from images), but also differentiate morphotype and general feeding habit to infer certain functional groups. This combination of information can allow us to rigorously evaluate how appropriate certain size-structured generalities are and potentially uncover new patterns or relationships that reflect both size and function.

After a recent review of published data on microzooplankton grazing, Schmoker et al. (2013) highlight the need for more time series and higher taxonomic resolution during grazing studies. Though long-term data sets of protist micrograzers are not common, a few studies have emphasized the power of studying systems over long periods of time. Modigh (2001) observed similar patterns of succession in ciliate taxa every year for $3 \mathrm{yr}$, possibly indicating reduced competition between taxa and a diversified grazing pressure. During a one-year study, Lawrence \& Menden-Deuer (2012) found seasonal changes in grazing rates corresponded more to prey community composition than environmental conditions such as temperature. This reflected a seasonal mismatch of predators and prey, which seemed to arise from more complex ecological interactions rather than simply resulting from physiological limitation of protists as previously argued (Caron et al., 2000; Sherr et al., 2009). The 
IFCB-S facilitates the much-needed longterm studies of microzooplankton communities in situ and with its high resolution images provides notable advantages for detailed exploration of diversity. Because the IFCB-S also samples phytoplankton communities, in future we expect this observational technology to enable unprecedented exploration of predator-prey interactions and patterns through space and time. 


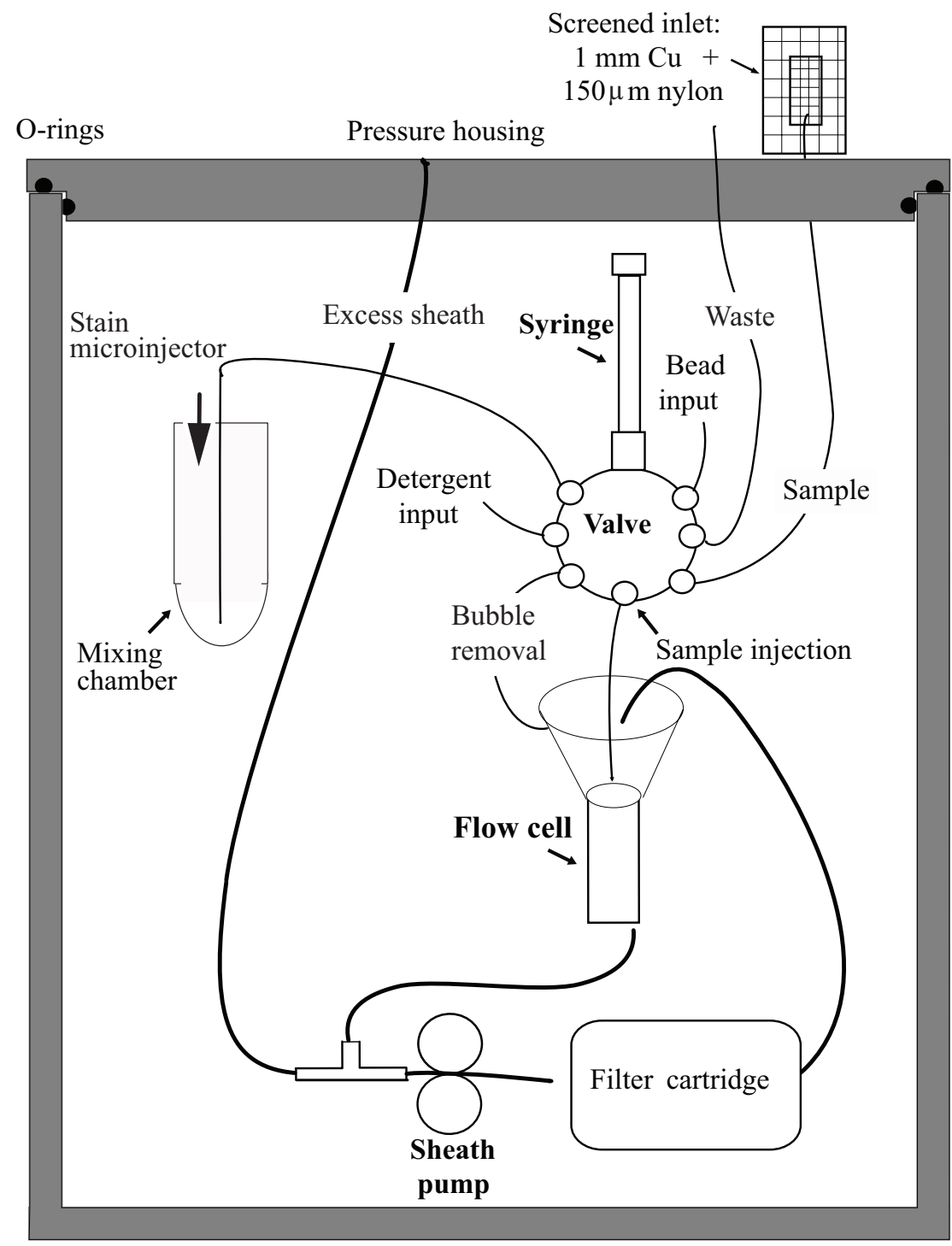

Figure 2-1: Schema of fluidics for IFCB-S showing flows for sample water and housekeeping operations (e.g. cleaning and bubble removal) as well as the higher flow rate sheath path (distinguished by thicker lines) 

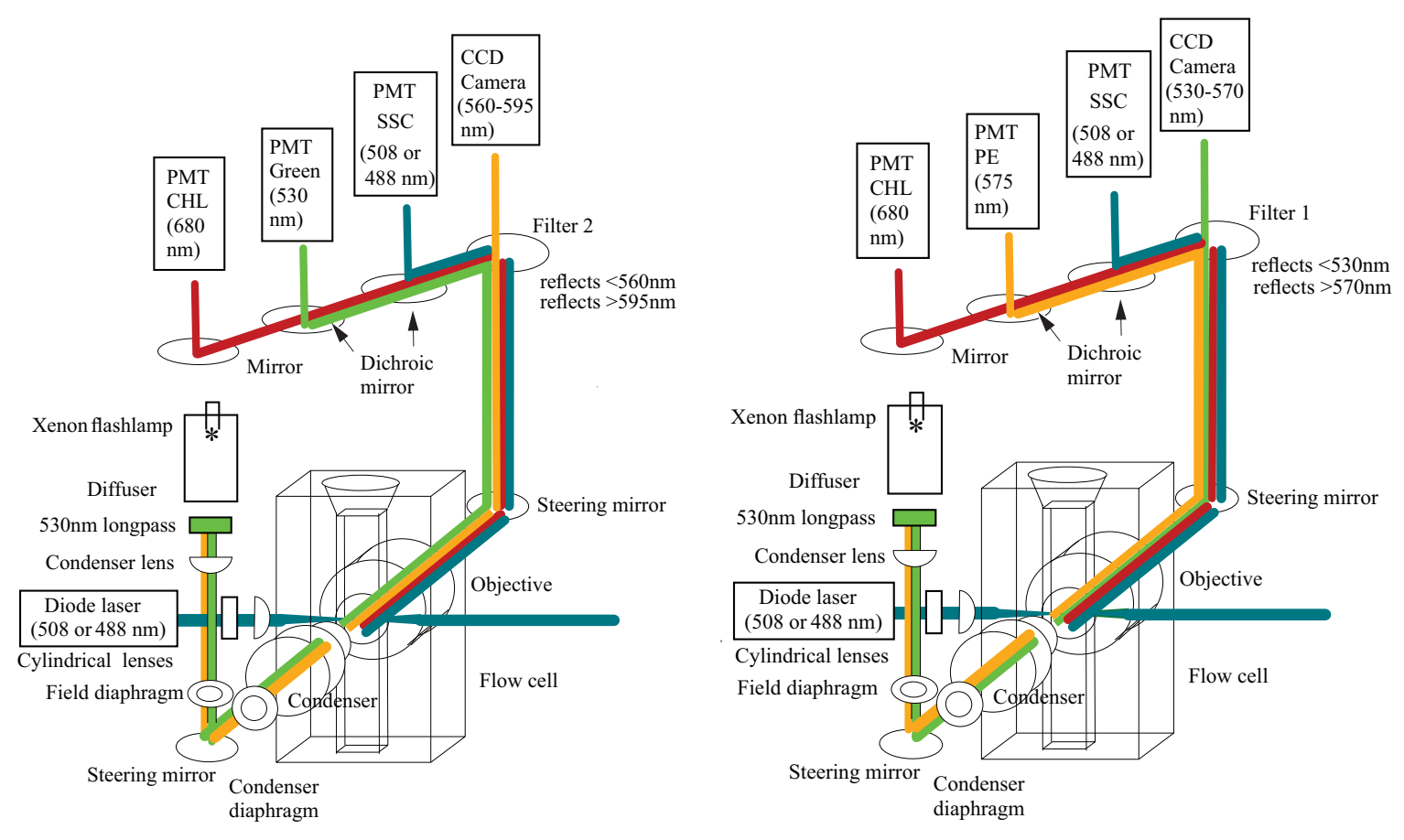

Figure 2-2: Schema of optical layouts for IFCB-S in staining mode (left panel) and nonstaining mode (right panel). Both modes enable collection of chlorophyll fluorescence (CHL) and side scattering (SSC) by photomultiplier tubes (PMT). The use of filter 2 in staining mode allows detection of FDA fluorescence (Green), while the substitution of filter 1 in non-staining mode allows detection of PE fluorescence. The filter substitution results in a shift of wavelengths passed to the camera 

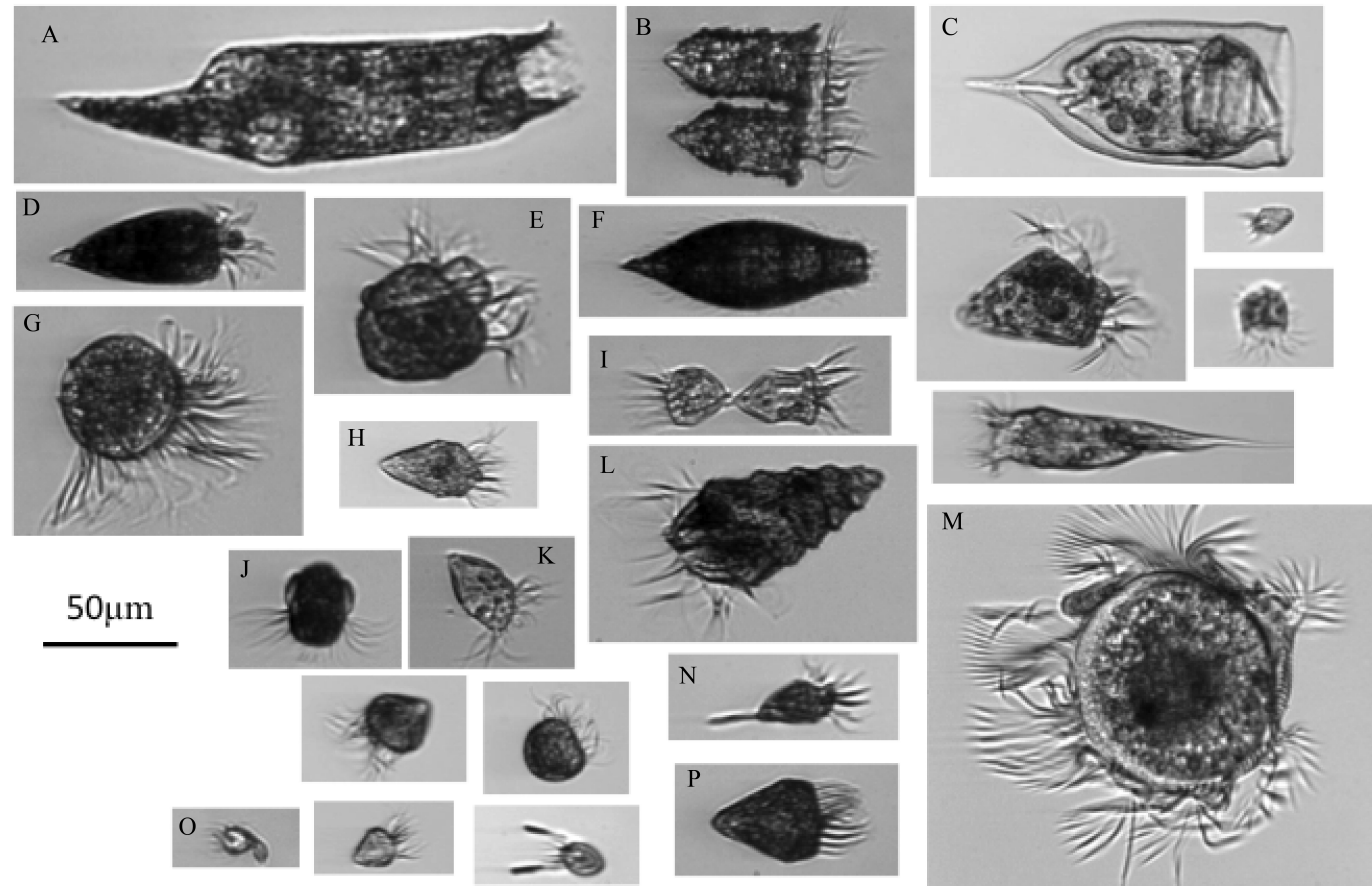

Figure 2-3: Examples of ciliate categories at MVCO as imaged by standard IFCB triggering on chlorophyll fluorescence. Ciliates are grouped by similar morphology and identified to genus and species as possible. (A) Strombidium conicum; (B \& C) tintinnid; (D) Strombidium oculatum; (E) Strombidium capitatum; (F) Tiarina fusus; (G) Strobilidium spp.; (H \& K) Strombidium spp.; (I) Strombidium inclinatum; (J) Mesodinium spp.; (L) Laboea strobila; (M) Strobilidium spp.; (N) Pseudotontonia simplicidens; (O) Tontonia gracillima; (P) Strombidium spp. The remaining categories are currently grouped together as "ciliate mix'because morphology is not always distinct. All images from the MVCO data set are publicly available (http://ifcb-data.whoi.edu/mvco), as is a large set of annotated ciliate images (Sosik et al. 2015) 

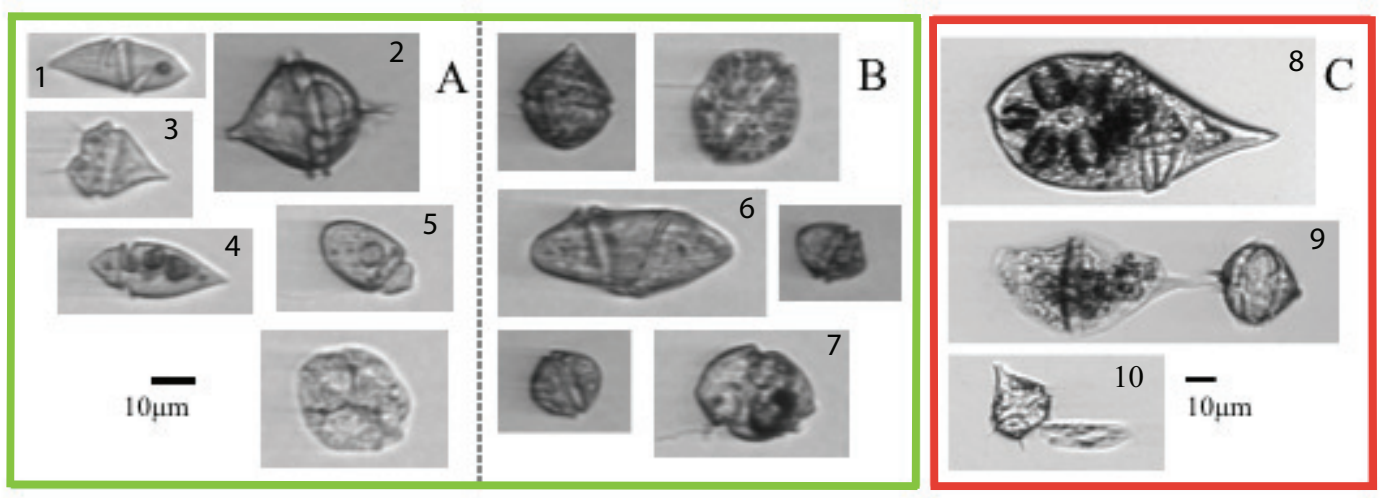

Figure 2-4: Examples of dinoflagellates from Woods Hole Harbor as imaged by IFCB-S triggering on FDA and chlorophyll fluorescence (green box; A \& B) and actively grazing dinoflagellates at MVCO as imaged by a standard IFCB triggering on chlorophyll fluorescence (red box; C). (A) Dinoflagellates with low chlorophyll and high stain fluorescence; (B) dinoflagellates with both high chlorophyll and stain fluorescence. Some categories are grouped by morphology, others have been identified to genus level: gyrodinoid dinoflagellate (1, 6, 8); Protoperidinium spp. (2, 9), Protoperidinium spp. (3, 10); Amphidinium spp. (4, $5)$; Proterythropsis spp. (7). The unnumbered examples are currently grouped together in our classification 

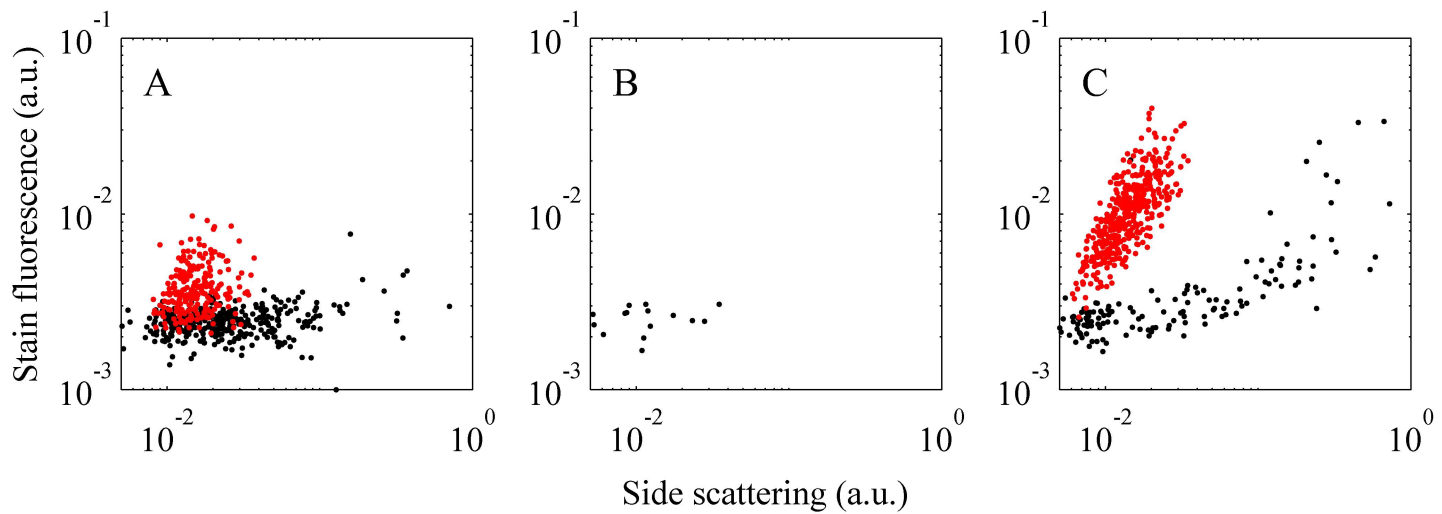

Figure 2-5: Relationship between FDA fluorescence and side angle light scattering (integrated signals) for subsamples of a scuticociliate culture analyzed with IFCB-S configured in different triggering modes. (A) Unstained sample with triggering on side scattering; (B) unstained sample with triggering on stain fluorescence; (C) stained sample triggering on stain fluorescence. Black dots indicate detrital particles and red dots are scuticociliates, as determined from visual inspection of associated images. a.u.: arbitrary units 


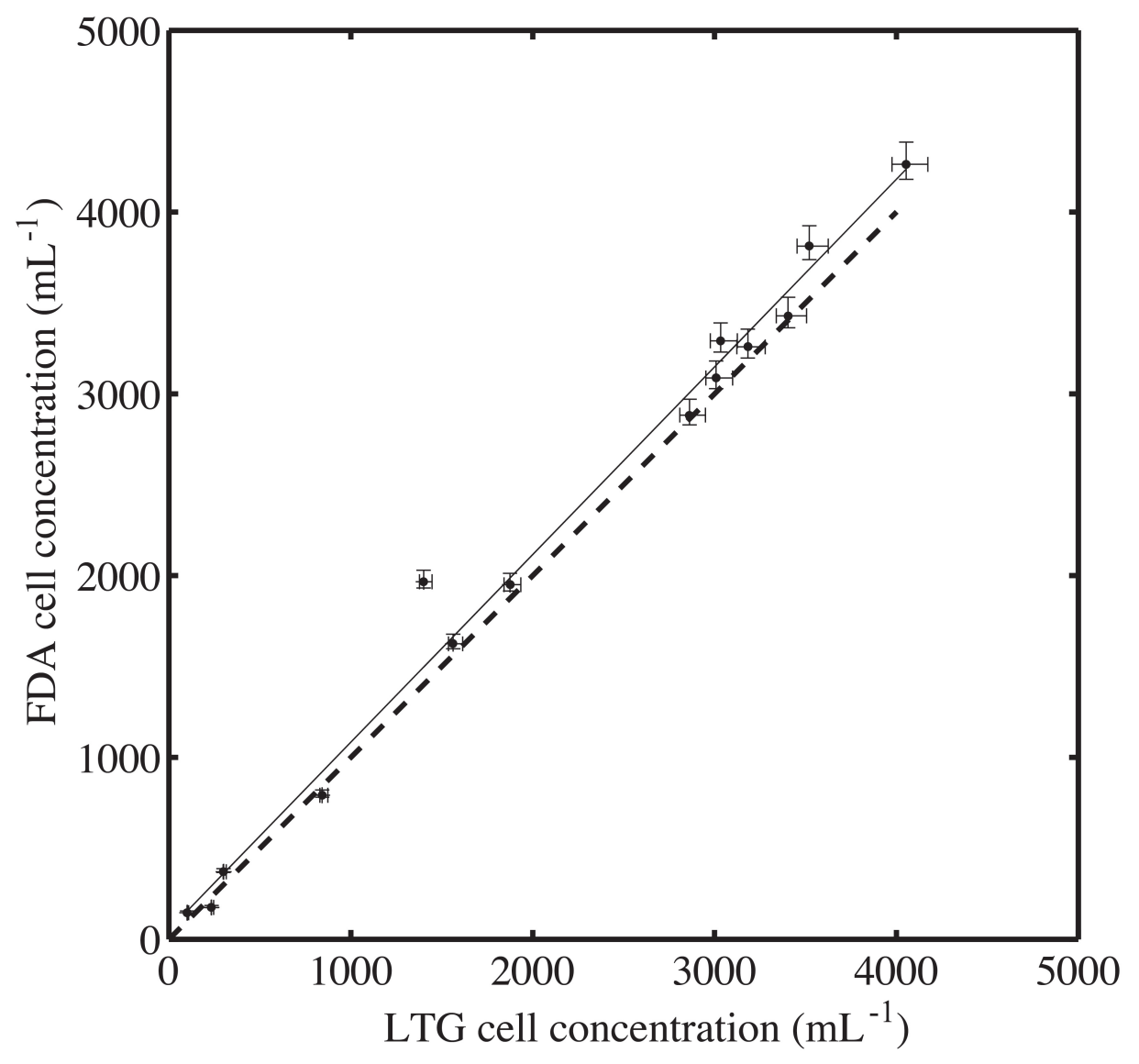

Figure 2-6: Comparison of flow cytometric detection of a scuticociliate culture stained with FDA or LTG. Solid line is best fit. Dashed line is 1:1. 95\% confidence intervals are shown for each count 

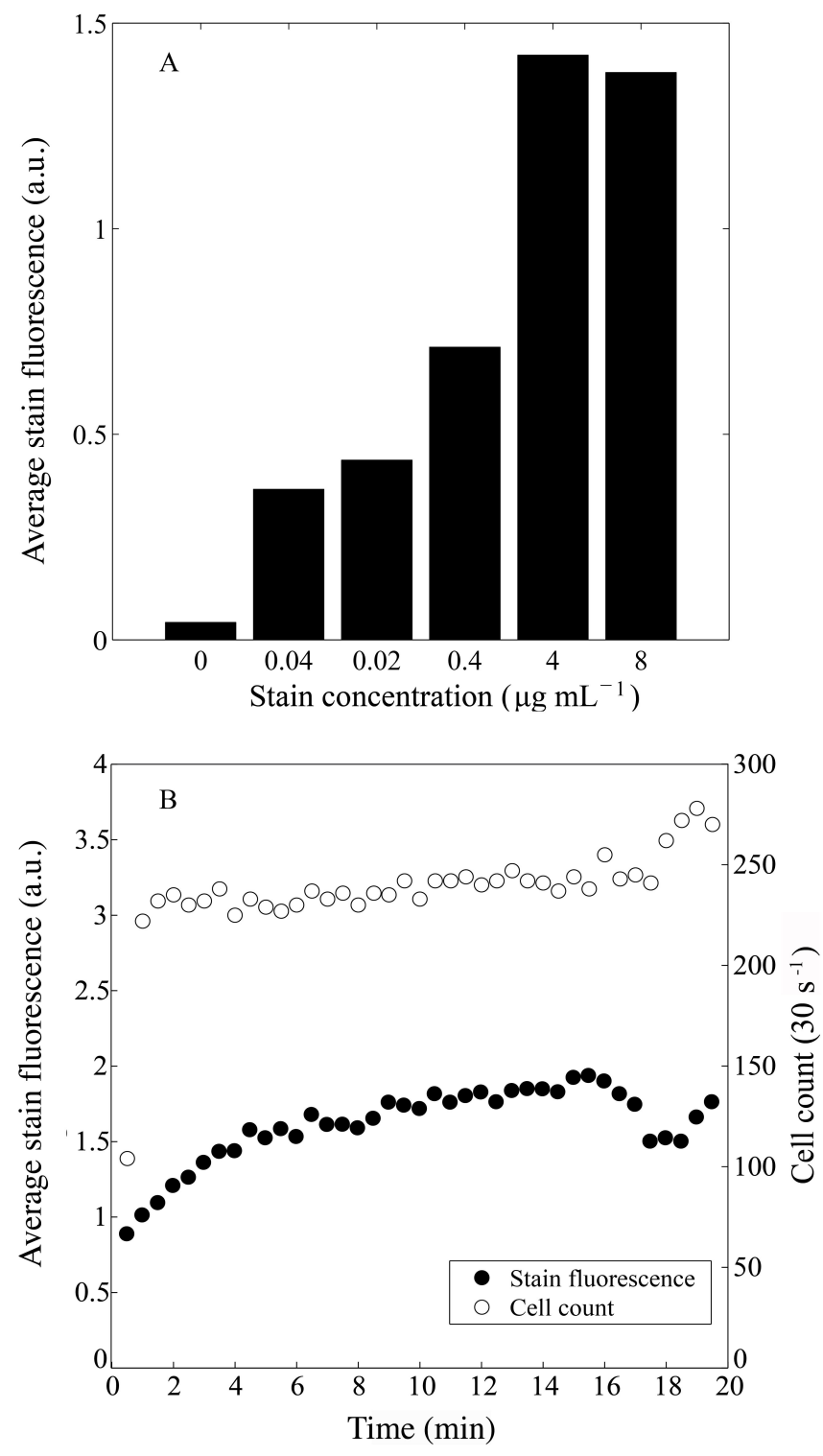

Figure 2-7: (A) Average stain fluorescence values of cells from a scuticociliate culture incubated with a range of final FDA stain concentration. Unstained sample $\left(0 \mu \mathrm{g} \mathrm{FDA} \mathrm{ml} \mathrm{F}^{-1}\right)$ was triggered on scattering. (B) Average stain fluorescence values and scuticociliate cell counts within $30 \mathrm{~s}$ bins during $20 \mathrm{~min}$ analysis of one $5 \mathrm{ml}$ sample. Open circles and closed circles represent whole cell counts and average stain fluorescence, respectively 

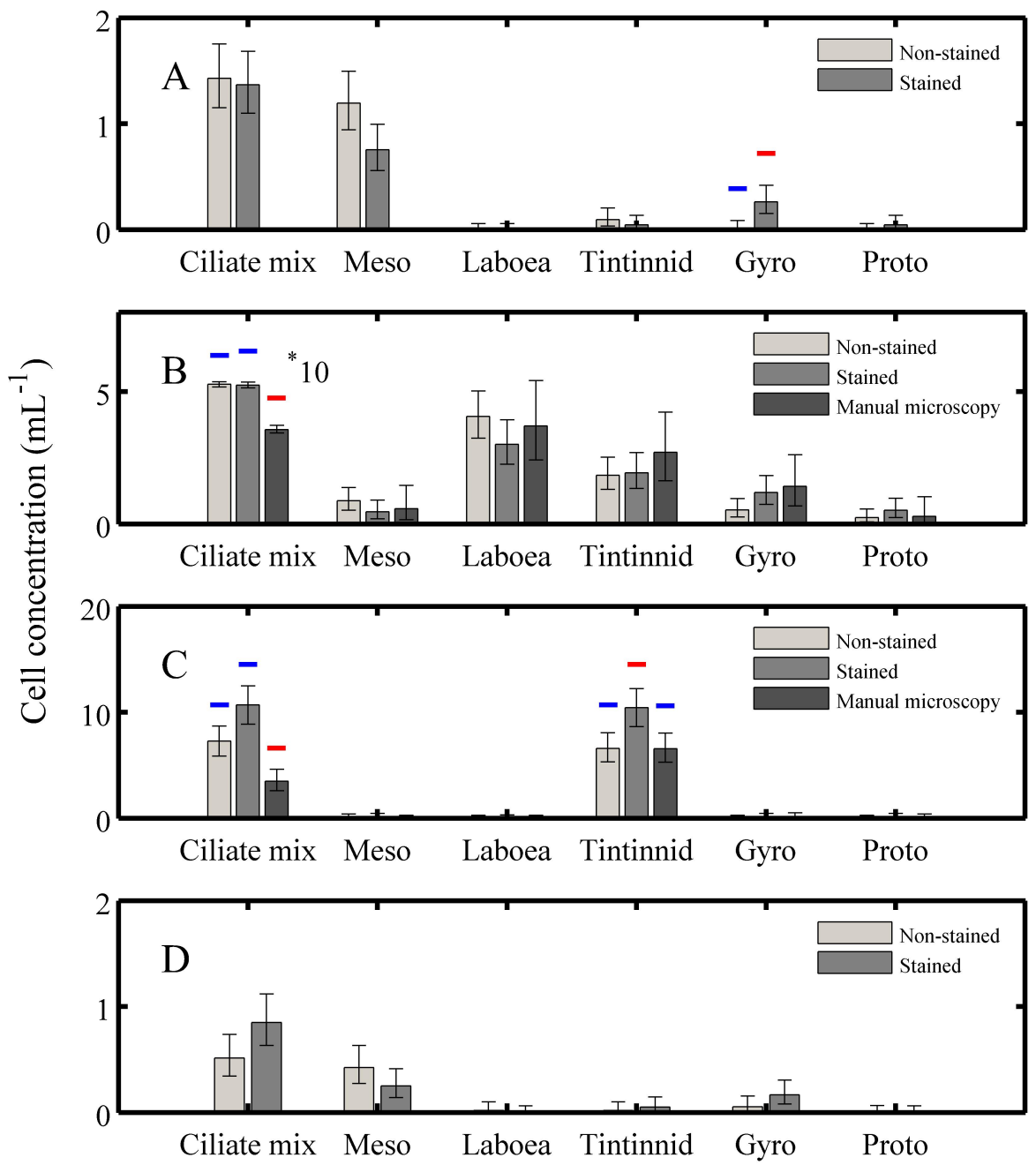

Figure 2-8: Cell concentrations (cells $\mathrm{ml}^{-1}$ ) for ciliate mix, Mesodinium spp., Laboea strobila, tintinnids, Gyrodinium spp., and Protoperidinium spp. comparing results from manual microscopy with samples analyzed by IFCB-S operated in staining and nonstaining modes. Samples were collected from Woods Hole Harbor in winter (A: January 19, 2014), spring (B: May 11, 2014), summer (C; July 2, 2014), and fall (D; October 18, 2014), with manual microscopy only available for winter and fall. Error bars indicate $95 \%$ confidence intervals computed assuming Poisson distributed counting statistics. Significance is indicated by colored bars; red and blue bars are significantly different from each other. If no significant differences were found within a taxonomic group, no bars are displayed. Total cell counts for winter, spring, summer, and fall range from 0 to 89,8 to 250,0 to 132 , and 0 to 51 , respectively) 


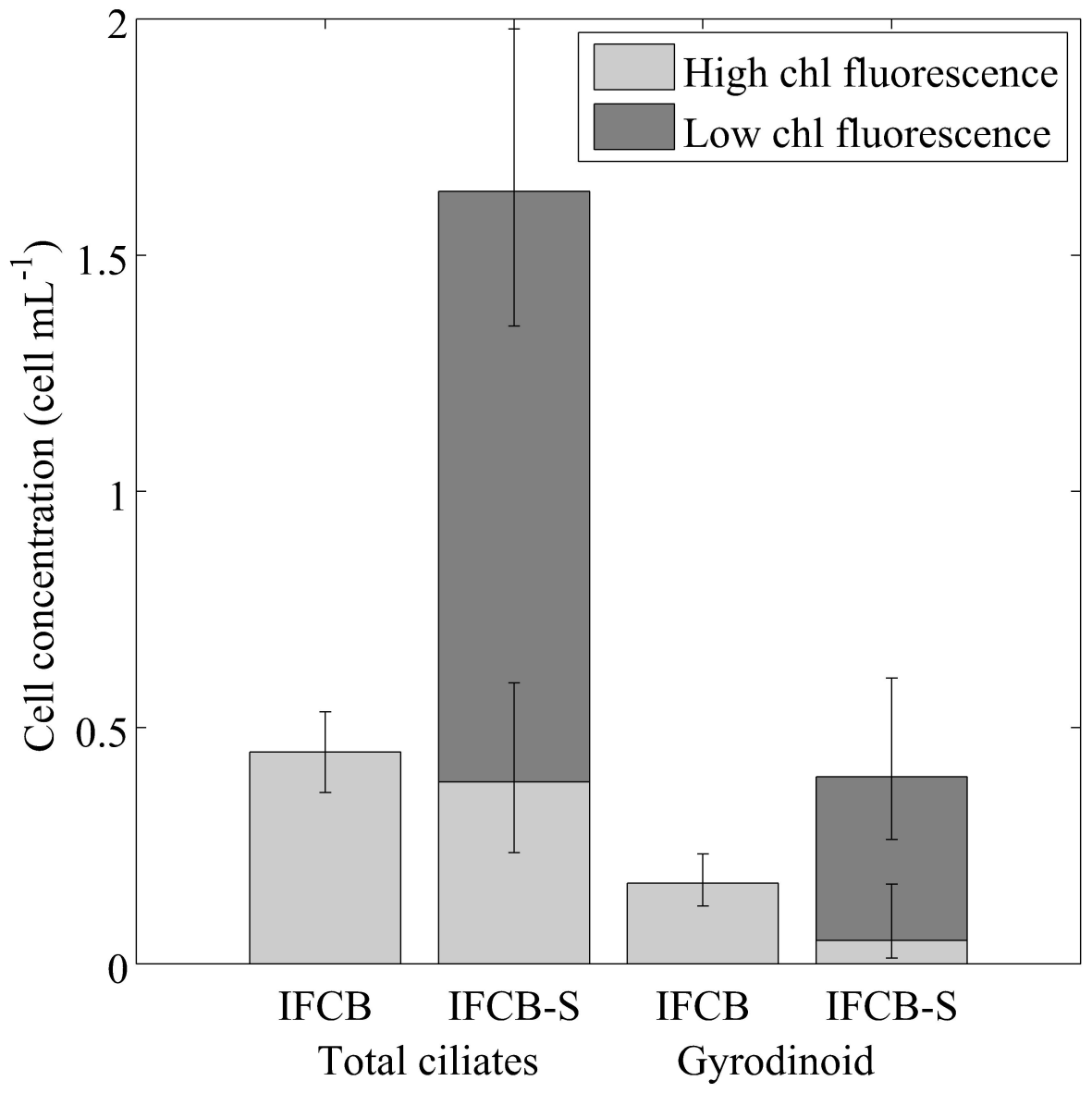

Figure 2-9: Daily-binned cell concentration for total ciliates and gyrodinoid dinoflagellates imaged on August 25, 2014, during the ECOMON cruise. Light and dark grey bars indicate populations with high and low chlorophyll fluorescence, respectively. Error bars indicate 95\% confidence intervals computed assuming Poisson distributed counting statistics. 


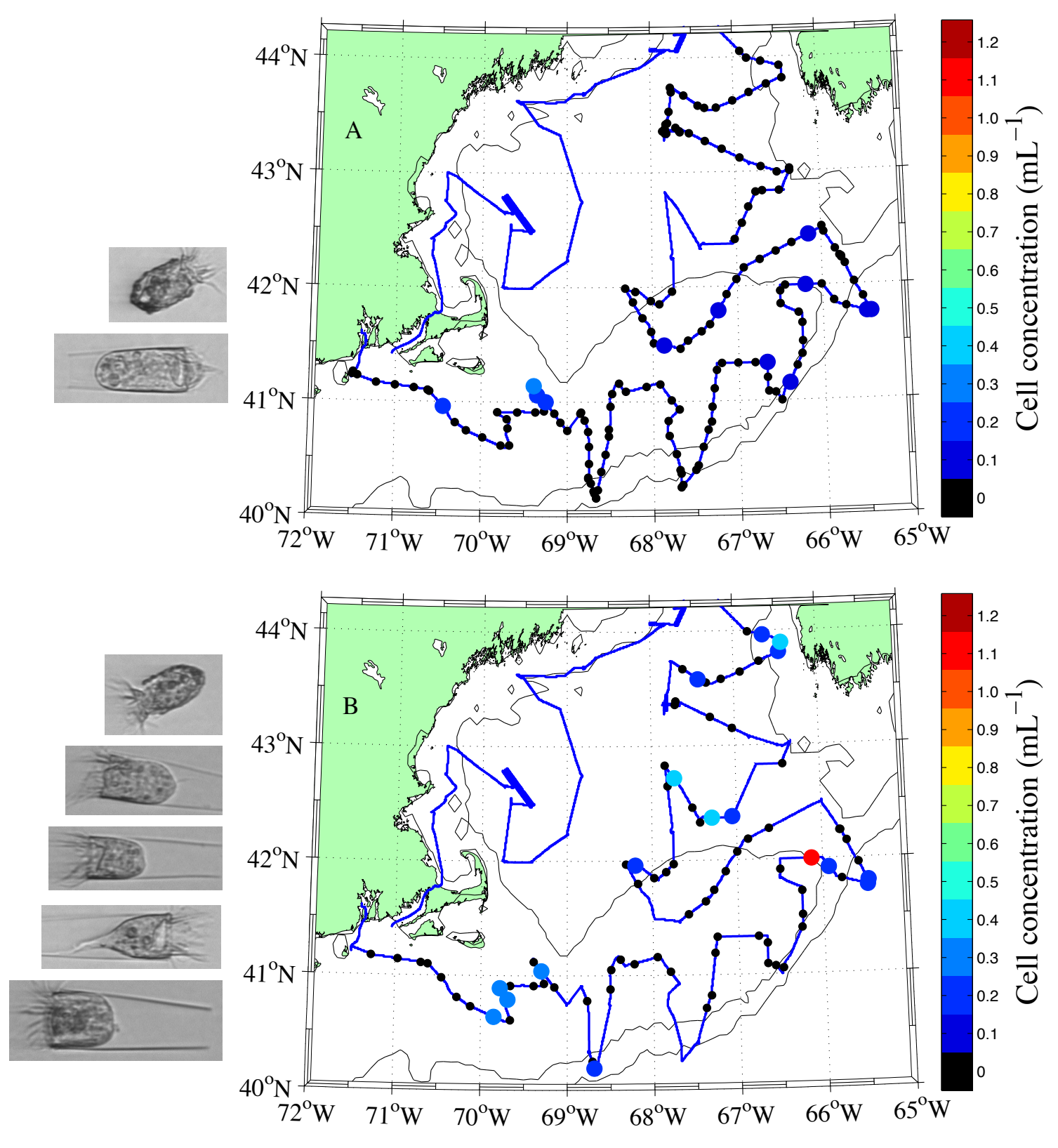

Figure 2-10: Concentration of tintinnids observed during hourly intervals in surface waters along the ECOMON cruise track in August-September 2013. Black symbols indicate locations where no tintinnids were observed. (A) Abundances observed with a standard IFCB. (B) Abundances observed with IFCB-S. Example images found around the tintinnid hotspot (station with $\sim 1.1 \mathrm{ml}^{-1}$ on lower map) are shown to the left of each map, with approximate frequency distribution of the observed morphotypes reflected in the examples shown. Hyaline morphotype (distinguished by transparent lorica) is Eutintinnus spp; agglomerated morphotype is Tintinnopsis spp. 

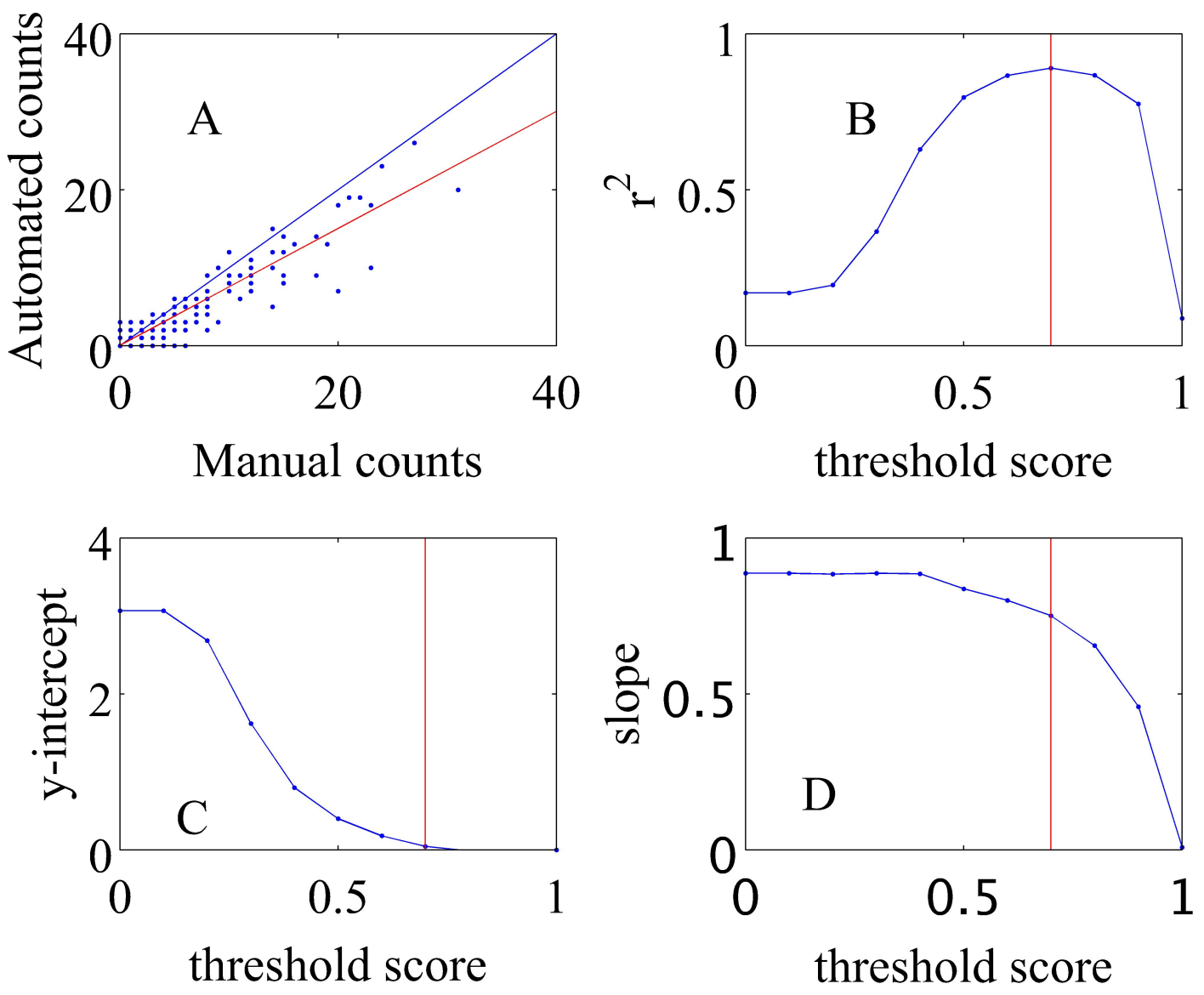

Figure 2-11: (A) Regression between hourly bins of manually identified Laboea strobila cell abundances at MVCO and automated classification results for score threshold 0.7. The blue line represents a 1:1 line and the red line is best fit; (B) $R^{2}$ values for all thresholds tested; (C) y-intercept values of best fit line for all thresholds tested; (D) slope values of best fit line for all thresholds tested. Vertical green line in B-D indicates selected threshold score of 0.7 


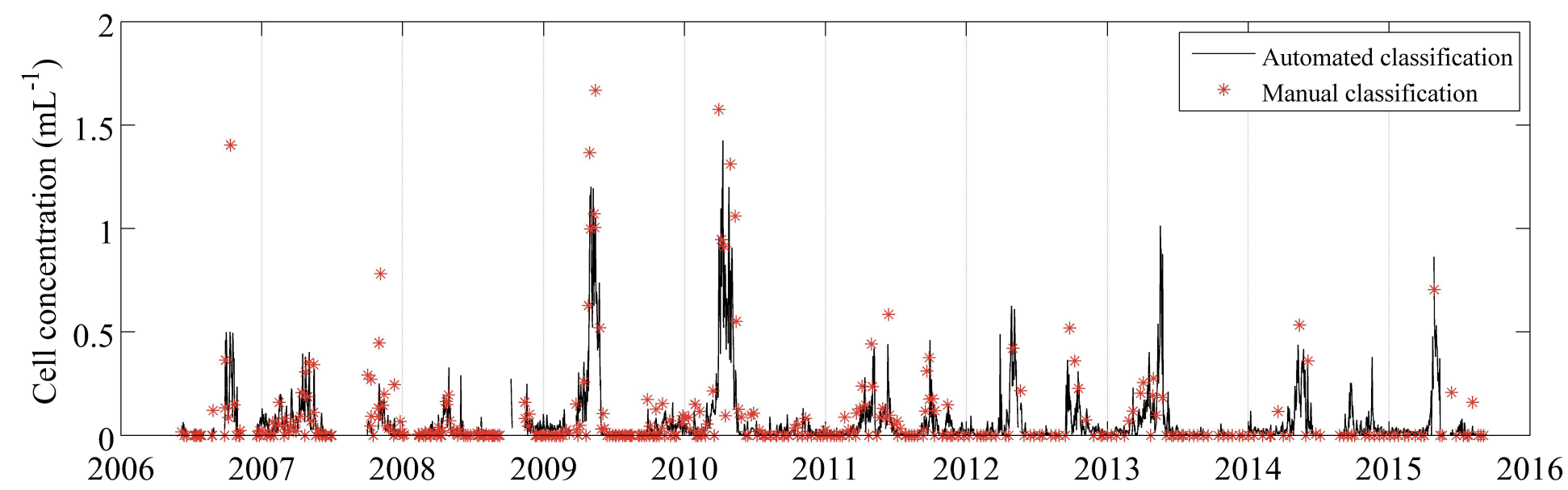

Figure 2-12: Daily resolution times series of Laboea strobila cell abundance at MVCO. Intermittent (approximately 2 wk interval) counts from manual identification (red stars) are shown with the high-resolution results from automated classification (black line) 


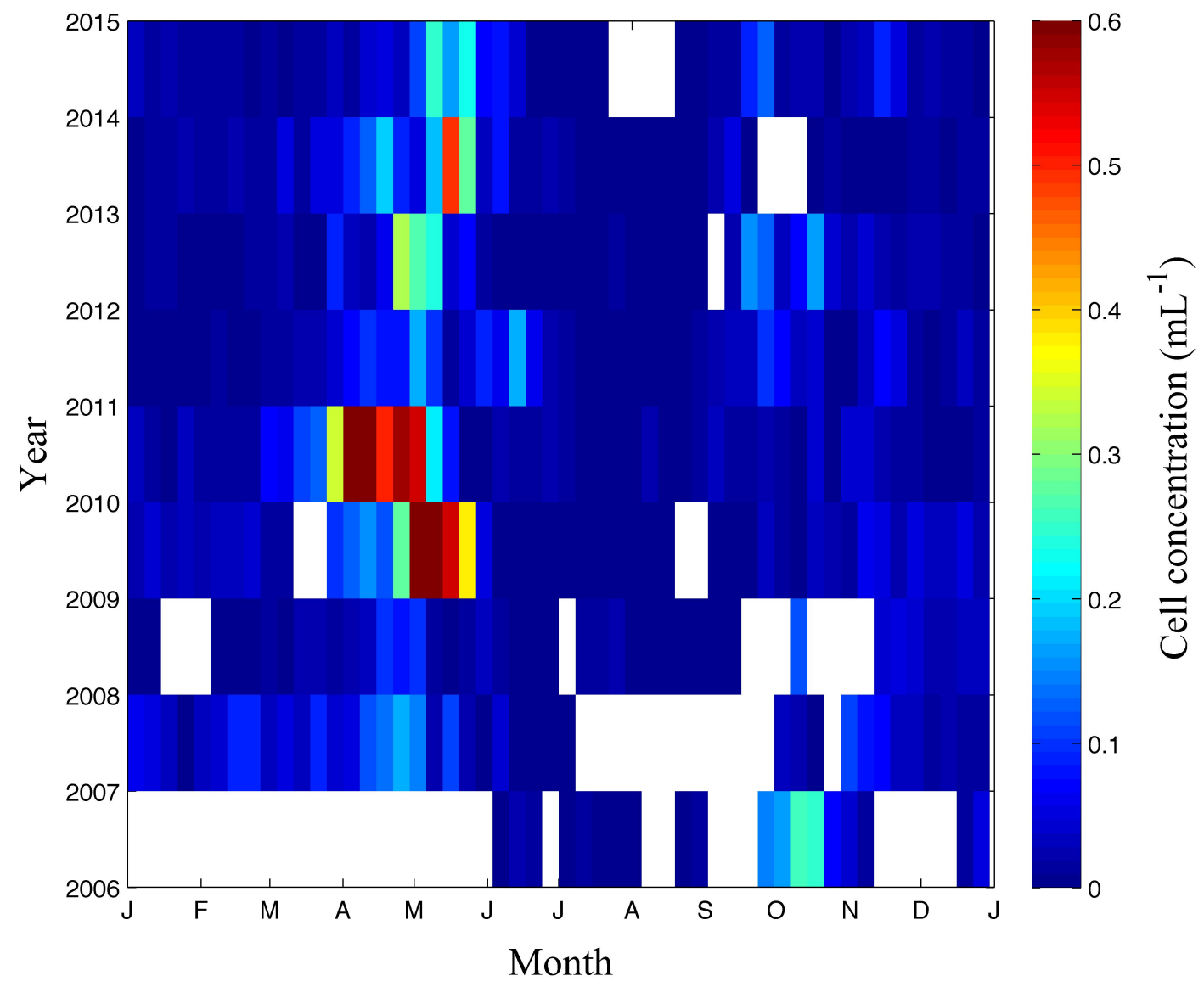

Figure 2-13: Multi-year records of weekly-binned Laboea strobila abundance at MVCO determined by IFCB sampling combined with automated image analysis and classification. White bars indicate times when no data is available 


\section{Chapter 3}

\section{Seasonal dynamics of herbivorous ciliates from a 10-year time series}

\subsection{Introduction}

Ciliate micrograzers are a major functional component in planktonic food webs (Pomeroy, 1974; Azam et al., 1983). They transfer carbon to higher trophic levels from small-sized phytoplankton, which are typically inaccessible to larger metazoan grazers, such as copepods. For example, dissolved organic carbon incorporated into bacterial biomass can then be transferred up the food web via ciliates and heterotrophic nanoflagellates. Ciliates also play a role in nutrient regeneration, recycling about $60 \%$ of the nitrogen ingested, and fueling primary productivity in nutrient-limited waters (Finlay \& Fenchel, 1996).

Because they are important trophic intermediaries, studies have been directed at quantifying impacts of ciliates in marine systems. Microzooplankton have been found to significantly affect the communities they graze upon, at times consuming $>50 \%$ of daily primary production (Calbet \& Landry, 2004). In Narragansett Bay, RI, for example, ciliate and dinoflagellate grazers remove an average 96\% (20 to 200\%) of primary production annually with peak grazing rates during summer (Lawrence \& Menden-Deuer, 2012). Verity (1987) found that a group of ciliates, tintinnids, in Narragansett Bay could potentially ingest $26 \%$ of total annual net primary production and $52 \%$ of the estimated production of $<10 \mu \mathrm{m}$ phytoplankton. In their classic work with nutrient-phytoplankton-zooplankton models, Evans \& Parslow (1985) estimated that protist grazing (when coupled with phytoplankton growth) 
could be powerful enough to suppress the annual spring phytoplankton bloom.

In temperate coastal waters, environmental conditions and biological processes exhibit large seasonal variation. These environments provide a valuable stage for studying the response of protist micrograzer communities to seasonality and longer-term trends associated with environmental and climate change, as well as associated effects on prey populations. In a temperate, nearshore environment, Tamigneaux et al. (1997) identified seasonal grazerdependent changes in food web structure evident as shifts in the biomass and size structure of phytoplankton and protist grazers. Their findings suggested two different food webs occur over the annual cycle: larger predators and consumers transfer carbon to higher trophic levels during the spring bloom, while smaller plankton concentrate carbon in the microbial loop during summer. These seasonal relationships between ciliate micrograzers and the base of the aquatic food web emphasize the importance of understanding ciliate dynamics temporally.

Ciliates are difficult to study due to collection, culture, and observation challenges. They are fragile and net collection can be harmful to their structure. Aloricate ciliates can slip through nets with mesh $20 \%$ of their size (Smetacek, 1981). Their soft bodies make preservation difficult as the process causes shrinkage, distortion, or disintegration (Stoecker et al., 1994). They are also challenging to keep in culture due to their sometimes complex nutritional needs (Gifford, 1985).

At the Martha's Vineyard Coastal Observatory (MVCO), we have been using new approaches to study ciliate communities in situ and in high temporal resolution. Long-term deployments of the autonomous, submersible imaging-in-flow cytometer, Imaging FlowCytobot (IFCB) (Olson \& Sosik, 2007), allows observation of live herbivorous ciliates in situ without the need to culture or preserve. IFCB provides continuous, high temporal resolution observations of abundance, taxonomy, and size during multi-month, unattended deployments in the ocean and back-to-back deployments provide multiyear coverage. From these multiyear, high temporal resolution records we find that population concentrations can be highly variable in time (Brownlee et al., 2016), a long recognized aspect (and observational challenge) of ciliate ecology.

Time series have great potential to help answer questions about ciliate communities and dynamics. Observations such as co-occurrence patterns between predator and prey or repeated responses to environmental changes allow for insights into ciliate ecology. Time series 
provide information about which types of events are ephemeral phenomena and which are recurrent. Time series may provide insights into responses to climate variables and other factors, such as eutrophication, and may ultimately offer insights about the system's resilience. Time series that are adequately resolved in time and long enough in duration can provide information spanning from short-lived biological interactions to large-scale oscillations in forcings such as those behind the North Atlantic Oscillation and El Niño.

Their value notwithstanding, time series data are challenging to interpret. Kamiyama \& Tsujino (1996) studied seasonality of tintinnid ciliates in the Sea of Japan every two weeks for three years. They used the 'run test' or Wald-Wolfowitz runs test, a non-parametric statistical analysis to determine if a data set is from a random process. The analysis tests the null hypothesis that the time series occurs in random order, against the alternative that the ordering is not random. The test is based on the number of runs of consecutive values above or below the median or mean of the time series. This can be an issue if there are time series that are inflated with zero concentrations (something inevitable in a long time series) and the mean or median may not be the appropriate parameters to use for that distribution. Autocorrelations are also used to determine if there are even intervals between events, by correlating a time series with its own past and future values. Positive correlation may indicate persistence of a system to stay in a certain state, but if events are changing slightly in time, this may not be captured. Simply averaging the same time bins of separate years to present a 'climatology' may also not be appropriate for data with low or nonexistent counts.

To understand underlying seasonality and deviations from such seasonality, we employed a statistical model that estimates a seasonal density pattern, which simultaneously accounts for and separates any annual-scale effects. This allows us to estimate a seasonal density pattern that is not obscured by interannual variations, similar to a model proposed by Cloern \& Jassby (2010) to decompose a chlorophyll- $a$ time series. The differences in our model lie in that we use count data from varying volumes of water (sampling effort), which necessitates the need for Poisson counting statistics. To determine the estimates for our components we used a maximum likelihood approach with inflated confidence intervals accounting for over-dispersion.

In this chapter, we first address broad patterns and seasonality of major ciliate classes and their components. We then focus on basic ecological questions that have been difficult 
to answer historically due to the practical trade-offs between long-term sampling effort and temporal resolution. Here, with multiyear high temporal resolution data, we explore the seasonal patterns of some ciliate taxa in more detail: an obligate mixotroph, Laboea strobila, a phototrophic ciliate, Mesodinium spp., and a subclass of strict heterotrophs, Tintinnida. Whether these patterns occur year to year and what influences or changes these patterns are the driving motivations for this chapter.

We address the following questions: Do groups of herbivorous ciliates on the New England shelf exhibit seasonal patterns? When identified to a further taxonomic level, how do (certain) morphotypes contribute to seasonal patterns? Do these patterns and contributions of different morphotypes recur every year? What are the possible drivers of these patterns?

\subsection{Materials and Methods}

\subsubsection{Observations and study site}

We characterized plankton communities, including the taxonomic composition and occurrence patterns of ciliates, at the Martha's Vineyard Coastal Observatory (MVCO) over the period from June 2006 to December 2016. MVCO is located on the New England shelf $3 \mathrm{~km}$ south of the island of Martha's Vineyard, Massachusetts (41 19.500' N, 70 $\left.34.0^{\prime} \mathrm{W}\right)$. This facility consists of a shore laboratory and cabled access to a meteorological mast at the shoreline, an undersea node at 12-m depth, and an offshore tower in 16-m water depth. The observatory hosts a wide variety of biological, meteorological, and hydrographic instruments, which collect data such as temperature, salinity, incident solar radiation, wind speed, and wave conditions. We used a MicroCat CTD (Seapbird Electronics) to make temperature measurements continuously at 4-m depth at the offshore tower. Gaps in that record were filled with the MVCO core measurements from the undersea node at $12-\mathrm{m}$. These core datasets were downloaded from the public MVCO website: http://www.whoi.edu/mvco/data.

For this study, we carried out specialized observations at MVCO. We used a combination of continuous observations from automated submersible flow cytometers and discrete measurements of samples collected approximately monthly by boat.

For nutrient analysis, discrete samples were filtered through a $0.2 \mu \mathrm{m}$ Sterivex ${ }^{\circledR}$ filter into acid-washed vials and frozen at $-20^{\circ} \mathrm{C}$ until subsequent analyses. These samples were 
analyzed at the Woods Hole Oceanographic Institution Nutrient Analytical Facility (Woods Hole, MA) for concentrations of phosphate, silicate, ammonium, and combined nitrate + nitrite.

To characterize large nanoplankton and microplankton, we used Imaging FlowCytobot (IFCB), a submersible flow cytometer, which records high-resolution images $(\sim 1 \mu \mathrm{m})$ and associated optical properties of individual cells (Olson \& Sosik, 2007). IFCB was deployed at $4 \mathrm{~m}$ depth on the MVCO offshore tower. The IFCB provides continuous long-term observations during unattended deployments, which started in June 2006 and are continuing presently.

IFCB processes a 5 -mL sample every 20 minutes. The sample is drawn into the instrument by a programmable syringe pump and injected into the center of a particle-free sheath flow where particles pass single file through a 635-nm laser. The particles scatter laser light and chlorophyll-containing cells emit red fluorescence $(680 \mathrm{~nm})$ (details in Olson \& Sosik (2007)). Chlorophyll fluorescence is used to trigger a 1- $\mu$ s pulse from a xenon flash lamp and an image is captured. Measurements of chlorophyll fluorescence and side scattering are recorded along with the image. This allows for in situ observations of chlorophyll-containing cells. Originally designed for phytoplankton, the IFCB detects mixotrophic and herbivorous ciliates as well (Brownlee et al., 2016) because it records images of any cells with chlorophyll fluorescence above the trigger threshold. The data are transferred to shore in near real-time and data processing begins automatically (Sosik \& Futrelle, 2012). The image data and associated features can be accessed at http://ifcb-data.whoi.edu/mvco.

Picophytoplankton and small nanophytoplankton were measured with FlowCytobot (FCB), a submersible flow cytometer (Olson et al., 2003). In contrast to IFCB, FCB does not image, but only makes scattering and fluorescence measurements of individual particles. The instrument is optimized for detecting cells $<10 \mu \mathrm{m}$. With a 532-nm laser, the instrument detects foward and side scattering and particle fluorescence at 575 and $680 \mathrm{~nm}$. Synechococcus cells were unambiguously separated from other cells due to their phycoerythrin (PE) fluorescence and low amount of light scattering (Olson et al., 1990). Picoeukaryotic phytoplankton have similar light scattering, but lack PE, while 2-10 $\mu$ m eukaryotic phytoplankton produce a larger amount of light scattering (Durand \& Olson, 1996; Marie et al., 2014). FCB processes $0.25 \mathrm{~mL}$ samples, but their rate can be varied $(0.25 \mathrm{~mL} / 5-20$ minutes $)$ to accommodate differing cell concentrations. 
The longterm deployments of IFCB and FCB entailed swapping between two of each instrument. A typical deployment is 6 months and same-day swaps were done whenever possible to minimize gaps in data records. Both instruments employ anti-fouling measures and automated analysis of polystyrene microspheres (beads) $(9 \mu \mathrm{m}$ and $1 \mu \mathrm{m}$ size in IFCB and FCB, respectively) to monitor data quality. Anti-fouling measures included are a daily release of sodium azide into the sheath fluid (final concentration $\sim 0.01 \%$ ) and chlorox $(20 \%)$ added to the sample tubing after bead analyses.

\subsubsection{Manual image classification}

We used computer-assisted manual identification of ciliates in IFCB images to categorize the ciliates into 26 taxonomic groups. The level of taxonomic identification allowed by IFCB images varies, but some identification is to genus or species level (Fig. 3-1). Images that cannot be identified to this level are placed into a group of 'miscellaneous Spirotrichs' (a group comprised of mainly the sublcasses Oligotrichia and Choreotrichia). Image identification was manually performed for observations corresponding to 1-4 hours (3 to 12 data files) for 2 days each month from mid-2006 to the present. We examined some full days for larger, less abundant ciliates (Laboea strobila and all tintinnid categories) resulting in 1-4 full days every two weeks from 2006-2010. During further analyses, we divided the broad genus Tintinnopsis into 3 size classes: small cells of $<40 \mu \mathrm{m}$ equivalent spherical diameter (ESD), medium-sized cells in the range $40-60 \mu \mathrm{m}$ ESD, and large cells $>60 \mu \mathrm{m}$ ESD. We also divided miscellaneous Spirotrichs into 3 size classes: small cells of $<20 \mu \mathrm{m}$ equivalent spherical diameter (ESD), medium-sized cells in the range 20 - $40 \mu \mathrm{m} \mathrm{ESD,} \mathrm{and} \mathrm{large} \mathrm{cells}$ $>40 \mu \mathrm{m}$ ESD. The ciliate, Mesodinium spp. was split into $<20 \mu \mathrm{m}$ and $>20 \mu \mathrm{m}$.

\subsubsection{Automated image classification}

Analysis of IFCB data included image processing, feature extraction, and supervised automated classification as described by Sosik \& Olson (2007) except that instead of the original support vector machine, we used a random forest classification algorithm after (Breiman, 2001). We applied a classifier with 50 categories, including L. strobila, mixed tintinnids, Mesodinium spp., and miscellaneous spirotrichs. For each unknown image, results from the classification algorithm (Tree-Bagger function in MATLAB, The Mathworks) provide an affiliation score for each category (scores sum to 1 across all categories). By selecting a score 
threshold above which classifications are accepted, it is possible to reduce the incidence of false positives, albeit typically at the expense of lower probability of detection for true positives. As described in Brownlee et al. (2016), linear regression analyses between manual and automated counts for various score thresholds were performed and values of $\mathrm{R}^{2}$, y-intercept, and slopes were used to select a threshold score. An ideal threshold would be one where the $\mathrm{R}^{2}$ is maximized, the $\mathrm{y}$-intercept is near zero, and the slope approaches 1 . Once a threshold score is selected, concentration estimates are determined by counting targets with scores above that cut-off, and an average correction efficiency is applied by dividing the total by the regression slope for the chosen threshold.

Probability of detection by the automated classifier was determined by $\mathrm{TP} /(\mathrm{TP}+\mathrm{FN})$, where $\mathrm{TP}=$ true positives (those classified as belonging to the category and manually verified as correct) and $\mathrm{FN}=$ false negatives (those classified as not belonging to the category, but manually verified as correct). The precision of the classifier was determined by $\mathrm{TP} /(\mathrm{TP}+\mathrm{FP})$, where $\mathrm{FP}=$ false positives (those classified as belonging to the category, but manually verified as incorrect).

Automated and manual image classification of the oligotrich, L. strobila, provided similar patterns of variability with both showing distinct seasonality in concentration (Fig. 3-9). As detailed in Brownlee et al. (2016), for this organism our automated classifier has a probability of detection $=0.97$ and precision $=0.90$ before application of any score threshold (with a correction factor of 0.7994$)$. With a score threshold of 0.7 , the corresponding probability of detection drops to 0.79 (19\% unclassified and $2 \%$ misclassified), while the precision increases to 0.99. At fine scales, there can be discrepancies between automated and manual identification. Some of these discrepancies may be caused by patchiness at MVCO interacting with sampling differences: For example, manually classified concentrations were often only for a few hours within a given day, while the daily estimate for automated classification reflects sampling over the entire day.

Automated and manual classification of total tintinnids provided similar patterns of concentration (Fig. 3-12). For this organism, the classifier has a probability of detection = 0.75 and precision $=0.69$ before application of any score threshold. With a score threshold of 0.5 (with a correction factor of 0.6602 ), the corresponding probability of detection drops to 0.39 , while the precision increases to 0.94 .

Automated and manual classification of Mesodinium spp. provided broadly similar pat- 
terns of concentration throughout the time series, though there were periods when classifier false positive rates were consistently high (e.g. late 2011, early 2015). (Fig. 3-17). For this organism, the classifier has a probability of detection $=0.64$ and precision $=0.67$ before application of any score threshold. With the selected score threshold of 0.3 , the corresponding probability of detection drops to 0.42 , while the precision increases to 0.85 .

\subsubsection{Data analysis}

For all analyses, cell concentrations of Laboea strobila and total tintinnids were determined by automated classification. Total ciliates, ciliate classes and subclasses, individual tintinnids, Mesodinium sp., and IFCB phytoplankton cell concentrations were determined by manual classification.

We determined cell concentration by dividing raw counts of images in each category with the volume of water analyzed in a sample (as calculated from flow rate and duration of analysis and accounting for time spent handling triggers). As appropriate, counts and volumes were binned daily, weekly, or bi-weekly. Estimated eqivalent spherical diameters were derived from cross-sectional area of imaged cells. Cell biovolumes were calculated for each image following Moberg \& Sosik (2012) and carbon values were calculated with volume-to-carbon ratios from Menden-Deuer \& Lessard (2000).

To examine potential relationships, Pearson's correlation coefficients were calculated between ciliate and potential prey cell concentrations with a Student's t-distribution calculated test statistic for weekly binned data.

To determine temperatures associated with certain taxonomic groups, temperatures averages were weighted by cell concentration and mean and standard deviation recorded.

\subsubsection{Time series model}

To understand the seasonal patterns of a taxonomic group, we need to be able to construct an expected seasonal cell concentration that is separate from interannual variation. Simply averaging the same time intervals over each year may obscure seasonal patterns due to over dispersed data towards zero. Use of a model that explicitly incorporates seasonal (expected seasonal cell concentrations) and annual (annual multipliers) components can be helpful, as in cases when cell concentrations are very high one year, but low or absent the next.

Typically a Poisson distribution represents biological count data well. We developed a 
Poisson model that incorporates expected seasonal cell concentrations and annual multipliers, while adjusting for over-dispersed counts with inflated confidence intervals. This model partitions variation of count data into either yearly or seasonal components, which allows for confidence intervals to better represent seasonal patterns. Examination of annual multipliers can illuminate how certain years vary in magnitude compared to others over a time series, while expected seasonal cell concentrations provide a pattern of seasonality without this influence.

We organized the data into two-week bins for counts and denote observed counts as $Y_{i j}$, where $i$ refers to year and $j$ refers to two-week bin. We assume the counts vary according to a Poisson distribution for each two-week window, where the mean is determined by cell concentration multiplied by volume measured:

$$
Y_{i j} \sim \operatorname{Poissson}\left(\mu_{i j} \cdot V_{i j}\right)
$$

Here $\mu_{i j}$ is the cell concentration and $V_{i j}$ is volume. We are able to separate the contributions of seasons and years by parameterizing the cell concentration as:

$$
\mu_{i j}=\alpha \cdot \exp \left(\beta_{i}+\gamma_{j}\right)
$$

where $\beta_{i}$ are annual multipliers and $\gamma_{j}$ are expected seasonal (two-week bin) cell concentrations. $\alpha$ is a constant determined by averaging the cell concentrations of the entire time series. This allows for the expected cell concentrations to have proper units, while $\beta_{i}$ and $\gamma_{j}$ are without units.

We used a maximum likelihood approach to fit the parameters of the above model and calculate the log likelihood (L) function as:

$$
\ln L(\beta, \gamma)=\sum_{i=1}^{N} \sum_{j=1}^{26}\left[Y_{i j}\left(\ln (\alpha) \beta_{i}+\gamma_{j}+\ln V_{i j}\right)-\alpha \cdot \exp \left(\beta_{i}+\gamma_{j}\right) V_{i j}\right],
$$

where $N$ is the total number of years in the dataset. To find a unique solution, we must impose an identifiability constraint, and choose

$$
\beta_{1}=-\sum_{i=2}^{N} \beta_{i}
$$


This constraint is needed as only the difference between parameters and not the values themselves determine a likelihood value. Without this constraint, many different solutions could fit equally well.

We find that our data are over-dispersed relative to an expected Poisson distribution, and we account for this with inflated confidence intervals based on the degree of over-dispersion.

To find a necessary inflation factor, we first form the Pearson statistic (denoted by $\chi^{2}$ ):

$$
\chi^{2}=\sum_{i=1}^{I} \sum_{j=1}^{J} \frac{\left(y_{i j}-\hat{y}_{i j}\right)^{2}}{\hat{y}_{i j}}
$$

where $\hat{y}_{i j}=\exp \left(\hat{\beta}_{i}+\hat{\gamma}_{j}\right) V_{i j}$, and $I$ is the total number of years and $J$ is the total number of seasons for which there is at least one non-zero count. We leave out seasons or years that have all zero counts as these will not contribute to overdispersion. When then define an inflation factor $c$ as:

$$
c=\max \left[1, \frac{\chi^{2}}{(I \cdot J-(I+J))}\right]
$$

The corrected $95 \%$ confidence interval for a parameter $\left(\beta_{i}, \gamma_{j}\right)$ is given by the values of that parameter that satisfy the following relationship based on the likelihood-ratio test. For example, for $\gamma_{2}$, we have

$$
\left.2\left[\ln L(\hat{\beta}, \hat{\gamma})-\ln L_{\text {prof }}\left(\gamma_{2}\right)\right)\right]<\chi_{1}^{2} \cdot c,
$$

where $\log L_{\text {prof }}$ is the profile $\log$ likelihood and here $\chi_{1}^{2}$ refers to the chi-squared distribution with 1 degree of freedom. Confidence intervals could not be calculated for $\beta_{1}$. Expected cell concentrations of a taxonomic group $\left(\hat{\mu_{i j}}\right)$ were calculated by:

$$
\hat{\mu_{i j}}=\alpha \cdot \exp \left(\hat{\beta}_{i}+\hat{\gamma_{j}}\right)
$$

with an expected seasonal cell concentration pattern represented by:

$$
\hat{\mu_{j}}=\alpha \cdot \exp \left(\hat{\gamma}_{j}\right)
$$




\subsection{Results}

\subsubsection{Total ciliate concentration and biomass}

Ciliates were always present at MVCO, with notable inter- and intra-annual variability in concentration and biomass (Fig. 3-2). Events with the highest cell concentration of all ciliates tended to occur in the latter half of the time series. The highest concentrations ranged between 20,000 and 30,000 cell $\mathrm{L}^{-1}$, consistent with other reports for the region (Stoecker et al. 1987, Woods Hole, MA; Stoecker et al. 1989b, Georges Bank; Sanders 1995, Gulf of Maine) and occurred in either spring or late fall. Ciliate biomass was also variable over the time series and reached highest concentrations of approximately 10 to $17 \mu \mathrm{g} \mathrm{C} \mathrm{L}^{-1}$ in select years $(2011,2013,2015$, and 2016).

\subsubsection{Ciliate class seasonality}

The expected seasonal cell concentration for total ciliates was characterized by spring and fall peaks separated by a mid-summer minimum (Fig. 3.3). Herbivorous ciliate concentrations at MVCO were dominated by the ciliate subclasses Oligotrichia and Choreotrichia. The dominant choreotrichs were of the order Tintinnida (15\% of total time series ciliate biomass) while the dominant known oligotrich was Laboea strobila (13.8\% of total time series ciliate biomass). The subclass Oligotrichia generally peaked in the spring and fall with lowest cell concentrations present in the summer and winter (Fig. 3-4A). The subclass Choreotrichia followed a similar, yet less pronounced pattern to Oligotrichia, but with a late fall/winter peak, which persisted throughout the winter (Fig. 3-4C). The class Haptorida was dominated by the photosynthetic ciliate, Mesodinium spp., which encompassed $6 \%$ of total time series ciliate biomass. While patterns of abundance and biomass followed similar patterns for most groups, the class Haptorida was characterized by cell concentration peaks in the fall and biomass peaks in the winter/spring (Fig. 3-4E). The class Prostomatida exhibited peaks in concentration during the spring and fall, though confidence intervals were large during those times indicating high interannual variance (Fig. 3-4G). Perhaps because the miscellaneous spirotrichs (32\% of total time series ciliate biomass) occupied many size classes and different species, no major systematic patterns in seasonality were detected (Fig. 3-4I). Its expected seasonal cell concentration was similar to that of total ciliates . 


\subsubsection{Ciliate size classes}

Ciliates at MVCO were predominantly in $<20 \mu \mathrm{m}$ and $20-40 \mu \mathrm{m}$ size classes (Fig. 3-5). While all size classes were detected year-round, $<20 \mu \mathrm{m}$ ciliates occurred in highest proportion except during the late winter to early spring when the $20-40 \mu \mathrm{m}$ size class dominated numerically. Larger size classes had their highest proportion in mid spring, but rarely exceeded $20 \%$ of cells. The patterns of size-class contributions to overall abundance varied interannually, most notably which size class dominated in late winter/early spring (Fig. 36). For years such as 2012 and 2016, <20 $\mu \mathrm{m}$ ciliates remained in high proportion from winter to spring. The total ciliate biomass at MVCO was dominated by the $20-40 \mu \mathrm{m}$ size class, which peaked in early spring and late summer (Fig. 3-5). The contribution to biomass of the larger size class peaked in mid spring while $<20 \mu \mathrm{m}$ ciliate contribution to biomass remained below $\sim 20 \%$.

Herbivorous ciliates at MVCO ranged from $\sim 10 \mu \mathrm{m}$ to $\sim 110 \mu \mathrm{m}$ in equivalent spherical diameter (ESD) (Fig. 3-7). Groups of ciliates at MVCO contributed to the overall size distribution differently. Miscellaneous spirotrichs and the class Haptorida were skewed toward smaller size classes. The known oligotrichs and choreotrichs ranged from $<20 \mu \mathrm{m}$ to $>100$ $\mu \mathrm{m}$. The class Prostomatida, while low in concentration, ranged from $<20 \mu \mathrm{m}$ to $<80 \mu \mathrm{m}$.

Some important taxa showed seasonal differences in size distribution (Fig. 3-8). The oligotrich, L. strobila, had a relatively stable size distribution year round, while total tintinnid populations were found to be $<40 \mu \mathrm{m}$ in the summer and fall and predominantly $>40$ $\mu \mathrm{m}$ in the fall, winter, and spring. The haptorid, Mesodinium spp., ranged from $<20 \mu \mathrm{m}$ to approximately $40 \mu \mathrm{m}$. Cells $<20 \mu \mathrm{m}$ occurred predominately in the summer and fall with a small winter peak, while $>20 \mu \mathrm{m}$ occurred in the winter and spring.

\subsubsection{Dominant known oligotrich: Laboea strobila}

Laboea strobila displayed a strong seasonality. It occurred during April-May in most years and had some fall peaks that were smaller and more variable in timing and amplitude (Fig. 3-10, 3-11). Laboea strobila demonstrated a noticeable drop in concentration during summer months. Over the timeseries, annual multipliers of Laboea strobila fluctuated with a general decrease after 2010. The highest annual multipliers were observed in 2009 and 2010.

We observed these seasonal patterns most years with peaks occurring systematically in 
the spring, reaching maximum yearly biomass no earlier than April and no later than the end of May (Fig. 3-11). Peak concentrations reached nearly 2000 cells $\mathrm{L}^{-1}$. The duration of the spring peak varied from a couple of weeks to as long as a month. The highest amplitude spring peaks occurred in the years 2009, 2010, and 2013 with concentrations $>\sim 1000$ cells $\mathrm{L}^{-1}$. Highest fall concentrations $\left(\sim 500\right.$ cells $\left.\mathrm{L}^{-1}\right)$ occurred in 2006, 2011, 2012, and 2015. Laboea strobila cell concentrations corresponded on average with temperatures around 11.1 ${ }^{\circ} \mathrm{C}( \pm 4.0)$ (Table 3-1).

\subsubsection{Dominant known choreotrichs: tintinnids}

Expected seasonal cell concentrations of total tintinnid populations showed distinct spring and late fall peaks that were similar in amplitude and duration (Fig. 3-13). Seasonal densities were at their lowest throughout the summer and early fall. A small and variable winter peak was also noted. Over the time series, annual multipliers of total tintinnids varied little, except for a low in 2012 and a high in 2014.

Peaks in daily-binned concentration of total tintinnids showed seasonal variation between years (Fig. 3-14). Peak concentrations reached up to $\sim 5000$ cells $\mathrm{L}^{-1}$ (2014). The highest spring peaks of the time series occurred in the years 2007, 2011, 2013, 2015, and 2016 with concentrations $>\sim 1000$ cells $\mathrm{L}^{-1}$. Highest fall/winter concentrations $\left(<1000\right.$ cells $\left.\mathrm{L}^{-1}\right)$ occurred in 2007, 2008, 2011, 2014, and 2015. The duration of the spring peaks varied from a couple of weeks to as long as a month, while late fall/early winter peaks at times lasted through both seasons.

Details about seasonality and which organisms contributed to it emerged when the tintinnid community was identified with finer taxonomic detail (Fig. 3-15). Stenosemella pacifica tended to occur in the fall and winter. Elevated concentrations occured in mid winter/early spring each year, but only some years during the fall (Fig. 3-16). Other Stenosemella species were more skewed toward late fall and elevated cell concentrations were observed only in certain years (e.g., 2011, 2014). The genus Tintinnopsis when subdivided by cell size, exhibited spring $(40-60 \mu \mathrm{m}$ and $>60 \mu \mathrm{m})$ and fall peaks $(40-60 \mu \mathrm{m}$ and $<40 \mu \mathrm{m})$. All classes exhibited higher concentrations in certain years, though notably $>60 \mu \mathrm{m}$ Tintinnopsis spp. increased in the latter half of the time series. The more rare tintinnids, Tintinnidium mucicola, Favella spp., and Eutintinnus spp. were found during the spring-fall, with high interannual variability in concentration (Fig. 3-16) . 
Each tintinnid group corresponded with a particular temperature range (Table 3-1). Both Stenosemella pacifica and Tintinnopsis spp. 40-60 $\mu \mathrm{m}$ occurred on average in $>10^{\circ} \mathrm{C}$. Stenosemella sp. and Tintinnopsis spp. $>60 \mu \mathrm{m}$ occurred on average around $\sim 11^{\circ} \mathrm{C}$. Tintinnopsis spp. $<40 \mu \mathrm{m}$, Tintinnidium mucicola, Favella spp., and Eutintinnus spp. occurred in waters $>\sim 12^{\circ} \mathrm{C}$.

\subsubsection{Dominant haptorid: Mesodinium spp.}

For Mesodinium spp., the highest expected seasonal cell concentrations were reached during the fall months and were approximately double the rest of the year (Fig. 3-18).Variable peaks in cell concentration occurred during the winter and throughout the spring (Fig. 3-18). For this group, annual multipliers were highest before 2009 and in 2013.

Peaks in daily-binned concentration of Mesodinium spp. occured during the fall of each year (Fig. 3-19). Peak concentration reached up to $\sim 5000$ cells $\mathrm{L}^{-1}$. The highest fall peaks of the time series occurred in the years 2006, 2011, 2012, 2013, and 2015 with concentrations $>\sim 2000$ cells $\mathrm{L}^{-1}$.

Mesodinium spp. exhibited distinct seasonality in size classes (Fig. 3-8). Mesodinium spp. cells $>20 \mu \mathrm{m}$ began to occur in late fall with progressive addition of larger sizeclasses through winter (Fig. 3-20). Highest concentrations fell within the $<20 \mu \mathrm{m}$ size class. Expected seasonal cell concentrations of Mesodinium spp. $<20 \mu \mathrm{m}$ showed this size class dominated from late summer through the fall (Fig. 3-21). Expected seasonal cell concentrations of Mesodinium spp. $>20 \mu \mathrm{m}$ displayed broad duration peaks in the late winter/ early spring and a short-lived peak in the fall. Annual multipliers of both size classes followed similar patterns as total Mesodinium spp. annual multipliers (Fig. 3-21). Annual multipliers were highest for Mesodinium spp. $<20 \mu \mathrm{m}$ in 2007 and 2013. Annual multipliers were highest for Mesodinium spp. >20 $\mu \mathrm{m}$ in 2006, 2008, and 2013.

Mesodinium spp. $<20 \mu \mathrm{m}$ concentrations corresponded on average with temperatures around $13.3{ }^{\circ} \mathrm{C}( \pm 5.9$ (Table $3-1)$. Mesodinium spp. $>20 \mu \mathrm{m}$ concentrations corresponded on average with temperatures around $8.5{ }^{\circ} \mathrm{C}( \pm 4.5$ (Table $3-1)$. The daily size mode of Mesodinium spp. size exhibited a negative relationship with temperature (Fig. 3-22). 


\subsubsection{Environmental and prey conditions}

Temperature and solar radiation were the major fluctuating environmental factors at MVCO. Temperature ranged from $\sim{ }^{\circ} \mathrm{C}$ to $\sim 20^{\circ} \mathrm{C}$ with season (Fig 3-23). Anomalously high fall temperatures as defined in Appendix A.1 were observed for the years 2007, 2011, 2012, 2014, and 2015. Anomalously high winter temperatures were observed for the years 2006, 2011, and 2015 (Fig. A-6). Daily solar radiation varied from 5-20 $\mathrm{Wm}^{2}$ over the annual cycle. Phytoplankton and nanoplankton populations were highly seasonal. The fall and winter seasons were dominated by diatoms. The diatoms began to decline in the late winter, followed by a small spring increase of mixed nanoplankton. The summer was characterized by a strong annual blooms of Synechococcus, mixed picophytoplankton, and 10-20 $\mu \mathrm{m}$ phytoplankton beginning mid-spring (Fig. 3-24) Following the decline of the $<2 \mu \mathrm{m}$ summer community, fall increases of the $>20 \mu \mathrm{m}$ community occurred. The 2-10 $\mu \mathrm{m}$ eukaryotes exhibited a small spring increase followed by rapid increases in the summer and late fall. Cryptophytes steadily increased starting in mid fall through early winter.

\subsection{Discussion}

\subsubsection{Herbivorous ciliate structure}

Herbivorous ciliate biomass and community structure varied both inter- and intra-annually at MVCO. Various taxonomic groups exhibited notable patterns. Understanding those patterns and whether they persist or change year-to-year is a long-standing challenge. We used an approach that allows us to quantify patterns of seasonality and separate them from interannual variation. To investigate patterns underlying these variations, we used a time series model that explicitly incorporates expected seasonal cell concentrations and annual multipliers, but also allows us to investigate them separately.

The seasonality of total herbivorous ciliate concentration at MVCO was comparable to that observed for total ciliates in other temperate locations. Peaks in ciliate abundance during the spring and fall have been found in the Gulf of Maine (Montagnes et al., 1988), the Kiel Bight (Smetacek, 1981; Smetacek et al., 1982), and Dutch coastal waters (Admiraal, 1986). In the Saanich Inlet, Takahashi (1978) saw spring peaks, but also increases in early winter biomass, something noted in certain years at MVCO. Such spring and fall peaks have suggested to many researchers that the ciliates are responding to increases in the 
phytoplankton. At MVCO, spring is a transition time between diatoms and the $<10 \mu \mathrm{m}$ phytoplankton. While we have observed aloricate ciliates grazing on diatoms in images from the IFCB (not shown), this is not a common occurrence. Due to the close relationship between ciliate size and prey size (Kivi \& Setala, 1995; Jonsson, 1987; Rassoulzadegan et al., 1988; Dolan et al., 2013), we can assume many ciliates at MVCO may be feeding on nanoplankton. Although the abundance of the $<10 \mu \mathrm{m}$ phytoplankton were low, ciliates may have responded quickly to their slight increases. Smetacek et al. (1982) showed that ciliate populations preceeding copepods in the spring out-graze them on phytoplankton blooms.

The lowest concentration of ciliates at MVCO occurred during the summer. At this time of the year, smaller size classes dominated (Fig. 3-3). It has been argued that small planktonic ciliates $(<20 \mu \mathrm{m})$ are bacterivorous (Landry \& Hassett, 1982; Sherr et al., 1986; Jonsson, 1987). If this is the case, our observations would underestimate ciliate concentrations since we can only detect ciliates with some chlorophyll fluorescence. Also, during the summer, pico and nano-phytoplankton populations were highly abundant, leading us to presume that small ciliates were unlikely to be food limited, but possibly high grazing on ciliates by copepods could help explain low summer ciliate concentrations (Dolan, 1991b).

There has been long-standing interest in exploring links among functional groups, size structure, and trophic transfer efficiency in planktonic communities. Ciliates in particular can be characterized into functional groups by their size (Dolan, 1991a; Johansson et al., 2004) due to a close relationship between oral cavity size and the size of prey they can graze upon. Previous studies have shown size distributions of ciliate micrograzers and their prey can help infer trophic transfer efficiency. For example, during an annual study, Gaedke \& Straile (1994) found when prey biomass is high compared to the biomass of the predator, this points to a low efficiency and vice versa. Our data set provides an opportunity to study if the size structure of the herbivorous ciliate community varied in systematic ways.

Some studies have suggested that environmental factors affect ciliate size (through species composition). For example, Montagnes et al. (1988) observed in the waters around the Isles of Shoals, Gulf of Maine that ciliate size structure was greatly affected by temperature; small ciliates occurred during the warmer, summer months, and ciliate size increased into the winter when it reached it's peak. We found something similar, with the exception of secondary increases in the populations of nanociliates $(<20 \mu \mathrm{m})$ during the winter.

When comparing the fraction each size class contributed to total abundance, trends were 
observed where nanociliates $(<20 \mu \mathrm{m})$ dominated throughout the year with an exception in

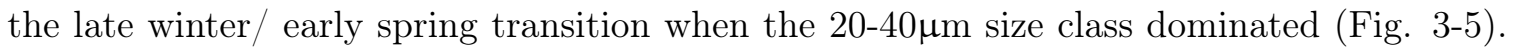
Not surprisingly, patterns of abundance and biomass were different. The 20-40 $\mu \mathrm{m}$ ciliates may represent small amounts in abundance, but in biomass they dominate for example early 2013. The $20-40 \mu \mathrm{m}$ ciliates represented on average over $50 \%$ of total ciliate biomass during late winter/early spring months and quickly decreased into the spring when larger size classes (40-60 and $>60 \mu \mathrm{m}$ ) increased in proportion. The $20-40 \mu \mathrm{m}$ then dominated during the late summer/early fall. High contributions to biomass of the 20-40 $\mu \mathrm{m}$ sized ciliates during the spring and late summer/fall may suggest enhanced efficiency of the transfer of carbon to higher trophic levels.

The nanociliates represented a small portion of the total biomass $(\sim 20 \%)$ throughout the year, but exhibited some increase during the spring-summer transition. The high abundance of nanociliates during the summer (though overall abundance of all size classes together was low) may indicate a system of higher cycling within the microbial loop.

We also observed that ciliate groups at MVCO contributed differently to the size distribution (Fig 3-7), but while size can be a useful proxy for communities, the robustness of biological and ecological interpretations should be related to the degree to which they can be tied to taxonomy. Thus we examined some ciliate taxa representative of different functional groups and size ranges. We studied the seasonality and possible drivers of the ciliate, $L$. strobila, the class Tintinnida, and the haptorid, Mesodinium spp. at in two week intervals.

\subsubsection{Laboea strobila}

Laboea strobila is an oligotrich, which exhibits obligate mixotrophy (Stoecker et al., 1988) and has been recorded to obtain $20 \%$ of its growth through photosynthesis (Putt, 1990b). This fraction grows higher when their entire carbon budget (i.e. respiration as well) is taken into account. In waters around Woods Hole, Massachusetts, L. strobila has been observed to represent almost half of the biomass of chloroplast-retaining ciliates (Stoecker et al., 1987), indicating its importance in the system. Because automated classification performs well on this ciliate, we have unprecedented resolution. From 2006 to present, L. strobila systematically exhibited annual peaks in biomass during the spring and to a lesser extent in the fall. Studies detailing L. strobila have noted varying timing. McManus \& Fuhrman (1986) observed L. strobila exceeding 1000 cells $\mathrm{L}^{-1}$ in Long Island Sound in the spring as 
we do, while Sanders (1995) noted high summer concentrations and one small fall peak in the Damariscotta estuary, Gulf of Maine.

Modigh (2001) noted very short L. strobila events in the Mediterranean Sea in March and April on 3 consecutive years, but did not discuss why. He did note, though, that they almost always occurred within a successional scheme, where they preceded Strombidium spp, then Tontonia spp, another mixotroph. L. strobila's role as first in the succession may indicate its ability to quickly respond to nanophytoplankton populations at MVCO. He also noted Tontonia spp. didn't occur in large amounts when L. strobila was present. This may indicate L. strobila's competitive nature between mixotrophic species of oligotrichs.

L. strobila events at MVCO vary in duration, at times being quite ephemeral, indicating it may not have been able to outlast other ciliates or possibly the events were highly patchy. Predation on L. strobila may also be a factor in these short-lived events. While the timing of the L. strobila spring event varies slightly, we can confidently say that it will occur in April and May. This recurring seasonality at MVCO may indicate that L. strobila's stability is established in this system and while winter and spring temperatures change year to year, $L$. strobila does not seem to be heavily affected.

When observing in situ populations, co-occurrence of predator and prey has long been considered an indicator of the trophic interaction of grazing. Continual co-occurrence of $L$. strobila peaks with 1-2 week lags in concentration of 2-10 $\mu$ m eukaryotic phytoplankton is a possible example. Certain years demonstrated this relationship quite remarkably (2009, 2010, 2011, 2012, 2014, 2015) (Fig. 3-25). Increases of 2-10 $\mu \mathrm{m}$ eukaryotic phytoplankton were also noted with declines of Laboea strobila (2010, 2013, 2014, 2015, and 2016). This juxtaposition may indicate a release in grazing pressure. In oligotrichs like L. strobila, the strategy of acquired photosynthesis has been thought to be advantageous at the onset of stratification, which in turn leads to an algal bloom (Macek et al., 2001). This mixotroph, with the ability to use externally obtained plastids as well as recycle nutrients, can couple its growth with this algal bloom. Even though much energy is utilized during the process of mixotrophy, these organisms can persist when food conditions are poor (Stoecker, 1998; Stoecker et al., 2009). This would make them more competitive on nanophytoplankton blooms, which can be temporally and spatially patchy.

L. strobila has been shown to prefer cryptophyte plastids, though other diets in culture have been found to include haptophytes and perhaps prasinophytes (Stoecker et al., 1988). 
While the detailed composition of the 2-10 $\mu \mathrm{m}$ eukaryotic phytoplankton community of MVCO was not known, images from IFCB have shown these prey groups to be present. L. strobila may also be a specialist feeder, taking advantage of the community that was responsible for the first pulse in concentration of 2-10 $\mu \mathrm{m}$ eukaryotic phytoplankton when daily solar radiation is high. Christaki et al. (1998) described selectivity in feeding behavior between two ciliate species during food limiting concentrations. The ciliates discriminated between particles with different surface properties. L. strobila, when occurring at the onset of the 2-10 $\mu \mathrm{m}$ eukaryotic phytoplankton population may be exhibiting selective behavior.

It must be noted that these interactions are very complicated and other factors must be taken into account including grazers of L. strobila as well as other ciliates grazing on the $2-10 \mu \mathrm{m}$ eukaryotic phytoplankton population. As a mixotroph, L. strobila also needs suitable amounts and types of prey/plastids, nutrients, and light conditions.

\subsubsection{Tintinnid}

Tintinnid ciliates are known to be strictly heterotrophic, representing a different functional group (Dolan et al., 2012) at MVCO. For this group, we observed strong spring and late fall seasonality. There was also a notable small winter peak, which occurred only during certain years (2011-2012, 2014, 2015-2016). These years also exhibited anomalously warm temperatures either in the fall (2014) or winter (2011-2012 and 2015-2016) (Fig. A-6). When suitable food is scarce, heterotrophic ciliates can enter a starvation mode in which they can decrease their respiration and even undergo encystment. These strategies are not available to mixotrophs, which seem to be unable to reduce their respiration rates in times of low light (Crawford \& Stoecker, 1996), as in deep water column mixing in the winter. This may explain the increase of tintinnids in the warmer fall/winter years.

The tintinnids may also be responding to unusually high prey populations for that time of year. In the months of December and January, total tintinnid cell concentration was significantly positively correlated with picophytoplankton concentrations (pico eukaryotes and Synechococcus) (Fig. 3-26), which typically dominated the summer months (Fig. 3-24). A significant negative relationship occurred in April. There were no significant relationships for other months. In the months of November, January, December, and September, total tintinnid concentration was significantly positively correlated with 2-10 $\mu$ m eukaryotic phytoplankton concentrations (Fig. 3-27). Lawrence \& Menden-Deuer (2012) observed that 
along with shifting grazer taxa, there were seasonal changes in grazing rates corresponding to temperature and prey community composition. Though grazing has traditionally been found to decrease in the colder, winter months (Caron et al., 2000; Sherr et al., 2009), Lawrence \& Menden-Deuer (2012) proposed that may reflect a seasonal mismatch of predators and prey more than a physiological limitation for ciliates. They found grazing in Narragansett Bay was high even in winter if the prey community composition was similar to that during summer conditions, something we see at MVCO during these particular winters. Aberle et al. (2007) found with controlled winter warming in mesocosms, the community of ciliates that responded were the Strobilidiids, a group of heterotrophic ciliates; supporting our observations of increases in this functional group. It is well known that temperature is a predominant controlling factor of ciliate growth rates (Montagnes, 1996; Montagnes \& Lessard, 1999), which may indicate why we see a direct relationship between tintinnids and picophytoplankton and 2-10 $\mu$ m eukaryotic phytoplankton rather than an inverse. The tintinnids may be responding to this community, but were not able to grow fast enough to keep populations low. It is important to further explore the predator-prey composition during the year and between years and how this can change predation pressure.

We observed distinct seasonality of tintinnid groups when identified further taxonomically. We saw that the genus Stenosemella was found to occur in late fall and through the winter, while Tintinnopsis size varied seasonally; exhibiting spring $(40-60 \mu \mathrm{m}$ and $>60 \mu \mathrm{m})$ and fall peaks $(40-60 \mu \mathrm{m}$ and $<40 \mu \mathrm{m})$. We saw that certain tintinnids such as Stenosemella

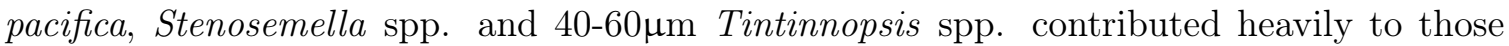
already mentioned warmer fall/winter peaks. These distinct patterns suggest a fine structuring of niches for parts of the tintinnid community. It was more difficult to describe seasonality for Tintinnidium mucicola, Favella spp., and Eutintinnus spp. as they were rare in the time series.

\subsubsection{Mesodinium spp.}

Mesodinium spp. is a common mixotroph in North Atlantic waters, which in high numbers can cause 'red' tides where it can be the dominant source of chlorophyll (Montagnes et al., 1999). It sequesters chloroplasts from its cryptophyte prey and essentially acts as a photoautotroph (Stoecker et al., 1989b). Because automated classification is not yet reliable for Mesodinium spp., we studied this organism with manually identified images. 
Timing of Mesodinium spp. occurrence in temperate regions has been found to vary greatly. Many seasonal studies have noted Mesodinium spp. occurring during the summer months for example in the Mediterranean (Bernard \& Rassouladegan, 1994; Modigh, 2001), the Gulf of Maine (Montagnes \& Lynn, 1989), and Southampton waters, England (Kifle \& Purdie, 1993), while Sanders (1995) observed Mesodinium spp. to be present in highest concentrations in the Damariscotta estuary (Gulf of Maine) between December and April and absent from June through November. McAlice (1968) and White et al. (1977) noted Mesodinium spp. occurred in red water events $\left(>200,000\right.$ cells $\left.\mathrm{L}^{-1}\right)$ in the coastal waters of Maine in the late summer/ early fall and Lindholm (1978) observed autumnal blooms in the Baltic Sea (within fjords around the Aland archipelago). Taylor et al. (1971) noted that maximum numbers of Mesodinium spp. tended to associate with temperature around $15^{\circ} \mathrm{C}$. These temperatures were observed at $\mathrm{MVCO}$ in the summer to early fall, indicating why highest Mesodinium spp. events occurred in the fall here. While we do observe these temperatures in the spring, optimum temperatures and high nutrients needed to support these organisms may not have occurred simultaneously.

At MVCO, Mesodinium spp. numbers were highest in fall (and similar to those Sanders (1995) noted in the winter/spring), low in the winter/spring, and very low in the summer; red water events did not occur. Absence of Mesodinium spp. during the summer months may indicate nutrient depletion during these times because as an obligate mixotroph, it relies on these sources to survive (Smith \& Barber, 1979; Stoecker \& Michaels, 1991).

In the winter at MVCO, biomass was higher than in the fall, due to the appearance of cells of larger size. We therefore treated Mesodinium spp. as two different size classes, $<20$ $\mu \mathrm{m}$ ESD, and those $>20 \mu \mathrm{m}$ ESD. Large Mesodinium spp. have historically been observed in colder environments (Modigh, 2001; Montagnes et al., 2008). Some noted large Mesodinium spp. in cold deep environments (Rychert, 2004). Large Mesodinium spp., may be able to survive during the colder winter months when mixing of the water column is high because its mobility allows it to maintain a favorable position above the mixed layer for photosynthesis (Stoecker et al., 1989b; Crawford \& Purdie, 1991).

In 2008, Montagnes et al. (2008) proposed a nutrient hypothesis explaining the size distribution of Mesodinium rubrum. They proposed that as inorganic nutrients increase, the cells grow and in a nutrient limiting environment, they quickly divide and result in smaller M. rubrum populations. In the case of MVCO, elevated nitrate + nitrite levels 
were recorded during the winter. However, there was little support found for the Montagnes Nutrient Hypothesis as the peaks of these nutrients did not always occur at the same time as the large M. rubrum (Fig. 3-28). We must note, though, that increased nutrient input may not be reflected in measured nitrate and nitrite (e.g., ammonium from recycling in which Wilkerson \& Grunseich (1990) found M. rubrum to uptake).

We found data supporting temperature regulation on size, ultimately leading to a hypothesis that temperature was the major controlling factor. During the winter, large Mesodinium spp. $(>20 . \mu \mathrm{m})$ dominated the assemblage reaching nearly $100 \%$ of total numbers (Fig. 3-29). These peaks in the proportion of large Mesodinium spp. corresponded with periods of low temperature. Temperatures dropping below $\sim 10^{\circ} \mathrm{C}$ were associated with a switch in assemblage from predominantly small to predominantly large cells. For example, in 2007 the cold water period started later than usual and was of shorter duration, and the peak of large Mesodinium spp. was also late and narrow. In 2008, a longer period of colder temperatures coincided with a broader peak of large Mesodinium spp. The mean annual pattern of percent contribution of large and small Mesodinium spp. displayed a switch in assemblages around $10-12^{\circ} \mathrm{C}$ (Fig. 3-30). Increases in smaller size classes followed increases in the temperature cycle closely.

Larger sizes of Mesodinium spp. may occur due to colder environments selecting for larger, slower growing organisms, cells not as rapidly dividing in colder temperatures, or even colder environments selecting for a certain genetic strain of Mesodinium spp. that was larger. While it was historically believed that all Mesodinium spp. belonged to the single species, Mesodinium rubrum deeper diversity has been thought to be exhibited through cell size (Rychert, 2004). Mesodinium major has been found to be larger than traditional Mesodinium rubrum (Garcia-Cuetos et al., 2012b). While these larger Mesodinium spp. may exhibit lower concentrations than their counterparts, they may have a greater contribution to primary productivity if photosynthetic rate is proportional to biomass. Stoecker \& Michaels (1991) found that smaller sized Mesodinium spp. may have reduced cellular rate of photosynthesis.

Solar radiation and prey conditions may also have an effect on why different sizes occur. Mesodinium spp. has been observed to alternate between two different types of growth styles: 'bloom' and 'slow growth-maintenance'. This way, Mesodinium spp. can grow for extended periods without having to feed. This is quite useful when suitable prey concentrations and 
irradiance are low as it can survive and remain photosynthetic for prolonged periods. On the other hand, in the absence of high cryptophyte concentrations, rates of photosynthesis and growth in Mesodinium spp. cannot reach bloom conditions Johnson (2011). This decline is much more rapid in high than low light. We did not note, though, any significant relationships between cryptopyte and Mesodinium spp. abundance. Mesodinium spp. has been noted to select for certain types of cryptophytes (Herfort et al., 2011; Johnson et al., 2016), which may complicate these relationships.

\subsubsection{Conclusions}

Temperate planktonic ciliate communities are episodically dominated by the plentiful and rich subclasses of Oligotrichia and Choreotrichia under the class Spirotrichea (Dale \& Dahl, 1987; Stoecker et al., 1989b; Edwards \& Burkill, 1995; Lynn, 2008). They are also very functional diverse, as choreotrichs have been found to be strict hetertrophs while oligotrichs have the potential to perform mixotrophy under appropriate conditions (Stoecker et al., 1987; Laval-Peuto \& Rassoulzadegan, 1988; Stoecker et al., 2009; Esteban et al., 2010; Johnson, 2011). As such, they are important in the transfer of carbon from small algae to higher trophic levels and secondary and primary production. At times, ciliate-based primary production can contribute large amounts to overall production (Putt, 1990a; Stoecker \& Michaels, 1991; Sanders, 1995). The ciliate Mesodinium spp., a haptorid, can also contribute significantly to primary production (Smith \& Barber, 1979; Stoecker \& Michaels, 1991). It is important to understand the seasonality and drivers of these functionally different grazers.

At MVCO, tintinnid populations appeared to be affected by warmer fall and winter temperatures, though this may be due to a match of predator and prey populations rather than temperature itself. Large tintinnids, such as the genus Stenosemella and $>40 \mu \mathrm{m}$ size classes of Tintinnopsis were more abundance during warm winters. This may have important implications during natural climate variations such as the North Atlantic Oscillation in which positive years exhibit warmer winters. On the other hand, L. strobila, occurring vernally, appeared to be driven by the onset of increases in concentration of the 2-10 $\mu \mathrm{m}$ eukaryotic phytoplankton population. While Mesodinium spp. typically exhibited strong fall blooms, it was also found at other times of the year and populations exhibited seasonality in size structure, possibly driven by shifting temperatures during the fall/winter transition. 
Patterns of variation in annual multipliers for these groups (Laboea strobila, tintinnids, and Mesodinium spp.) provided us with information about certain years and whether different types of ciliates responded similarly to interannual variations. L. strobila experienced decreasing annual multipliers over the last seven years of the time series while total tintinnids were quite stable interannually. These two taxa are functionally different and even though they occurred at similar times of the year, they did not have the same responses year to year. At MVCO, the nanophytoplankton populations have been decreasing over the time series (unpublished data). It may be possible that Laboea strobila was responding to this decrease as their prey preferences lie within this size class. Tintinnids, on the other hand, which are strictly heterotrophic, may have wider prey preferences and remain unaffected by this decrease in nanophytoplankton. Further study into the multi-year trends of individual tintinnid groups may give insight into whether these annual multiplier are similar to that of the overall tintinnid population.

We noted that both large and small Mesodinium spp. had similar patterns of annual multipliers even though the size classes exhibited differing seasonality. This may indicate these two groups respond similarly to prey types or nutrient levels characteristic of the particular year. The highest annual multiplier occurred in 2013, which was similar to total ciliates. In 2013, the highest total ciliate abudance occurred in the spring, while highest Mesodinium spp. concentrations occurred in the fall. Future study is required to determine whether these patterns might have been associated with limited top down control throughout that year.

With images from MVCO, we have valuable information on both taxonomy and size of ciliates; both properties which have been found to be strongly determined by the taxonomy and size of prey populations (Montagnes et al., 1988; Kivi \& Setala, 1995; Johansson et al., 2004). Cell sizes can provide insight on the potential pathway of carbon by categorizing grazers into functional groups as ciliates have been found to graze on certain size classes. This has been noted more heavily for tintinnids as they are restricted by their lorica opening diameter (Dolan et al., 2013). Larger grazers may increase the efficiency of energy transfer to higher trophic levels while smaller heterotrophs determine the fate of bacterial carbon and increase carbon transfer in the microbial loop (Tamigneaux et al., 1997).

Seasonal taxonomic changes in community composition and function have been also been studied and found to play a major role in shaping plankton communities. Sanders (1995) 
noted strong seasonality in ciliate communities in an estuary of the Gulf of Maine with prostist assemblages switching from predominantly aloricate to mixotrophic ciliates during the winter/spring transition (i.e., L. strobila). The fact that these these mixotrophic ciliates contributed $25 \%$ of total community photosynthesis emphasizes their importance in nonbloom periods, which are often not heavily sampled. These photosynthetic (i.e., Mesodinium spp.) and mixotrophic ciliates have also been found to be an important part of communities when phytoplankton biomass is low as they form an important link between the smaller autotrophs and higher trophic levels (Stoecker et al., 1989b). These photosynthetic ciliates can become disproportionately important in the carbon flux to higher trophic levels when phytoplankton assemblages are largely $<5$ um (Dolan \& Marrasé, 1995). We have shown that size alone, while providing important insights, does not capture the notable and important events that taxonomy does. Approaches such as automated imaging and high throughput sequencing are effective ways to resolve this gap. 

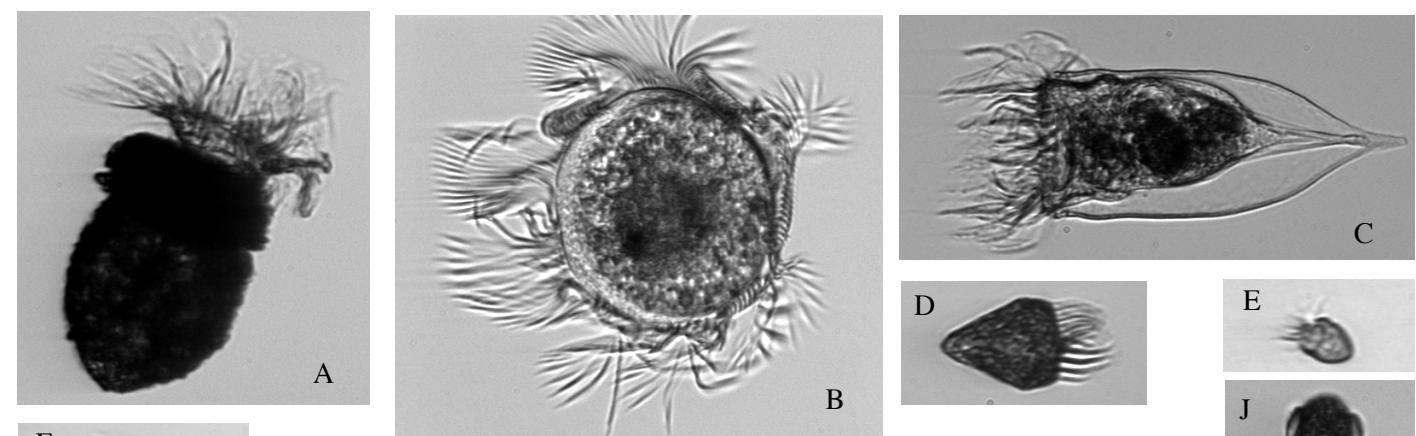

B
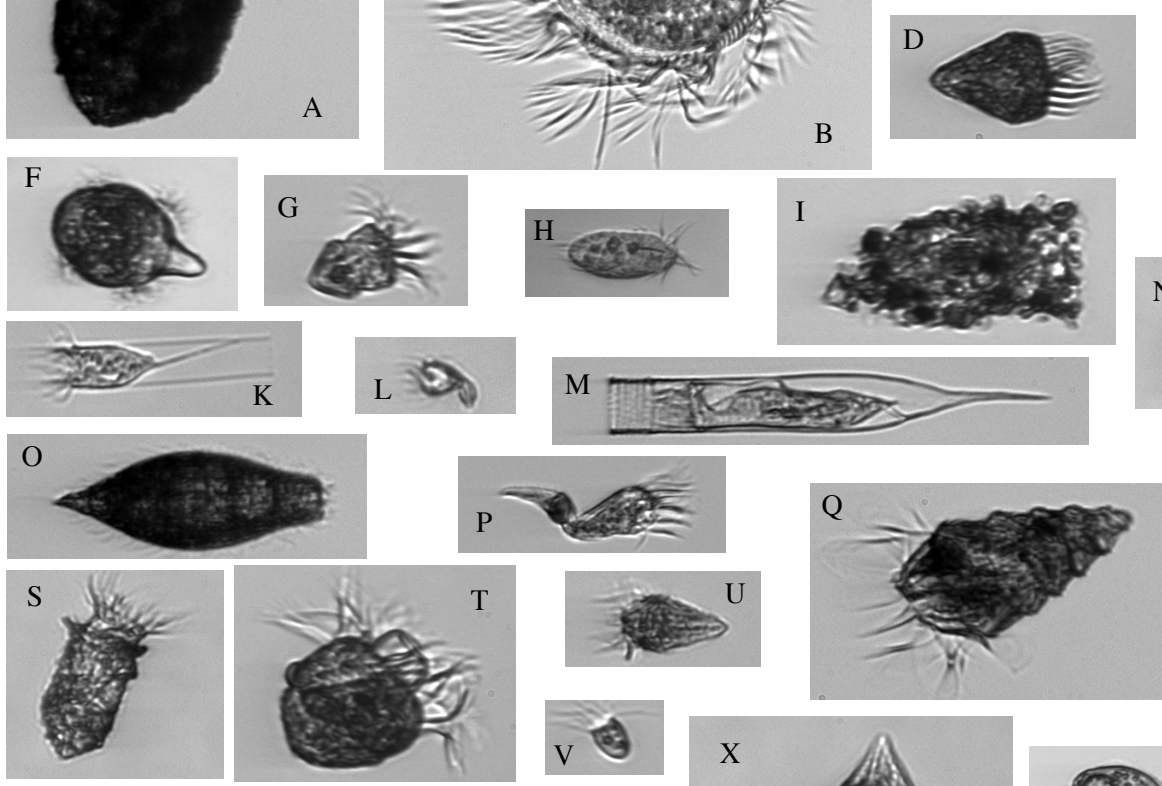

$\mathrm{T}$
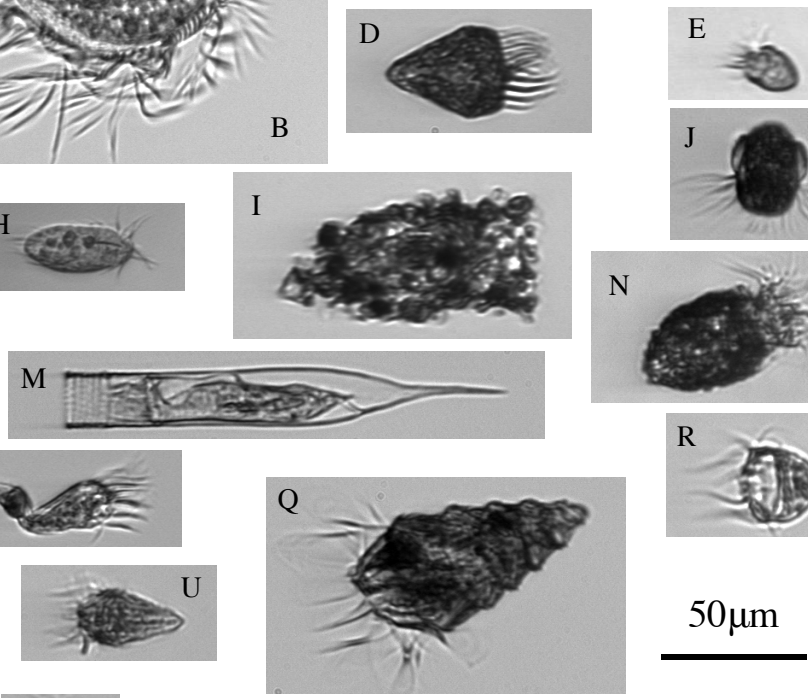

$\mathrm{J}$

$\mathrm{J}$
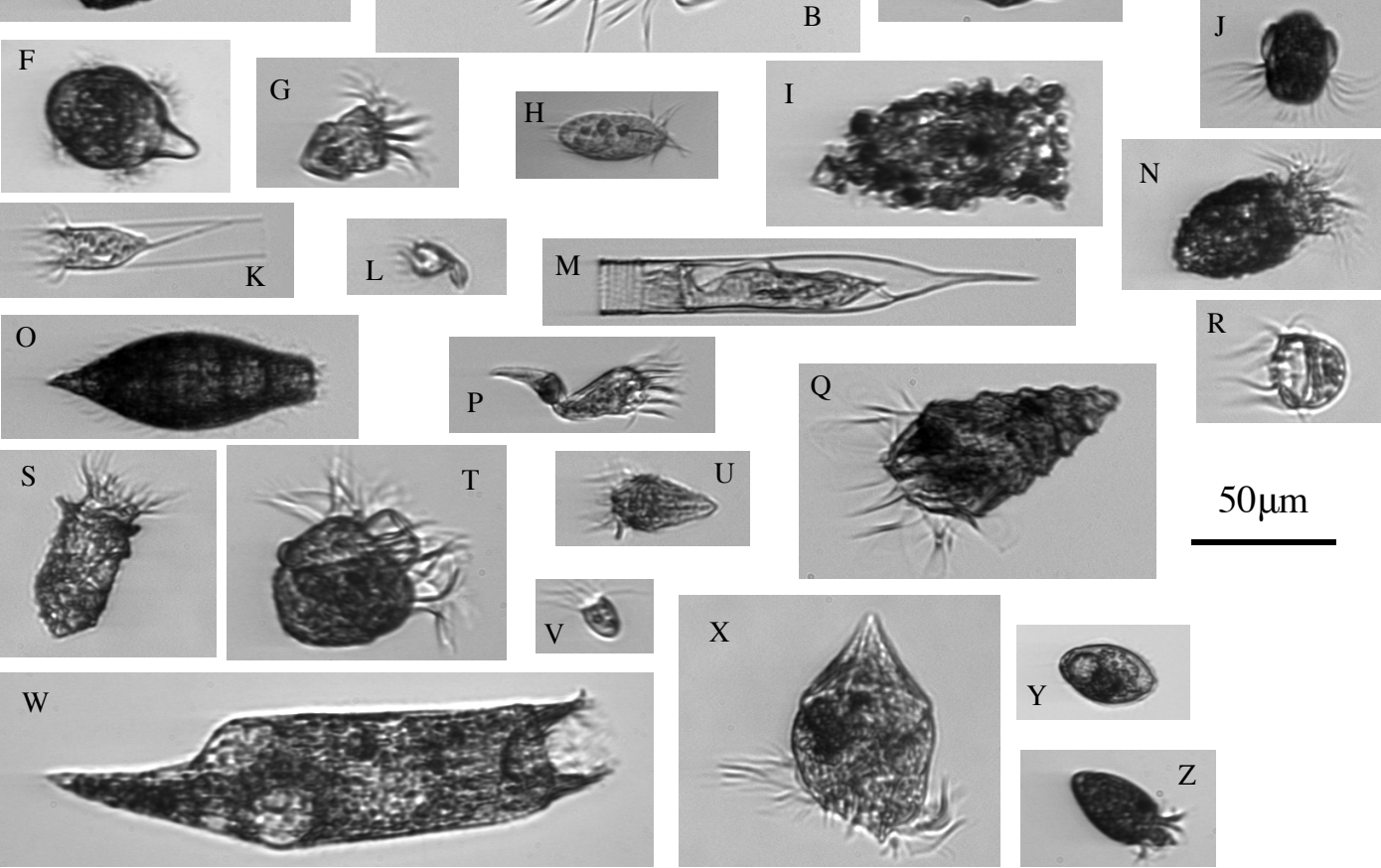

Figure 3-1: Examples of all ciliate categories at MVCO as imaged by standard IFCB triggering on chlorophyll fluorescence. Ciliates are grouped by similar morphology and identified to genus and species as possible. (A)Stenosemella spp.; (B) Strobilidium sp; (C) Favella spp.; (D) Strombidium sp; (E) 'miscellaneous spirotrich'; (F) Didinium spp.; (G) Strombidium inclinatum; (H) Euplotes spp.; (I) Tintinnidium mucicola.; (J) Mesodinium spp.; (K) Eutintinnus spp.; (L) Tontonia gracillima; (M) Helicostomella subulata; (N) Stenosemella pacifica spp.; (O) Tiarina fusus; (P) Tontonia appendiculariformis; (Q) Laboea strobila; (R Leegaardiella ovalis; (S) Tintinnopsis spp.; (T) Strombidium capitatum; (U) Strombidium wulffi; (V) Balanion spp.; (W) Strombidium conicum; (X) Strombidium sp.; (Y) Prostomatida; (Z) Strombidium oculatum. All images from the MVCO data set are publicly available (http://ifcb-data.whoi.edu/mvco), as is a large set of annotated ciliate images (Sosik et al. 2015) 

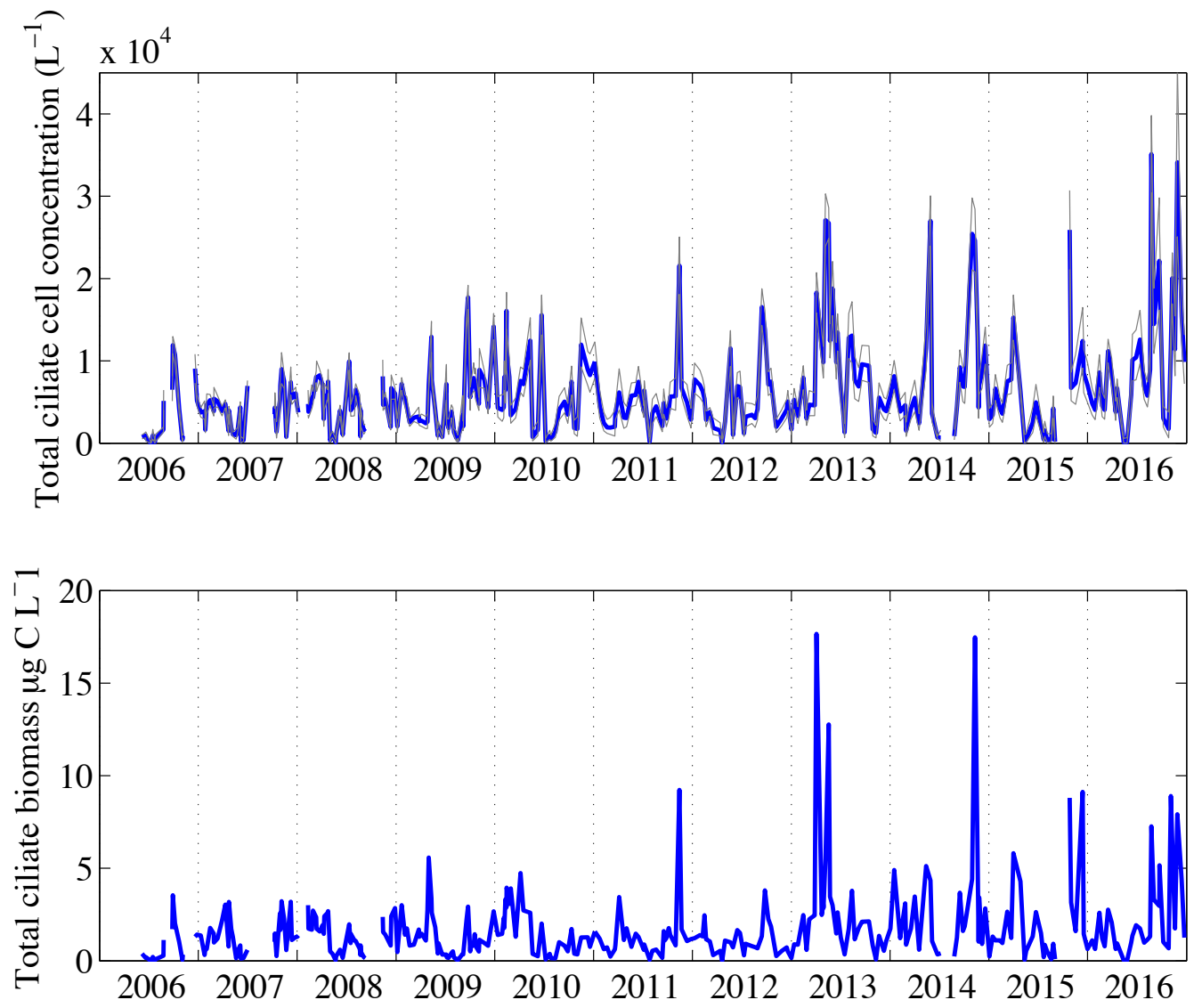

Figure 3-2: Total ciliate concentration with 95\% confidence intervals (grey line) and biomass at MVCO from June 2006 - September 2016. 

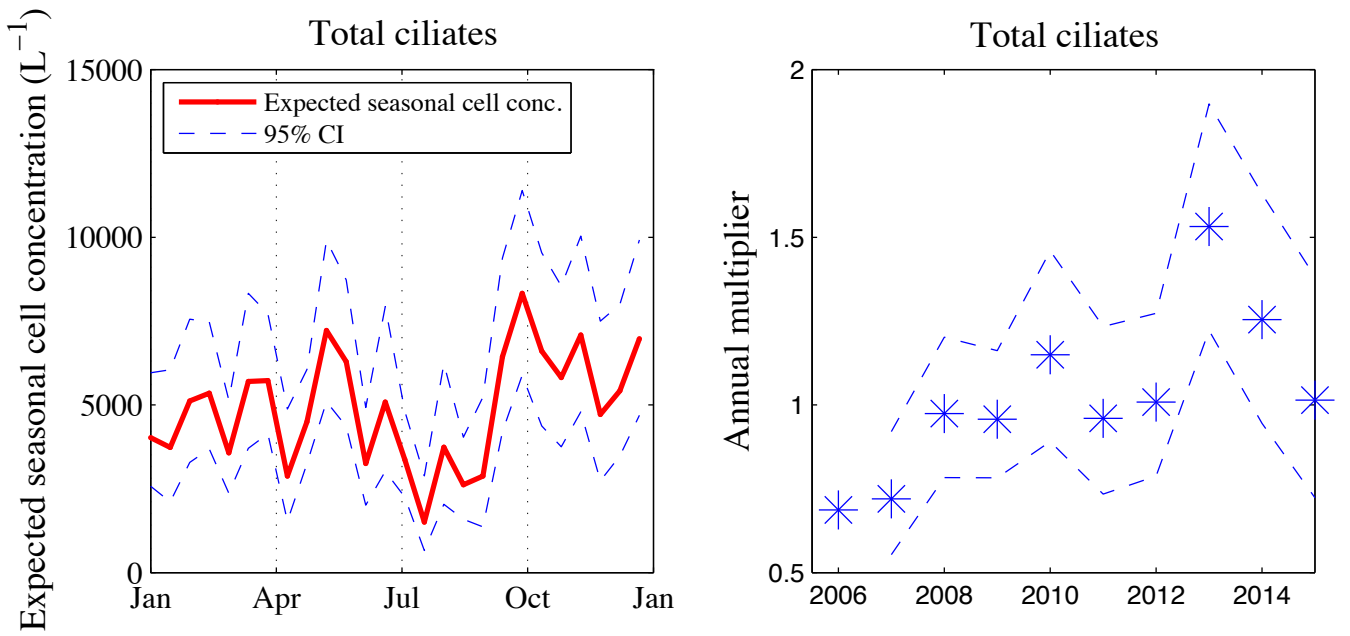

Figure 3-3: Expected seasonal cell concentration $\left(\alpha \cdot \mathrm{e}^{\gamma}\right)$ and annual multipliers $\left(\mathrm{e}^{\beta}\right)$ of 2-week binned total ciliate concentration at MVCO with $95 \%$ confidence intervals. 

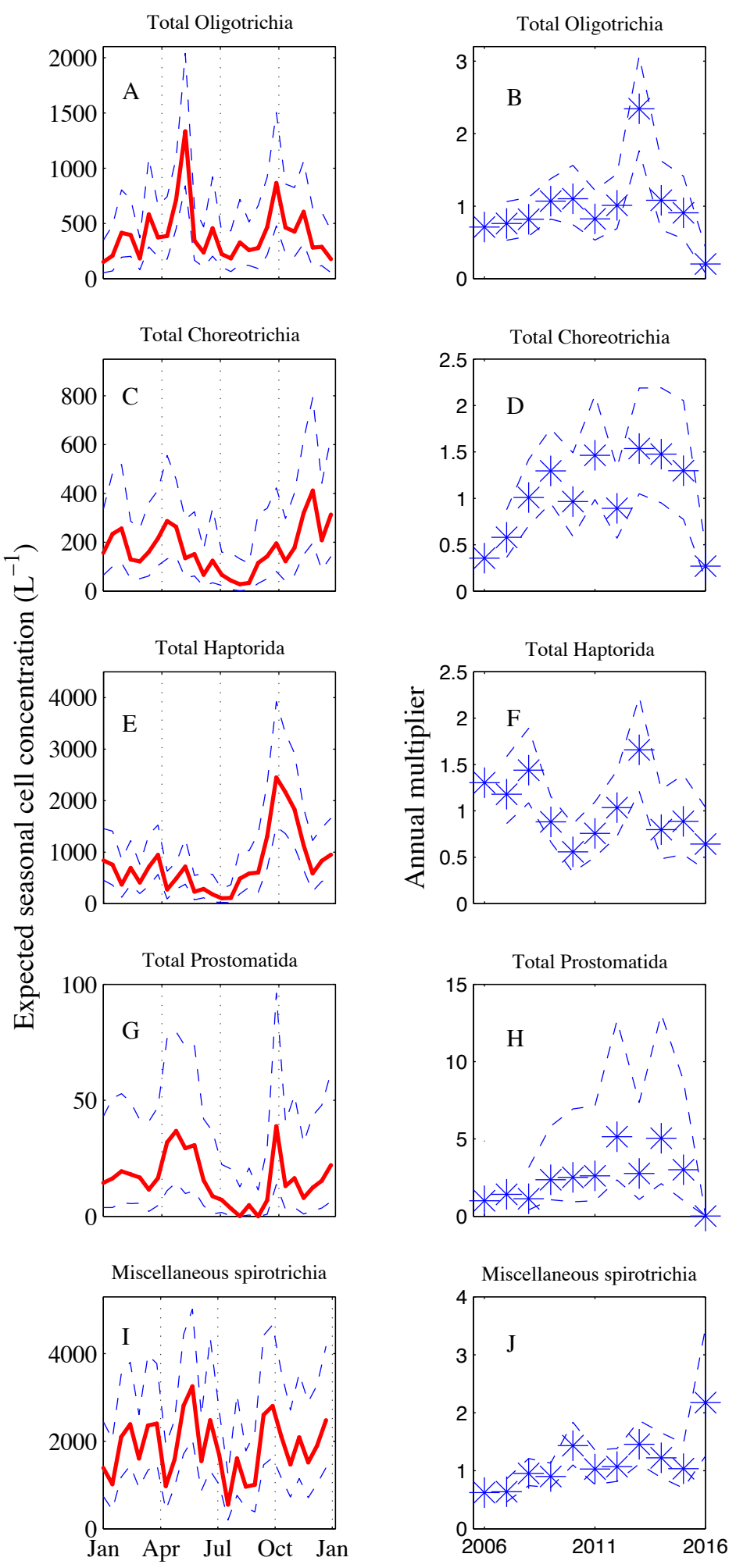

Figure 3-4: Expected seasonal cell concentrations $\left(\alpha \cdot \mathrm{e}^{\gamma}\right)$ and annual multipliers $\left(\mathrm{e}^{\beta}\right)$ of 2week binned ciliate groups at MVCO with $95 \%$ confidence intervals. 

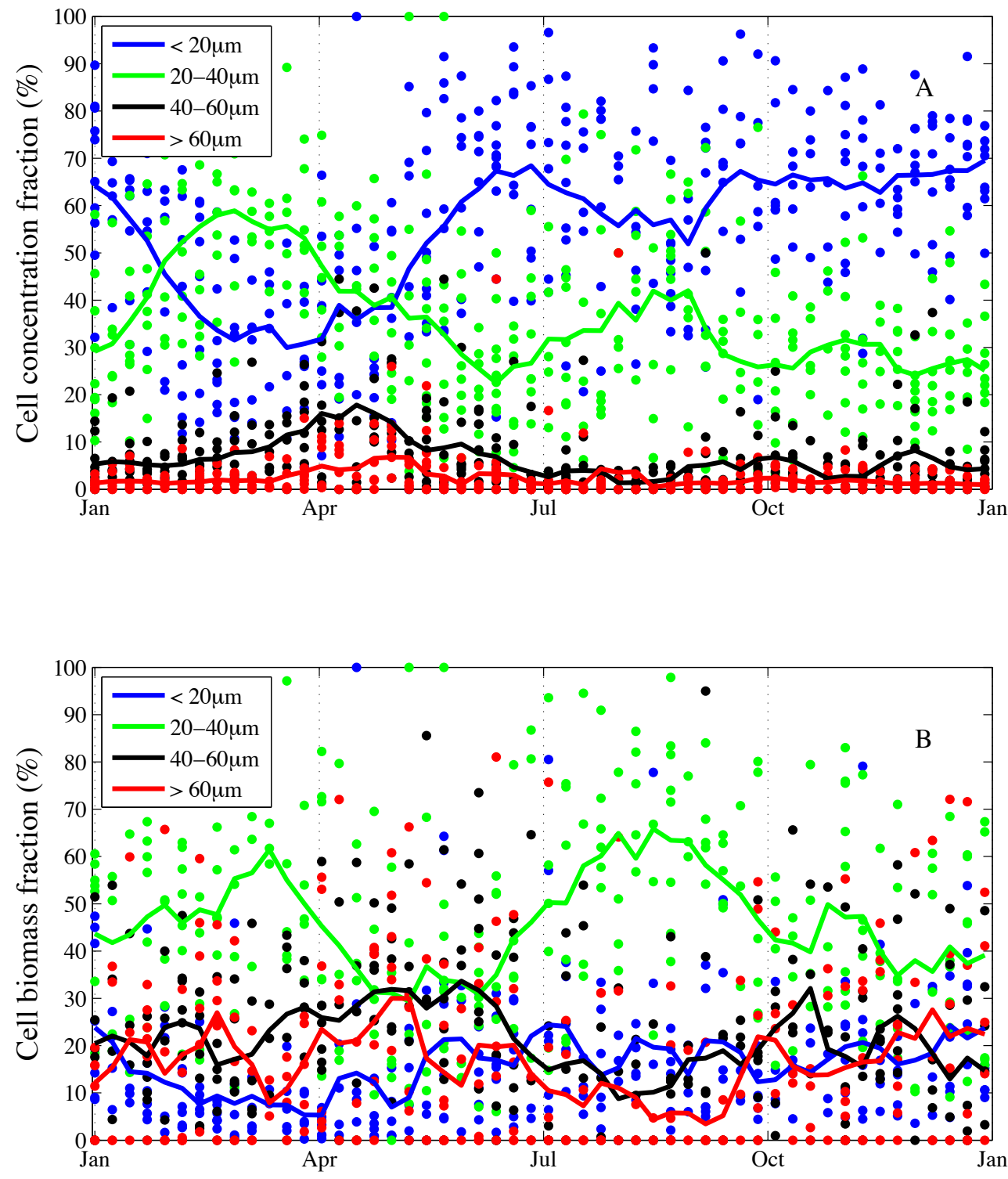

Figure 3-5: Mean annual pattern of size-class contribution to total ciliate concentration and biomass. 

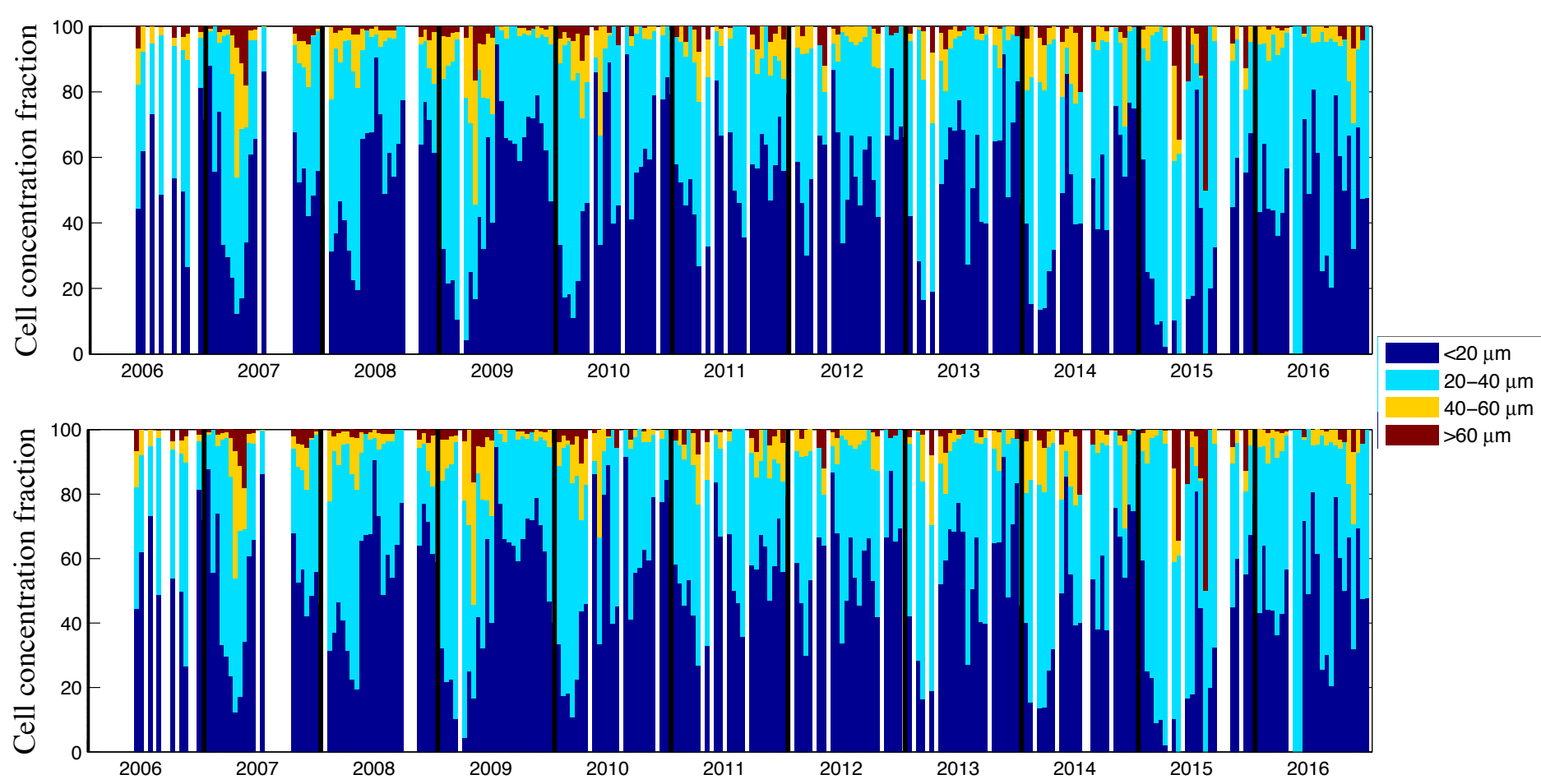

Figure 3-6: Size class contribution to total ciliate concentration and biomass. 


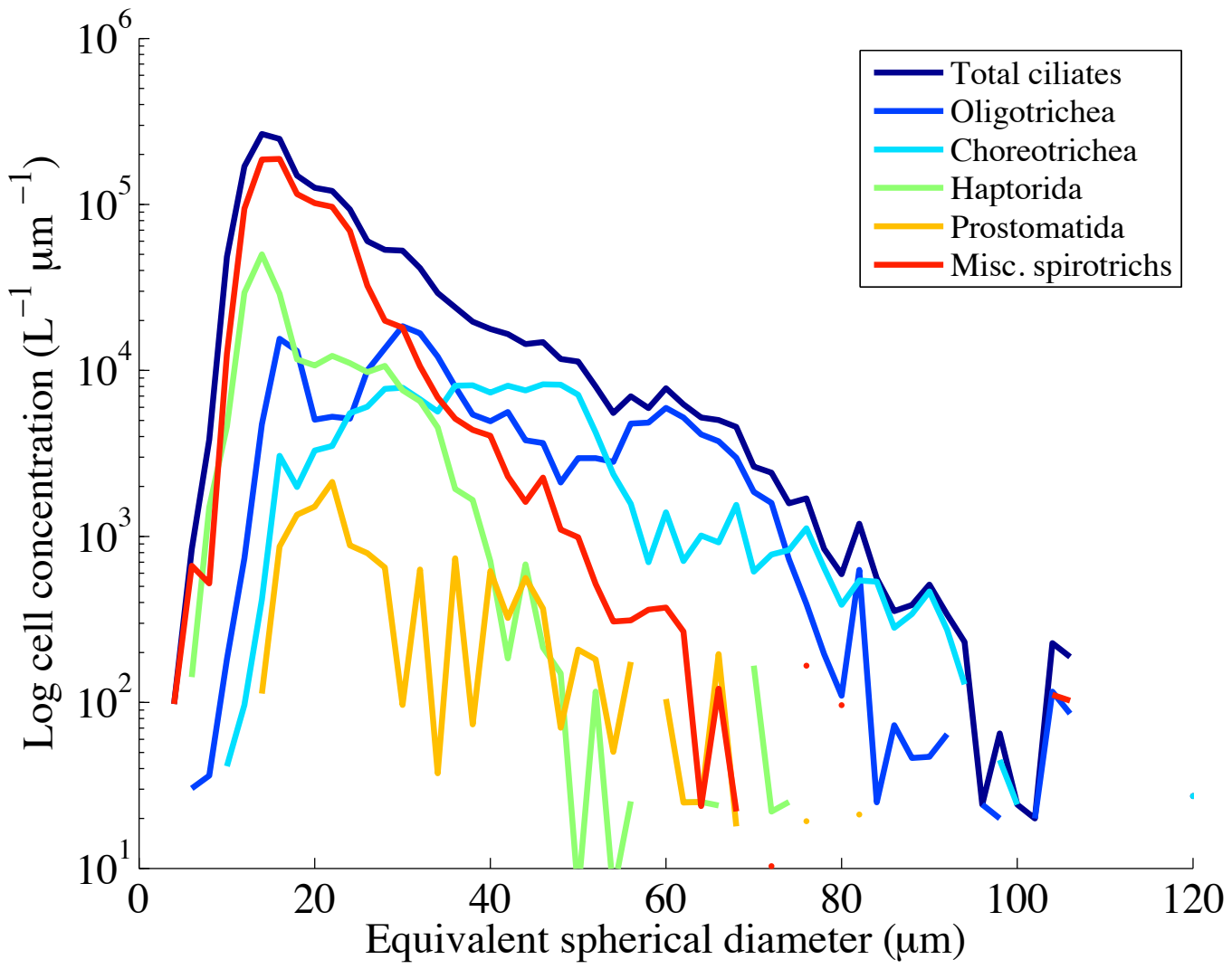

Figure 3-7: Size distributions of total ciliates and ciliate groups images pooled over the period June 2006- September 2016. 

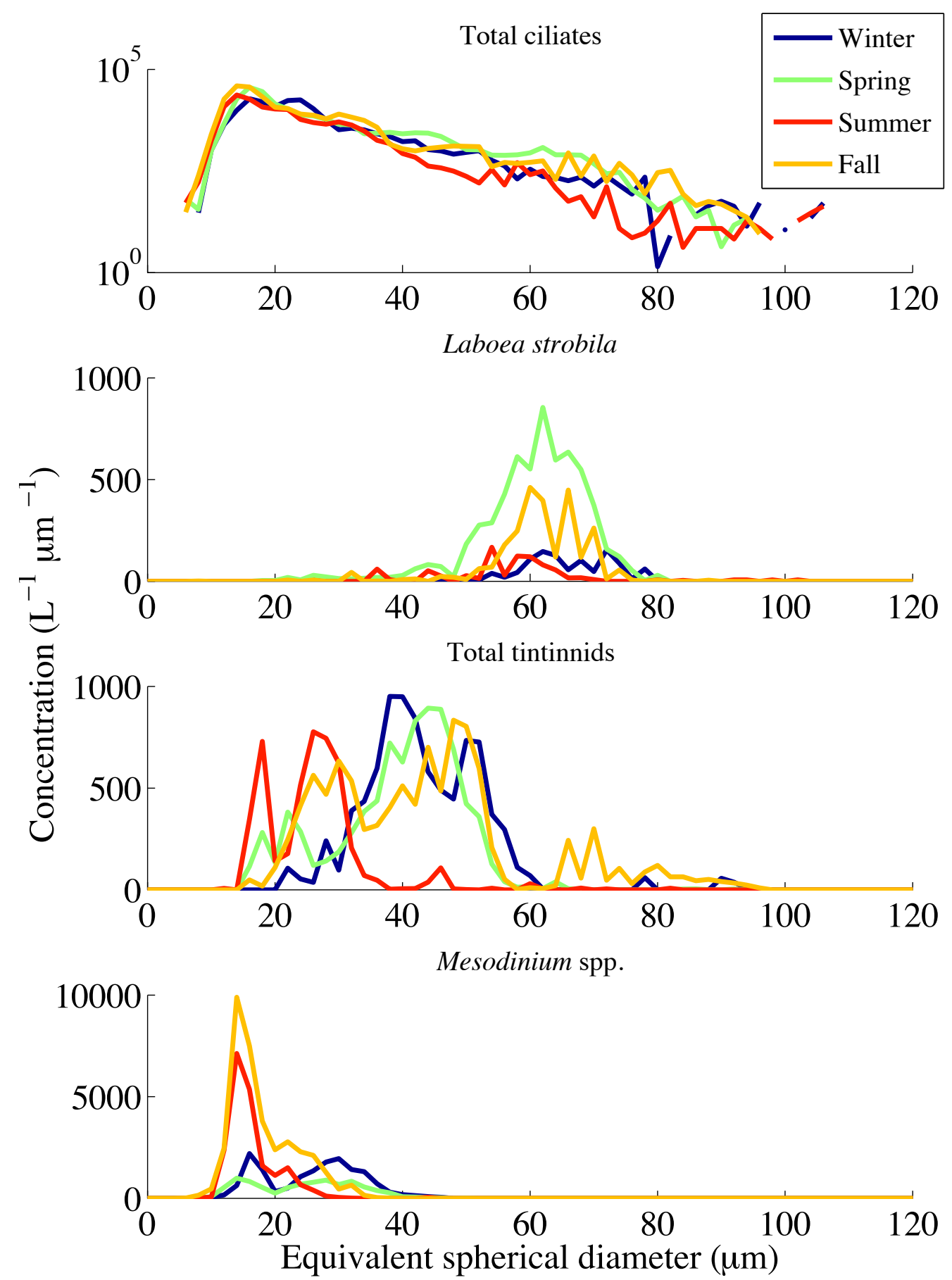

Figure 3-8: Size histograms of select ciliate groups summed by season by $2 \mu \mathrm{m}$ bins. Note top panel on log scale 


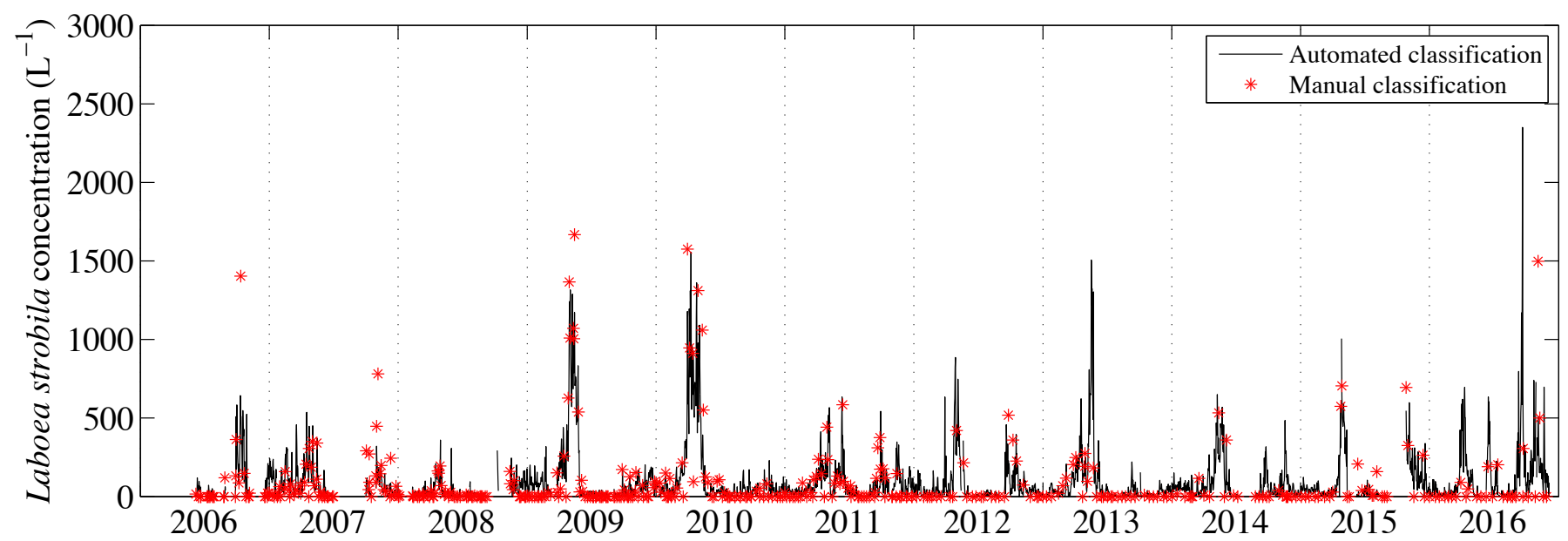

Figure 3-9: Daily resolved times series of Laboea strobila concentration at MVCO from automated classification (black). Red stars indicate counts from manual identification (approximately $2 \mathrm{wk}$ interval). 

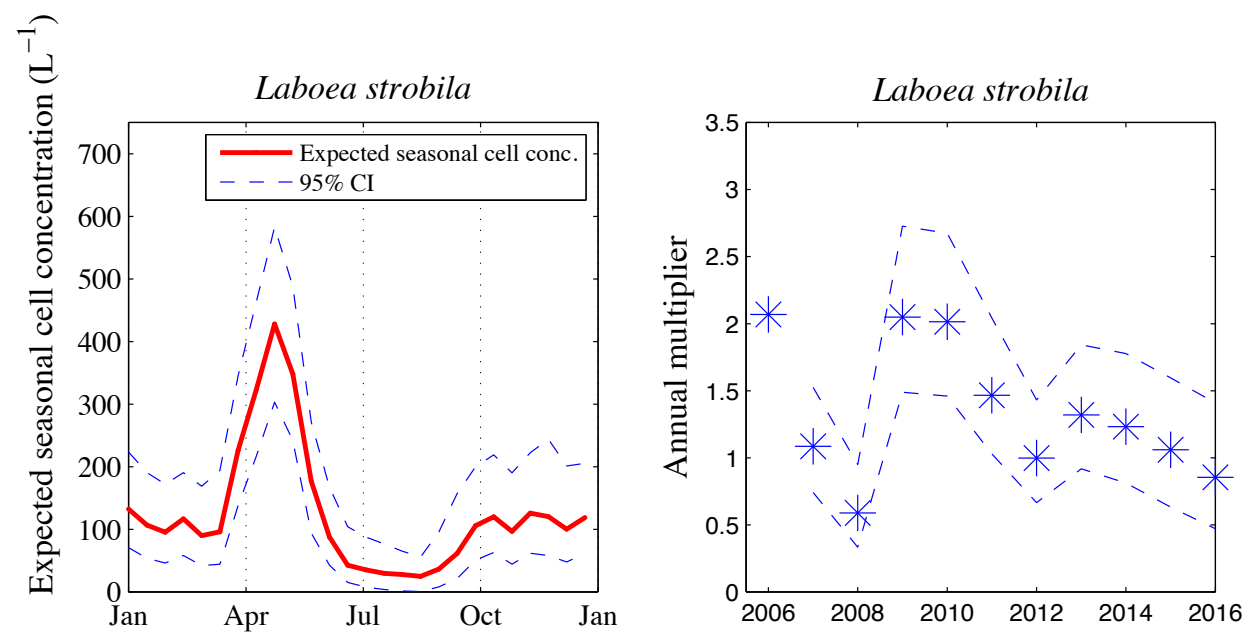

Figure 3-10: Laboea strobila expected seasonal cell concentration $\left(\alpha \cdot \mathrm{e}^{\gamma}\right)$ and annual multipliers $\left(\mathrm{e}^{\beta}\right)$ with $95 \%$ confidence intervals for 2 -week binned data. 

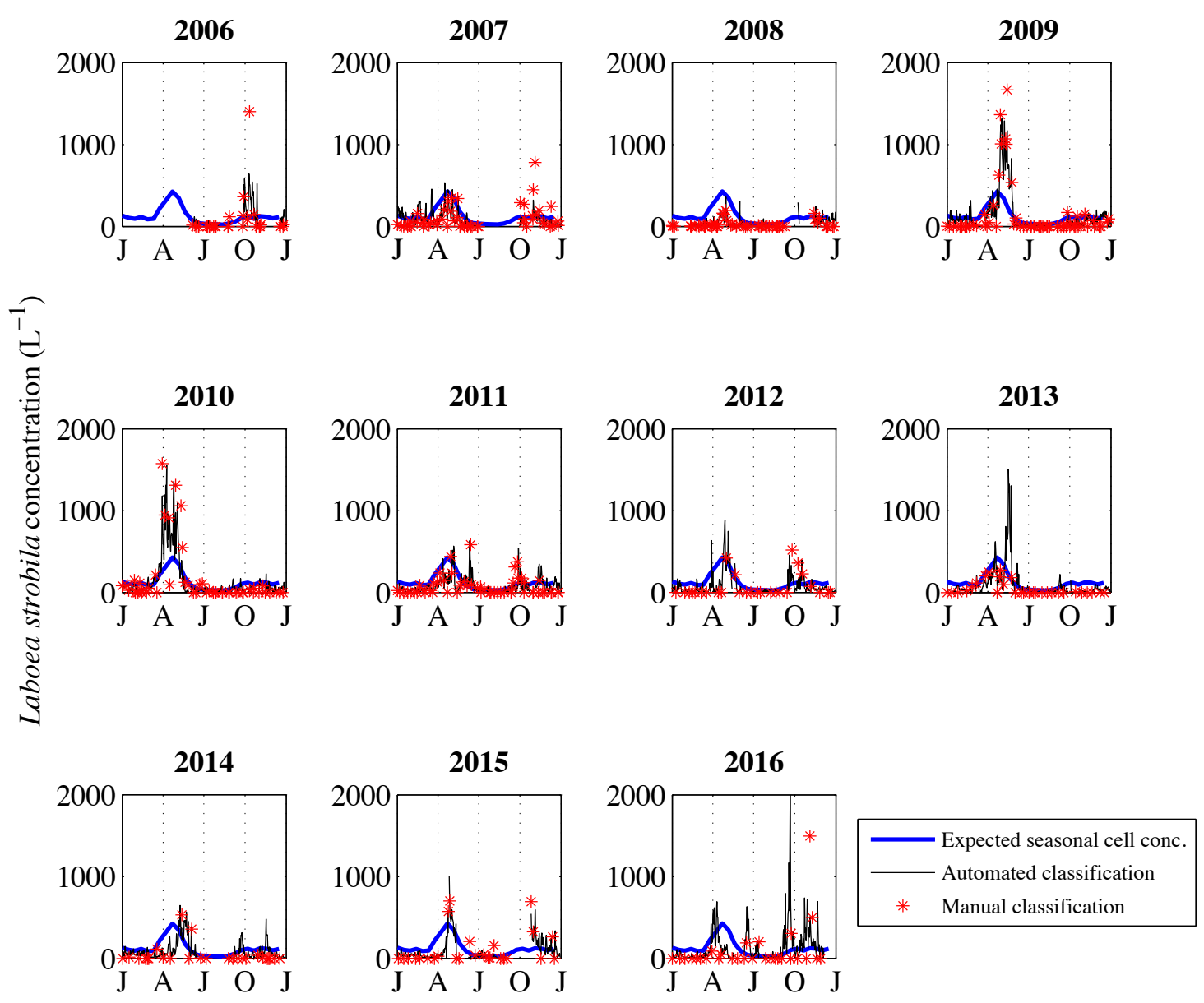

Figure 3-11: Daily resolved times series of Laboea strobila concentration at MVCO from automated classification (black) for each year in time series. Red stars indicate counts from manual identification (approximately 2 wk interval). Expected seasonal cell concentration $\left(\alpha \cdot \mathrm{e}^{\gamma}\right)$ is shown in blue. 


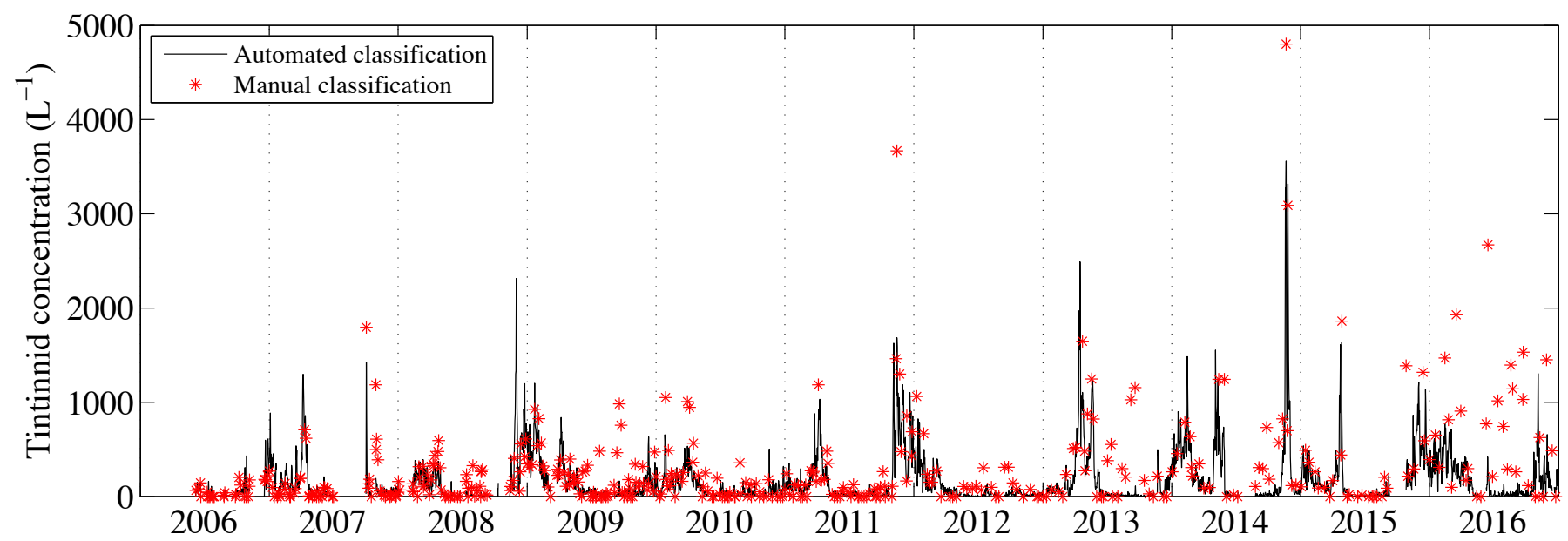

Figure 3-12: Daily resolved times series of total tintinnid concentration at MVCO (black). Red stars indicate counts from manual identification (approximately 2 wk interval). 

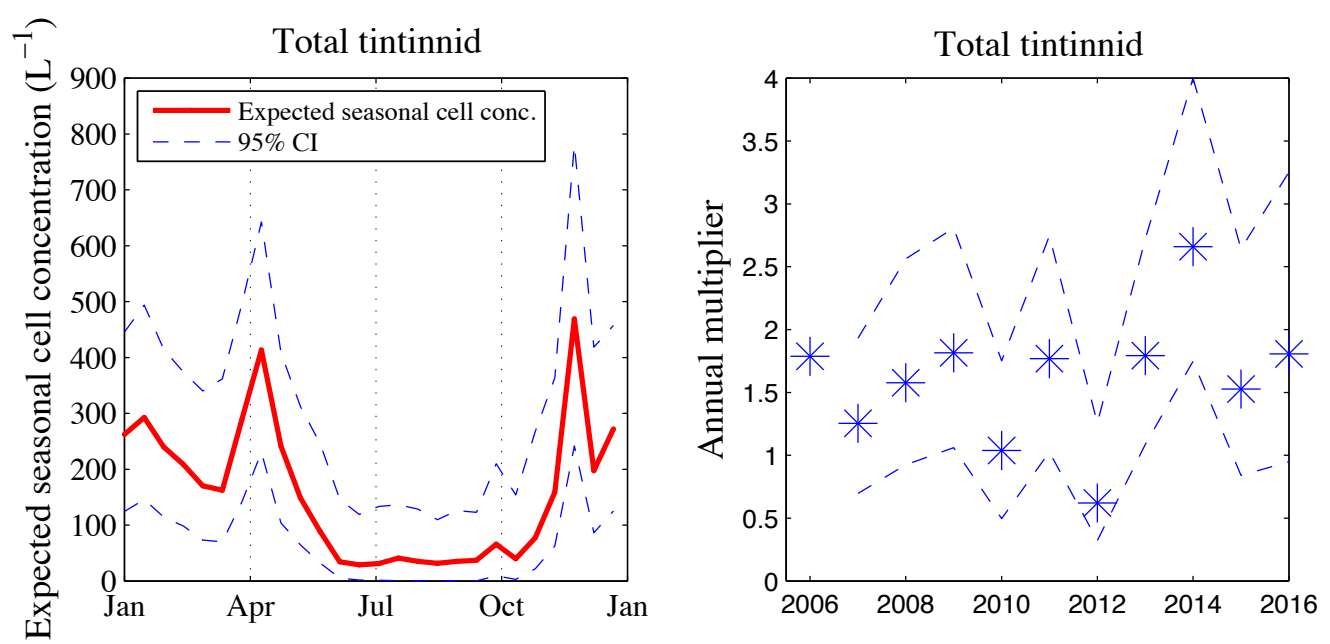

Figure 3-13: Total tintinnid expected seasonal cell concentration $\left(\alpha \cdot \mathrm{e}^{\gamma}\right)$ and annual multipliers $\left(\mathrm{e}^{\beta}\right)$ with $95 \%$ confidence intervals 2 -week binned data. 

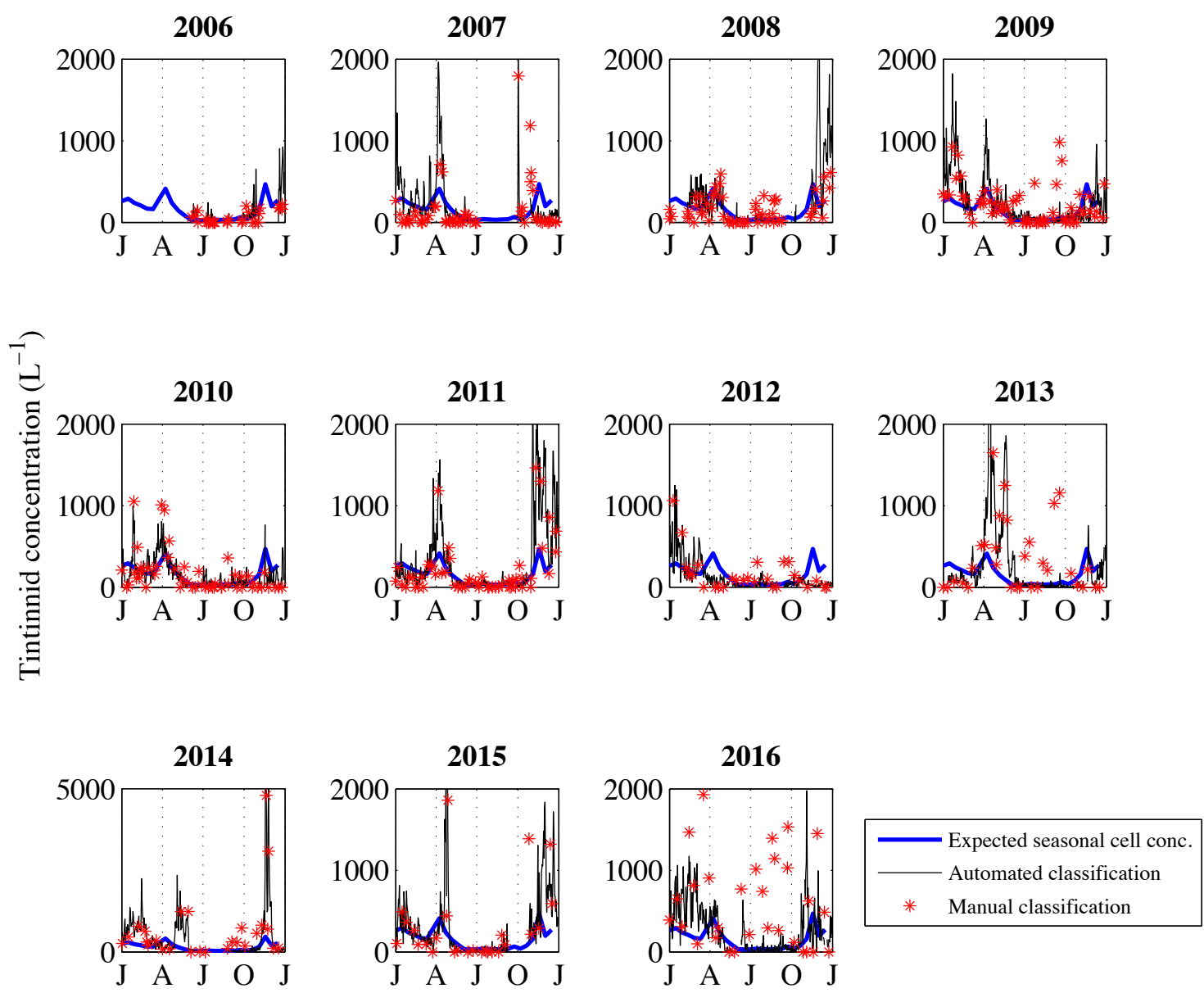

Figure 3-14: Daily resolved times series of total tintinnid concentration at MVCO from automated classification (black) for each year in time series. Red stars indicate counts from manual identification (approximately $2 \mathrm{wk}$ interval). expected seasonal cell concentration $\left(\alpha \cdot \mathrm{e}^{\gamma}\right)$ is shown in blue. Note differing scale of y-axis in 2014. 
Tintinnopsis spp. $>60 \mu \mathrm{m} \quad$ Tintinnopsis spp. 40-60 $\mu \mathrm{m} \quad$ Tintinnopsis spp. $<40 \mu \mathrm{m}$
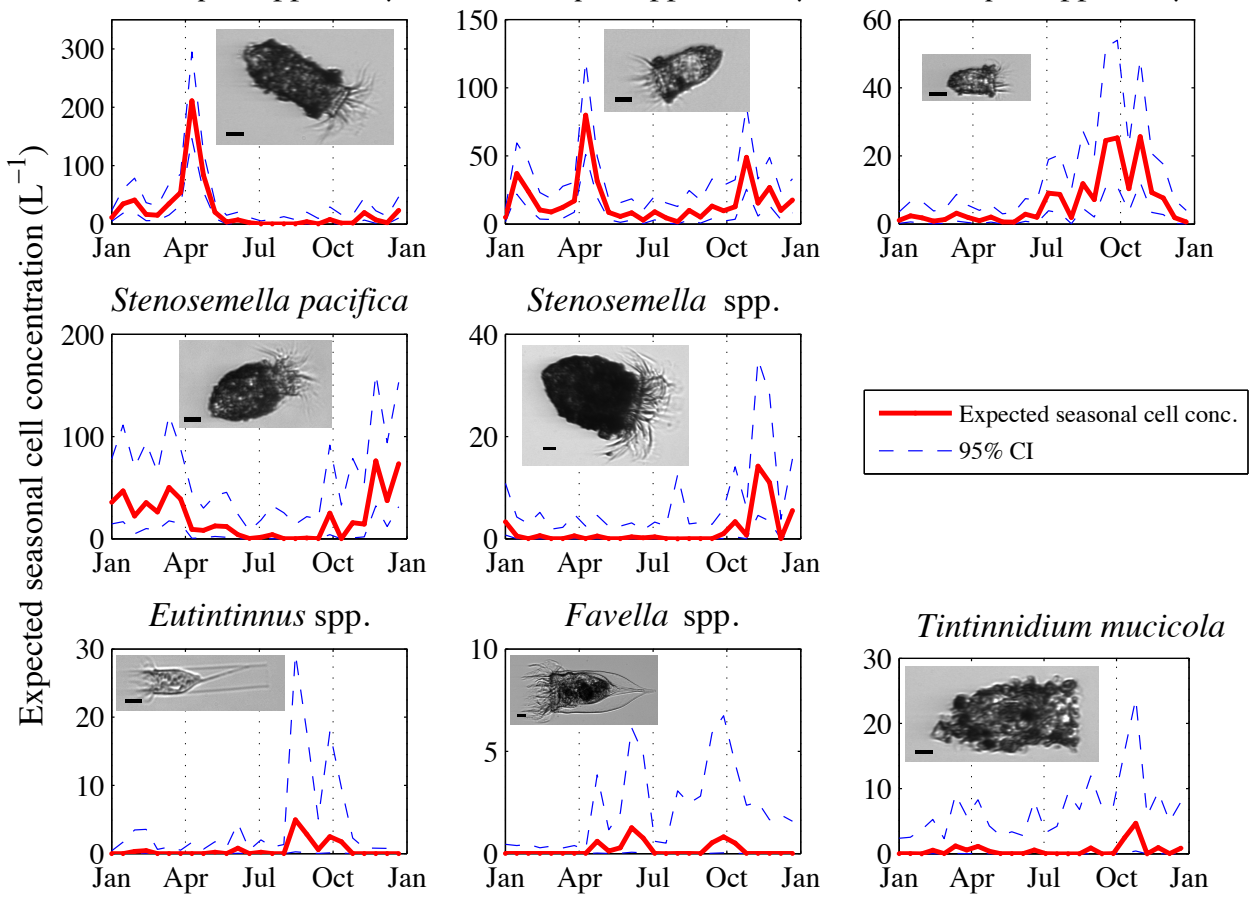

Favella spp.
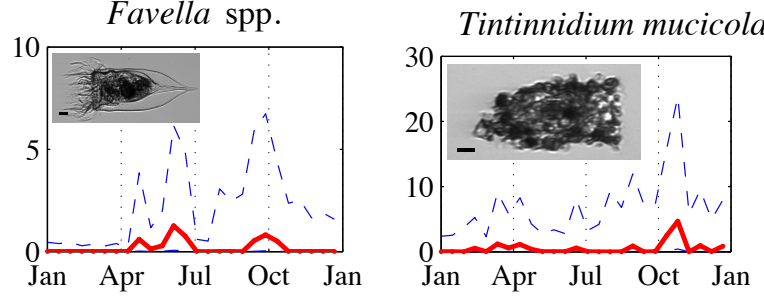

Figure 3-15: Tintinnid group expected seasonal cell concentration $\left(\alpha \cdot \mathrm{e}^{\gamma}\right)$ with $95 \%$ confidence intervals for 2 -week binned data. Scale bar represents $10 \mu \mathrm{m}$ 


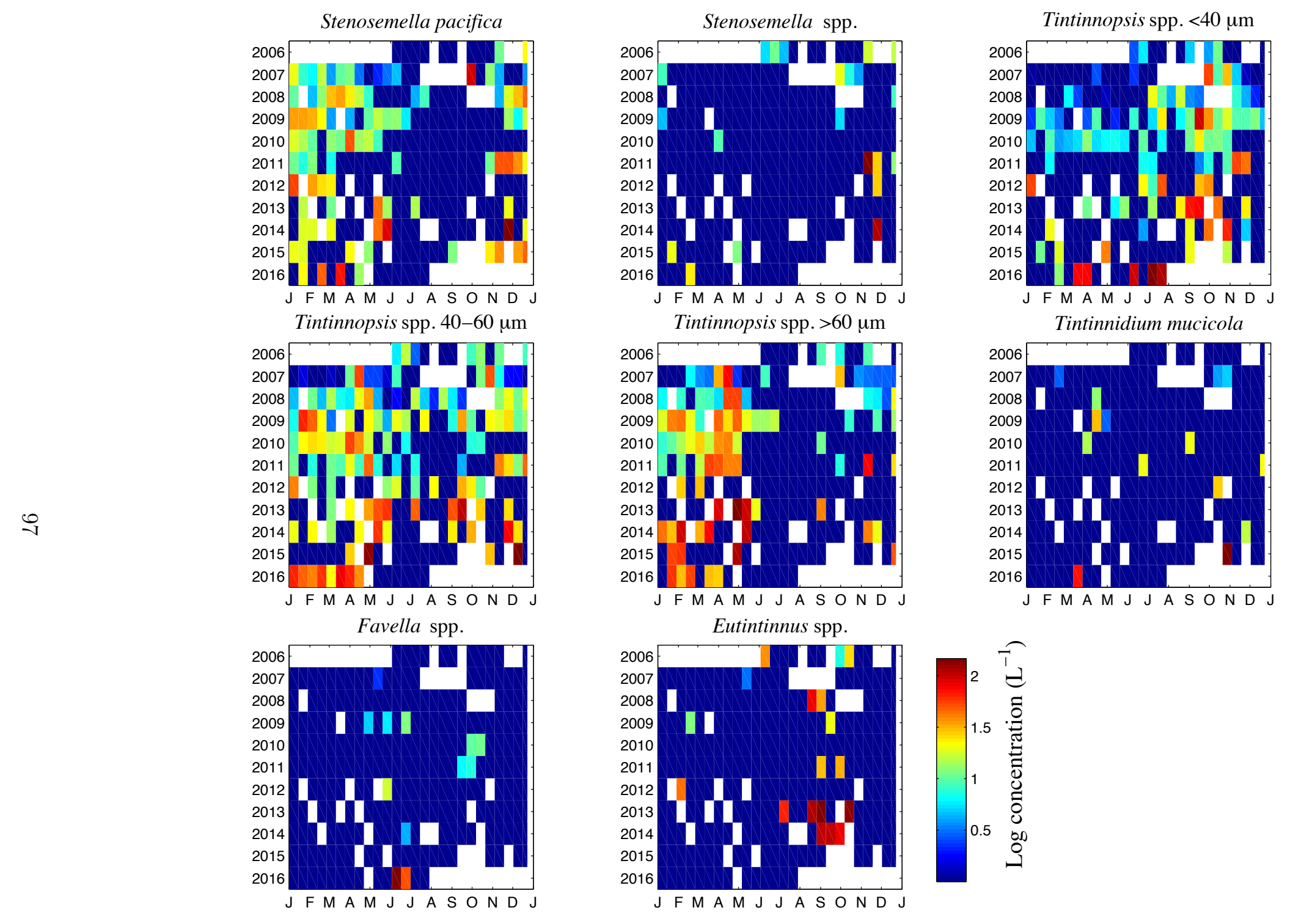

Figure 3-16: Multiyear records of two week binned tintinnid group log concentration at MVCO. White bars indicate times when no data is available. 


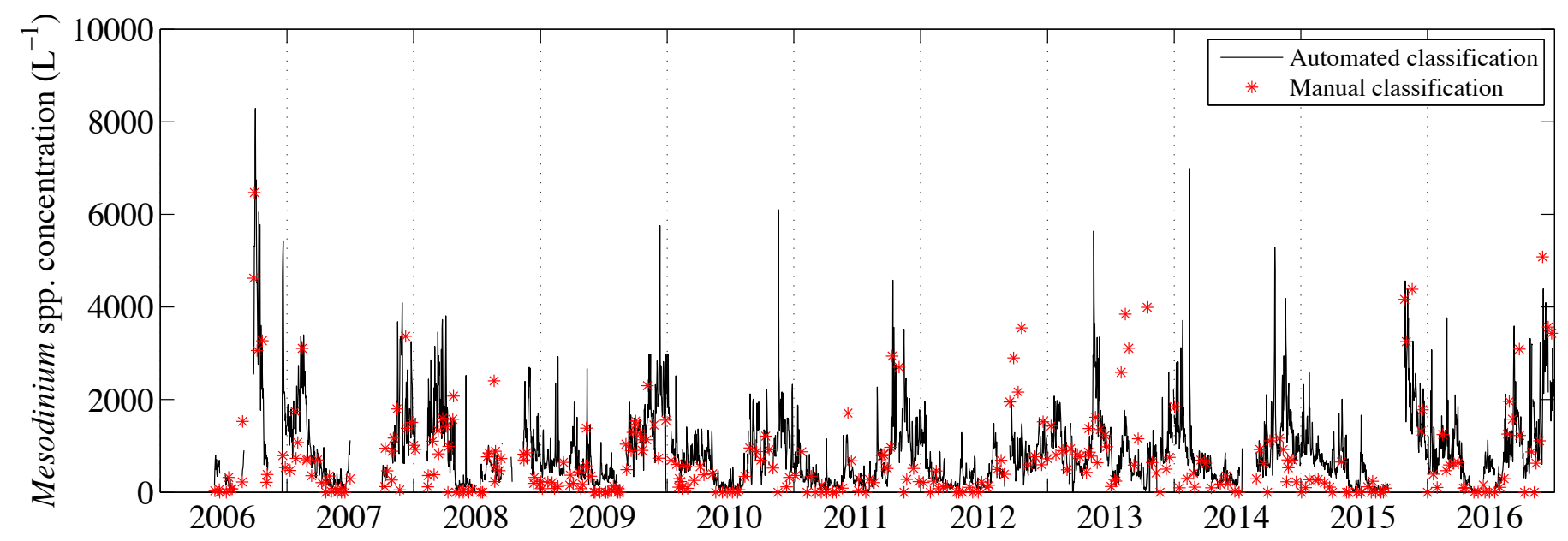

Figure 3-17: Daily resolved times series of Mesodinium spp. concentration at MVCO from automated classification (black). Red stars indicate counts from manual identification (approximately $2 \mathrm{wk}$ interval). 

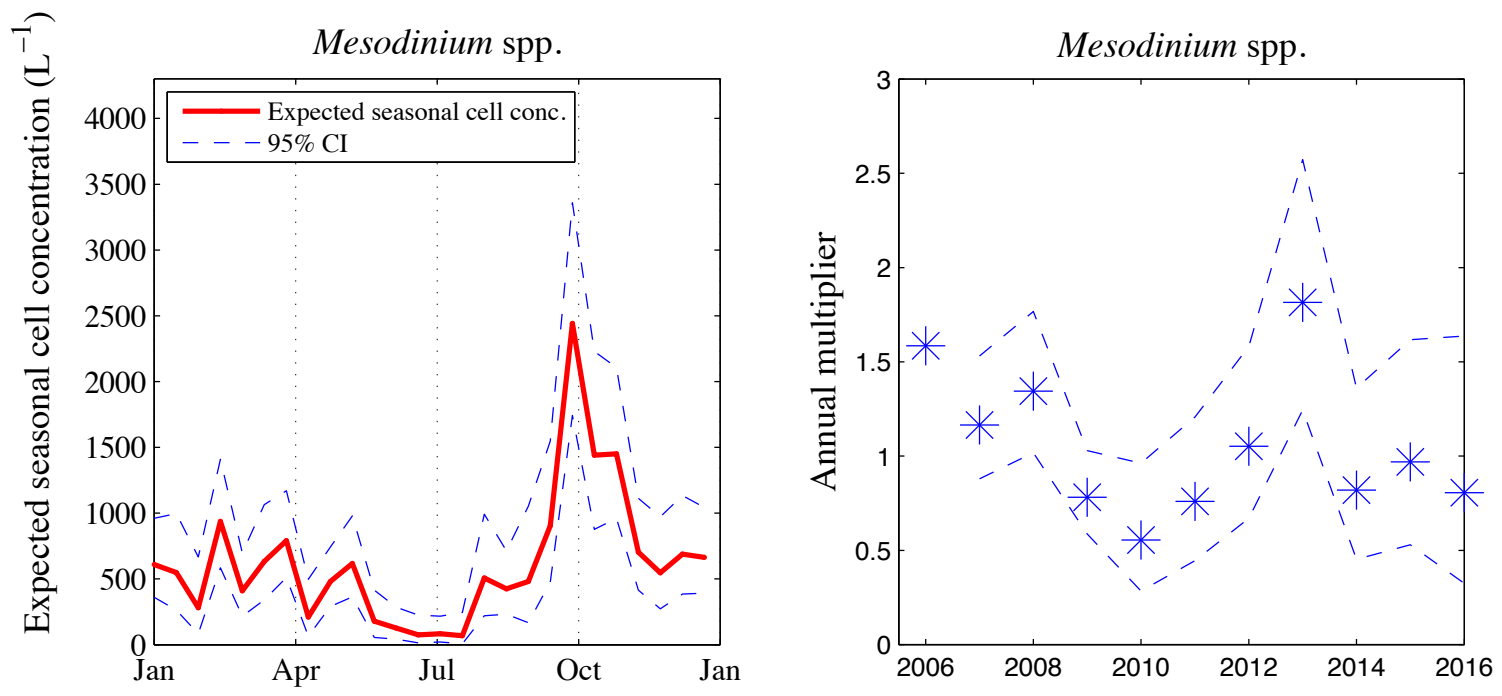

Figure 3-18: Mesodinium spp. expected seasonal cell concentration $\left(\alpha \cdot \mathrm{e}^{\gamma}\right)$ and annual multipliers $\left(\mathrm{e}^{\beta}\right)$ with $95 \%$ confidence intervals for 2-week binned data. 

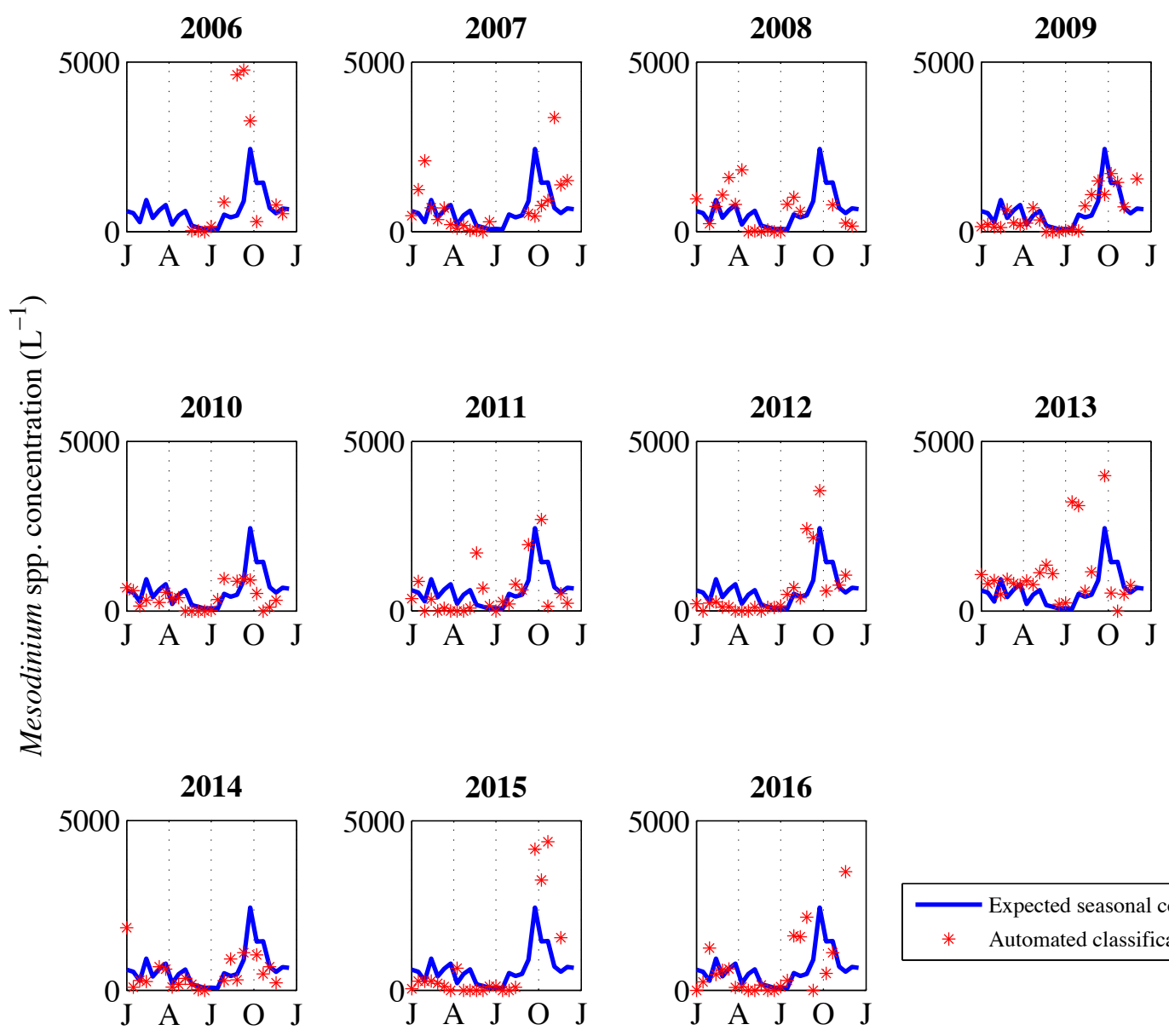

Expected seasonal cell conc.
* Automated classification

Figure 3-19: Daily resolved times series of Mesodinium spp. concentration at MVCO from approximately $2 \mathrm{wk}$ intervals (red stars) for each year in time series. Expected seasonal cell concentration $\left(\alpha \cdot \mathrm{e}^{\gamma}\right)$ is shown in blue. 


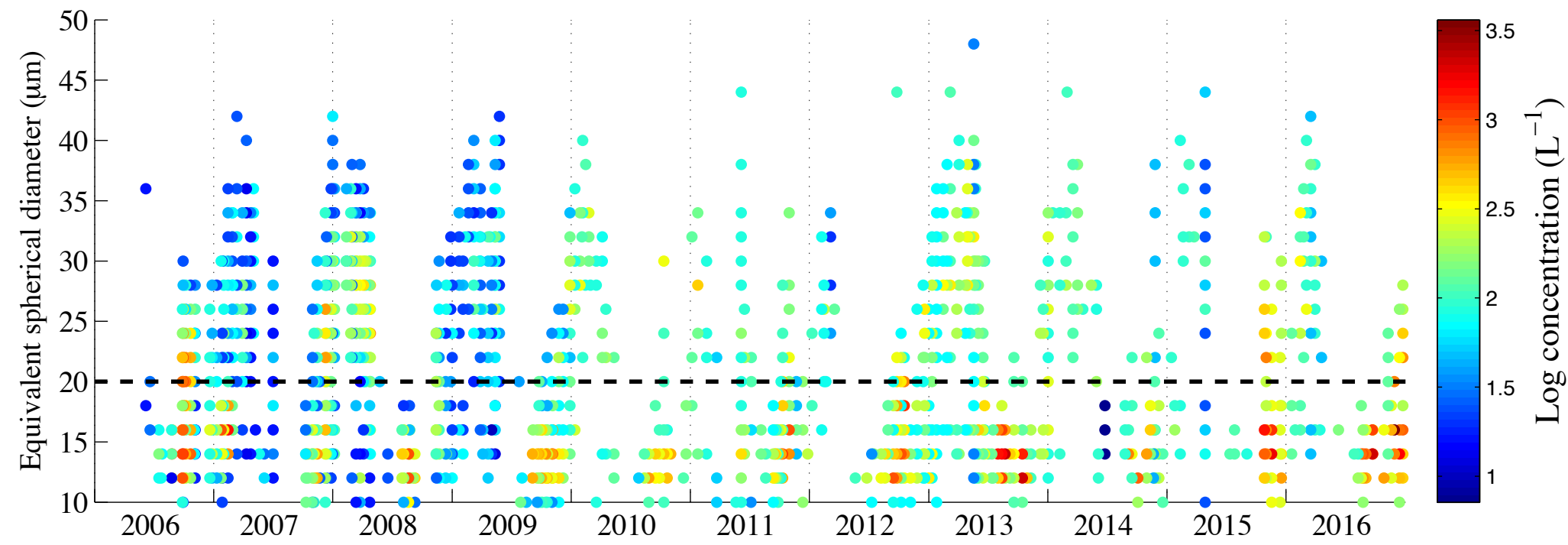

Figure 3-20: All Mesodinium spp. cell sizes in $2 \mu \mathrm{m}$ bins from. Data colored by log concentration. 

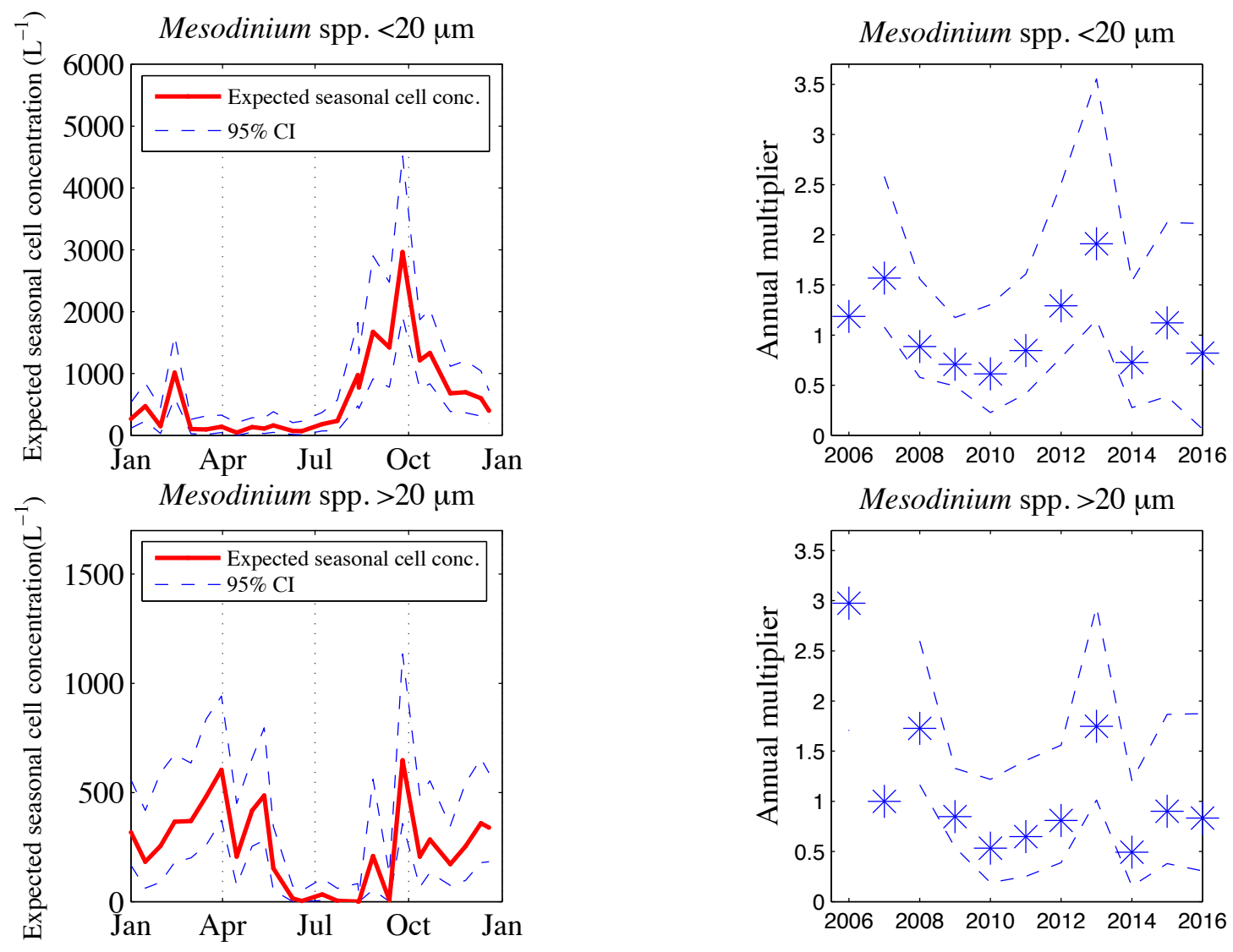

Figure 3-21: Two-week resolved Mesodinium spp. size class expected seasonal cell concentration $\left(\alpha \cdot \mathrm{e}^{\gamma}\right)$ and annual multipliers $\left(\mathrm{e}^{\beta}\right)$ with $95 \%$ confidence intervals. 


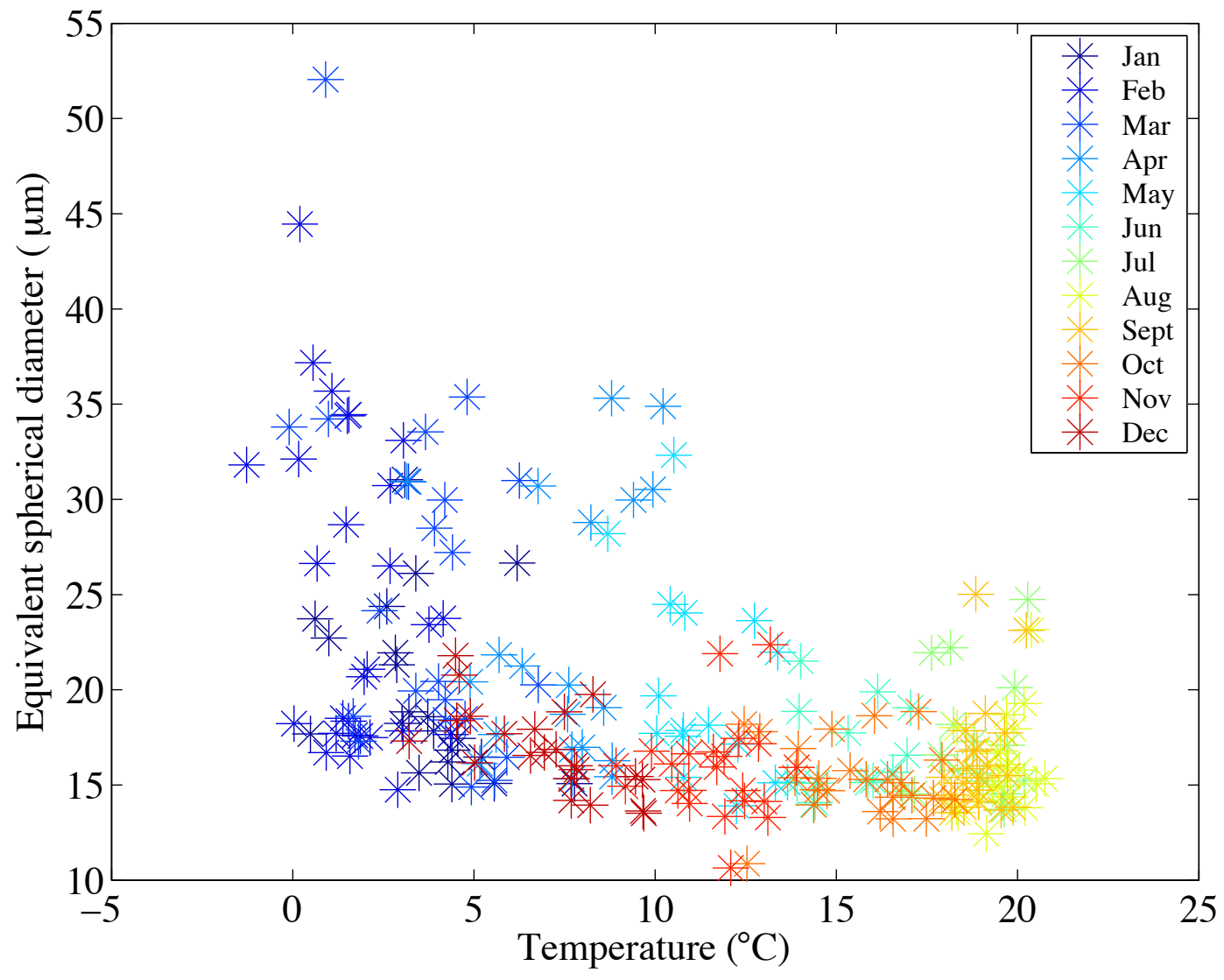

Figure 3-22: Mesodinium spp. daily size mode versus temperature. Data colored by month. 

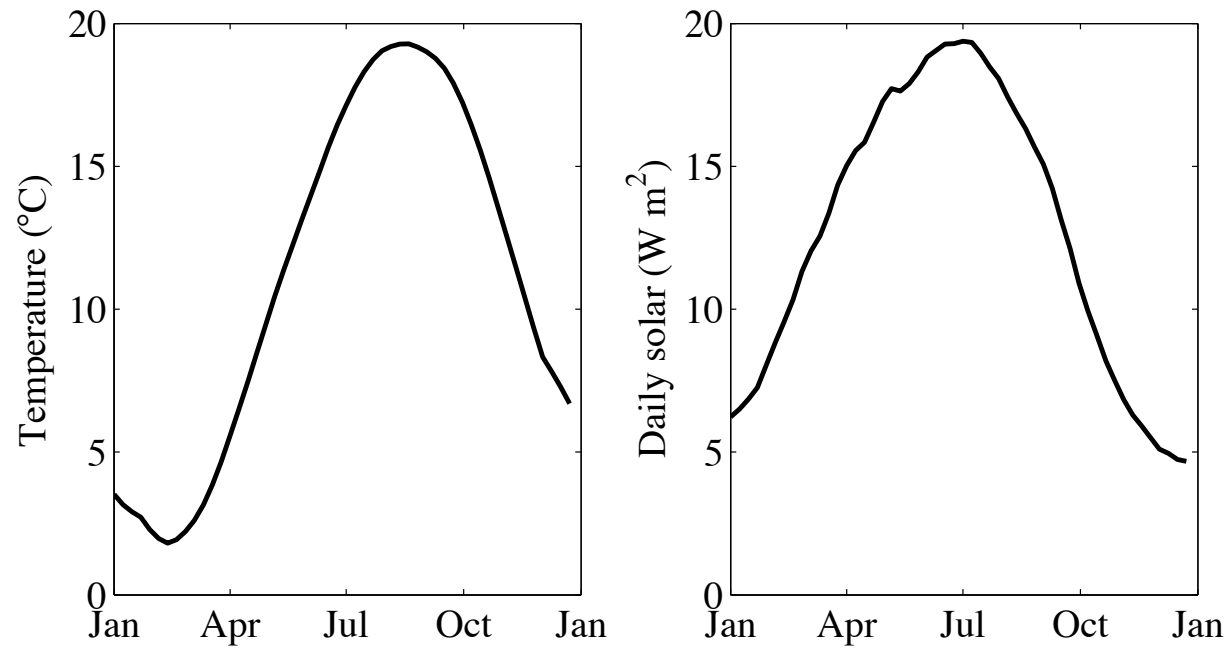

Figure 3-23: Mean seasonal pattern of temperature and daily solar radiation. 

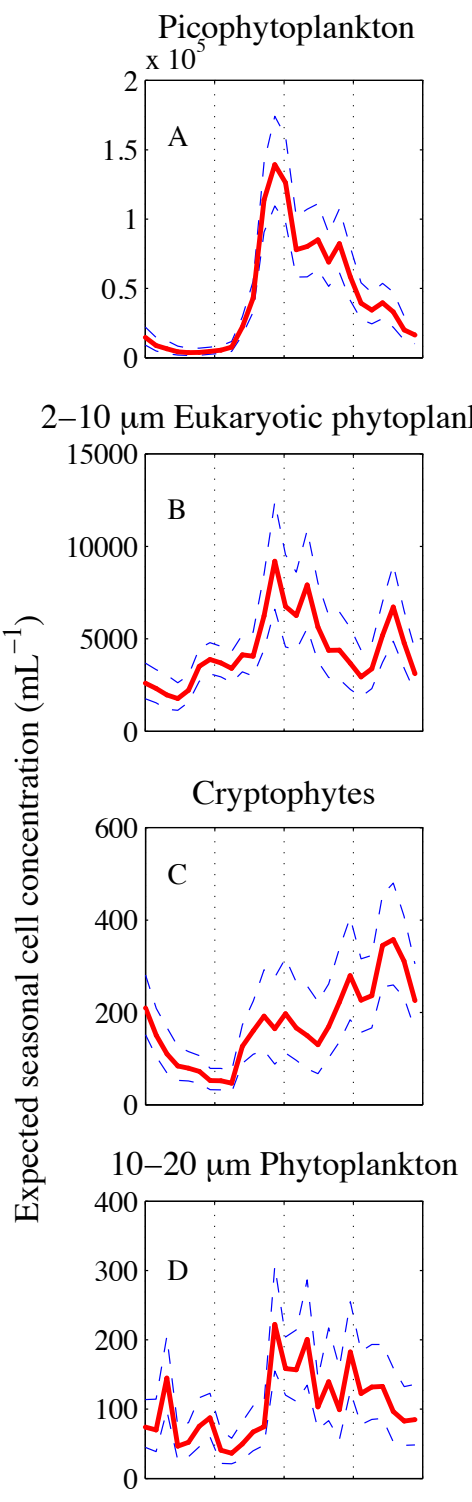

$>20 \mu \mathrm{m}$ Phytoplankton

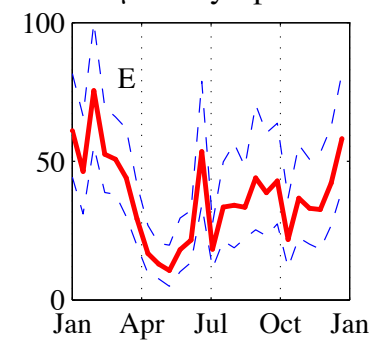

Figure 3-24: Expected seasonal cell concentrations $\left(\alpha \cdot \mathrm{e}^{\gamma}\right)$ and $95 \%$ confidence intervals for 2-

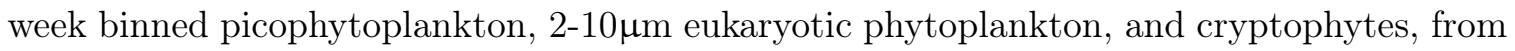
FCB and $10-20 \mu \mathrm{m}$ phytoplankton and $>20 \mu \mathrm{m}$ phytoplankton. 


\begin{tabular}{lccc} 
Taxon & $\begin{array}{c}\text { Biomass range } \\
\left(\mu \mathrm{g} \mathrm{L}^{-1}\right)\end{array}$ & $\begin{array}{c}\text { Cell conc. range } \\
\text { cells L }{ }^{-1}\end{array}$ & $\begin{array}{c}\text { Avg temp and std } \\
{ }^{\circ} \mathrm{C}\end{array}$ \\
\hline \hline Mesodinium spp. $<20 \mu \mathrm{m}$ & $0.001-2.6$ & $16-3272$ & $13.3 \pm 5.9$ \\
Mesodinium spp. $>=20 \mu \mathrm{m}$ & $0.002-0.32$ & $13-459$ & $8.5 \pm 5.6$ \\
Laboea strobila & $0.006-21.2$ & $4-3136$ & $11.1 \pm 4.0$ \\
Stenosemella pacifica & $0.02-10.6$ & $4-3441$ & $8.7 \pm 4.5$ \\
Stenosemella sp. & $0.02-15$ & $8-880$ & $11.7 \pm 2.7$ \\
Tintinnopsis spp. $<40 \mu \mathrm{m}$ & $0.003-74$ & $4-1015$ & $12.3 \pm 5.6$ \\
Tintinnopsis spp. $40-60 \mu \mathrm{m}$ & $0.001-1.84$ & $4-1056$ & $6.7 \pm 3.7$ \\
Tintinnopsis spp. $>60 \mu \mathrm{m}$ & $0.01-4.84$ & $4-1433$ & $11.8 \pm 6.7$ \\
Tintinnidium mucicola & $0.004-4.25$ & $4-463$ & $12.1 \pm 4.8$ \\
Favella spp. & $0.15-1.98$ & $7-209$ & $15.9 \pm 3.0$ \\
Eutintinnus spp. & $0.01-0.6$ & $11-207$ & $17.5 \pm 4.1$
\end{tabular}

Table 3.1: Biomass and abundance ranges and weighted average temperature by cell abundance for ciliate groups. 

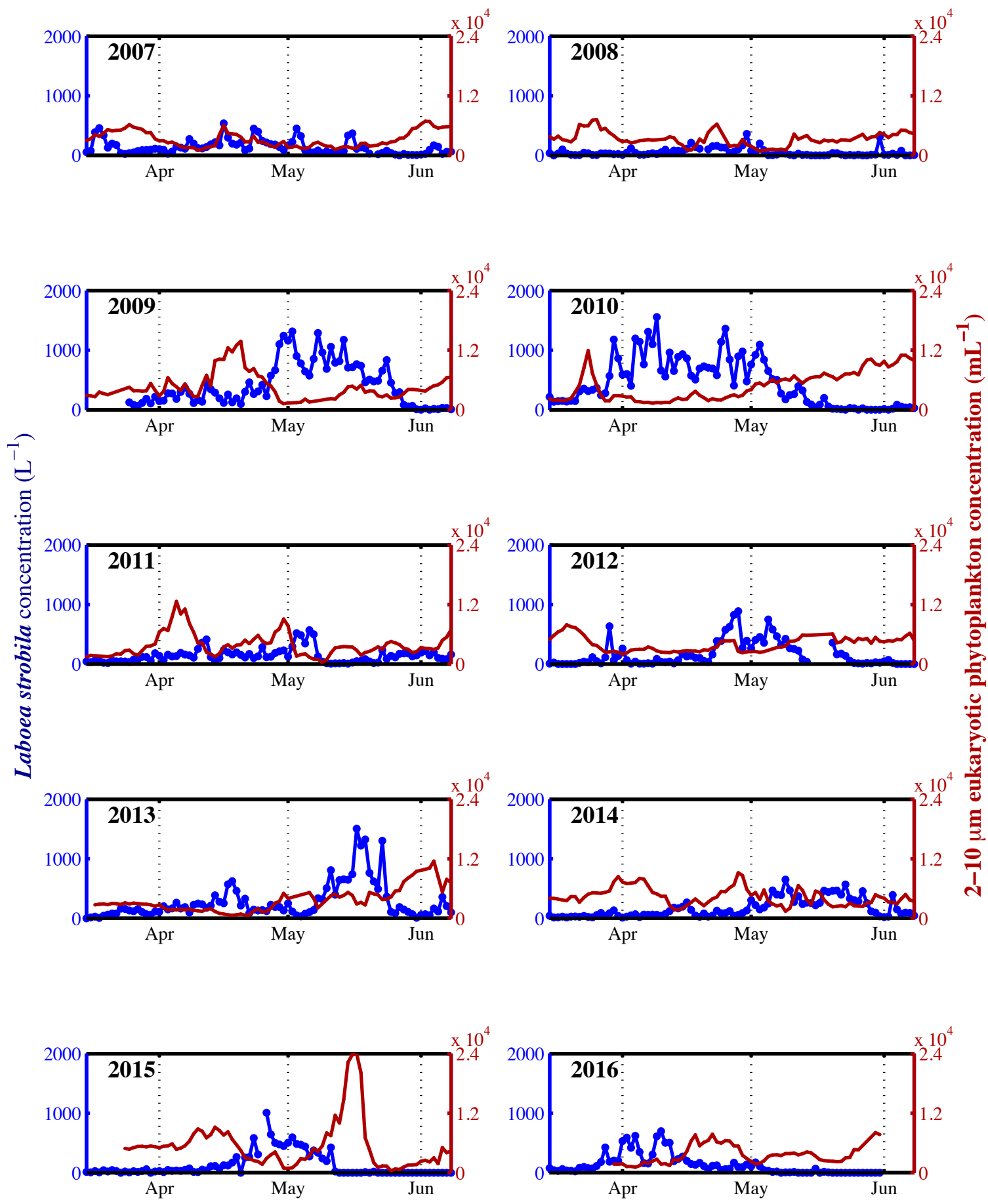

Figure 3-25: Daily resolved times series of Laboea strobila concentration (dark blue) and with 2-10 $\mu \mathrm{m}$ eukaryotic phytoplankton concentration (red) for each spring in the time series. 

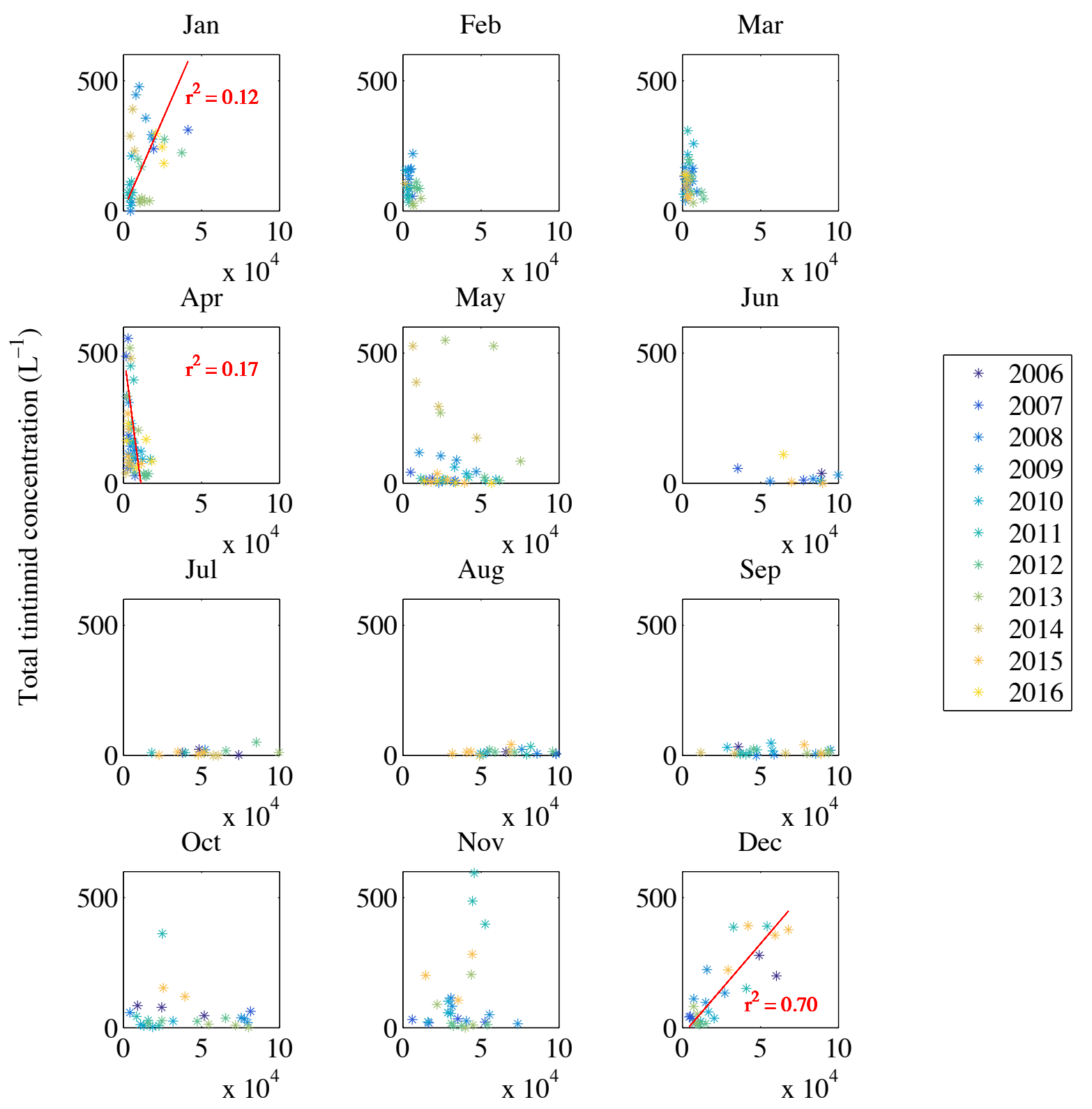

Picophytoplankton concentration $\left(\mathrm{mL}^{-1}\right)$

Figure 3-26: Total tintinnid concentration relationship with picophytoplankton concentration for weekly binned data by month. Red lines indicate significant relationship $(\mathrm{p}<0.05)$ 


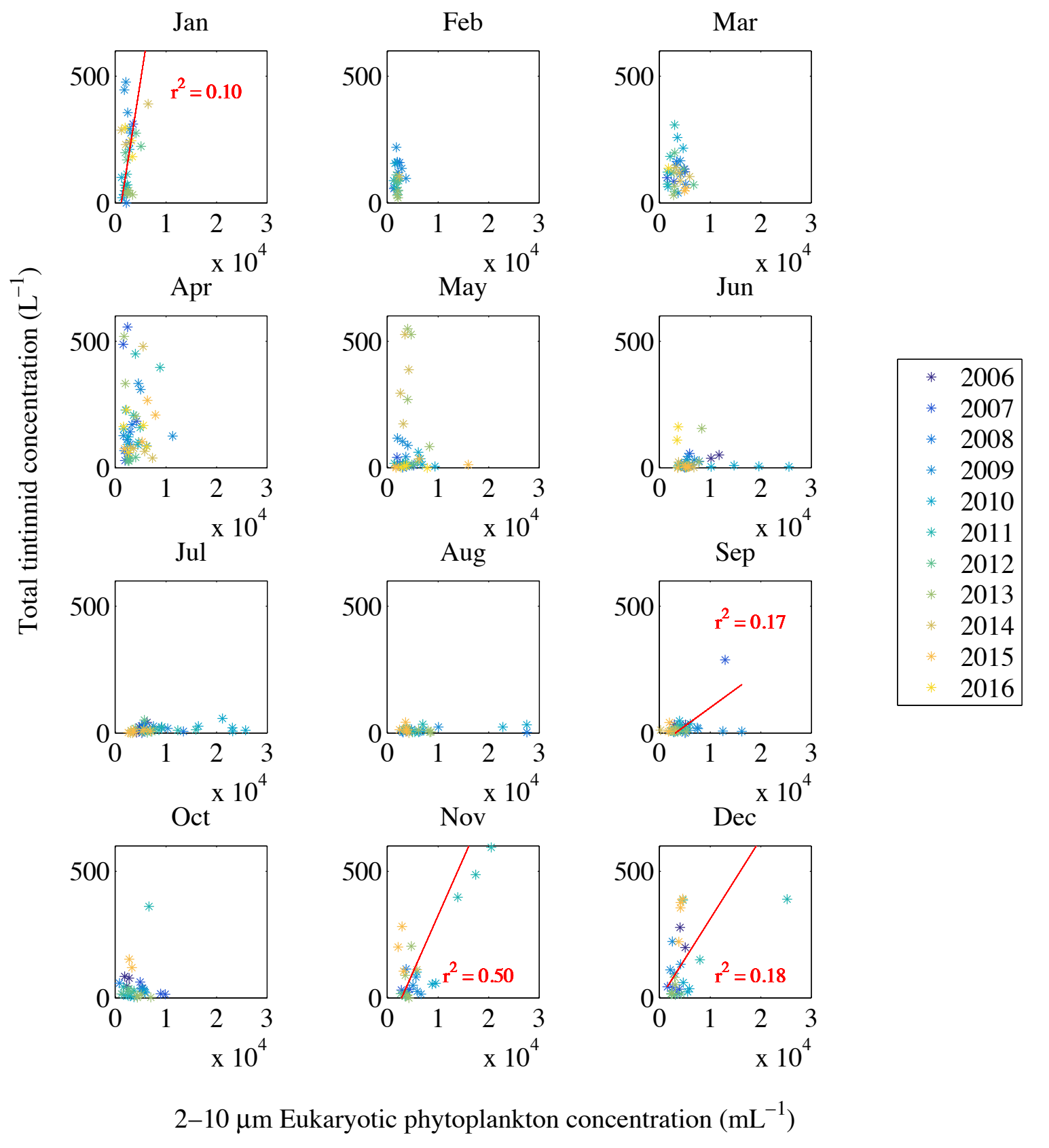

Figure 3-27: Total tintinnid concentration relationship with 2-10 $\mu \mathrm{m}$ eukaryotic phytoplankton concentration for weekly binned data by month. Red lines indicate significant relationship $(\mathrm{p}<0.05)$ 


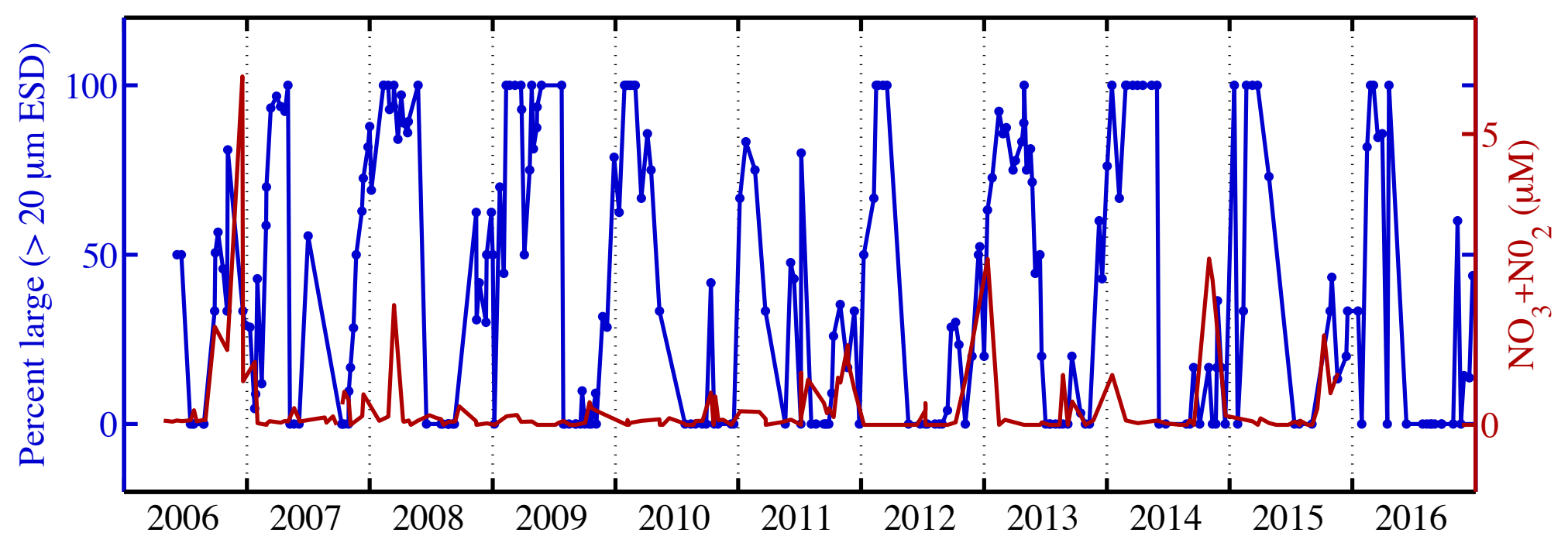

Figure 3-28: Proportion of large Mesodinium spp. $(>20 \mu \mathrm{m})$ in response to nitrate and nitrite concentrations $(\mu \mathrm{M})$ 


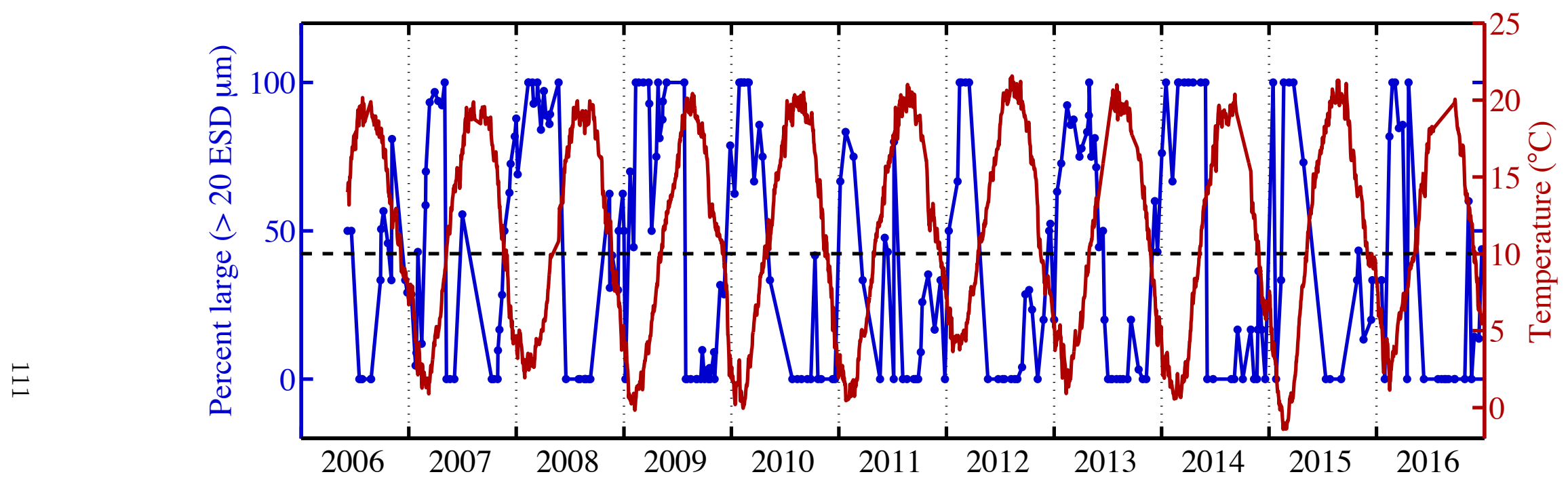

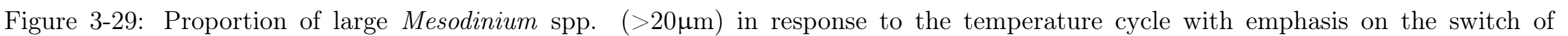
assemblage at $10^{\circ} \mathrm{C}$ 


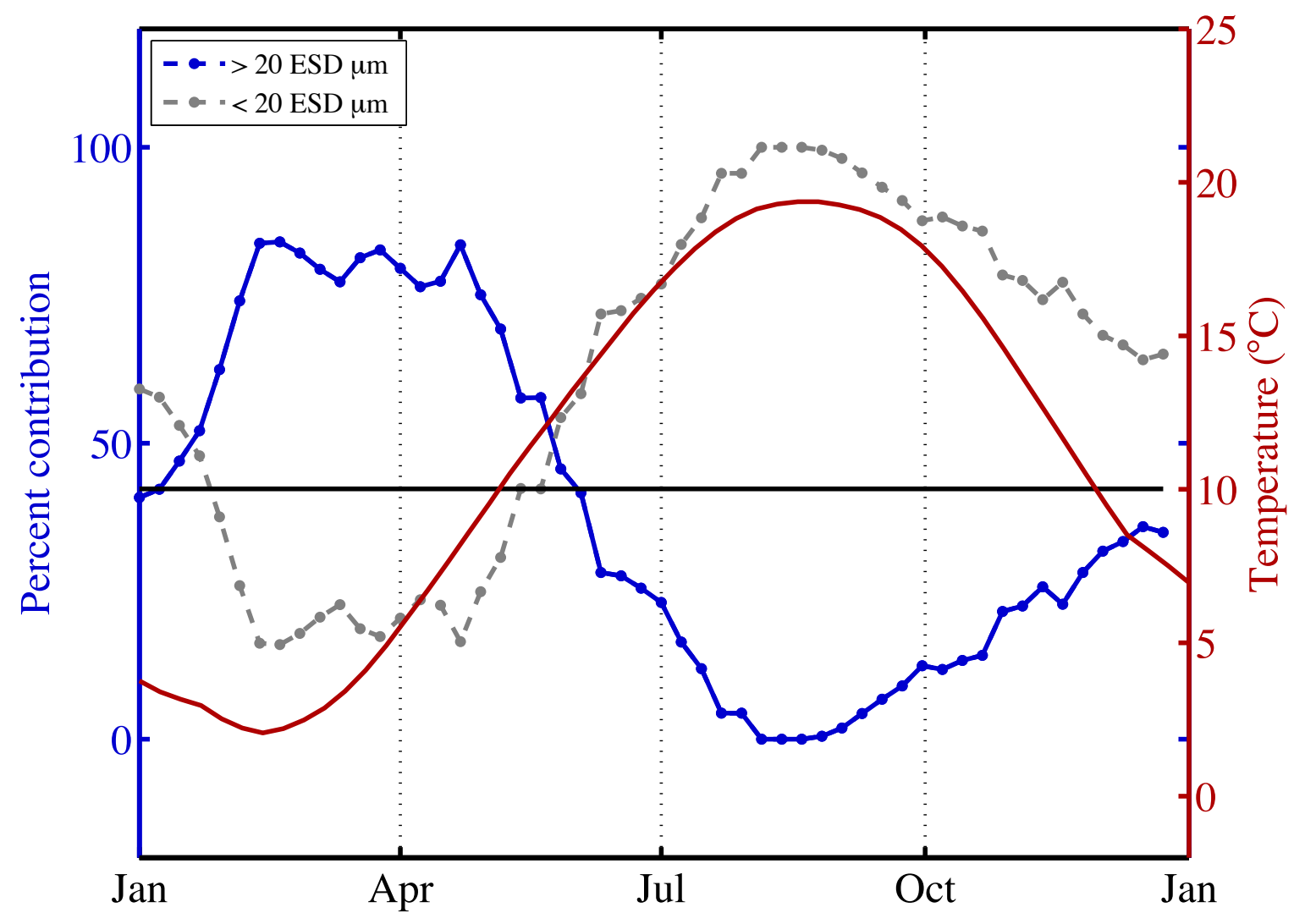

Figure 3-30: Mean seasonal pattern of water temperature and Mesodinium spp. size class contribution to total abundance. 


\section{Chapter 4}

\section{Seasonality in ciliate communities characterized by morphotype and genotype}

\subsection{Introduction}

Ciliates play important roles in marine food webs, but many aspects of their diversity and variations in community structure remain unexplored. Ciliates serve as an important trophic link between smaller plankton and metazoans (Pierce \& Turner, 1992) and are key players in the microbial loop (Pomeroy, 1974; Azam et al., 1983). Ciliate assemblages respond rapidly to biotic and abiotic pressures so the ability to identify them is essential for studying natural populations and tracking their behavior over space and time. Ciliate species delineation has traditionally been based on cell morphologies since certain structural traits can be quite distinct. Morphology, while a standard method for identifying many protists, has limitations. For many ciliate taxa, identification relies on fine-scale characteristics (Lynn, 2008), so only broad groups such as 'aloricate ciliates' can be separated when cells are viewed without specialized staining or electron microscopy. Also, different collection and preservation methods can select for different subsets of ciliate taxa (Stoecker et al., 1994). These challenges inevitably lead to the loss of certain fractions of ciliate communities. DNA sequencing has contributed to the study of protist communities, providing new insight into diversity (Pawlowski et al., 2016), predator-prey interactions (Martinez-Garcia et al., 2012), 
and discrepancies between morphologically defined species and genotypes (Stoupin et al., 2012; Santoferrara et al., 2016) .

While the use of molecular methods is on the rise, the combination of genotyping and morphological taxonomy is not always straightforward. Morphology may also not be helpful in situations when different variants of the same species would traditionally be identified as distinguished morphotypes, when in fact they are genetically similar (Dolan, 2015). Cryptic species can also arise in which genetically distinct species are morphologically indistinguishable (Weiner et al., 2012; Santoferrara et al., 2015). For some small protists, such as microchlorophytes, which can be difficult to identify due to their small size, high genetic diversity has been observed when morphotype characterization had suggested otherwise (Fawley et al., 2004) Conversely, in environmental samples, it can be difficult to assess whether genetic diversity has any morphological or physiological implications.

The few studies that have combined molecular and microscopic techniques for ciliates have provided new insights about the diversity of planktonic ciliates. In a study comparing natural communities between two years, Doherty et al. (2007) observed high diversity and shifting assemblages in choreotrich and oligotrich ciliates with culture-independent sequencing of clone libraries. Notably, though, they observed with traditional light microscopy, the morphological diversity of oligotrichs was much higher than with sequencing. Comparing high-throughput sequencing of ribosomal amplicons (HTS), cloning, and micoscopy, Santoferrara et al. (2014) found that richness estimates could vary up to an order of magnitude between the methods, despite taxon identification being relatively consistent. In this study, we compare HTS and image-based morphotype identification and explore complementary aspects of the two methods.

A multiyear time series at the Martha's Vineyard Coastal Observatory (MVCO) provides a unique opportunity to explore ciliate genotype and morphotype variations over time. At MVCO, an autonomous, submersible imaging-in-flow cytometer, Imaging FlowCytobot (IFCB) (Olson \& Sosik, 2007) allows for the observation of live herbivorous ciliates in situ without the need for culture or preservation (Brownlee et al., 2016). IFCB provides continuous, high temporal resolution observations during multimonth, unattended deployments in the ocean with back-to-back deployments providing multiyear coverage. With this time series, herbivorous ciliates have been studied (Chapter 3), but the images can sometimes provide only coarse morphology and identifying ciliates to species can be difficult. Here 
we complement the high temporal resolution image time series with HTS analysis on discrete samples collected over a three-year period. This provides information about what ciliate genotypes are present and when, which may supply new information compared to image-based morphology because with HTS approaches, the discovery of novel lineages and increased diversity has been known to occur (Bik et al., 2012; Zinger et al., 2012). A majority of the herbivorous ciliates at MVCO (as identified by morphotype) are members of the class Spirotrichea. To investigate this class in further detail (in particular, the subclasses Oligotrichia and Choreotrichia), we used hypervariable regions of the SSU rDNA gene that have been identified for use with this class (Doherty et al., 2007).

Another key ciliate at MVCO is the mixotrophic ciliate, Mesodinium spp. This ciliate sequesters chloroplasts from its cryptophyte prey and essentially acts as a photoautotroph (Stoecker et al., 1989b). Mesodinium spp. have been found to be part of a species complex (M. rubrum/major complex) of subclades (Garcia-Cuetos et al., 2012b), which have been associated with different cell sizes. While other species have been described in the Mesodiniidae family, we focused on this specific complex. With the use of primers designed to specifically amplify the internally transcibed spacer region (ITS) of the Mesodinium spp. subclades, we explored patterns of correspondence between genetic variants and Mesodinium spp. cell size distributions at MVCO.

In this chapter, we will explore how morphotypes characterized from IFCB images can be used to characterize seasonal community change in spirotrich ciliates, as well as aspects of how genotypes and morphotypes correspond.

\subsection{Materials and Methods}

\subsubsection{Sample collection}

Environmental samples were collected approximately $3 \mathrm{~km}$ south of Martha's Vineyard, Massachusetts near the MVCO offshore tower (41 19.500' N, 7034.0 "W) or at the MVCO subsea node (41 20.1950'N, 70 33.3865'W). The observatory hosts biological, meteorological, and hydrographic instruments, which collect data including temperature, salinity, incident solar radiation, wind speed, and wave conditions. We used a MicroCat CTD (Seapbird Electronics) to make additional temperature measurements continuously at 4-m depth at the offshore tower. Gaps in that record were filled with the MVCO core measurements from 
the 12-m undersea node.

Samples for molecular analysis were collected approximately every 1-2 months (and occasionally twice monthly) from February 2013-July 2015 (27 total samples). Seawater was collected at either $2 \mathrm{~m}$ depth via Niskin bottles on a rosette sampler or at the surface via bucket sample. Water was kept cool and in the dark for return to the laboratory and throughout sample processing, with about 1.5 hours between collection and filtering. Whole water samples with volumes ranging from $0.75-2.5 \mathrm{~L}$ were filtered in duplicate on $45 \mathrm{~mm}$ $0.22 \mu \mathrm{m}$ Durapore ${ }^{\circledR}$ GV filters under vacuum pressure of less than $10 \mathrm{kPa}$. Filters were cut in half, placed into autoclaved $1.5 \mathrm{~mL}$ centrifuge tubes, and frozen at $-80^{\circ} \mathrm{C}$ until subsequent analysis.

\subsubsection{Manual image classification}

To characterize herbivorous ciliates, we used IFCB, a submersible flow cytometer, which records high-resolution $(\sim 1 \mu \mathrm{m})$ images and associated optical properties (Olson \& Sosik, 2007). IFCB is deployed at $4 \mathrm{~m}$ depth on the MVCO offshore tower. The continuous longterm IFCB observations were started in June 2006 and are continuing. IFCB processes a 5-mL water sample every 20 minutes. The sample is drawn into the instrument by a programmable syringe pump and injected into the center of a particle-free sheath flow where particles pass single file through a 635 -nm laser beam path. Particles in the sample scatter laser light and chlorophyll-containing cells emit red fluorescence $(680 \mathrm{~nm}$ ) (details in Olson \& Sosik (2007)). Chlorophyll fluorescence is used to trigger a 1- $\mu$ s pulse from a xenon flash lamp and an image is captured. Measurements of chlorophyll fluorescence and side scattering are recorded for each image. This allows for in situ observations of chlorophyll-containing cells. Originally designed for phytoplankton, the IFCB detects mixotrophic and herbivorous ciliates as well (Brownlee et al., 2016) because it records images of any organisms with chlorophyll fluorescence above a trigger threshold. The data are transferred to shore in near real-time and data processing begins automatically (Sosik \& Futrelle, 2012). The image data and associated features can be accessed at http://ifcb-data.whoi.edu/mvco.

We have used routine computer-assisted manual identification of ciliates in IFCB images and categorized the ciliate data into 20 categories from the subclasses Oligotrichia and Choreotrichia (Table 4.1) (Fig. 4-1). The level of taxonomic identification allowed by IFCB images varies, but most identification is to genus or species level. Images that cannot be 
identified to this level are placed into a group of 'miscellaneous spirotrichs' (an aloricated group comprised of both sublcasses Oligotrichia and Choreotrichia). Image identification was manually performed for observations corresponding to 1-4 hours (3 to 12 samples) each day when water samples were collected for laboratory analysis. We manually examined IFCB images from entire days for larger, less abundant ciliates (Laboea strobila and all tintinnid categories). During further analyses, we automatically divided the broad category Tintinnopsis into 3 size classes: small cells of $<40 \mu \mathrm{m}$ equivalent spherical diameter (ESD), medium-sized cells in the range $40-60 \mu \mathrm{m}$ ESD, and large cells $>60 \mu \mathrm{m}$ ESD (Fig. 4-2). Miscellaneous spirotrichs were also divided into 3 size classes: small cells of $<20 \mu \mathrm{m}$ ESD, medium cells in the range $20-40 \mu \mathrm{m}$ ESD, and large cells $>40 \mu \mathrm{m}$ ESD (Fig. 4-3).

We determined cell concentration by dividing counts of images in each category by the volume of water analyzed in a sample (as calculated from the flow rate of the syringe pump, length of analysis, and time spent handling triggers). Cell concentrations were fourth root transformed $\left(\mathrm{C}_{\mathrm{IFCB}}\right)$ to preserve information about zero values. Confidence intervals $(95 \%)$ were calculated for counts assuming Poisson distributed statistics.

\subsubsection{DNA extraction}

DNA extraction was performed with the Zymo Research Fungal/Bacterial DNA MicroPrep ${ }^{T M}$ Kit. Filters were thawed and placed in 2-mL centrifuge tubes with silica beads (ZymoBeads, Zymo Research Products) and lysis buffer. The tubes were placed onto a Vortex Genie 2 (Fisherbrand) and shaken forcefully for 5 minutes to break open cells. DNA extraction was completed with Zymo Research reagents following kit protocols and final eluted DNA was kept frozen at $-20^{\circ} \mathrm{C}$.

\subsubsection{DNA amplification}

A specific region of eukaryotic DNA was targeted for amplification and sequencing: the small subunit ribosomal DNA (SSU rDNA), a gene which is highly conserved; yet variable enough to identify ciliates. The OCSP primers described in Doherty et al. (2007) were designed to target a part of the SSU rDNA gene (positions 152-528) specific enough to amplify DNA from ciliates of the class Spirotrichea (more specifically, the sublasses Oligotrichia and Choreotricia).

PCR reactions were performed in triplicate with OSCP primers that have linker se- 
quences attached (Foward: 5'-TCGTCGGCAGCGTCAGATGTGTATAAGAGACAGTTAC ATGGATAACCGTGGTAATTC-3' and Reverse: 5'-GTCTCGTGGGCTCGGAGATGTGT ATAAGAGACAGCCCGGCCCGTTATTTCTTGT-3'). Reactions contained $1 \mu \mathrm{l}$ of DNA template, $0.2 \mu \mathrm{M}$ of each OCSP primer, 1.25 unit of AmpliTaq GoldR 360 DNA polymerase (Thermo Fisher Scientific), $2 \mathrm{mM} \mathrm{MgCl}_{2}, 2 \mu \mathrm{L}$ of $2.5 \mu \mathrm{M}$ dNTPs, and $2.5 \mu \mathrm{L}$ of AmpliTaq GoldR 360 Buffer 10X (Thermo Fisher Scientific) in a total volume of $25 \mu \mathrm{L}$. Reactions were performed on a 2720 Thermal Cycler (Applied Biosystems) with the following conditions: $94^{\circ} \mathrm{C}$ for $3 \mathrm{~min}$; followed by 30 cycles of 30 seconds at $94^{\circ} \mathrm{C}, 30$ seconds at $58^{\circ} \mathrm{C}$, and 90 seconds at $72^{\circ} \mathrm{C}$. Every amplification was examined for the presence of positive products (an expected 418 bp length). To ensure the DNA concentration was high enough for sequencing, samples were purified with the DNA Clean \& Concentrator ${ }^{T M}-5$ Kit (Zymo Research) and analyzed with a NanoDrop 1000 Spectrophotometer (Thermo-Scientific). Samples needed at least $5 \mathrm{ng} \mathrm{DNA} / 20 \mu \mathrm{L}$ in a clean (remaining PCR reagents removed) reaction. PCR reaction triplicates were pooled and sent to the University of Rhode Island (URI) Genomics and Sequencing Center for library preparation and sequencing with an Illumina MiSeq Next Generation Sequencer.

\subsubsection{Data preparation}

Illumina sequences were returned from URI trimmed and demultiplexed. QIIME 1.9.0 (Caporaso et al., 2010) was used to join paired ends with a minimum overlap of 150 base pairs. Within this overlap, a minimum allowed percent difference was set at $98 \%$. The minimum number of high quality base calls to include in a read was set as $90 \%$ of the input read length. Operational taxonomic units (OTUs) were clustered at 99\% similarity with the UCLUST algorithm resulting in 47,453 OTUs. Chimeric sequences were identified with Blast and removed in Qiime resulting in 47,273 OTUs . Taxonomy was assigned by Blast 2.2.22 with the Silva 119 SSURef database (Quast et al., 2013). Singleton OTUs (those appearing in only 1 sample) were removed resulting in 539 OTUs. Non-target taxa (those not belonging to the subclasses Oligotrichia and Choreotrichia) were removed resulting in 67 OTUs.

\subsubsection{Multivariate analyses}

Read abundances were normalized with MetagenomeSeqs cumulative sum scaling (CSS) (Paulson et al., 2013). CSS normalization through Qiime results in log-transformed values, 
which we first untransformed, and then retransformed by the taking fourth root of normalized values. CSS normalization is an appropriate technique for HTS data that accounts for under sampling. Raw counts are divided by the cumulative sum of counts up to a certain percentile. This normalization makes it feasible to compare read counts of different samples. We used fourth root transformation for consistency with IFCB cell concentration results. Fourth root transformed normalized OTU counts $\left(\mathrm{N}_{\mathrm{OTU}}\right)$ were used for all downstream analyses.

$\mathrm{N}_{\text {OTU }}$ analyses were performed in MATLAB (Mathworks, Inc.) with the Fathom Toolbox (Jones 2015). We implemented non-metric multidimensional scaling (NMDS) with BrayCurtis dissimilarity matrices of OTUs. Non-metric multidimensional scaling (NMDS) is an indirect gradient analysis approach, which does not use absolute abundances, but rather rank orders making it more flexible in accepting various types of data. In our case, it produces an ordination based on Bray-Curtis dissimilarity. Bray-Curtis dissimilarity is ideal because it is invariant to changes in units and can recognize differences in total abundances even when relative abundances are the same. NMDS works to represent the pairwise dissimilarity between samples instead of trying to maximize correspondence or variability in a typical ordination. The NMDS axes are arbitrary as they can be rotated or inverted. The points on the plot represent samples and those more similar to each other are closer together. The vectors indicate the linear correlation of NMDS scores with morphospecies and the vector length is scaled by the strength of the correlation.

We also used analysis of similarity (ANOSIM) for ciliate communities separated according to their occurrence in four environmental temperature bins $\left(<5{ }^{\circ} \mathrm{C}, 5-10{ }^{\circ} \mathrm{C}, 10-15{ }^{\circ} \mathrm{C}\right.$, and $>15^{\circ} \mathrm{C}$ ). Global $\mathrm{R}$ values were determined between each comparison and indicate the effect of temperature on the samples; an R-value close to 1 indicates high separation between samples, while an R-value close to zero indicates no separation. Finally, to identify the OTUs driving the significant differences between water temperature regimes, we used Simper. Fourth root transformed concentrations of ciliates $\left(\mathrm{C}_{\mathrm{IFCB}}\right)$ from the subclasses Oligotrichia and Choreotrichia as manually identified from IFCB images were subjected to the same analyses. Pearson's correlation coefficients were calculated between $\mathrm{N}_{\mathrm{OTU}}$ and $\mathrm{C}_{\mathrm{IFCB}}$ and significance was evaluated with Student's t-distribution. 


\subsubsection{Mesodinium spp. amplification and sequencing}

Eight samples were amplified and sequenced for Mesodinium sp. haplotypes (4 April 2013, 13 August 2013, 15 October 2013, 2 February 2014, 2 April 2014, 31 October 2014, 11 November 2014, and 10 March 2015) following Johnson et al. (2016). PCR was conducted with GoTaq (Promega) or GoTaq G2 Hot Start mix in $50 \mathrm{~mL}$ reactions, with a final concentration of 2.5 $\mathrm{mM} \mathrm{MgCl} 2,200 \mu \mathrm{M}$ dNTPs, $2.5 \mathrm{U}$ GoTaq Flexi polymerase, and $0.1 \mu \mathrm{M}$ primers for normal and $0.2 \mu \mathrm{M}$ for Hot Start. Primers for Mesodinium spp., designed to amplify the majority of the SSU and LSU rRNA genes, and the entire ITS region, resulted in an approximately $1880 \mathrm{bp}$ amplicon. PCR conditions were as follows: $95^{\circ} \mathrm{C}$ for 5 minutes; followed by 40 cycles of $95^{\circ} \mathrm{C}$ for 60 seconds, $55^{\circ} \mathrm{C}$ for 60 seconds, and $72^{\circ} \mathrm{C}$ for 90 seconds, and a final step at $72^{\circ} \mathrm{C}$ for 7 minutes. The genus-specific primers $\mathrm{MESO} \_245 \mathrm{~F}$ and MESO_28s_R were used to amplify a combined fragment of the Mesodinium spp. 18S-ITS-28S genes. PCR conditions were as follows: $95^{\circ} \mathrm{C}$ for 5 minutes; followed by 40 cycles of $95^{\circ} \mathrm{C}$ for 60 seconds, $57^{\circ} \mathrm{C}$ for 60 seconds, and $72^{\circ} \mathrm{C}$ for 90 seconds, and a final step at $72^{\circ} \mathrm{C}$ for 7 minutes. PCR products were excised and purified from agarose gels with the Zymoclean Gel DNA Recovery Kit (Zymo Research). Clone libraries were constructed with the pGEM-T Easy Vector in the pGEM-T Easy Vector System II cloning kit (Promega Corporation) according to the manufacturer's protocol. Clones were submitted for Sanger sequencing with a single primer to either Beckman Coulter Genomics (Single Pass Sequencing) or the W.M. Keck Ecological and Evolutionary Genetics Facility at the Marine Biological Laboratory (Woods Hole, MA). Sequences were edited and assembled into contigs with Sequencher (Gene Codes Corporation). With a sequence similarity criterion of $99 \%$ for Mesodinium spp., independent contigs were constructed. Sequence comparisons were performed with known phylotypes in Genbank and similarity was found to be in the range $98-99 \%$ for different genotypes.

\subsection{Results}

\subsubsection{Spirotrich composition}

Among the 27 samples analyzed by HTS, we detected 29 tintinnid species from the genera Amphorellopsis, Codonella, Eutintinnus, Favella, Metacylis, Helicostomella, Tintinnopsis, Salpingella, Stenosemella, and Tintinnidium. Non-tintinnid choreotrich genera detected were Pelagostrobilidium, Strobilidium, Parastrombidinopsis, and Rimostromidium. Six 
unidentified species were most closely related to aloricated choreotrich ( $>90 \%$ similarity) sequences in the NCBI database. For oligotrich genera, we found Laboea, Spirostrombidium, Pseudotontonia, Strombidium, and Varistrombidium. Seven unidentified oligotrich species were also noted. We queried representative sequences of these seven OTUs against the NCBI database, but they remained unidentified.

With morphology from IFCB images, we detected tintinnids from the genera Tintinnopsis, Stenosemella, Tintinnidium, Eutintinnus, and Favella (Table 4.1). We recorded two morphotypes of aloricate choreotrichs, Leegaardiella ovalis and Strobilidium sp. In the subclass Oligotrichia, we separated ten morphotypes (of which eight were identified to species) belonging to the genera Strombidium, Laboea, and Tontonia. The rest of the aloricated choreotrichs and oligotrichs were placed into a group of 'miscellaneous spirotrichs', which were subsequenctly split by cell size. While many of the imaged species were found in the NCBI database, only five overlapped with our HTS results. Of the 24 morphotypes identified in IFCB images, 23 were present on at least one date when samples were collected for sequencing; only Helicostomella subulata was missing. While we have detected Helicostomella subulata at other times during the full IFCB time series (2006-2016), we did not observe it in images on the days when samples were collected for sequencing.

\subsubsection{Spirotrich relationship with temperature}

NMDS revealed separations in the choreotrich and oligotrich ciliate community by temperature (stress 0.14) (Fig. 4-4). There were large differences in the ciliate OTU composition between samples collected from $>15^{\circ} \mathrm{C}$ and $<5^{\circ} \mathrm{C}$ waters, and smaller differences between middle temperatures. An analysis of similarity (ANOSIM) detected significant separation between samples. The significantly different comparisons were $<5^{\circ} \mathrm{C}$ and $10-15^{\circ} \mathrm{C}$ (Global $\mathrm{R}=0.43)$ and $<5^{\circ} \mathrm{C}$ and $>15^{\circ} \mathrm{C}($ Global $\mathrm{R}=0.51)$ (Table 4-2).

The first $25 \%$ of the dissimilarity between $<5^{\circ} \mathrm{C}$ and $10-15^{\circ} \mathrm{C}$ was driven by the hyaline tintinnids, Amphorellopsis quinquealata, Eutintinnus tubulosus, and Salpingella sp. (Table. 4-3) (which were associated with $10-15^{\circ} \mathrm{C}$ ). An additional $50 \%$ of the dissimilarity was driven by mostly species associated with warmer temperatures with the exception of Stenosemella pacifica and an uncultured choreotrich species, which were associated with colder temperatures. The first $25 \%$ of the dissimilarity between $<5^{\circ} \mathrm{C}$ and $>15^{\circ} \mathrm{C}$ was driven by the same warm temperature species of hyaline tintinnids, with the exception of an 
aloricated choreotrich Pelagostrobilidium sp. in place of Salpingella sp. An additional 50\% of the dissimilarity was driven by almost equal parts species associated with warm temperatures (Tintinnopsis cylindrica, uncultured choreotrich and oligotrich species, and the hyaline tintinnid Salpingella sp.) and those associated with colder temperatures (Stenosemella pacifica, Tintinnopsis sp. 9 LS-2012, and the same uncultured choreotrich as with the $<5^{\circ} \mathrm{C}$ and $10-15^{\circ} \mathrm{C}$ comparison) .

Separation by temperature was not as strong for ciliate communities characterized from IFCB images (stress 0.18 for 3-dimensional NMDS analysis)(Fig. 4-3, Fig. A-7). Community structure was most distinctive in waters $>15^{\circ} \mathrm{C}$, while lower temperatures were less clearly separated from each other. ANOSIM detected weak, but significant separation between communities collected from conditions $<5^{\circ} \mathrm{C}$ and $5-10^{\circ} \mathrm{C}$ conditions (Global $\mathrm{R}=0.1$ ), $<5^{\circ} \mathrm{C}$ and $10-15^{\circ} \mathrm{C}($ Global $\mathrm{R}=0.19),<5^{\circ} \mathrm{C}$ and $>15^{\circ} \mathrm{C}($ Global $\mathrm{R}=0.2)$, and $10-15^{\circ} \mathrm{C}$ and $>15^{\circ} \mathrm{C}$ (Global $\mathrm{R}=0.01)$ (Table 4.2).

For image-based results, there were many similarities between the $<5^{\circ} \mathrm{C}$ and $5-10^{\circ} \mathrm{C}$ comparison, the $<5^{\circ} \mathrm{C}$ and $10-15^{\circ} \mathrm{C}$ comparison, and the $<5^{\circ} \mathrm{C}$ and $>15^{\circ} \mathrm{C}$ comparison (Table 4-4). In these three comparisons, a cold water and a warm water species contributed to the top 20-25\% of dissimilarity (Table 4-4). In these cases, Tintinnopsis spp. 40-60 $\mu \mathrm{m}$, associated with cooler regimes was in the top two while its warm water counterpart was either Tintinnopsis spp. $<40 \mu \mathrm{m}\left(<5^{\circ} \mathrm{C}\right.$ and $5-10^{\circ} \mathrm{C}$ comparison) or miscellaneous spirotrichs $20-40$ $\mu \mathrm{m}$ size class $\left(<5^{\circ} \mathrm{C}\right.$ and $10-15^{\circ} \mathrm{C}$ comparison and $<5^{\circ} \mathrm{C}$ and $>15^{\circ} \mathrm{C}$ comparison $)$.

For these same three comparisons there were also similarities in the next $50-55 \%$ of species contributing to dissimilarity in groups (Table 4-4). The cold water groups were always Stenosemella pacifica and Leegaardiella ovalis. The warm temperature groups were a mixture of Strombidium species, Laboea strobila, $<40 \mu \mathrm{m}$ Tintinnopsis spp. (if not in the top 20-25\%), and the smaller size classes of miscellaneous spirotrichs $(<20$ and $20-40 \mu \mathrm{m}$ if not in the top 20-25\%).

For the fourth comparison, $10-15^{\circ} \mathrm{C}$ and $>15^{\circ} \mathrm{C}$, the top $20 \%$ of the dissimilarity was driven by two warm temperature species: miscellaneous spirotrichs $20-40 \mu \mathrm{m}$ and miscellaneous spirotrichs $<20 \mu \mathrm{m}$ (Table $4-4$ ). The next $55 \%$ of dissimilarity associated with cooler temperatures were a mixture of Strombidium species, Laboea strobila, and the choreotrichs Stenosemella sp., Strobilidium sp., and 40-60 $\mu \mathrm{m}$ Tintinnopsis spp. The warm temperature associated species were Tintinnopsis spp. $<40 \mu \mathrm{m}$ and two Strombidium species. 


\subsubsection{Genotype and morphotype comparisons}

There were a subset of tintinnid genera that overlapped between HTS and image-based morphology. When we considered just these groups and compared $\mathrm{N}_{\mathrm{OTU}}$ and $\mathrm{C}_{\mathrm{IFCB}}$ of total tintinnids, we observed similar late summer/early fall lows, winter elevations in 2013, and fall elevations in 2014 (Fig. 4-6) $(\mathrm{r}=0.47, \mathrm{p}<0.05)$. When all tintinnid genera from HTS were considered, elevated $\mathrm{N}_{\mathrm{OTU}}$ also occurred in the summer of 2014.

There were four common tintinnid genera identified with both HTS and image-based morphology. $\mathrm{C}_{\mathrm{IFCB}}$ for the genus Stenosemella spp. displayed late fall/winter elevated concentrations in both 2014 and 2015 (Fig. 4-7A). Lowest counts were observed during the late summer/early fall. At the genus level for Stenosemella, $\mathrm{N}_{\mathrm{OTU}}$ correlated significantly (r=0.62) with $\mathrm{C}_{\mathrm{IFCB}}$. Eutintinnus $\mathrm{N}_{\mathrm{OTU}}$ exhibited seasonality, occurring in the late summer/fall, though it was also elevated earlier in 2013 (Fig. 4-7B). $\mathrm{C}_{\mathrm{IFCB}}$ for the Eutintinnus genus peaked in the late summer/early fall of 2013 and 2014. At the genus level for Tintinnopsis, $\mathrm{C}_{\mathrm{IFCB}}$ and $\mathrm{N}_{\mathrm{OTU}}$ were significantly correlated $(\mathrm{r}=0.43)$, though patterns of seasonality were more difficult to discern than that of Stenosemella and Eutintinnus (Fig. 4-7C). In particular, the patterns from the two methods tended to diverge in late winter. The genus Favella was only detected by image-based morphology in 2014, when it exhibited peaks in spring and early fall (Fig. 4-7D). The fall peak coincided with elevated $\mathrm{N}_{\mathrm{OTU}}$, but the spring peak coincided with low $\mathrm{N}_{\mathrm{OTU}}$.

There were several genera detected by sequencing, but not by imaging: Salpingella, Amphorellopsis, Codonellopsis, and Metacylis, (Fig. 4-8). For Salpingella, $\mathrm{N}_{\mathrm{OTU}}$ values were highest in summer months, but smaller peaks were also observed during the late fall and winter (Fig. 4-8A). Amphorellopsis displayed elevated $\mathrm{N}_{\text {OTU }}$ each year during the summer (Fig. 4-8B). Codonellopsis displayed lowest $\mathrm{N}_{\mathrm{OTU}}$ each year in the latter half of summer into fall (Fig. 4-8C). Metacylis displayed no systematic seasonal pattern through time (Fig. $4-8 \mathrm{D})$.

Three Eutintinnus species were identified with HTS and displayed similar patterns of occurence (Fig. 4-9) except that only one species (E. tubulosus) was detectable in winter, though at very low amounts. N $\mathrm{N}_{\text {OTU }}$ was elevated throughout most of 2013, but decreased during the fall. $\mathrm{N}_{\mathrm{OTU}}$ peaks in 2014 and 2015 coincided during the summer/ early fall for

all three species. $\mathrm{C}_{\mathrm{IFCB}}$ for Eutintinnus displayed similar peaks in the late summer/early 
fall of 2013 and 2014, but not in 2015 .

Between HTS and image-based morphology, there were four overlapping identifications at the species level (Fig. 4-10): Stenosemella pacifica, Tintinnidium mucicola, Strombidium conicum, and Laboea strobila. The highest correspondance between methods occurred for Stenosemella pacifica $(\mathrm{r}=0.69)$ and Tintinnididum mucicola $(\mathrm{r}=0.57)$. S. pacifica exhibited late fall/winter peaks and summer lows (Fig. 4-10A). T. mucicola was only detected by image-based morphology in one out of the three years studied, while it was detected by HTS all three years (Fig. 4-10B). Laboea strobila, a ciliate easily identified in images, and abundant seasonally at MVCO (Brownlee et al., 2016), happened to be very low on days of sample collection for sequencing, making comparison difficult (Fig. 4-10D). Some correspondence did occur, but overall the relationship was not significant $(\mathrm{r}=0.1)$. Strombidium conicium was rarely observed in images and we could not discern a systematic relationship between the methods (Fig. 4-10C). Helicostomella subulata, a morphotype we do detect at low levels by image-based morphology, did not occur in images on dates when HTS samples were taken and thus no relationship could be detected (Fig. 4-10E).

We cannot reliably identify Tintinnopsis to species from images, so we instead investigated whether OTUs of Tintinnopsis were associated with particular size classes as assessed from images (Fig. 4-11). As a guide for this, we used species-specific cell size ranges described by Santoferrara et al. (2012). We found significant positive relationships between T. parvula and Tintinnopsis spp. $<40 \mu \mathrm{m}$ and between T. cylindrica and Tintinnopsis spp. $>60 \mu \mathrm{m}(\mathrm{r}=0.45$ and $\mathrm{r}=0.46$, respectively) (Fig. 4-11AF). There were no significant relationships between Tintinnopsis spp. 40-60 $\mu \mathrm{m}$ and any of the OTUs that correspond to medium-sized species as described by Santoferrara et al. (2012): T. sp. 4 LS-2012, T. sp. 9 LS-2012,T. sp. 8 LS-2012, and T. sp. 7 LS-2012 (Fig. 4-11B-E).

\subsubsection{Mesodinium spp. subclades}

From IFCB analysis, we observed varying cell size distributions of Mesodinium spp. occurring at different times of the year. To explore whether differences in cell size were indicative of genetic variability, we analyzed eight samples spanning a range of water temperatures and sample years for the presence of Mesodinium spp. subclades (Fig. 4-12). M. rubrum subclade A dominated three samples collected when waters were $<5{ }^{\circ} \mathrm{C}$ and when images of Mesodinium spp. showed that cells averaged $>20 \mu \mathrm{m}$. M. rubrum subclade E was only 
detected in two samples in 2013; it dominated one of those samples associated with approximately $20^{\circ} \mathrm{C}$ water and $<20 \mu \mathrm{m}$ cells. M. rubrum subclade F was only detected in the latter half of the time series; it dominated when waters were $>10{ }^{\circ} \mathrm{C}$ and cells averaged $<20 \mu \mathrm{m}$. M. rubrum subclade $\mathrm{G}$ was detected in three samples across the time series, but was always less than $20 \%$ of the assemblage. M. rubrum subclade C was detected once at a very low level, and an unresolved variant, a novel M. rubrum subclade (closest in relation to subclades $\mathrm{C}$ and $\mathrm{E}$ ) was also detected only once. M. major (subclade D) was observed in five samples across the time series, and twice represented nearly all (>95\%) of the Mesodinium spp. subclades present. One of those times was associated with water $>15{ }^{\circ} \mathrm{C}$ and cells $<20$ $\mu \mathrm{m}$, while the other was associated with water $<15{ }^{\circ} \mathrm{C}$ and cells $>20 \mu \mathrm{m}$. A third sample, when M. major represented close to half of the clones, was associated with water $>15{ }^{\circ} \mathrm{C}$ and cells $<20 \mu \mathrm{m}$.

\subsection{Discussion}

At MVCO, we are able to study herbivorous ciliates in situ and in high temporal resolution with images captured by the IFCB. Limitations, though, arise when these images do not provide enough taxonomic information due to cell orientation or the inability to distinguish fine scale characteristics key for identification. We are also limited to detecting cells that are herbivorous or mixotrophic, as images are collected only above a trigger threshold for chlorophyll fluorescence. For this reason, questions arise about the extent to which groups identified morphologically from images may be missing aspects of variation in communities. HTS of ribosomal amplicons provides separate means to characterize patterns of seasonality.

The targets for amplicon-based diversity are the hypervariable regions of the SSU rDNA gene, which is amplified with universal eukaryotic primers (Amaral-Zettler et al., 2009; Stoeck et al., 2009; Monchy et al., 2012). This study used primers designed to amplify a part of the SSU rDNA gene specific enough to identify ciliates of the class Spirotrichea (Doherty et al., 2007). Not only do ciliates of the Spirotrichea subclasses Oligotrichia and Choreotrichia comprise a majority of the herbivorous ciliate community at MVCO, they typically dominate planktonic ciliates (Grattepanche et al., 2015; Massana et al., 2015; Grattepanche et al., 2016). While it is difficult to directly compare data between morphotypes and genotypes because sampling efforts were different, we used two methods to do 
so; one indirect (comparisons of beta diversity) and one direct (comparisons between $\mathrm{N}_{\mathrm{OTU}}$ and $\mathrm{C}_{\mathrm{IFCB}}$ ). For beta diversity analyses, we used morphotypes and genotypes to examine whether oligotrich and choreotrich community delineations could be detected between temperature regimes. For direct comparisons, we compared temporal patterns between genera, or species when possible, indicated by $\mathrm{N}_{\mathrm{OTU}}$ from HTS and $\mathrm{C}_{\mathrm{IFCB}}$ from image-based morphology; our aim was to assess congruence between the methods and to identify taxa with distinctive seasonal patterns.

\subsubsection{Beta diversity between temperature regimes}

Analyses on $\mathrm{N}_{\mathrm{OTU}}$ showed separation between samples collected from warmer water temperatures and those from cooler temperatures (Fig. 4-4). Specifically, we detected significant differences between the $<5{ }^{\circ} \mathrm{C}$ samples and $10-15{ }^{\circ} \mathrm{C}$ samples and $<5{ }^{\circ} \mathrm{C}$ samples and $>15{ }^{\circ} \mathrm{C}$ samples; highest separation occurred between the latter (Table 4.2). The hyaline loricated tintinnids, Amphorellopsis quinquealata and Eutintinnus tubulosus, contributed the most (in the first 25\%) to these differences between temperatures bins. Both of these ciliates were associated with warmer temperature conditions in summer. These results emphasize the importance of these species at a time of year when total tintinnid $\mathrm{C}_{\mathrm{IFCB}}$ was low (Fig. 4-6).

With image-based morphology, we found the groups contributing the most to dissimilarity between regimes were groups that were not identified down to species. These groups were Tintinnopsis and miscellaneous spirotrichs, both of which we separated into size classes. Tintinnopsis spp. 40-60 $\mu \mathrm{m}$ and miscellaneous spirotrichs $20-40 \mu \mathrm{m}$ were major contributors to the differences between temperature regimes. The big role these two groups play may be due to the fact that they are combinations of a number of species. It is interesting, however, that these defined cell size ranges emerge as important. HTS-based differences between temperature ranges highlight the importance of Tintinnopsis sp. 4 LS-2012 and Tintinnopsis sp. 9 LS-2012 (Table 4-3). Notably, Santoferrara et al. (2012), report that both of these species are in the $40-60 \mu \mathrm{m}$ size ranges so this result is consistent with the image-based approach.

We found that both image-based morphology and HTS revealed community differences between temperature regimes. Interestingly, these differences occurred in more of the temperature bin comparisons with image-based morphology than HTS, though HTS global R values were higher. These higher global $\mathrm{R}$ values with HTS samples may have occurred 
because we were capturing two communities differentially feeding. This kind of result would be expected if the warmer temperature communities were grazing on organisms without chlorophyll fluorescence above the trigger threshold, and were thus not captured by IFCB. The communities captured by image-based morphology may exhibit less separation because they were all feeding similarly (i.e., IFCB only captures herbivorous ciliates).

The importance of differences in prey types was particularly emphasized with the tintinnid community. With HTS, hyaline loricated tintinnids (asociated with the warmer temperatures) were top contributors to community differences between temperature regimes. With morphotypes from IFCB, the agglomerated species were more represented than hyaline, many belonging to the colder temperature regimes. Combined, these two approaches emphasize the importance of different types of ciliates to the communities as they changed seasonally and support a view of agglomerated species preferentially feeding on chlorophyllcontaining prey. Furthermore, with HTS, many uncultured spirotrich genotypes were responsible for the differences between temperature regimes. While we may not know their taxonomic identity, we are able to learn something about temperature niches.

\subsubsection{Genotype and morphotype comparisons}

We focused direct comparisons between HTS and imaged-based morphology on the tintinnid community, as there were common genera between amplicon OTUs and images from the IFCB. Compared across all common tintinnid genera, we found significantly correlated occurrence patterns between $\mathrm{C}_{\mathrm{IFCB}}$ and $\mathrm{N}_{\mathrm{OTU}}$ (Fig. 4-6). We can additionally analyze the congruency of HTS and imaged-based morphology in characterizing tintinnids at the genus or species level. From HTS, the taxa that contributed the most to communitiy differences between temperature regimes favored warmer conditions. For some of these tintinnid genera, $\mathrm{N}_{\mathrm{OTU}}$ revealed distinct seasonal patterns. Particularly, this occurred for genera not detected with IFCB, Amphorellopsis and Salpingella. Amphorellopsis displayed summer increases each year, and while the Salpingella genus was less systematic, peaks in NOTU also occurred during summer months (Fig. 4-8A). HTS allowed us to detect the seasonality of these warm-regime ciliates when image-based morphology did not.

We captured the seasonality of the genus Eutintinnus with both methods (significantly correlated) (Fig 4-7B). For this genus, HTS was valuable in identifying separate species when images allowed us to identify to genus. Three different species were detected, E. pectinis, 
E. stramentus, and E. tubulosus. E. tubulosus was especially important in defining warm temperature communities (Table 4-3) (Fig. 4-9). While patterns of $\mathrm{N}_{\text {OTU }}$ were generally similar between species, E. tubulosus was the only species detected during the colder winter months (though at very low amounts). This was another case when we did not observe the genus in images, suggesting the possibility they were not feeding on chlorophyll-containing cells.

Tintinnopsis cylindrica and Tintinnopsis sp. 4 LS-2012, two species of agglomerated tintinnids associated with warmer temperatures were important contributors to community differences, (Table 4-3) (Fig. 4-11FB). NotU for T. cylindrica (known to be $>60 \mu \mathrm{m}$ in length) displayed a positive significant correlation with $\mathrm{C}_{\mathrm{IFCB}}$ for Tintinnopsis spp. $>60$ $\mu \mathrm{m}$ size, indicating size can be an appropriate proxy for examining patterns of this species. Tintinnopsis sp. 4 LS-2012 as described by Santoferrara et al. (2012) is in the 40-60 $\mu \mathrm{m}$ size class, but we found no significant relationship with $\mathrm{C}_{\mathrm{IFCB}}$ for Tintinnopsis spp. 40$60 \mu \mathrm{m}$. This is not surprising as the Tintinnopsis spp. 40-60 $\mu \mathrm{m}$ group was associated with colder temperature regimes and consists of a variety of species. The highest positive relationship between Tintinnopsis spp. 40-60 $\mu \mathrm{m}$ and a species identified by HTS was an $\mathrm{r}$ of 0.25 (with Tintinnopsis sp. 8 LS-2012), though this relationship was not significant (Fig. 4-11D). $\mathrm{C}_{\mathrm{IFCB}}$ for Tintinnopsis spp. $<40 \mu \mathrm{m}$ was positively correlated with $\mathrm{N}_{\mathrm{OTU}}$ for Tintinnopsis parvula, a species within this size class. Although T. parvula alone did not emerge as important for community differences (Table 4-3), the Tintinnopsis spp. $<40 \mu \mathrm{m}$ group as a whole was important (Table 4-4). This may indicate that the $<40$ and $>60 \mu \mathrm{m}$ size classes may be dominated by their respective genotypes or that those genotypes are highly representative of this size community. On the other hand, the 40-60 $\mu \mathrm{m}$ size class is not an appropriate proxy for identifying underlying species dynamics.

Although Laboea strobila was not an important contributor to HTS-based differences in temperature regimes (Table 4-3), it was important (associated with warmer water temperatures) when considering image-based morphology (Table 4-4). For L. strobila, $\mathrm{C}_{\mathrm{IFCB}}$ was very low during this time series, possibly contributing to the weak relationship found between $\mathrm{N}_{\mathrm{OTU}}$ and $\mathrm{C}_{\mathrm{IFCB}}$. Patterns of $\mathrm{N}_{\mathrm{OTU}}$ for Laboea strobila suggest it may be reflecting the spring and fall seasonality observed with morphotypes (Brownlee et al., 2016), but $\mathrm{N}_{\mathrm{OTU}}$ was sometimes elevated when $\mathrm{C}_{\mathrm{IFCB}}$ was not (e.g., Fall 2013 and Winter 2015, Fig. 4-10D).

We noted that tintinnids contributing to the colder temperature regimes were of the 
agglomerated variety. For the Stenosemella genus, we observed similar patterns between $\mathrm{N}_{\mathrm{OTU}}$ and $\mathrm{C}_{\mathrm{IFCB}}$, with both capturing winter increases and summer decreases (4-4A). For the species, Stenosemella pacifica, the correlation between $\mathrm{N}_{\mathrm{OTU}}$ and $\mathrm{C}_{\mathrm{IFCB}}$ was even higher (Fig. 4-11A).

Codonellopsis, a tintinnid similar in morphology to Stenosemella, with the exception of a conspicuous clear collar on the oral end of the lorica (Lynn, 2008), was identified by HTS but not observed in images. $\mathrm{N}_{\mathrm{OTU}}$ was low during the late summer/early fall. While we have not seen a morphotype with an oral collar in images at MVCO, it may be that the collar is fragile or not detectable given the image resolution. Phylogenetic investigations by Li et al. (2009) suggested that, because Stenosemella and Codonellopsis are very closely related genetically, they should possibly be merged into one genus. Agatha \& Tsai (2008), when describing Stenosemella pacifica noted a high degree of polymorphisms of the lorica. While unsure if this plasticity also occurs for the Codonellopsis genus since they are so closely related, there remains the possibility that these ciliates may have been detected by IFCB, but we were unable to distinguished them from Stenosemella images.

HTS was important to quantify some types of ciliates that were undersampled by IFCB. Notably, three genera of hyaline loricated tintinnids (Amphorellopsis, Salpingella, Metacylis) were not observed with image-based morphology. The lorica diameter on the oral end of tintinnids restricts the size of prey cells they can consume (Dolan et al., 2013). For Salpingella, these openings are quite narrow $(4-20 \mu \mathrm{m})$, and combined with the fact that they rarely exhibit chlorophyll fluorescence, this may suggest their diet consists of bacteria or small heterotrophic protists. In fact, Brownlee et al. (2016), during a summer-time cruise, found high concentrations of the hyaline tintinnid, Eutintinnus, were only captured by IFCB when a live stain was applied. It is also important to note that with Salpingella and Amphorellopsis, HTS was critical to detect and identify a certain niche associated with warmer temperatures and when combined with IFCB results provides hypotheses about food preferences.

We detected only four ciliates that could be identified to species by both HTS and image-based morphology, which may reflect the inability to identify species with $1 \mu \mathrm{m}$ resolution images. Of those, only two had significant relationships between $\mathrm{N}_{\text {OTU }}$ and $\mathrm{C}_{\mathrm{IFCB}}$, Stenosemella pacifica and Tintinnidium mucicola. We did not note any significant relationships between between HTS and image-based morphology when $\mathrm{N}_{\text {OTU }}$ was below 10 , 
indicating when OTUs are rare, they may not be able to provide an accurate snapshot of patterns for that particular species or genus. Furthermore, Santoferrara et al. (2014) compared HTS, cloning, and microscopy and found that during extensive quality controlling of the data ('denoising'), they lost many known morphospecies. Bachy et al. (2013) found densoising techniques during data processing can lead to different assessments of rare haplotypes, including missing them and attributing them to sequencing errors. This may have occurred in our data as very stringent quality control, OTU clustering, and taxonomy assignment parameters were used. While we can only identifiy many of the current IFCB morphotypes down to genus, we do have species-level image identification for six species of the genus Strombidium, of which only one appeared in the amplicon OTU data. Santoferrara et al. (2014) also noted discrepancies in dominant or extremely rare species in certain samples, and suggested that high-throughput data processing be very carefully applied. Another issue that impacts the comparison of OTU and image data is that reference databases for protist rDNA sequence identification are limited by what has been cultured, identified, and sequenced. We used the SILVA database, which is appropriate for protists, but there were still organisms that were not represented in the data, as well as many that have not been sequenced. Phylogenetic based approaches may be helpful to establish taxonomic affinities (Porter \& Goldin, 2011) and is something that we will pursue in the future.

\subsubsection{Mesodinium spp. genetic and morphological variations}

When exploring subclades of the Mesodinium rubrum/major complex, we observed possible evidence of the interplay of genetic variation and physiological plasticity. When temperatures were $<10^{\circ} \mathrm{C}$, we detected high proportions of $M$. rubrum subclade A and M. major (subclade D)(Fig 4-12). On all three dates when we observed M. rubrum subclade A, it represented $>75 \%$ of the sequences, Mesodinium spp. cells were on average $>20 \mu \mathrm{m}$, and temperatures were $<10{ }^{\circ} \mathrm{C}$. M. rubrum subclade A has been found in environments, such as the Gulf of Finland and California Current, at temperatures $>10{ }^{\circ} \mathrm{C}\left(17.4\right.$ and $12.8{ }^{\circ} \mathrm{C}$, respectively) (Johnson et al., 2016), though never dominating samples. This may indicate it only dominates in cold temperatures. M. rubrum subclade A was originally observed in McMurdo Sound, Antarctica (Johnson et al., 2016) further suggesting its affinity for colder waters. These results suggest that larger sized morphotypes observed at MVCO belong to specific M. rubrum/major subclades (A and D), with subclade A possibly occupying a cold 
water temperature niche.

When a majority of sequences belonged to Mesodinium major in February of 2014, we observed large Mesodinium spp. cells and $<10^{\circ} \mathrm{C}$ water (Fig. 4-12). This contradicted two other samples when M. major was in high proportion (Oct 2013 and Oct 2014), but waters were $>10{ }^{\circ} \mathrm{C}$ and cells were small. In all previous studies, M. major has been described as exhibiting large cell sizes, reaching 50 x $40 \mu \mathrm{m}$ (Garcia-Cuetos et al., 2012b). GarciaCuetos et al. (2012b) collected their samples in the winter/early spring around Copenhagen, when water temperatures were low. Polymorphism and temperature dependence should be investigated further. Our work has shown $M$. major can be more variable in size than previously suggested and more studies in warm water are needed. In our case, M. major may be exhibiting size plasticity in which sequencing or clade specific qPCR is necessary to unambiguously track this species.

M. rubrum subclade B and M. major have been found to be responsible for bloom events in the Columbia River Estuary, Long Island Sound, and coastal Brazil and Chile (Johnson et al. 2016). Subclade B was one of two we did not detect at MVCO, nor did we detect bloom abundances of Mesodinium spp. We did not observe average equivalent spherical diameters of potential M. major reaching maximum observed sizes, though we did observe M. major to be present. This may indicate that if conditions are not favorable enough to obtain these large sizes, they may not be favorable enough for bloom conditions either.

When temperatures were $>10{ }^{\circ} \mathrm{C}$, we observed high proportions of $M$. rubrum subclades E and F. These subclades, though both associated with warm water and small cells, were present at different times of the year: high proportions of M. rubrum subclade E occurred in the summer and high proportions of M.rubrum subclade F occurred in the fall. This may indicate that these certain subclades prefer warmer waters. Subclade E has only been found along the North Pacific coast of the US and this was the first documentation of its occurrence along the Atlantic Coast of the US.

\subsubsection{Conclusions}

In this study, seasonality was evident from both image-based and HTS-based approaches. We also found not only do genotype and morphotype correspond in certain instances, but we examined the time series in a novel way to do so. We found that with fourth foot transformation of CSS normalized sequence counts, we can detect seasonal abundance patterns of 
certain taxa. Often proportions of sequences are compared with morphological abundances or proportions, which may not always be appropriate. While CSS normalization results in counts that are proportional to the cumulative sum of counts up to a certain percentile, we found good agreement when compared to fourth root transformed cell concentrations. CSS normalization was originally created to aid in the clustering of OTU counts (Paulson et al., 2013) in beta diversity analyses, and this is the first assessment of its utility as a direct proxy for concentration of organisms. For certain species and genera, these normalized OTU counts captured similar seasonal patterns as image-based morphology.

Correlation between methods did not always occur; and there are various reasons one might expect discrepancies between morphotypes and genotypes. Sampling effort may play a role in differential detection of taxa. We performed amplicon HTS analysis on approximately 0.75-2.5 L of discrete water samples, while manual image analysis was performed on $5 \mathrm{~mL}$ samples taken every 20 minutes over the course of an entire day and would likely represent different water parcels as they moved past the site. Primer and amplification biases may also favor certain taxa over others, while databases used for assigning taxonomy may not be complete enough to include all taxa sampled by the IFCB. With images from IFCB, it is not always possible to identify species depending on cell orientation and the distinctiveness of small scale features. Furthermore, unless ciliates are mixotrophic or feeding on chlorophyllcontaining cells, they are unlikely to be measured by IFCB in its current configuration.

In recent years, the number of studies comparing morphotypes and genotypes have increased with varying results. Stoeck et al. (2014) found many quantitative and qualitative differences between amplicons and morphotypes. They saw that taxon abundance from amplicon data did not necessarily track morphotype abundance. In contrast, Harvey et al. (2017), found some agreement between OTU counts and zooplankton biomass for specific taxa; though they also noted biases for each method and that not all taxa were comparable. This is consistent with our results, in that there was not always agreement between methodologies within ciliate genera and species. Both our study and Harvey et al. (2017) emphasize that HTS can often provide finer taxonomic resolution when morphological detail is not adequate.

Our study has shown that the use of morphotype and amplicon HTS complement each other in ways that give us insight into seasonality and ecology. Morphotypes are useful for verification especially when taxa have not been sequenced and are not available in genetic 
databases. At MVCO, many of the ciliates that could be identified to species were rare and only 5 species were found in common between morphotypes and genotypes. It was also the case that many oligotrichs and choreotrichs could not be identified down to species in either method. Single cell genetic analyses in combination with morphotype analysis will be needed to sort out these unknowns in the future. Tintinnids, which have distinct lorica characteristics, provided more sources of comparison in this study. In particular, it was possible to compare common genera between methods, as well as investigate species patterns identified through amplicon OTUs. HTS made it possible to detect tintinnid genera that were not efficiently captured with the IFCB, thus allowing further understanding into the seasonality of these ciliates at MVCO, as well as possible prey preferences of these ciliates. 

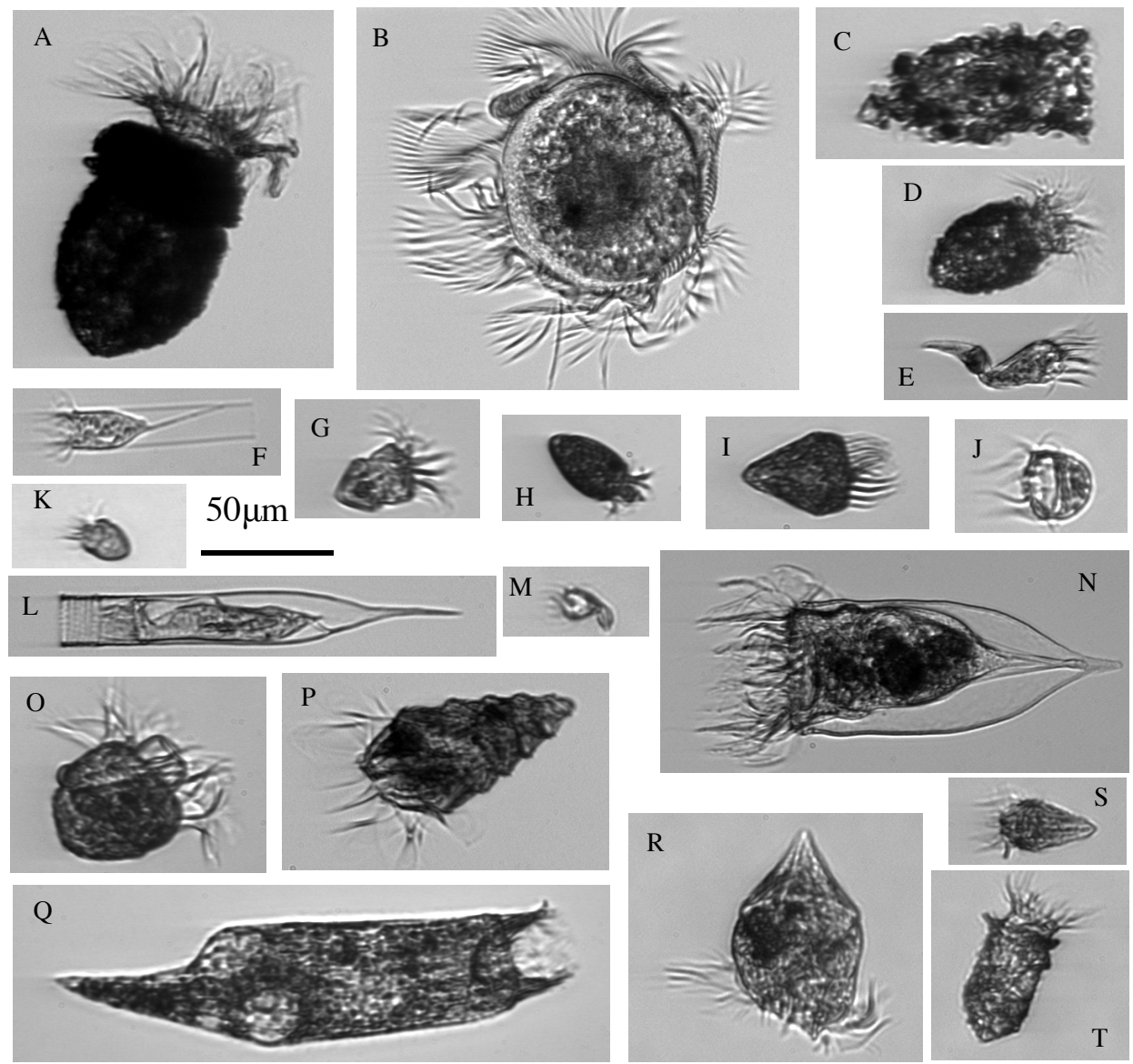

Figure 4-1: Examples of ciliates categories from the subclasses Oligotrichia and Choreotrichia at MVCO as imaged by standard IFCB triggering on chlorophyll fluorescence. Ciliates are grouped by similar morphology and identified to genus and species as possible. (A) Stenosemella spp.; (B) Strobilidium sp; (C) Tintinnidium mucicola; (D) Stenosemella pacifica; (E) Tontonia appendiculariformis; (F) Eutintinnus spp.; (G) Strombidium inclinatum; (H) Strombidium oculatum; (I) Strombidium sp..; (J) Leegaardiella ovalis; (K) 'miscellaneous spirotrich'; (L) Helicostomella subulata; (M) Tontonia gracillima; (N) Favella spp.; (O) Strombidium capitatum; (P) Laboea strobila; (Q) Strombidium conicum; (R) Strombidium sp.; (S) Strombidium wulff; (T) Tintinnopsis spp. All images from the MVCO data set are publicly available (http://ifcb-data.whoi.edu/mvco), as is a large set of annotated ciliate images (Sosik et al. 2015). 


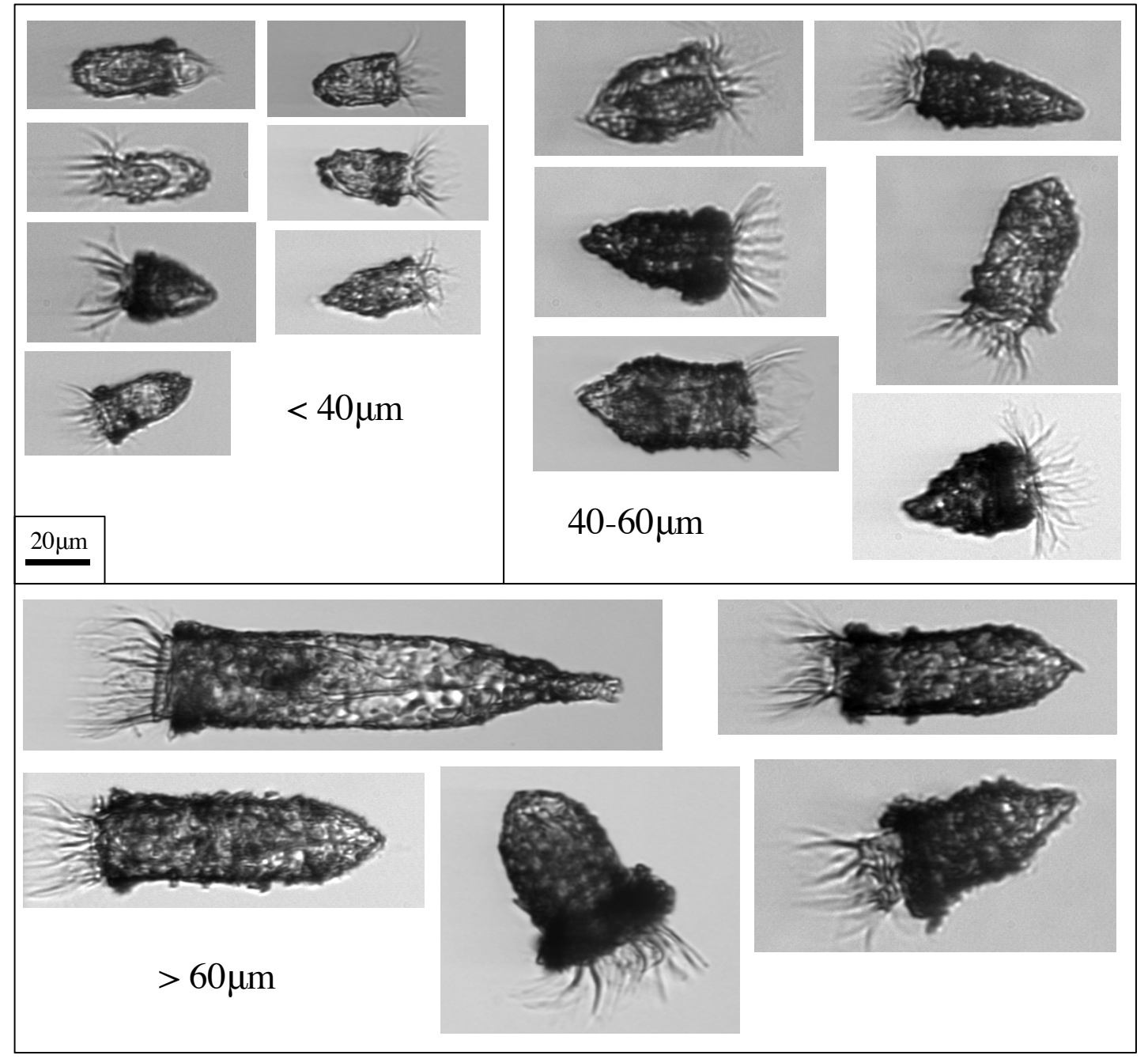

Figure 4-2: Examples of image-based Tintinnopsis size classes (small cells of $<40 \mu \mathrm{m}$ equivalent spherical diameter (ESD), medium-sized cells in the range 40 - $60 \mu \mathrm{m} \mathrm{ESD,} \mathrm{and} \mathrm{large}$ cells $>60 \mu \mathrm{m}$ ESD) from 2006-2016. 


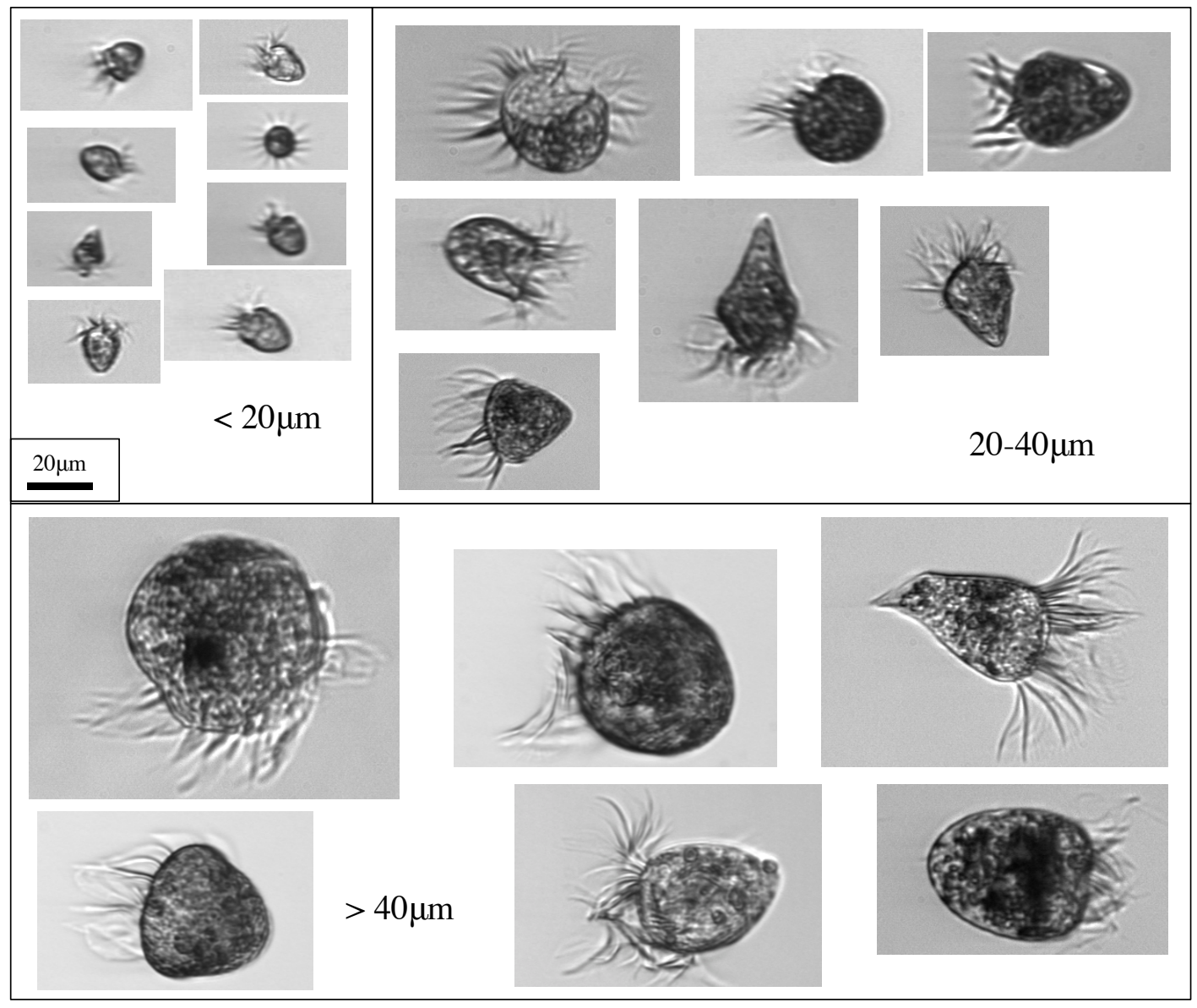

Figure 4-3: Examples of image-based 'miscellaneous spirotrichs' size classes (small cells of $<20 \mu \mathrm{m}$ equivalent spherical diameter (ESD), medium-sized cells in the range $20-40 \mu \mathrm{m}$ ESD, and large cells $>40 \mu \mathrm{m}$ ESD) from 2006-2016. 


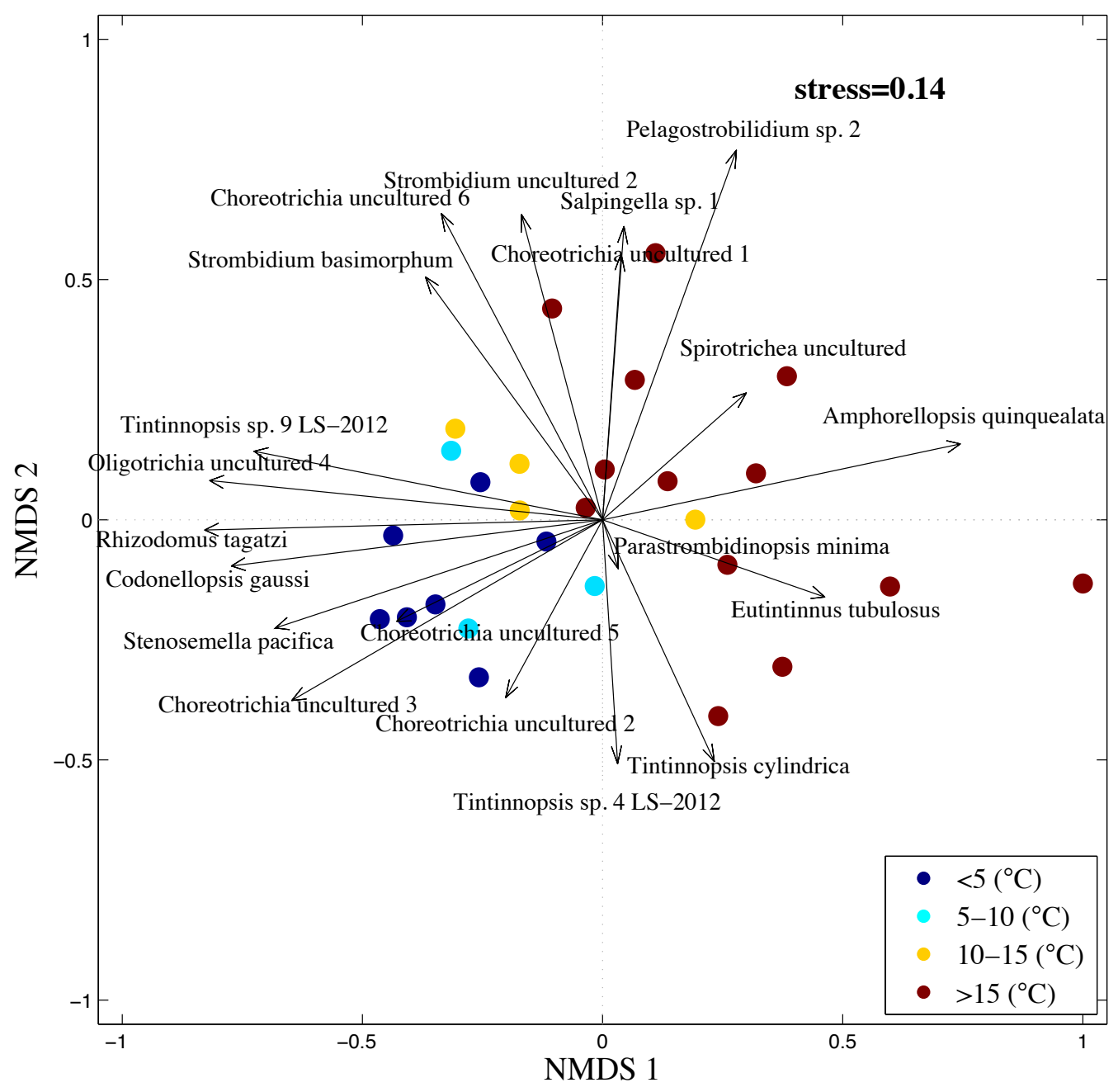

Figure 4-4: NMDS based on Bray-Curtis similarity matrices of OTUs. Samples are colored by temperature bin. Vectors indicate the linear correlation of NMDS scores with OTUs (vector length scaled by the strength of the correlation). The top 20 OTUs are displayed. 


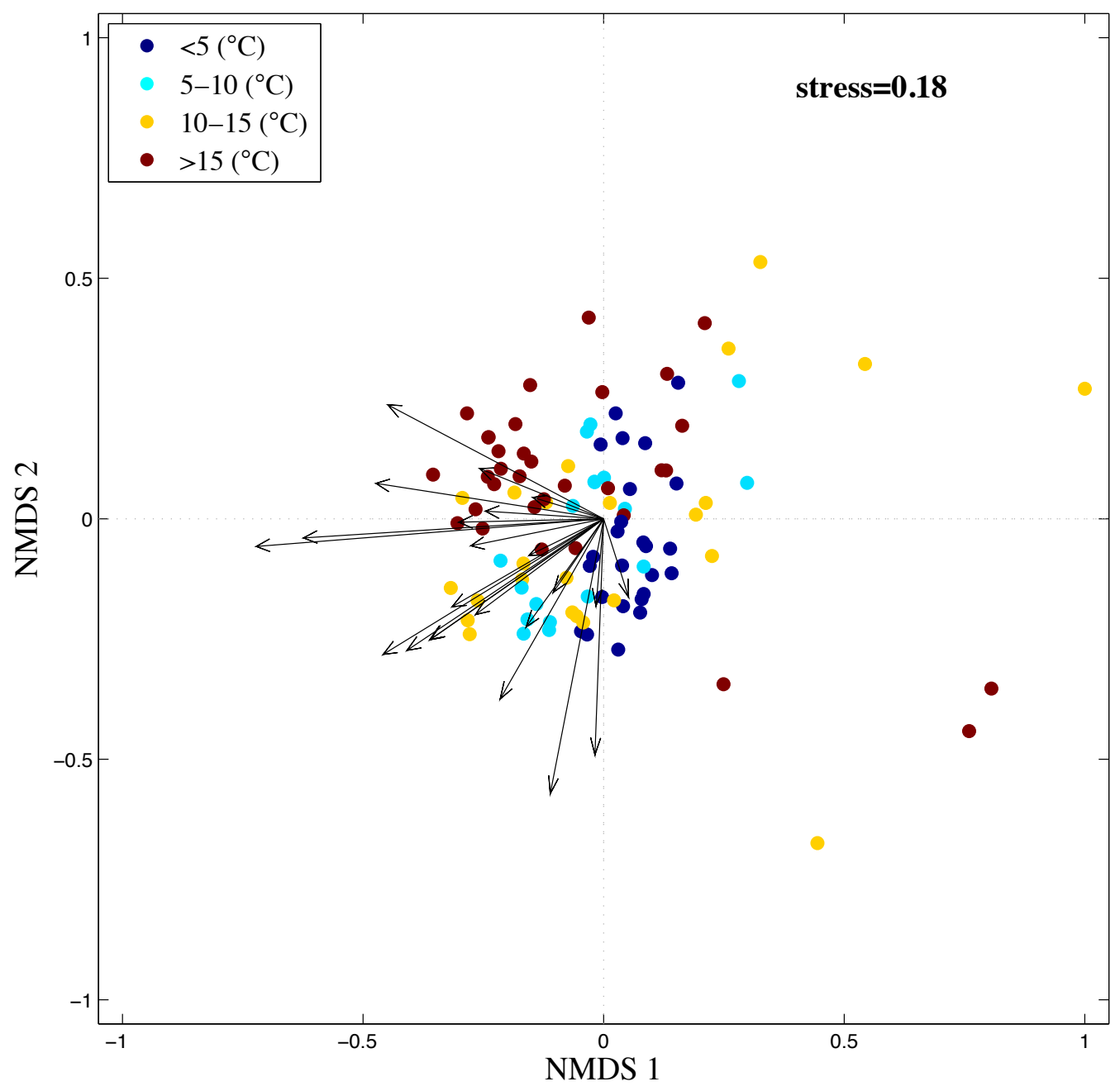

Figure 4-5: NMDS based on Bray-Curtis similarity matrices of image-based morphospecies. Samples are colored by temperature bin. Vectors indicate the linear correlation of NMDS scores with morphospecies (vector length scaled by the strength of the correlation. Two dimensions are shown for an analysis performed in 3 dimensions. (See Fig A-7 for vector labels. 


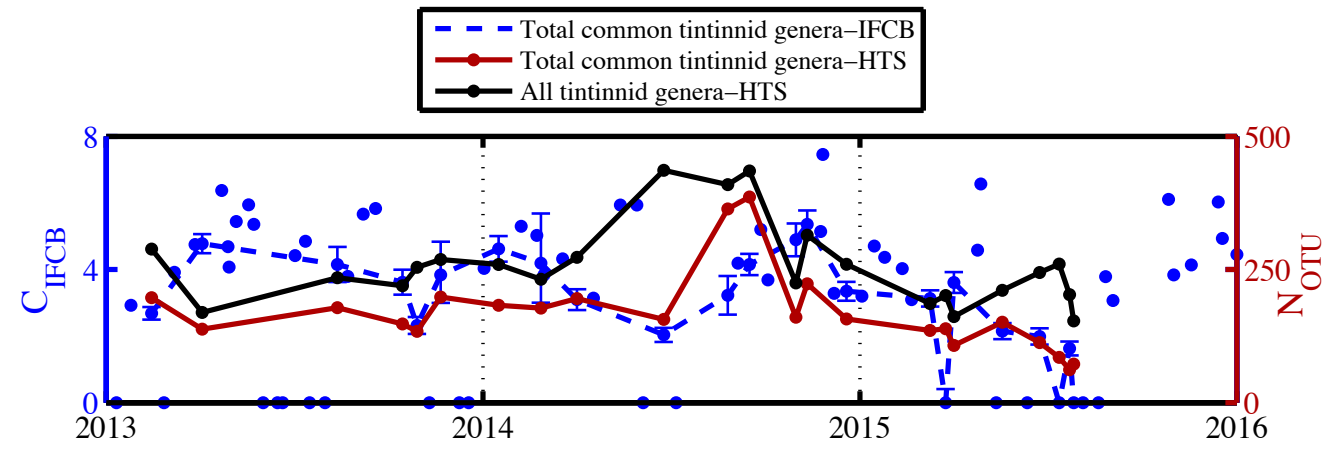

Figure 4-6: Total $\mathrm{N}_{\mathrm{OTU}}$ for all tintinnid genera (black) and the subset observed by both HTS (red) and image-based morphology(blue) (Eutintinnus, Favella, Helicostomella, Tintinnopsis, Stenosemella, and Tintinnidium) (extra included for all genera are: Amphorellopsis, Codonella, Metacylis, Salpingella). All points in image-based morphology time series are included, but only dates common with HTS samples are connected. $\mathrm{C}_{\mathrm{IFCB}}$ shown with $95 \%$ confidence intervals. $\mathrm{R}=0.47(\mathrm{p}<0.05)$ for $\mathrm{C}_{\mathrm{IFCB}}$ and $\mathrm{N}_{\mathrm{OTU}}$ of the subset observed by both HTS and image-based morphology. 

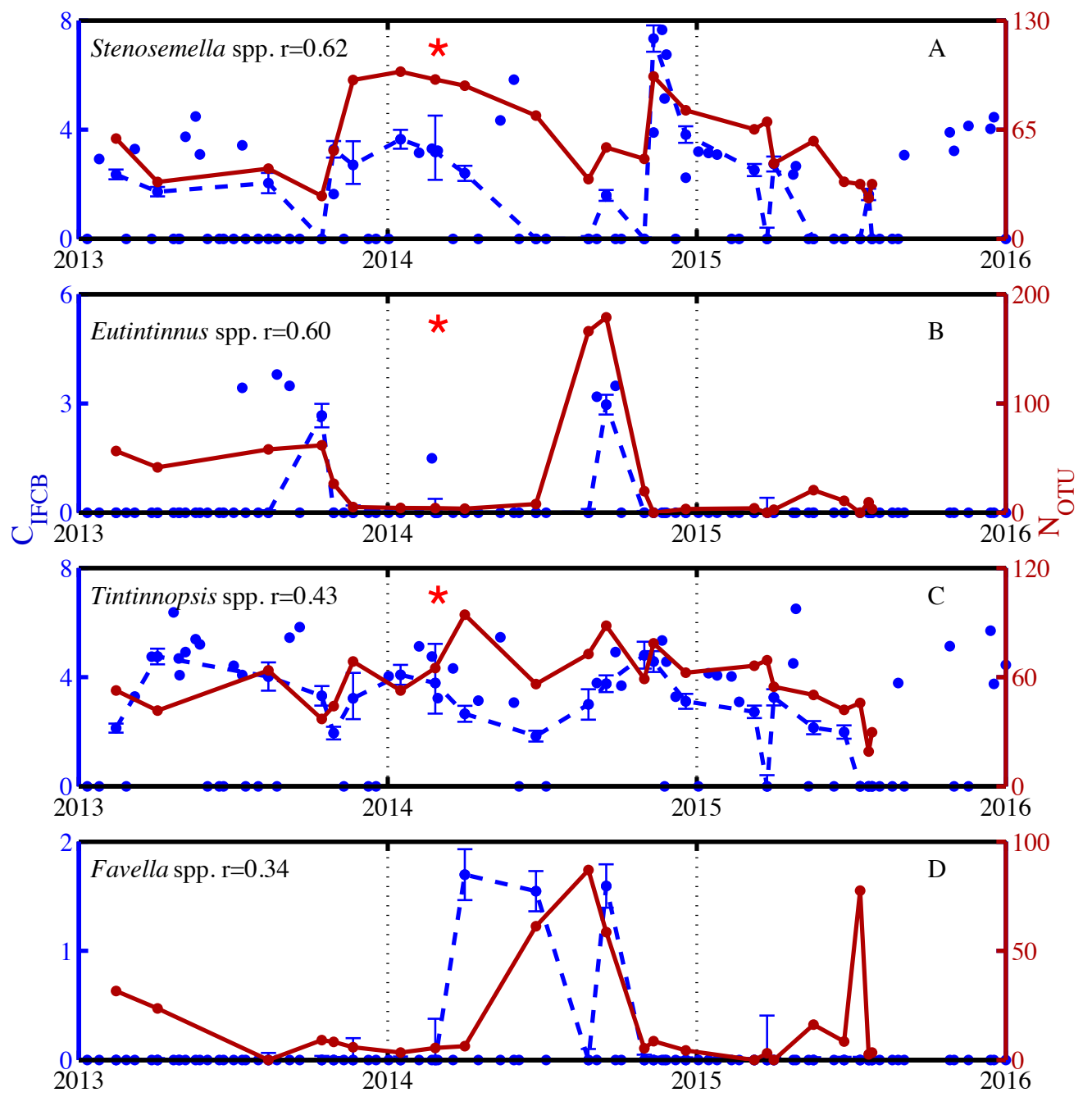

Figure 4-7: Time series comparing $\mathrm{C}_{\mathrm{IFCB}}$ (blue) and $\mathrm{N}_{\text {OTU }}$ (red) of tintinnid genera detected in both HTS and image-based morphology. All points in image-based morphology time series are included, but only dates common with HTS samples are connected $\mathrm{C}_{\mathrm{IFCB}}$ shown with 95\% confidence intervals. Red stars denote when correlations are significant $(\mathrm{p}<0.05)$. 

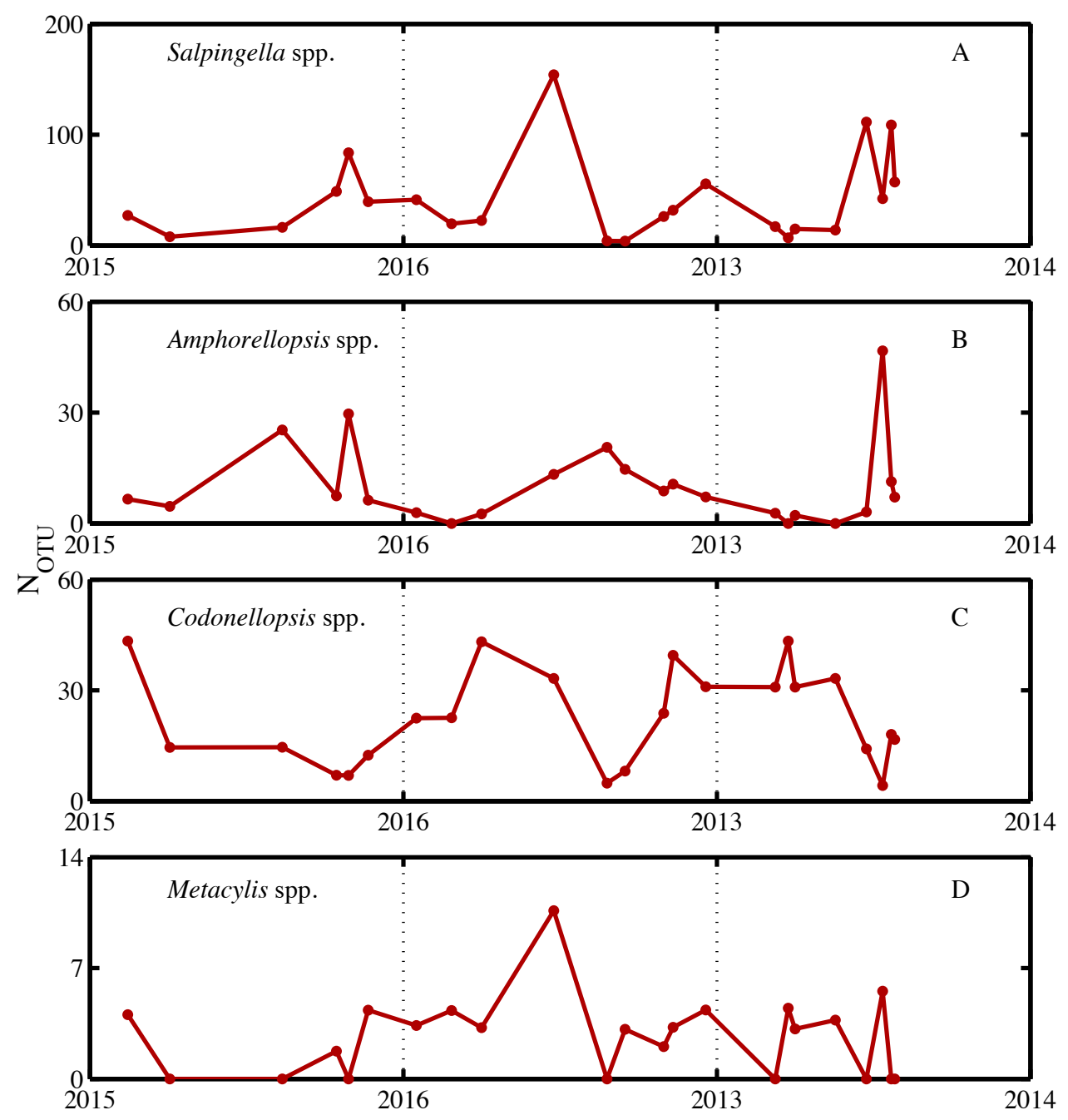

Figure 4-8: Time series of $\mathrm{N}_{\mathrm{OTU}}$ for tintinnid genera not resolved in IFCB sampling. 


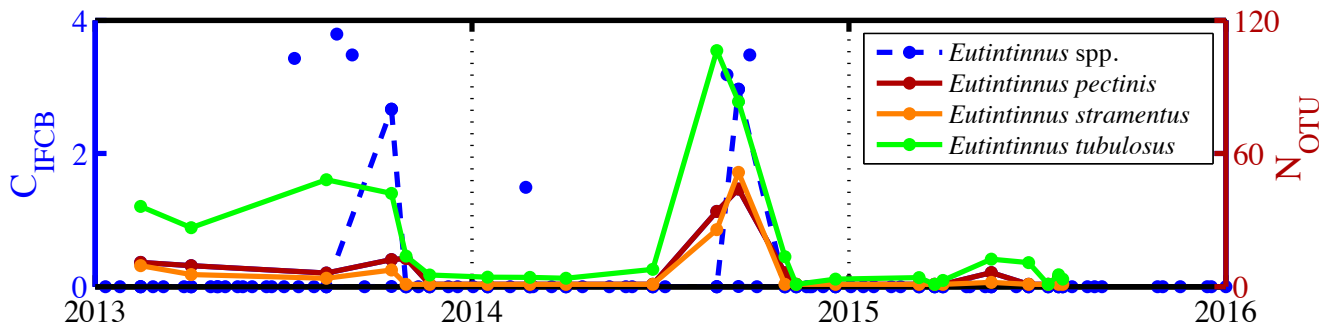

Figure 4-9: Time series comparing $\mathrm{N}_{\mathrm{OTU}}$ and $\mathrm{C}_{\mathrm{IFCB}}$ (dashed line) of the genus Eutintinnus. 

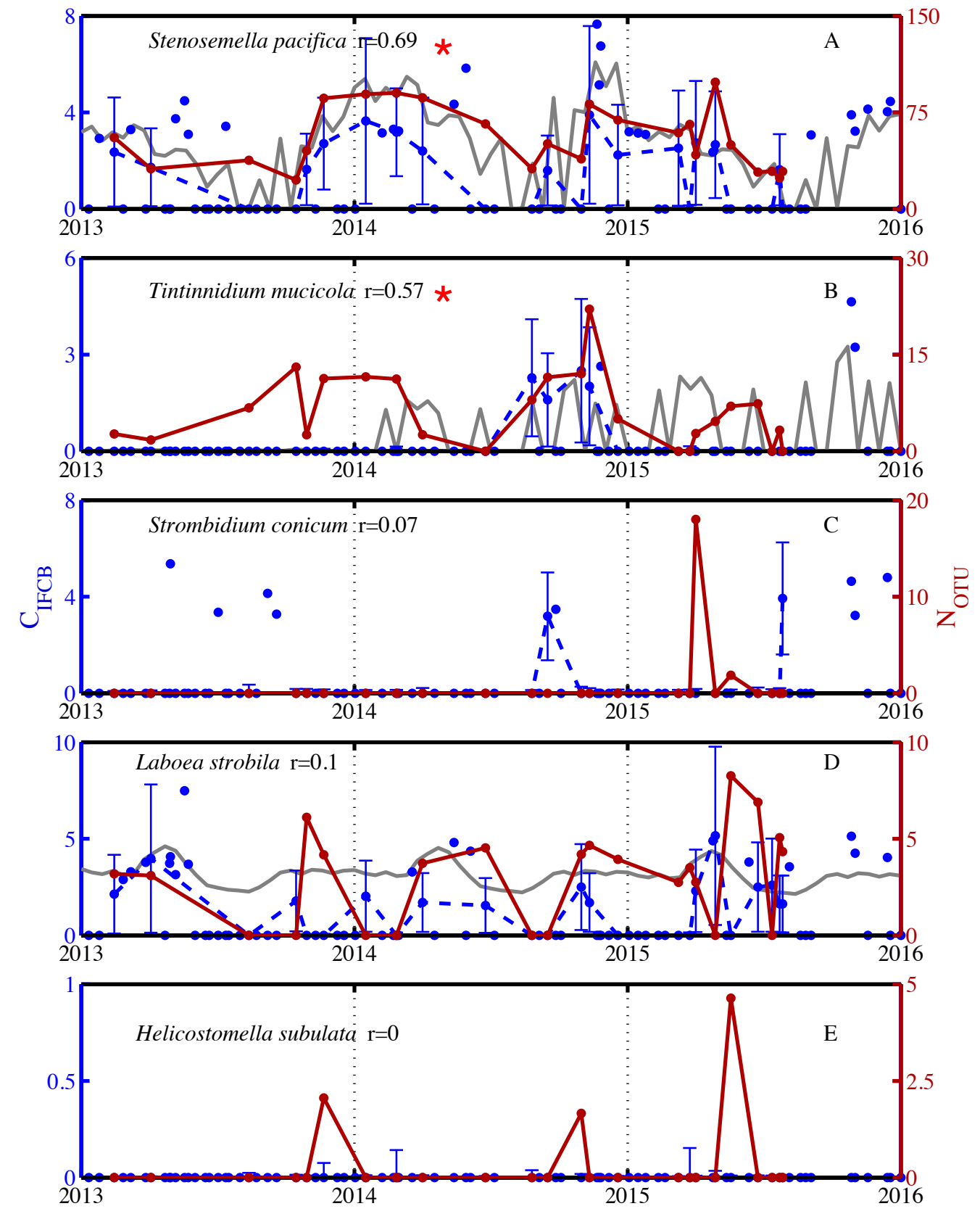

Figure 4-10: Time series comparing $\mathrm{C}_{\mathrm{IFCB}}$ (blue) and $\mathrm{N}_{\mathrm{OTU}}$ (red) of commonly defined species detected by both HTS and image-based morphology. All points in image-based morphology time series are included, but only dates common with HTS samples are connected. Grey lines indicate modeled image-based morphology densities from the complete IFCB time series (2006-2016)(Chapter 3). $\mathrm{C}_{\mathrm{IFCB}}$ shown with $95 \%$ confidence intervals. Red stars denote when correlations are significant $(\mathrm{p}<0.05)$. 

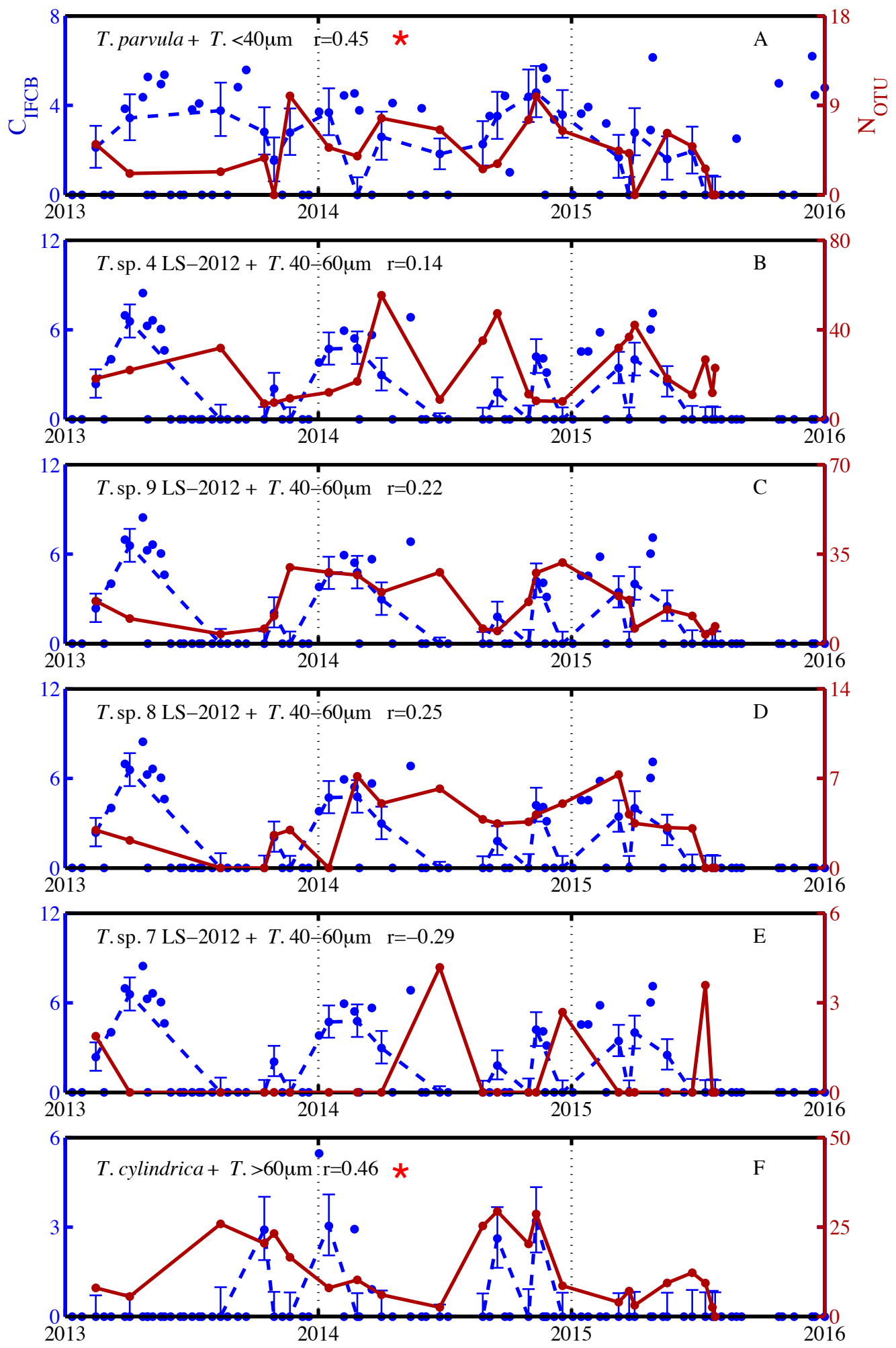

Figure 4-11: Time series comparing $\mathrm{C}_{\mathrm{IFCB}}$ (blue) for Tintinnopsis size classes from imagebased morphology and $\mathrm{N}_{\mathrm{OTU}}$ (red) of Tintinnopsis species detected by HTS. All points in image-based morphology time series are included, but only dates common with HTS samples are connected. $\mathrm{C}_{\mathrm{IFCB}}$ shown with $95 \%$ confidence intervals. Red stars denote when correlations are significant $(\mathrm{p}<0.05)$. 

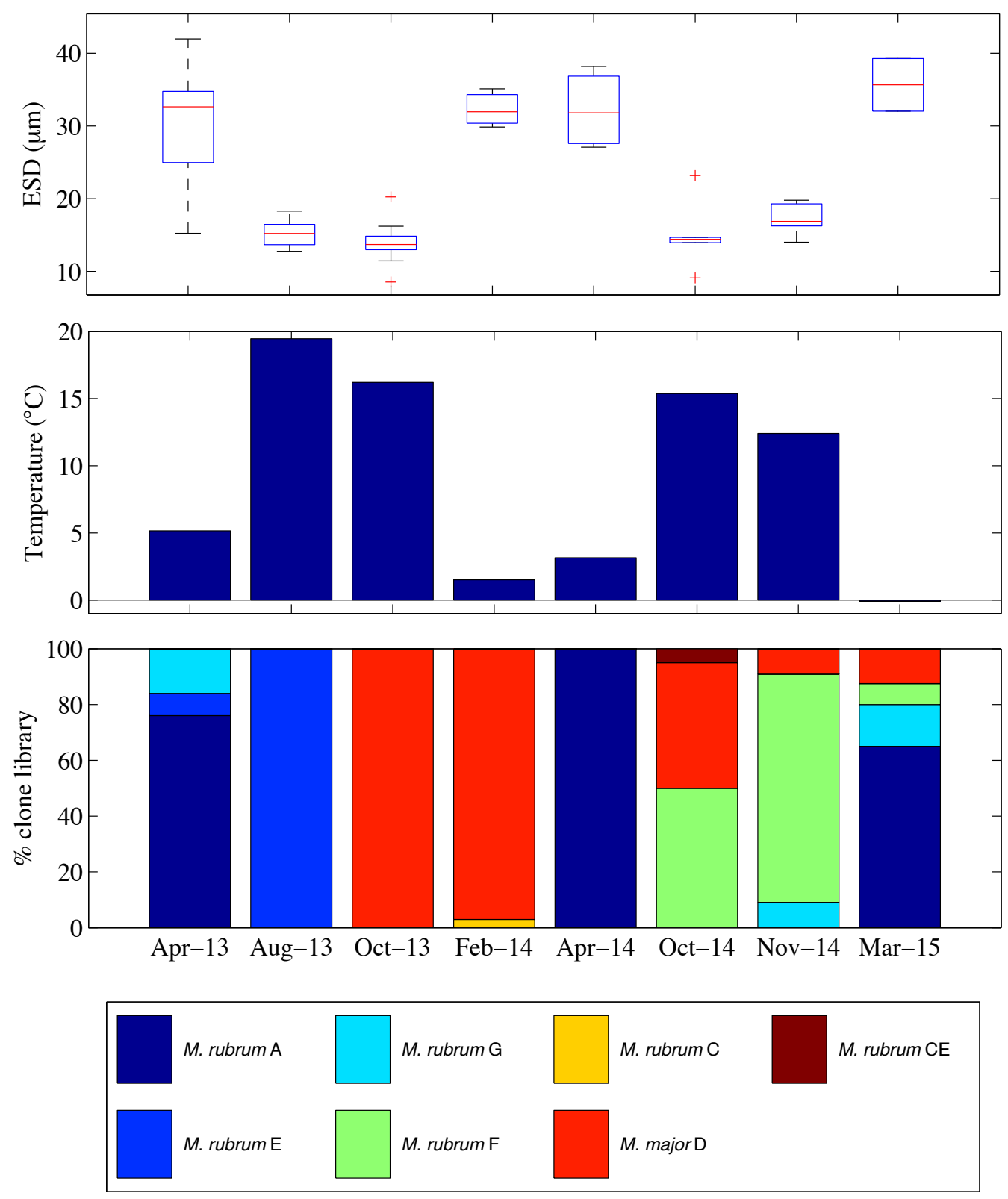

Figure 4-12: Top panel: Boxplot of Mesodinium spp. equivalent spherical diameter from IFCB images. Middle panel: Water temperature. Bottom panel: Percent contribution of individual Mesodinium spp. subclades to total subclades detected. 


\begin{tabular}{|c|c|}
\hline Miscellaneous spirotrichs $<20 \mu \mathrm{m}$ & N/A \\
\hline Miscellaneous spirotrichs $20-40 \mu \mathrm{m}$ & N/A \\
\hline Miscellaneous spirotrichs $<40 \mu \mathrm{m}$ & N/A \\
\hline Oligotrichs & \\
\hline Laboea strobila $*$ & Yes \\
\hline Strombidium capitatum & Yes \\
\hline Strombidium conicum $*$ & Yes \\
\hline Strombidium inclinatum & Yes \\
\hline Strombidium sp. 1 & N/A \\
\hline Strombidium sp. 2 & N/A \\
\hline Strombidium oculatum & Yes \\
\hline Strombidium wulffi & No \\
\hline Tontonia appendiculariformis & No \\
\hline Tontonia gracillima & No \\
\hline Aloricated Choreotrichs & \\
\hline Leegaardiella ovalis & No \\
\hline Strobilidium sp. & N/A \\
\hline Loricated Choreotrichs & \\
\hline Eutintinnus spp. $* *$ & N/A \\
\hline Favella spp. $* *$ & N/A \\
\hline Helicostomella subulata $*$ & Yes \\
\hline Stenosemella spp. $* *$ & N/A \\
\hline Stenosemella pacifica $*$ & Yes \\
\hline Tintinnidium mucicola $*$ & Yes \\
\hline Tintinnopsis spp. $<40 \mu m * *$ & N/A \\
\hline Tintinnopsis spp. 40-60 $\mu \mathrm{m} * *$ & N/A \\
\hline Tintinnopsis spp. $>60 \mu m * *$ & N/A \\
\hline
\end{tabular}

Table 4.1: List of ciliates identified from IFCB images in the subclasses Oligotrichia and Choreotrichia with details on whether there are sequences are associated with the corresponding species in the NCBI database. Ciliates not identified to species are labeled N/A. All morphotypes except for Helicostomella subulata were detected on at least one date when samples were taken for HTS. * Species captured by HTS. ** Genera identified in images with species information in HTS. 


\begin{tabular}{|cc|}
\hline \multicolumn{2}{|c|}{ OTUs - Global R } \\
\hline \multicolumn{2}{|c|}{ Groups } \\
$<5^{\circ} \mathrm{C}, 5-10{ }^{\circ} \mathrm{C}$ & 0.13 \\
$<5^{\circ} \mathrm{C}, 10-15^{\circ} \mathrm{C}$ & $0.43^{*}$ \\
$<5^{\circ} \mathrm{C},>15^{\circ} \mathrm{C}$ & $0.51^{*}$ \\
$5-10^{\circ} \mathrm{C}, 10-15^{\circ} \mathrm{C}$ & -0.1 \\
$5-10{ }^{\circ} \mathrm{C},>15^{\circ} \mathrm{C}$ & 0.21 \\
$10-15^{\circ} \mathrm{C},>15^{\circ} \mathrm{C}$ & 0.24 \\
\hline
\end{tabular}

\begin{tabular}{|cccc|}
\hline \multicolumn{4}{c|}{ IFCB Manual Identification -Global R } \\
\hline All dates in range & Exact dates of & All dates \\
Groups & $(2013-2015)$ & sequence samples & $(2006-2016)$ \\
$<5^{\circ} \mathrm{C}, 5-10{ }^{\circ} \mathrm{C}$ & $0.1^{*}$ & -0.1 & $0.05^{*}$ \\
$<5^{\circ} \mathrm{C}, 10-15^{\circ} \mathrm{C}$ & $0.19^{*}$ & $0.25^{*}$ & $0.13^{*}$ \\
$<5^{\circ} \mathrm{C},>15^{\circ} \mathrm{C}$ & $0.2^{*}$ & $0.16^{*}$ & $0.21^{*}$ \\
$5-10^{\circ} \mathrm{C}, 10-15^{\circ} \mathrm{C}$ & -0.02 & -0.4 & 0.01 \\
$5-10^{\circ} \mathrm{C},>15^{\circ} \mathrm{C}$ & 0.21 & -0.2 & $0.1^{*}$ \\
$10-15^{\circ} \mathrm{C},>15^{\circ} \mathrm{C}$ & $0.01^{*}$ & 0.15 & $0.11^{*}$ \\
\hline
\end{tabular}

Table 4.2: Similarity between spirotrich community compositions compared across temperature bins (ANOSIM) for HTS and image-based morphology $(*=\mathrm{p}<0.05)$. The analysis was repeated for three subsets of the IFCB data: all dates manually classified in the range of HTS dates, exact dates as HTS samples, and all dates in time series (Jun 2006-Sept 2016). 


\begin{tabular}{|c|c|c|c|}
\hline \multicolumn{4}{|c|}{ (Average Dissimilarity $=0.15)<5^{\circ} \mathrm{C}, 10-15^{\circ} \mathrm{C}$} \\
\hline Contribution & Cumulative contribution & & \\
\hline $9.20 \%$ & $9.20 \%$ & Amphorellopsis quinquealata & + \\
\hline $8.14 \%$ & $17.34 \%$ & Eutintinnus tubulosus & + \\
\hline $8.07 \%$ & $25.40 \%$ & Salpingella sp. 1 & + \\
\hline $7.29 \%$ & $32.69 \%$ & Stenosemella pacifica & - \\
\hline $7.26 \%$ & $39.95 \%$ & Tintinnopsis sp. 4 LS-2012 & + \\
\hline $6.94 \%$ & $46.89 \%$ & Spirotrichea uncultured & + \\
\hline $6.78 \%$ & $53.67 \%$ & Pelagostrobilidium sp. 2 & + \\
\hline $6.49 \%$ & $60.17 \%$ & Choreotrichia uncultured 1 & + \\
\hline $5.66 \%$ & $65.83 \%$ & Choreotrichia uncultured 3 & - \\
\hline $5.58 \%$ & $71.41 \%$ & Tintinnopsis cylindrica & + \\
\hline $5.19 \%$ & $76.60 \%$ & Choreotrichia uncultured 2 & - \\
\hline
\end{tabular}

\begin{tabular}{|cccc|}
\hline \multicolumn{5}{|c|}{ (Average Dissimilarity $=0.23)<5^{\circ} \mathrm{C},>15^{\circ} \mathrm{C}$} \\
\hline Contribution & Cumulative contribution & & \\
$9.38 \%$ & $9.38 \%$ & Eutintinnus tubulosus & + \\
$8.71 \%$ & $18.09 \%$ & Amphorellopsis quinquealata & + \\
$8.65 \%$ & $26.74 \%$ & Pelagostrobilidium sp. 2 & + \\
$8.14 \%$ & $34.89 \%$ & Choreotrichia uncultured 3 & - \\
$8.11 \%$ & $43.00 \%$ & Choreotrichia uncultured 1 & + \\
$6.81 \%$ & $49.81 \%$ & Oligotrichia uncultured 4 & - \\
$6.34 \%$ & $56.15 \%$ & Spirotrichea uncultured & + \\
$5.91 \%$ & $62.06 \%$ & Stenosemella pacifica & - \\
$5.32 \%$ & $67.38 \%$ & Tintinnopsis sp. LS 2012 & - \\
$5.24 \%$ & $72.62 \%$ & Salpingella sp. 1 & + \\
$5.01 \%$ & $77.63 \%$ & Tintinnopsis cylindrica & + \\
\hline
\end{tabular}

Table 4.3: SIMPER analysis showing ranked contributions of OTUs to significant differences between communities in different temperature ranges. First column represents individual contribution to dissimilarity and second column represents the cumulative contribution. + or - indicates association with higher or lower temperature bin, respectively. 


\begin{tabular}{|cccc|}
\hline \multicolumn{5}{|c|}{ (Average Dissimilarity $=0.45)<5^{\circ} \mathrm{C}, 5-10{ }^{\circ} \mathrm{C}$} \\
\hline Contribution & Cumulative contribution & \\
$12.75 \%$ & $12.75 \%$ & Tintinnopsis $40-60 \mathrm{um}$ & - \\
$10.69 \%$ & $23.44 \%$ & Tintinnopsis $<40 \mathrm{um}$ & + \\
$8.27 \%$ & $31.71 \%$ & Strombidium $\mathrm{sp}$. & + \\
$8.10 \%$ & $39.81 \%$ & Tontonia gracillima & + \\
$7.90 \%$ & $47.71 \%$ & Stenosemella pacifica & - \\
$7.18 \%$ & $54.89 \%$ & Leegaardiella ovalis & - \\
$6.62 \%$ & $61.51 \%$ & Misc. spirotrichs 20-40 um & + \\
$5.91 \%$ & $67.42 \%$ & Strombidium oculatum & + \\
$5.81 \%$ & $73.23 \%$ & Laboea strobila & + \\
\hline
\end{tabular}

\begin{tabular}{|cccc|}
\hline \multicolumn{5}{|c|}{ (Average Dissimilarity $=0.57)<5^{\circ} \mathrm{C},>15^{\circ} \mathrm{C}$} \\
\hline Contribution & Cumulative contribution & & \\
$10.41 \%$ & $10.41 \%$ & Tintinnopsis $40-60 \mathrm{um}$ & - \\
$9.54 \%$ & $19.95 \%$ & Misc. spirotrichs $20-40$ & + \\
$8.27 \%$ & $28.22 \%$ & Strombidium sp. & + \\
$8.15 \%$ & $36.37 \%$ & Tintinnopsis $<40 \mathrm{um}$ & + \\
$6.90 \%$ & $43.27 \%$ & Strombidium inclinatum & + \\
$6.72 \%$ & $49.99 \%$ & Strombidium sp. 2 & + \\
$6.53 \%$ & $56.52 \%$ & Misc. spirotrichs $<20 \mathrm{um}$ & + \\
$6.44 \%$ & $62.96 \%$ & Stenosemella pacifica & - \\
$6.38 \%$ & $69.34 \%$ & Leegaardiella ovalis & - \\
$4.68 \%$ & $74.02 \%$ & Laboea strobila & + \\
\hline
\end{tabular}

\begin{tabular}{|cccc|}
\hline \multicolumn{5}{|c|}{ (Average } & Dissimilarity $=0.45)<5^{\circ} \mathrm{C}, 10-15^{\circ} \mathrm{C}$ \\
\hline Contribution & Cumulative contribution & & \\
$10.39 \%$ & $10.39 \%$ & Misc. spirotrichs $20-40 \mathrm{um}$ & + \\
$9.71 \%$ & $20.10 \%$ & Tintinnopsis $40-60 \mathrm{um}$ & - \\
$8.19 \%$ & $28.29 \%$ & Misc. spirotrichs $<20 \mathrm{um}$ & + \\
$8.08 \%$ & $36.37 \%$ & Tintinnopsis $<40 \mathrm{um}$ & + \\
$7.88 \%$ & $44.25 \%$ & Strombidium $\mathrm{sp}$. & + \\
$7.80 \%$ & $52.05 \%$ & Stenosemella pacifica & - \\
$6.39 \%$ & $58.44 \%$ & Leegaardiella ovalis & - \\
$5.69 \%$ & $64.13 \%$ & Laboea strobila & + \\
$5.14 \%$ & $69.27 \%$ & Strombidium $\mathrm{sp} .2$ & + \\
$5.08 \%$ & $74.35 \%$ & Strobilidium $\mathrm{sp}$. & + \\
\hline
\end{tabular}

\begin{tabular}{|cccc|}
\hline \multicolumn{5}{|c|}{ (Average Dissimilarity $=0.64) 10-15{ }^{\circ} \mathrm{C},>15^{\circ} \mathrm{C}$} \\
\hline Contribution & Cumulative contribution & & \\
$10.59 \%$ & $10.59 \%$ & Misc. spirotrichs $20-40 \mathrm{um}$ & + \\
$9.08 \%$ & $19.67 \%$ & Misc. spirotrichs <20um & + \\
$7.60 \%$ & $27.28 \%$ & Strombidium $\mathrm{sp}$. & - \\
$7.20 \%$ & $34.47 \%$ & Tintinnopsis $<40 \mathrm{um}$ & + \\
$7.11 \%$ & $42.59 \%$ & Stenosemella sp. & - \\
$6.43 \%$ & $48.02 \%$ & Strombidium inclinatum & + \\
$5.97 \%$ & $53.98 \%$ & Strombidium $\mathrm{sp} .2$ & + \\
$5.82 \%$ & $59.80 \%$ & Laboea strobila & - \\
$5.09 \%$ & $64.89 \%$ & Strobilidium sp. & - \\
$4.54 \%$ & $69.43 \%$ & Tintinnopsis $40-60 \mathrm{um}$ & - \\
$4.49 \%$ & $73.93 \%$ & Strombidium oculatum & - \\
\hline
\end{tabular}

Table 4.4: SIMPER analysis showing ranked contributions of image-based morphotypes to significant differences between communities in different temperature ranges. First column represents individual contribution to dissimilarity and second column represents the cumulative contribution. + or - indicates association with higher or lower temperature bin, respectively. 


\section{Chapter 5}

\section{Conclusions and future directions}

\subsection{Thesis summary}

In this thesis, I have studied ciliates of the New England shelf and applied three lines of methods to understand more about feeding preferences, seasonality, and how well morphotype and genotype correspond. At the Martha's Vineyard Coastal Observatory (MVCO), there is a rich, high temporal resolution data set of herbivorous planktonic ciliates from the last ten years provided by the Imaging FlowCytobot (IFCB). I not only used this instrument to analyze ciliate variability over time, but I also worked to expand its capabilities and combined its conventional use with a modern genetic technique, high-throughput sequencing (HTS).

In chapter 2, I introduced an updated Imaging FlowCytobot (IFCB-S) modified with automated staining capabilities, which allowed for a more complete view of the ciliate community including non chlorophyll-containing cells. At times, IFCB-S revealed higher abundances of grazers than the traditional IFCB. Not only were some cell types detected that were not previously, but the comparison of fluorescence properties between staining and non-staining offered insight into the seasonal feeding habits of morphotypes. Grazers lacking chlorophyll fluorescence, but captured with stain fluorescence could either be without food vacuoles or feeding on heterotrophic organisms. I also found that with IFCB, cell abundances were consistently similar to or higher than counts from manual light microscopy indicating that capturing cell abundances with a live application may be more accurate than traditional sampling and preservation. With further time series applications, I expect IFCB$\mathrm{S}$ to provide unprecedented exploration of feeding modes and predator-prey interactions over 
longer time scales and with more resolution than studied before.

In Chapter 3, I analyzed a ten-year time series of mixotrophic and herbivorous ciliates from 2006-2016 as captured by a standard IFCB. A time series of this length in highresolution (2-week) affords the ability to investigate seasonality and multi-year trends of these protists. The herbivorous ciliate community at MVCO exhibits a wide diversity of groups and notable functionalities are observed within this diversity. So while I described the general ciliate dynamics of the community through abundance, biomass, and size, I also focused on a subset of three ciliate groups: a mixotrophic ciliate, Laboea strobila, a phototrophic ciliate, Mesodinium spp., and a group of strict heterotrophs, tintinnids.

To assess seasonality, I used a model that decomposes time series abundances into expected seasonal cell concentrations and annual effects using Poisson distribution statistics and allowing for samples of varying volume to be considered. I could then quantify the seasonal patterns of a taxonomic group without annual variation obscuring them. I found significant variability both on interannual and month-to-month time scales, but typically groups I studied had strong seasonality. Laboea strobila exhibited highest abundance in spring with a smaller more variable fall peak. Because this spring event occurred every year, I investigated various avenues to explain why. The most intriguing relationship presented itself through the co-occurrence of predator and prey. I noted continual co-occurrence of L. strobila peaks with 1-2 week lags in concentration of 2-10 $\mu \mathrm{m}$ eukaryotic phytoplankton and certain years demonstrated this relationship quite remarkably. Increases of 2-10 $\mu \mathrm{m}$ eukaryotic phytoplankton were also noted with declines of Laboea strobila. This juxtaposition may indicate a release in grazing pressure. L. strobila has been shown to prefer cryptophyte plastids, though other diets in culture have been found to include haptophytes and perhaps prasinophytes (Stoecker et al., 1988), all which may fall within the 2-10 $\mu \mathrm{m}$ prey. Laboea strobila displayed a distinct decrease in annual abundances over the last seven years of the time series. Coincidentally, the nanoplankton community has also been decreasing over the time series (unpublished data), further supporting the effect of prey populations on this ciliate.

At higher taxonomic resolution, tintinnid groups exhibited distinct patterns and fine structuring of niches, which is not uncommon (Kamiyama \& Tsujino, 1996; Urrutxurtu, 2004). When investigated as a whole population total tintinnids were high in the spring and fall, but exhibited late fall/winter increases that varied interannually. While changing 
abundances of prey most likely have an effect on these grazers, I propose that this may also be tied to warming temperatures. For example, the notable small winter peak of total tintinnids only occurred during certain years (2011-2012, 2014, 2015-2016). These years also exhibited anomalously warm temperatures either in the fall (2014) or winter (20112012 and 2015-2016) (Fig. A-6). Also during these times, there were unusually high prey populations for that time of year and total tintinnid cell concentration was significantly positively correlated with picophytoplankton concentrations. This supports experimental work by Aberle et al. (2007) who found with controlled winter warming in mesocosms, heterotrophic ciliates were the major groups to respond. Kane (2011) observed increasing phytoplankton populations in the Gulf of Maine over a multidecadal study associated with positive North Atlantic Oscillation index years, characterized by warm, nutrient-rich waters. At MVCO, we have seen a series of anomalously warm winters. Whether these tintinnids are responding to climate forcings may need to be studied over longer periods of time, but these results suggest possible associations.

At MVCO the total Mesodinium spp. community was characterized by a strong fall peak, though many studies have noted varying seasonality (Summer: Montagnes \& Lynn 1989; Kifle \& Purdie 1993; Bernard \& Rassouladegan 1994; Modigh 2001, Winter: Sanders 1995, Fall: White et al. 1977; Lindholm 1978). I believe at MVCO, the fall event is driven by the cryptophyte populations which exhibit a seasonal increase from the summer into the fall (Fig. 3-24). Mesodinium spp. was unique in that biomass and abundance exhibited varying seasonality due to significant changes in cell size, possibly linked with temperature.

It is unclear what actually drives the peaks in abundance of these particular functional groups at MVCO from just observations and correlations. Analysis of a time series such as this can give insight into recurring co-occurrence patterns of predator and prey and relationships with environmental parameters. With a time series, the occurrence of interannual variability of ciliate abundances coinciding with similar variability of other biological and environmental parameters can provide directions of study. More investigations into the cause of these dynamics is needed using laboratory studies to observe the responses of ciliates to perturbations in conditions such as temperature and prey communities.

While morphotypes from images provide valuable information, recent advances in genetic sequencing have provided questions into whether genotypes and morphotypes correspond and reveal similar patterns of variability in natural communities. In Chapter 4, I explored 
seasonality over three years with high-throughput sequencing and image-based morphotypes. I also compared temporal patterns between genotypes and morphotypes. Seasonality was evident with both approaches, but for HTS the seasonality was especially driven by warm water hyaline loricated tintinnids, while tintinnids of the agglomerated variety were responsible for much of the seasonality captured with image-based approaches. Even though these two approaches emphasized the importance of different types of organisms to the communities, the combination of the two methods supported the view that agglomerated species were preferentially preying upon chlorophyll-containing cells, while the hyaline loricated tintinnids may have preyed upon organisms without chlorophyll fluorescence. Santoferrara et al. (2016) also noted differences in the composition of the community between hyaline and agglomerated tintinnids, though spatially instead of temporally, indicating these types of ciliates groups can be very finely structured. Comparisons between image-based cell concentrations and OTU counts of common genera and species showed significant correlations for certain groups suggesting that HTS may be quantitive, which could have valuable implications for future sequencing work. Size, though, for certain taxa remained complex, and may not always be an appropriate proxy for identifying underlying species dynamics.

Because of hypotheses about seasonal changes in the Mesodinium spp. size structure posed in Chapter 3, I pursued genetic verification of Mesodinium spp. variants of the $M$. rubrum/major complex and how they related with temperature and average cell size over time. I found large cell sizes occurring in cold waters were primarily associated with two sublcades, M. rubrum A and M. major, but notably, M. major was also found associated with small cell size and higher temperatures. This contradicts previous work which has only associated M. major with large cell sizes (Garcia-Cuetos et al., 2012b; Johnson et al., 2016). Different subclades were also found associated with small cell sizes, further supporting genetic variation in the Mesodinium spp. morphotype. These results suggest the interplay of genetic and physiological factors regulating size structure/temperature relationships for Mesodinium spp. This is also the first study documenting the seasonal changes of Mesodinium variants of this complex as previous studies have focused on spatial observations (Herfort et al., 2011; Johnson et al., 2016).

As mentioned by Landry (1994), 'hybrid' techniques combining methods are needed to overcome inherent limitations. While the combination of genotyping and morphological taxonomy is not always straightforward, we have shown that the use of morphotype and HTS 
complement each other in ways that give us insight into seasonality and ecology. Integrated observations combined from various methodologies can provide new perspectives on ciliate dynamics especially when they are performed on in situ populations.

\subsection{Conclusions and future directions}

As with any exploratory observational research, more questions arise and new hypotheses are brought forth. These observations also highlight many aspects of ciliate ecology we do not understand. Remaining questions of particular interest center around what drives the patterns of these organisms. My research has shown distinct seasonality in ciliate communities with both image-based and genetic approaches. Both the time series model and high-throughput sequencing in combination with IFCB images over time are broadly applicable and can be used to study other communities such as important phytoplankton populations. Comprehensive analyses of the model's sensitivity to different time scales (if the full resolution of the time series was used instead of just two weeks) as well as the incorporation of modeling biomass and size can propel this method one step further. For example, modeling of Mesodinium spp. size structure in combination with more genetically resolved samples may aid in further understanding the complex interplay between cell size and temperature, which may be guided by underlying diversity structure.

Laboratory investigations will also be critical to understanding ciliate seasonal dynamics. To provide context to our observations, experimental studies must be conducted under varying environmental and biological conditions. Having Mesodinium major in culture would provide the opportunity to explore temperature regulation of size, while tintinnid cultures may help give further insight into how these heterotrophs respond to increasing winter temperatures. Laboea strobila in particular represents a ripe opportunity to understand why an organism occurs almost every year with similar timing. Single cell analyses performed on freshly picked L. strobila during the rise and fall of the spring peak and targeting both predator and prey plastids will be important for understanding the grazing preferences of this mixotroph. Identification of appropriate prey will provide a starting point for further insights into ecology. Various combinations of potential prey in an experimental setting with Laboea strobila cultures may also prove useful in determining why this ciliate occurs as it does. Many of these experiments will be aided by the IFCB to provide real time and 
quick analysis of abundance, size, and taxonomy. IFCB-S can also be useful in laboratory situations where prey are fluorescently labeled and those ciliates expressing fluorescence are the responsible predators. Once these questions and further investigations into the ecology of these extraordinarily complex species have been performed, we can take another even more educated look back into the time series.

Further combinations of DNA sequencing and image-based morphology will be essential to understanding diversity that is largely underestimated. Single cell genetic analyses of small aloricated ciliates that are typically unidentified in IFCB images in combination with morphotype analysis will be essential to tapping into the identity and structure of this community that is relatively unknown. Once morphotypes are genetically verified, the development of qPCR primers will be key to tracking the temporal dynamics of these species.

This thesis presents developments in our ability to study varying aspects of ciliate dynamics including feeding modes, seasonality, and genetic diversity that range from engineering to observational ecology to molecular biology. Applying these developments to a time series in proper resolution and length, in particular, provides a starting point to understanding long term trends associated with environmental and climate change. 
Appendix 


\section{A.1 Appendix for Chapter 3}



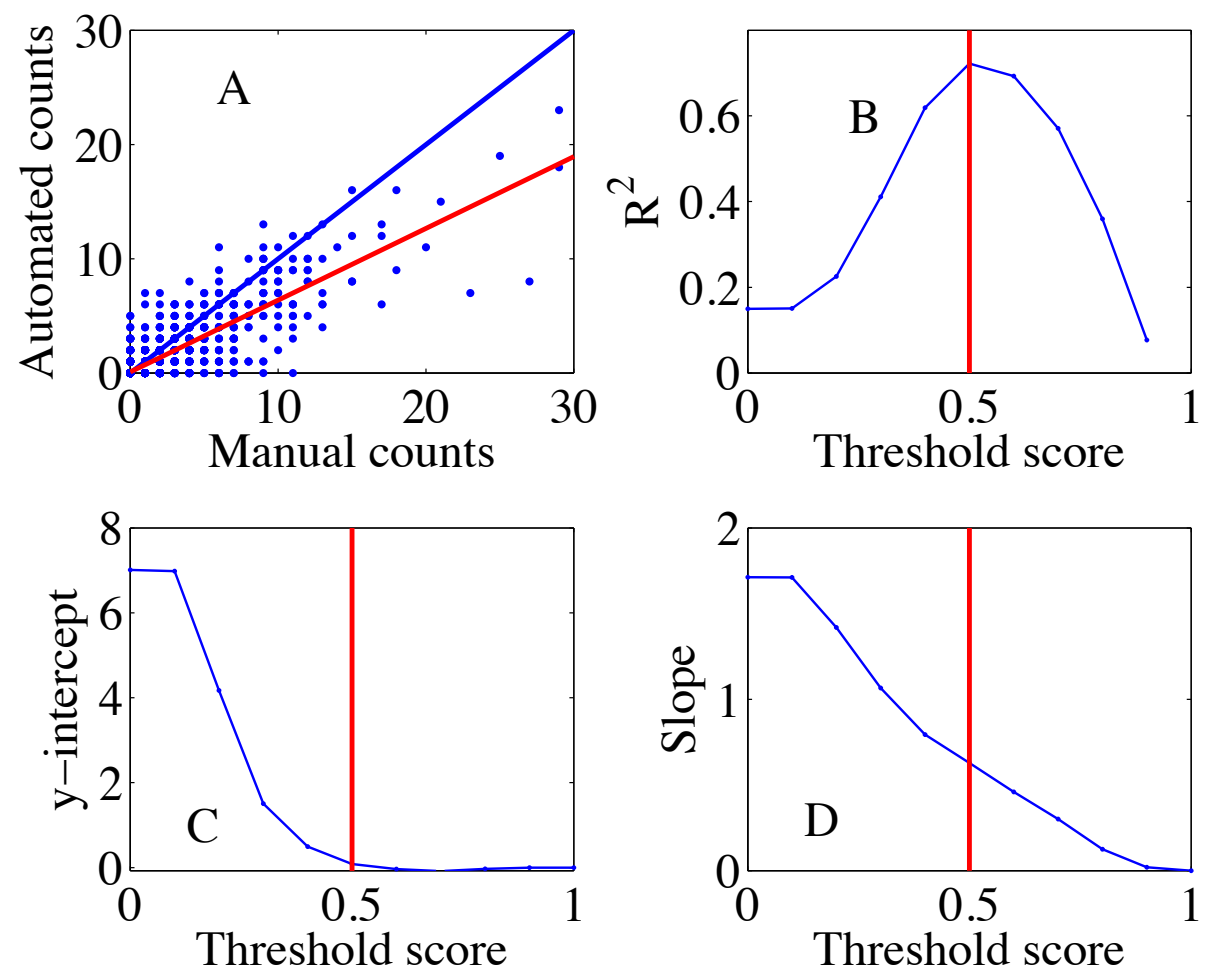

Figure A-1: (A) Regression between hourly bins of manually identified total tintinnid cell concentration at MVCO and automated classification results for score threshold 0.5. The blue line represents a 1:1 line and the red line is best fit; (B) $\mathrm{R}^{2}$ values for all thresholds tested; (C) y-intercept values of best fit line for all thresholds tested; (D) slope values of best fit line for all thresholds tested. Vertical red line in B-D indicates selected threshold score of 0.5 

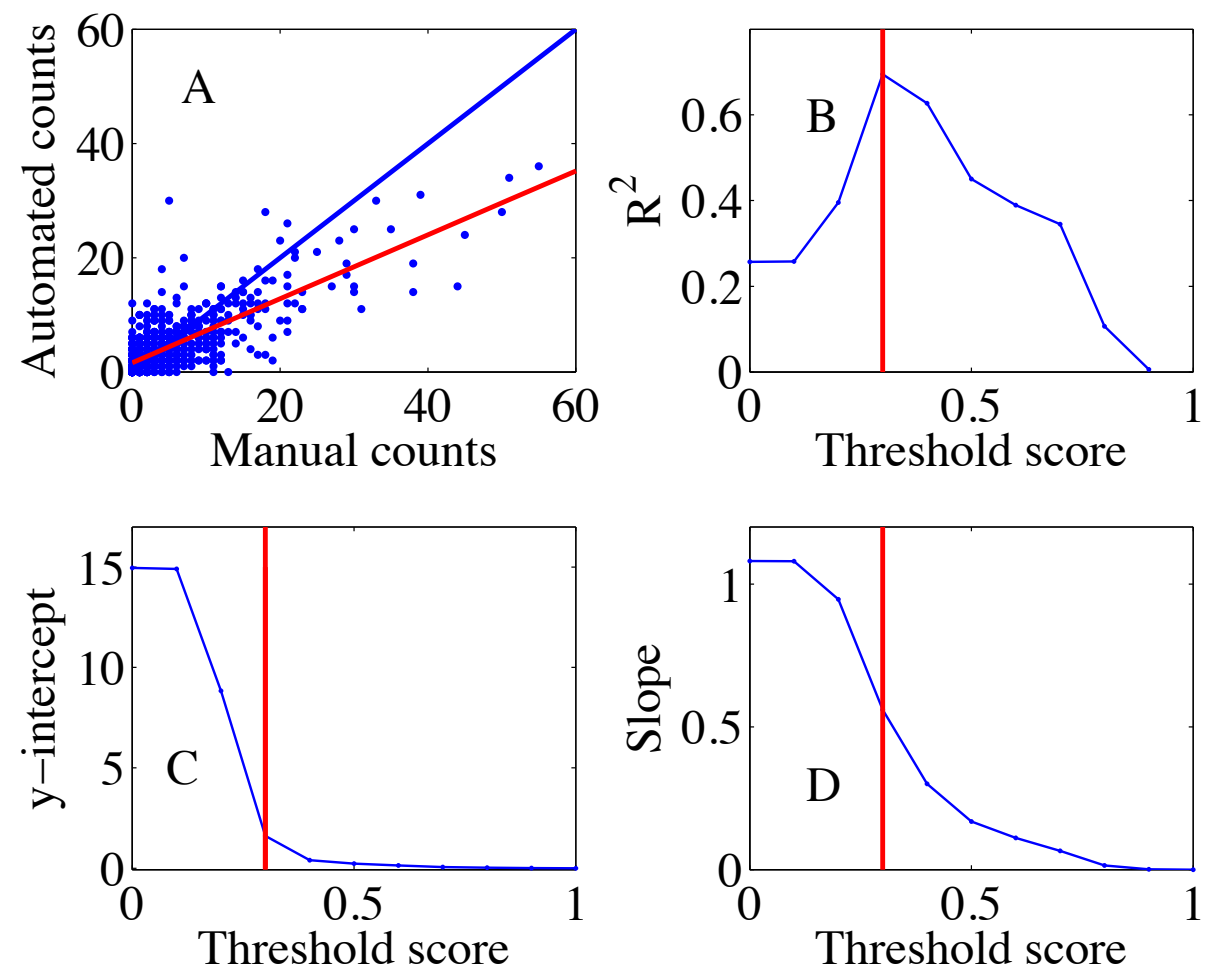

Figure A-2: (A) Regression between hourly bins of manually identified Mesodinium spp. cell concentration at MVCO and automated classification results for score threshold 0.3. The blue line represents a 1:1 line and the red line is best fit; (B) $R^{2}$ values for all thresholds tested; (C) y-intercept values of best fit line for all thresholds tested; (D) slope values of best fit line for all thresholds tested. Vertical red line in B-D indicates selected threshold score of 0.3 
Methods:

We computed residuals of the model by the following equation:

\section{Observed densities-Expected densities \\ $\sqrt{\text { Variance }}$}

Because the variance equals the mean in a Poisson distribution, the variance is the same as the expected density as calculated by the model. These residuals are interpreted as anomalies from the expected model densities.

Climatologies for environmental data were calculated computing the mean within the same time window for each year. Anomalies were then computed by subtracting each climatological value from the corresponding time bin. 

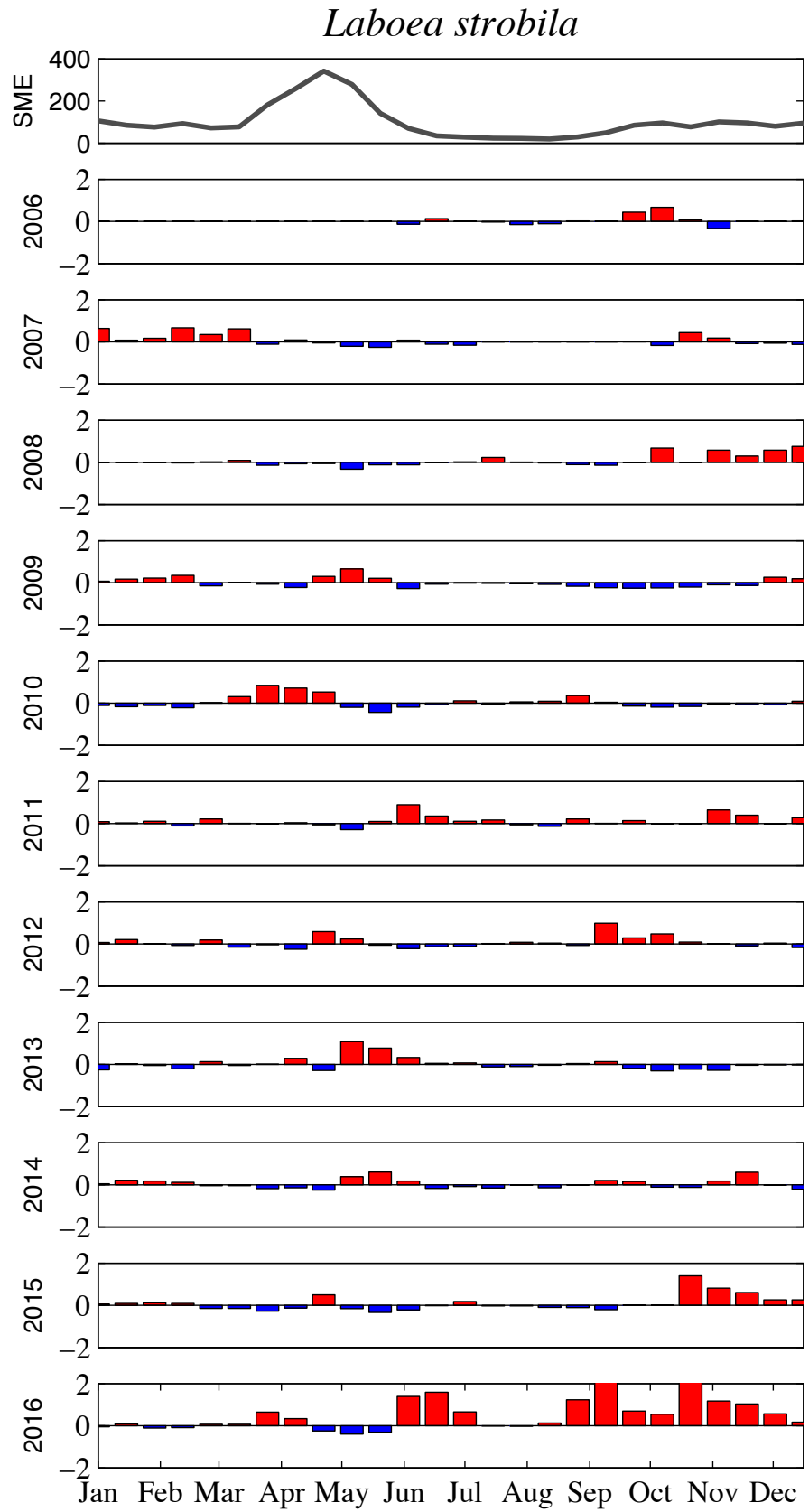

Figure A-3: Two-week resolved Laboea strobila anomalies by year. Expected seasonal cell concentrationst on top panel. 

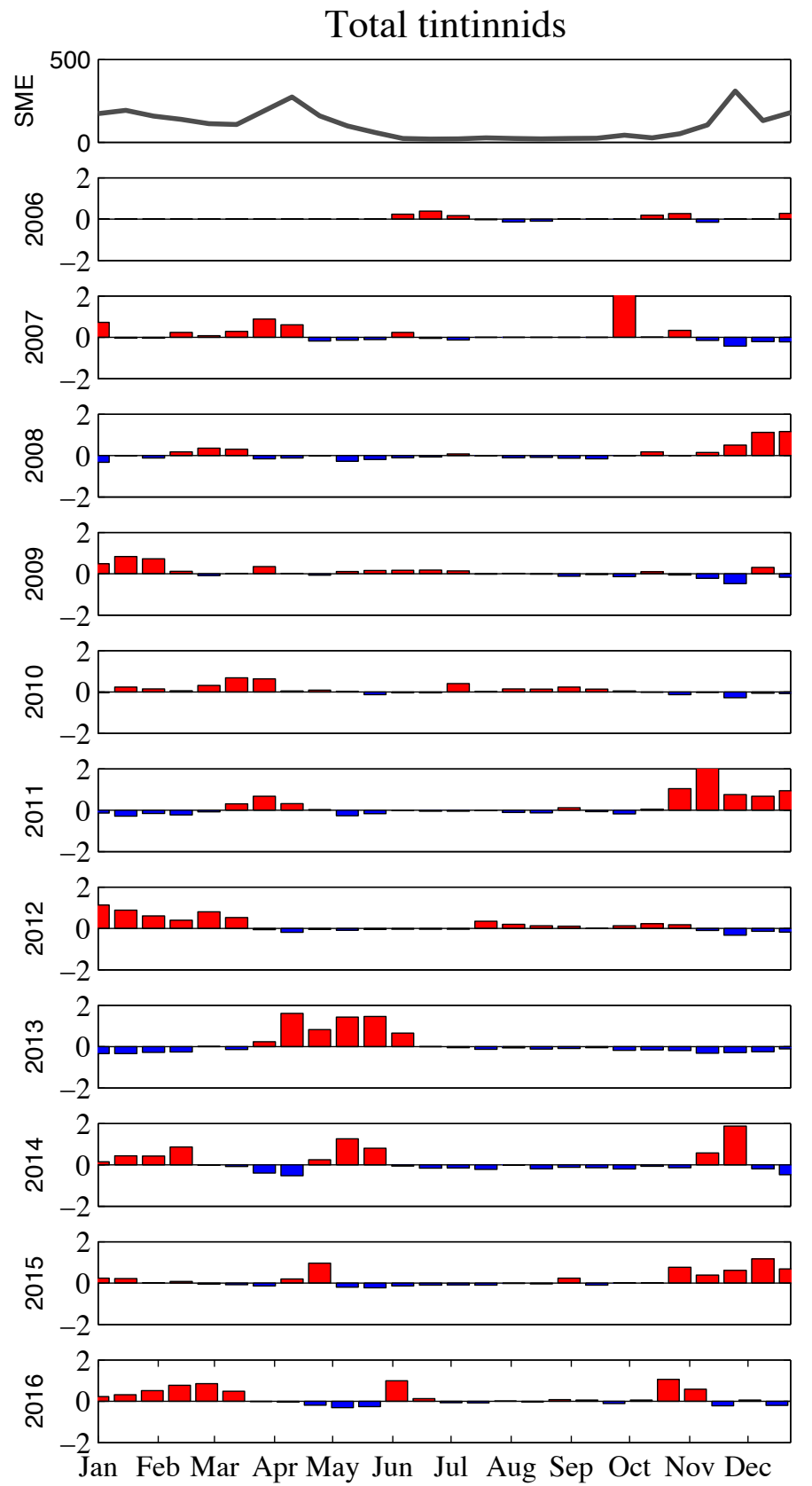

Figure A-4: Two-week -resolved total tintinnid anomalies by year. Expected seasonal cell concentrations on top panel. 


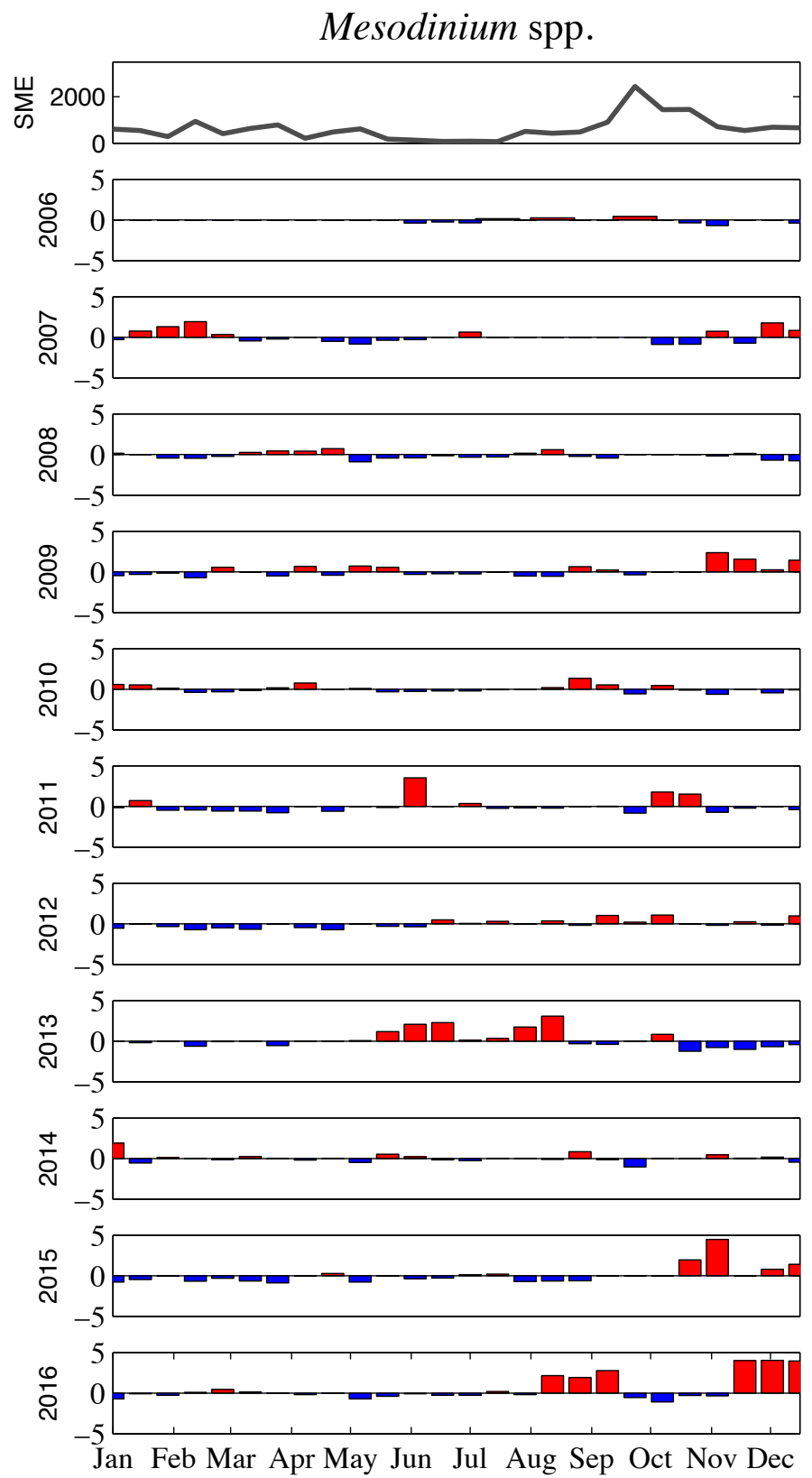

Figure A-5: Two-week resovled Mesodinium spp. anomalies by year. Expected seasonal cell concentrations on top panel. 

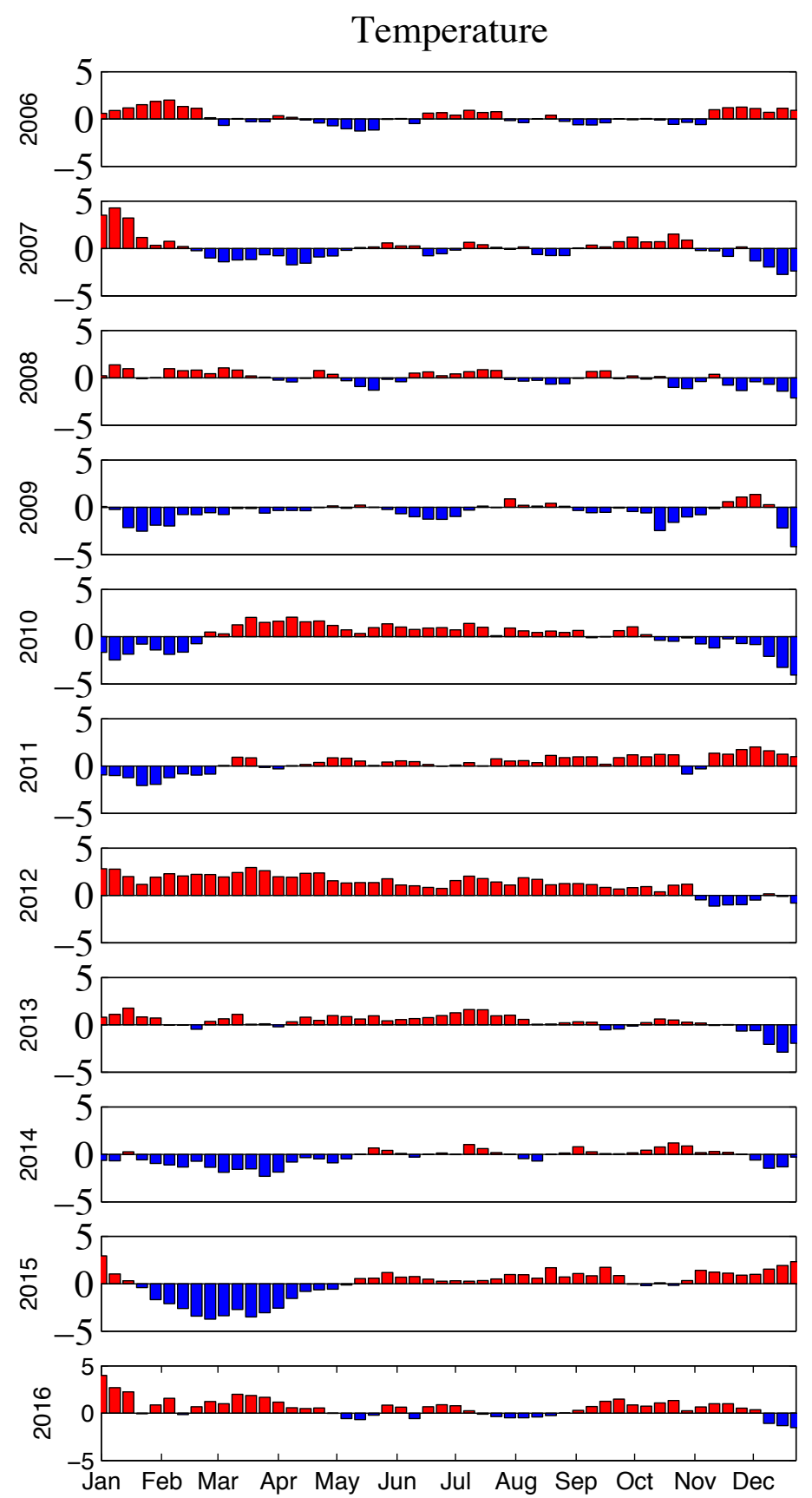

Figure A-6: Two-week resolved temperature anomalies by year. 
A.2 Appendix for Chapter 4 


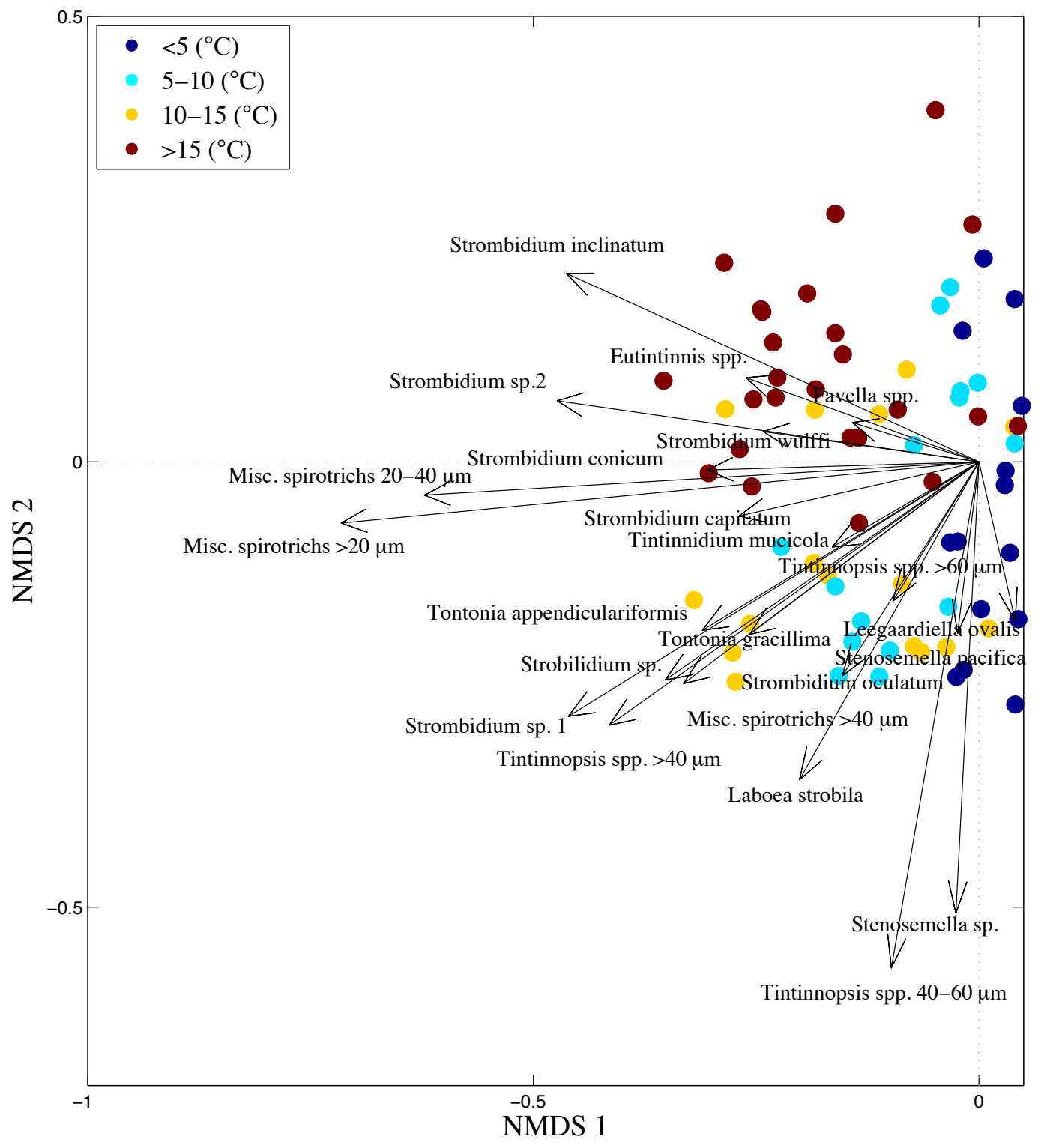

Figure A-7: Zoomed in non-metric multidimensional scaling based on Bray-Curtis similarity matrices of manually identified morphospecies. Samples are colored by temperature bin. Vectors plot the linear correlation of NMDS scores with morphospecies (vector length scaled by the strength of the correlation). This plot is a $2 \mathrm{D}$ visualization of the analysis performed in 3 dimensions. 


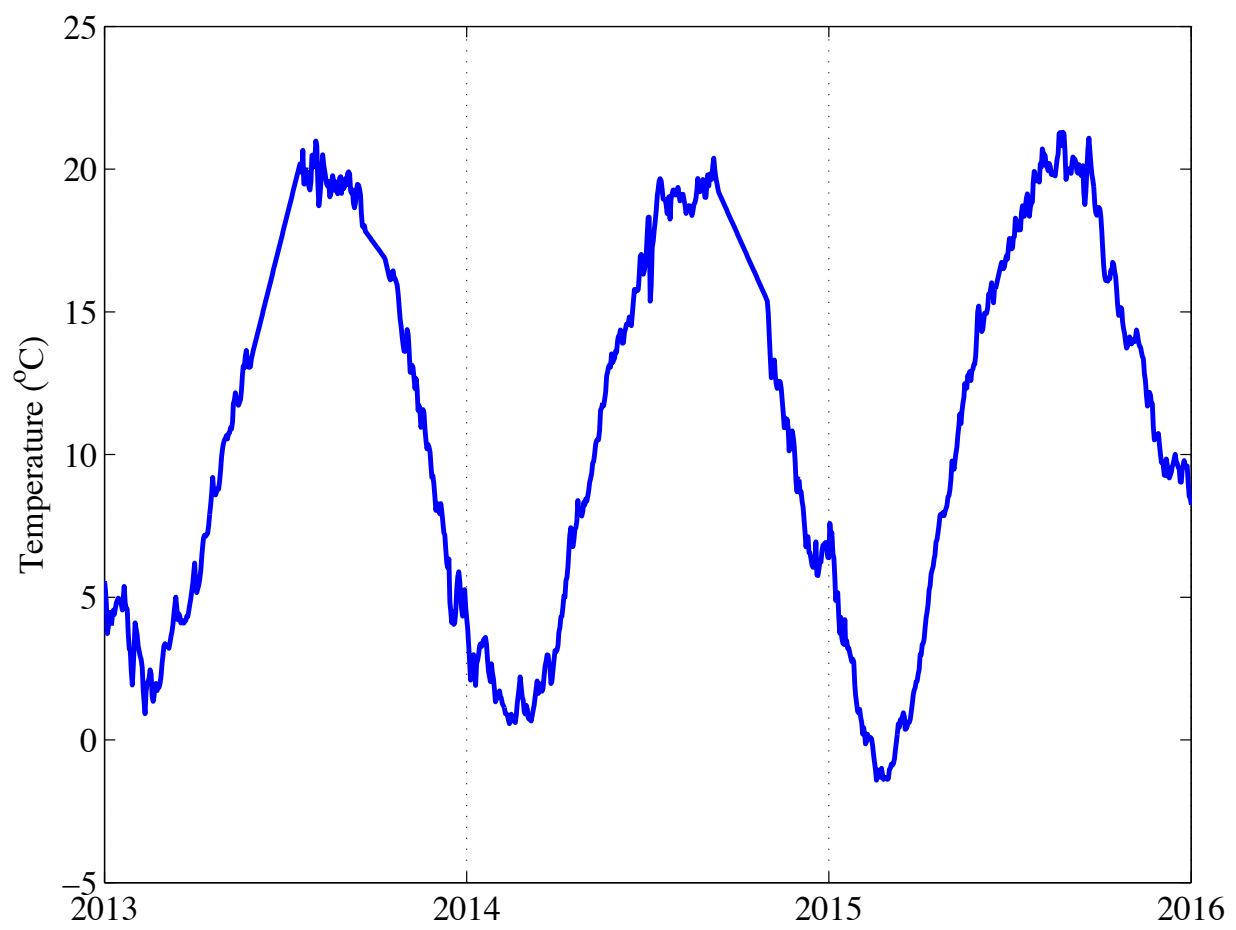

Figure A-8: Water temperature record from 2013-2016. 


\section{Bibliography}

Aberle, N., Lengfellner, K., \& Sommer, U. (2007). Spring bloom succession, grazing impact and herbivore selectivity of ciliate communities in response to winter warming. Oecologia, $150(4), 668-681$.

Admiraal, W. (1986). Significance of tintinnid grazing during blooms of Phaeocystis pouchetii (Haptophyceae) in Dutch coastal waters. Netherlands Journal of Sea Research, 20(1), 6166 .

Agatha, S. (2011). Global diversity of aloricate oligotrichea (Protista, Ciliophora, Spirotricha) in marine and brackish sea water. PLoS ONE, 6(8).

Agatha, S., \& Tsai, S.-F. (2008). Redescription of the tintinnid Stenosemella pacifica Kofoid and Campbell, 1929 (Ciliophora, Spirotricha) based on live observation, protargol impregnation, and scanning electron microscopy. The Journal of eukaryotic microbiology, $55(2), 75-85$.

Amaral-Zettler, L. A., McCliment, E. A., Ducklow, H. W., \& Huse, S. M. (2009). A method for studying protistan diversity using massively parallel sequencing of V9 hypervariable regions of small-subunit ribosomal RNA genes. PLOS ONE, 4(7), e6372.

Azam, F., Fenchel, T., Field, J. G., Gray, J. S., Meyer-Reil, L. A., \& Thingstad, F. (1983). The ecological role of water-column microbes in the sea. Marine Ecology Progress Series, 10, 257-263.

Bachy, C., Dolan, J. R., López-García, P., Deschamps, P., Moreira, D., Bachy, C., Dolan, J. R., Moreira, D., López-García, P., Deschamps, P., Moreira, D., Bachy, C., Dolan, J. R., \& Moreira, D. (2013). Accuracy of protist diversity assessments: morphology compared with cloning and direct pyrosequencing of $18 \mathrm{~S}$ rRNA genes and ITS regions using the conspicuous tintinnid ciliates as a case study. The ISME Journal, 7(2), 244-255.

Banas, N. S. (2011). Adding complex trophic interactions to a size-spectral plankton model: Emergent diversity patterns and limits on predictability. Ecological Modelling, 222(15), $2663-2675$.

Banse, K. (1962). Net zooplankton and total zooplankton. Rapports et Process-Verbaux Reunion de la Conseil International pour Exploration de la Mer, 153, 211-215.

Banse, K. (1982). Cell volumes, maximal growth rates of unicellular algae and ciliates, and the role of ciliates in the marine pelagial. Limnology and Oceanography, 27(6), 1059-1071.

Beers, J. R., \& Stewart, G. L. (1967). Micro-zooplankton in the euphotic zone at five locations across the California Current. Journal of Fisheries Research, 24, 2053-2068. 
Beers, J. R., \& Stewart, G. L. (1969). The Vertical Distribution of Microzooplankton and Some Ecological Observations. ICES Journal of Marine Science, 33(1), 30-44.

Bernard, C., \& Rassouladegan, F. (1994). Seasonal variations of mixotrophic ciliates in the northwest Mediterranean Sea. Marine Ecology Progress Series, 108(3), 295-302.

Bernard, C., \& Rassoulzadegan, F. (1990). Bacteria or microflagellates as a major food source for marine ciliates: possible implications for the microzooplankton. Marine Ecology Progress Series, 64, 147-155.

Bik, H. M., Porazinska, D. L., Creer, S., Caporaso, J. G., Knight, R., \& Thomas, W. K. (2012). Sequencing our way towards understanding global eukaryotic biodiversity. Trends in Ecology Evolution, 27(4), 233-243.

Bjørnsen, P. K., \& Kuparinen, J. (1991). Growth and herbivory by heterotrophic dinoflagellates in the Southern Ocean, studied by microcosm experiments. Marine Biology, 109 (3), 397-405.

Blackbourn, D. J., Taylor, F. J. R., \& Blackbourn, J. (1973). Foreign Organelle Retention by Ciliates. The Journal of Protozoology, 20(2), 286-288.

Bockstahler, K., \& Coats, D. (1993). Grazing of the mixotrophic dinoflagellate Gymnodinium sanguineum on ciliate populations of Chesapeake Bay. Marine Biology, 116, 477-487.

Boyd, V., Cholewa, O., \& Papas, K. (2008). Limitations in the use of fluorescein diacetate/propidium iodide (FDA/PI) and cell permeable nucleic acid stains for viability measurements of isolated islets of Langerhans. Current Trends in Biotechnology and Pharmacy, 2(2), 66-84.

Breiman, L. (2001). Random forests. Machine learning, 45, 5-32.

Brosnahan, M. L., Velo-Suarez, L., Ralston, D. K., Fox, S. E., Sehein, T. R., Shalapyonok, A., Sosik, H. M., Olson, R. J., \& M, A. D. (2015). Rapid growth and concerted sexual transitions by a bloom of the harmful dinoflagellate Alexandrium fundyense (Dinophyceae). Limnology and Oceanography, 60, 2059-2078.

Brownlee, E. F., Olson, R. J., \& Sosik, H. M. (2016). Microzooplankton community structure investigated with imaging flow cytometry and automated live-cell staining. Marine Ecology Progress Series, 550, 65-81.

Calbet, A., \& Landry, M. R. (2004). Phytoplankton growth, microzooplankton grazing, and carbon cycling in marine systems. Limnology and Oceanography, 49, 51-57.

Calbet, A., \& Saiz, E. (2013). Effects of trophic cascades in dilution grazing experiments: from artificial saturated feeding responses to positive slopes. Journal of Plankton Research, 35(6), 1183-1191.

Calbet, A., Saiz, E., Almeda, R., Movilla, J. I., \& Alcaraz, M. (2011). Low microzooplankton grazing rates in the Arctic Ocean during a Phaeocystis pouchetii bloom (Summer 2007): fact or artifact of the dilution technique? Journal of Plankton Research, 33(5), 687-701. 
Campbell, L., Olson, R. J., Sosik, H. M., Abraham, A., Henrichs, D. W., Hyatt, C. J., \& Buskey, E. J. (2010). First harmful Dinophysis (Dinophyceae, Dinophysiales) bloom in the U.S. is revealed by automated imaging flow cytometry. Journal of Phycology, 46(1), $66-75$.

Caporaso, J. G., Kuczynski, J., Stombaugh, J., Bittinger, K., Bushman, F. D., Costello, E. K., Fierer, N., Pena, A. G., Goodrich, J. K., Gordon, J. I., Huttley, G. A., Kelley, S. T., Knights, D., Koenig, J. E., Ley, R. E., Lozupone, C. A., McDonald, D., Muegge, B. D., Pirrung, M., Reeder, J., Sevinsky, J. R., Turnbaugh, P. J., Walters, W. A., Widmann, J., Yatsunenko, T., Zaneveld, J., \& Knight, R. (2010). QIIME allows analysis of highthroughput community sequencing data. Nature Methods, 7(5), 335-336.

Caron, D. A., Dennett, M. R., Lonsdale, D. J., Moran, D. M., \& Shalapyonok, L. (2000). Microzooplankton herbivory in the Ross Sea Antarctica. Deep Sea Research Part II: Topical Studies in Oceanography, 47, 3249-3272.

Caron, D. A., Lessard, E. J., Voytek, M., \& Dennett, M. (1993). Use of tritiated thymidine (Tdr) to estimate rates of bacterivory: implications of label retention and release by bacterivores. Marine Microbial Food Webs, 7(177-196).

Christaki, U., Dolan, J. R., Pelegri, S., \& Rassoulzadegan, F. (1998). Consumption of picoplankton-size particles by marine ciliates: Effects of physiological state of the ciliate and particle quality. Limnology and Oceanography, 43(3), 458-464.

Cloern, J. E., \& Jassby, A. D. (2010). Patterns and Scales of Phytoplankton Variability in Estuarine-Coastal Ecosystems. Estuaries and Coasts, 33(2), 230-241.

Crawford, D. W., \& Purdie, D. A. (1991). Evidence for avoidance of flushing from an estuary by a planktonic, phototrophic ciliate. Marine Ecology Progress Series, 79, 259-265.

Crawford, D. W., \& Stoecker, D. K. (1996). Carbon content, dark respiration and mortality of the mixotrophic planktonic ciliate Strombidium capitatum. Marine Biology, 126(3), 415-422.

Dale, T., \& Dahl, E. (1987). Mass occurrence of planktonic oligotrichous ciliates in a bay in southern Norway. Journal of Plankton Research, 9(5), 871-879.

de Vargas, C., Audic, S., Henry, N., Decelle, J., Mahé, F., Logares, R., Lara, E., Berney, C., Le Bescot, N., Probert, I., Carmichael, M., Poulain, J., Romac, S., Colin, S., Aury, J.-M., Bittner, L., Chaffron, S., Dunthorn, M., Engelen, S., Flegontova, O., Guidi, L., Horák, A., Jaillon, O., Lima-Mendez, G., Lukeš, J., Malviya, S., Morard, R., Mulot, M., Scalco, E., Siano, R., Vincent, F., Zingone, A., Dimier, C., Picheral, M., Searson, S., Kandels-Lewis, S., Acinas, S. G., Bork, P., Bowler, C., Gorsky, G., Grimsley, N., Hingamp, P., Iudicone, D., Not, F., Ogata, H., Pesant, S., Raes, J., Sieracki, M. E., Speich, S., Stemmann, L., Sunagawa, S., Weissenbach, J., Wincker, P., \& Karsenti, E. (2015). Eukaryotic plankton diversity in the sunlit ocean. Science, $348(6237)$.

Doherty, M., Costas, B. A., McManus, G. B., \& Katz, L. A. (2007). Culture-independent assessment of planktonic ciliate diversity in coastal northwest Atlantic waters. Aquatic Microbial Ecology, 48, 141-154. 
Dolan, J. R. (1991a). Guilds of ciliate microzooplankton in the Chesapeake Bay. Estuarine, Coastal and Shelf Science, 33(2), 137-152.

Dolan, J. R. (1991b). Microphagous ciliates in mesohaline Chesapeake Bay waters: Estimates of growth rates and consumption by copepods. Marine Biology, 111(2), 303-309.

Dolan, J. R. (2015). Planktonic protists: little bugs pose big problems for biodiversity assessments. Journal of Plankton Research.

Dolan, J. R., \& Coats, D. W. (1991). Preliminary prey digestion in a predacious estuarine ciliate and the use of digestion data to estimate ingestion. Limnology and Oceanography, $36(3), 558-565$.

Dolan, J. R., Gallegos, C. L., \& Moigis, A. (2000). Dilution effects on microzooplankton in dilution grazing experiments. Marine Ecology Progress Series, 200(2), 127-139.

Dolan, J. R., Landry, M. R., \& Ritchie, M. E. (2013). Species rich assemblages of tintinnids (marine planktonic protists) are structured by mouth size. ISME Journal, 7, 1237-1243.

Dolan, J. R., \& Marrasé, C. (1995). Planktonic ciliate distribution relative to a deep chlorophyll maximum: Catalan Sea, N.W. Mediterranean, June 1993. Deep-Sea Research Part I, 42(11-12), 1965-1987.

Dolan, J. R., Montagnes, D. J. S., Agatha, S., Coasts, D. W., \& Stoecker, D. K. (2012). The Biology and Ecology of Tintinnid Ciliates. Wiley-Blackwell.

Dorsey, J., Yentsch, C. M., Mayo, S., \& McKenna, C. (1989). Rapid analytical technique for the assessment of cell metabolic activity in marine microalgae. Cytometry, 10, 622-628.

Durand, M. D., \& Olson, R. J. (1996). Contributions of phytoplankton light scattering and cell concentration changes to diel variations in beam attenuation in the equatorial Pacific from flow cytometric measurements of pico-, ultra- and nanoplankton. Deep Sea Research Part II: Topical Studies in Oceanography, 43(4), 891-906.

Edwards, E. S., \& Burkill, P. H. (1995). Abundance, biomass and distribution of microzooplankton in the Irish Sea. Journal of Plankton Research, 17(4), 771-782.

Esteban, G. F., Fenchel, T., \& Finlay, B. J. (2010). Mixotrophy in Ciliates. Protist, $161(5)$, 621-641.

Evans, G. T., \& Parslow, J. S. (1985). A model of annual plankton cycles. Biological Oceanography, 3, 327-344.

Faure-Fremiet, E. (1908). Le Tintinnidium inquilinum. In Archiv fur Protistenkunde, (pp. 225-252 + Plate 12). 2 ed.

Fawley, M. W., Fawley, K. P., \& Buchheim, M. A. (2004). Molecular diversity among communities of freshwater microchlorophytes. Microbial ecology, 48(4), 489-99.

Finlay, B. J., \& Fenchel, T. (1996). Ecology: Role of ciliates in the natural environment. In K. Haussman, \& P. M. Bradbury (Eds.) Ciliates. Cells as organisms, (pp. 417-440). Stuttgart: Gustav-Fischer Verlag. 
Gaedke, U., \& Straile, D. (1994). Seasonal changes of trophic transfer efficiencies in a plankton food web derived from biomass size distributions and network analysis. Ecological Modelling, 75-76, 435-445.

Gaines, G., \& Elbrachter, M. (1987). Heterotrophic nutrition. In F. J. R. Taylor (Ed.) The biology of dinoflagellates, (pp. 224-268). Oxford.: Wiley-Blackwell.

Garcia-Cuetos, L., Moestrup, O., \& Hansen, P. J. (2012a). Studies on the genus mesodinium II. Ultrastructural and molecular investigations of five marine species help clarifying the taxonomy. Journal of Eukaryotic Microbiology, 59(4), 374-400.

Garcia-Cuetos, L., Moestrup, Ø., \& Hansen, P. J. (2012b). Studies on the genus Mesodinium II. Ultrastructural and molecular investigations of five marine species help clarifying the taxonomy. Journal of Eukaryotic Microbiology, 59(4), 374-400.

Gifford, D. (1985). Laboratory culture of marine planktonic oligotrichs (Ciliophora, Oligotrichida). Marine Ecology Progress Series, 23(1), 257-267.

Gimmler, A., Korn, R., de Vargas, C., Audic, S., \& Stoeck, T. (2016). The Tara Oceans voyage reveals global diversity and distribution patterns of marine planktonic ciliates. Scientific Reports, 6(September), 1-13.

Gonzalez, J. M., Sherr, E. B., \& Sherr, B. F. (1990). Size-selective grazing on bacteria by natural assemblages of estuarine flagellates and ciliates. Applied and Environmental Microbiology, 56(3), 583-589.

Grattepanche, J. D., Santoferrara, L. F., McManus, G. B., \& Katz, L. A. (2015). Distinct assemblage of planktonic ciliates dominates both photic and deep waters on the New England shelf. Marine Ecology Progress Series, 526, 1-9.

Grattepanche, J.-D., Santoferrara, L. F., McManus, G. B., \& Katz, L. A. (2016). Unexpected biodiversity of ciliates in marine samples from below the photic zone. Molecular Ecology, 25(16), 3987-4000.

Graziano, C. (1989). On the ecology of tintinnids (Ciliophora: Oligotrichida) in the north Irish Sea. Estuarine, Coastal and Shelf Science, 29(3), 233-245.

Gustafson, D. E., Stoecker, D. K., Johnson, M. D., Van Heukelem, W. F., \& Sneider, K. (2000). Cryptophyte algae are robbed of their organelles by the marine ciliate Mesodinium rubrum. Nature, 405(6790), 1049-1052.

Hansen, B., Bjornsen, P. K., \& Hansen, P. J. (1994). The size ratio between planktonic predators and their prey. Limnology and Oceanography, 39(2), 395-403.

Hansen, P. J. (1991). Quantitative importance and trophic role of heterotrophic dinoflagellates in a coastal pelagial food web. Marine Ecology Progress Series, 73(2-3), 253-261.

Hansen, P. J. (1992). Prey size selection, feeding rates and growth dynamics of heterotrophic dinoflagellates with special emphasis on Gyrodinium spirale. Marine Biology, 114, 327334 . 
Harvey, J. B. J., Johnson, S. B., Fisher, J. L., Peterson, W. T., \& Vrijenhoek, R. C. (2017). Comparison of morphological and next generation DNA sequencing methods for assessing zooplankton assemblages. Journal of Experimental Marine Biology and Ecology, 487, $113-126$.

Heinbokel, J. F., \& Beers, J. R. (1979). Studies on the functional role of tintinnids in the Southern California Bight. III. Grazing impact of natural assemblages. Marine Biology, 52, 23-32.

Herfort, L., Peterson, T., McCue, L., Crump, B., Prahl, F., Baptista, A., Campbell, V., Warnick, R., Selby, M., Roegner, G., \& Zuber, P. (2011). Myrionecta rubra population genetic diversity and its cryptophyte chloroplast specificity in recurrent red tides in the Columbia River estuary. Aquatic Microbial Ecology, 62(1), 85-97.

Hu, S., Campbell, V., Connell, P., Gellen, A. G., Liu, Z., Terrado, R., \& Caron, D. A. (2016). Protistan diversity and activity inferred from RNA and DNA at a coastal ocean site in the eastern North Pacific. FEMS Microbial Ecology, (213), 1-39.

Jacobson, D. (1987). The ecology and feeding behavior of thecate heterotrophic dinoflagellates. Ph.D. thesis, Massachusetts Institute of Technology/Woods Hole Oceanographic Institution.

Jeong, H. J., Seong, K. A., Yoo, Y. D., Kim, T. H., Kang, N. S., Kim, S., Park, J. Y., Kim, J. S., Kim, G. H., \& Song, J. Y. (2008). Feeding and grazing impact by small marine heterotrophic dinoflagellates on heterotrophic bacteria. Journal of Eukaryotic Microbiology, 55(4), 271-288.

Jochem, F. J. (1999). Dark survival strategies in marine phytoplankton assessed by cytometric measurement of metabolic activity with fluorescein diacetate. Marine Biology, 135, 721-728.

Johansson, M., Gorokhova, E., \& Larsson, U. (2004). Annual variability in ciliate community structure, potential prey and predators in the open northern Baltic Sea proper. Journal of Plankton Research, 26(1), 67-80.

Johnson, M. D. (2011). Acquired phototrophy in ciliates: a review of cellular interactions and structural adaptations. The Journal of Eukaryotic Microbiology, 58(3), 185-95.

Johnson, M. D., Beaudoin, D. J., Laza-Martinez, A., Dyhrman, S. T., Fensin, E., Lin, S., Merculief, A., Nagai, S., Pompeu, M., Setälä, O., \& Stoecker, D. K. (2016). The genetic diversity of Mesodinium and associated cryptophytes.

Johnson, M. D., Oldach, D., Delwiche, C. F., \& Stoecker, D. K. (2007). Retention of transcriptionally active cryptophyte nuclei by the ciliate Myrionecta rubra. Nature, 445(7126), $426-428$.

Jonsson, P. (1987). Particle size selection, feeding rates and growth dynamics of marine planktonic oligotrichous ciliates (Ciliophora: Oligotrichina). Marine Ecology Progress Series, 33, 265-277.

Kamiyama, T., \& Tsujino, M. (1996). Seasonal variation in the species composition of tintinnid cilates in Hiroshima Bay, the Seto Inland Sea of Japan. Journal of Plankton Research, 18(12), 2313-2327. 
Kane, J. (2011). Multiyear variability of phytoplankton abundance in the Gulf of Maine. ICES Journal of Marine Science: Journal du Conseil, 68(9), 1833-1841.

Katz, L. A., McManus, G. B., Snoeyenbos-West, O. L. O., Griffin, A., Pirog, K., Costas, B., \& Foissner, W. (2005). Reframing the 'Everything is everywhere' debate: evidence for high gene flow and diversity in ciliate morphospecies. Aquatic Microbial Ecology, 41, $55-65$.

Kifle, D., \& Purdie, D. A. (1993). The seasonal abundance of the phototrophic ciliate Mesodinium rubrum in Southampton Water, England. Journal of Plankton Research, $15(7), 823-833$.

Kivi, K., \& Setala, O. (1995). Simultaneous measurement of food particle selection and clearance rates of planktonic oligotrich ciliates (Ciliophora: Oligotrichina). Marine Ecology Progress Series, 119, 125-137.

Krishnamoorthy, K., \& Thomson, J. (2004). A more powerful test for comparing two Poisson means. Journal of Statistical Planning and Inference, 119, 23-35.

Landry, M. (1994). Methods and controls for measuring the grazing impact of planktonic protists. Marine Microbial Food Webs, 8(1-2), 37-57.

Landry, M. R., \& Hassett, R. P. (1982). Estimating the grazing impact of marine microzooplankton. Marine Biology, 67(3), 283-288.

Laval-Peuto, M., \& Rassoulzadegan, F. (1988). Autofluorescence of marine planktonic Oligotrichina and other ciliates. Hydrobiologia, 159(1), 99-110.

Lawrence, C., \& Menden-Deuer, S. (2012). Drivers of protistan grazing pressure: seasonal signals of plankton community composition and environmental conditions. Marine Ecology Progress Series, 459, 39-52.

Lessard, E. J., \& Swift, E. (1985). Species-specific grazing rates of heterotrophic dinoflagellates in oceanic waters, measure with a dual-label radioisotope technique. Marine Biology, 87, 289-296.

Li, Z., Yi, Z., Yang, J., Gong, J., Clamp, J. C., Al-Rasheid, K. A. S., Al-Arifi, S., AlKhedhairy, A. A., \& Song, W. (2009). Phylogenetic investigation on five genera of tintinnid ciliates (Ciliophora, Choreotrichia), based on the small subunit ribosomal RNA gene sequences. Progress in Natural Science, 19(9), 1097-1101.

Lindholm, T. (1978). Autumnal mass development of the "red water" ciliate Mesodinium rubrum in the Aland archipelago. Memoranda Soceity Fauna Flora Fennica, 54, 1-5.

Lynn, D. (2008). The ciliate protozoa. Characterization, classification, and guide to the literature. Dordrecht: Springer Verlag.

Macek, M., Šimek, K., \& Bittl, T. (2001). Conspicuous peak of oligotrichous ciliates following winter stratification in a bog lake. Journal of Plankton Research, 23(4), 353-363.

Marie, D., Rigaut-Jalabert, F., \& Vaulot, D. (2014). An improved protocol for flow cytometry analysis of phytoplankton cultures and natural samples. Cytometry Part A, 85(11), 962-968. 
Martinez, R. A., Isari, S., \& Calbet, A. (2014). Use of live, fluorescently-labeled algae for measuring microzooplankton grazing in natural communities. Journal of Experimental Marine Biology and Ecology, 457, 59-70.

Martinez-Garcia, M., Brazel, D., Poulton, N. J., Swan, B. K., Gomez, M. L., Masland, D., Sieracki, M. E., \& Stepanauskas, R. (2012). Unveiling in situ interactions between marine protists and bacteria through single cell sequencing. The ISME journal, 6(3), 703-7.

Massana, R., Gobet, A., Audic, S., Bass, D., Bittner, L., Boutte, C., Chambouvet, A., Christen, R., Claverie, J.-M., Decelle, J., Dolan, J. R., Dunthorn, M., Edvardsen, B., Forn, I., Forster, D., Guillou, L., Jaillon, O., Kooistra, W. H. C. F., Logares, R., Mahé, F., Not, F., Ogata, H., Pawlowski, J., Pernice, M. C., Probert, I., Romac, S., Richards, T., Santini, S., Shalchian-Tabrizi, K., Siano, R., Simon, N., Stoeck, T., Vaulot, D., Zingone, A., \& de Vargas, C. (2015). Marine protist diversity in European coastal waters and sediments as revealed by high-throughput sequencing. Environmental Microbiology, 17(10), 4035-4049.

McAlice, B. J. (1968). An occurrence of ciliate red water in the Gulf of Maine. Journal of the Fisheries Research Board of Canada, 25(8), 1749-1751.

McManus, G. B., \& Fuhrman, J. A. (1986). Photosynthetic pigments in the ciliate Laboea strobila from Long Island Sound, USA. Journal of Plankton Research, 8, 317-327.

Menden-Deuer, S., \& Lessard, E. J. (2000). Carbon to volume relationships for dinoflagellates, diatoms, and other protist plankton. Limnology and Oceanography, 45(3), 569-579.

Moberg, E. A., \& Sosik, H. M. (2012). Distance maps to estimate cell volume from twodimensional plankton images. Limnology and Oceanography: Methods, 10, 278-288.

Modigh, M. (2001). Seasonal variations of photosynthetic ciliates at a Mediterranean coastal site. Aquatic Microbial Ecology, 23, 163-175.

Moe, S. J., Dudley, B., \& Ptacnik, R. (2008). REBECCA databases: Experiences from compilation and analyses of monitoring data from 5,000 lakes in 20 European countries. Aquatic Ecology, 42(2), 183-201.

Monchy, S., Grattepanche, J. D., Breton, E., Meloni, D., Sanciu, G., Chabé, M., Delhaes, L., Viscogliosi, E., Sime-Ngando, T., \& Christaki, U. (2012). Microplanktonic community structure in a coastal system relative to a Phaeocystis bloom inferred from morphological and tag pyrosequencing methods. PLOS ONE, 7(6).

Montagnes, D. J. S. (1996). Growth responses of planktonic ciliates in the genera Strobilidium and Strombidium. Marine Ecology Progress Series, 130, 241-254.

Montagnes, D. J. S., Allen, J., Brown, L., Bulit, C., Davidson, R., Díaz-Ávalos, C., Fielding, S., Heath, M., Holliday, N. P., Rasmussen, J., Sanders, R., Waniek, J. J., \& Wilson, D. (2008). Factors Controlling the Abundance and Size Distribution of the Phototrophic Ciliate Myrionecta rubra in Open Waters of the North Atlantic. Journal of Eukaryotic Microbiology, 55(5), 457-465.

Montagnes, D. J. S., \& Lessard, E. J. (1999). Population dynamics of the marine planktonic ciliate Strombidinopsis multiauris: Its potential to control phytoplankton blooms. Aquatic Microbial Ecology, 20(2), 167-181. 
Montagnes, D. J. S., \& Lynn, D. H. (1989). The annual cycle of Mesodinium rubrum in the waters surrounding the Isles of Shoals, Gulf of Maine. Journal of Plankton Research, $11(2), 193-201$.

Montagnes, D. J. S., Lynn, D. H., Roff, J. C., \& Taylor, W. D. (1988). The annual cycle of heterotrophic planktonic ciliates in the waters surrounding the Isles of Shoals, Gulf of Maine: an assessment of their trophic role. Marine Biology, 99(1), 21-30.

Montagnes, D. J. S., Poulton, A. J., \& Shammon, T. M. (1999). Mesoscale, finescale and microscale distribution of micro- and nanoplankton in the Irish Sea, with emphasis on ciliates and their prey. Marine Biology, 134, 167-179.

Morales, E. A. (1976). Studies on the sizes, shapes and the development of the lorica of agglutininated Tintinnida. Biological Bulletin, 112, 377-392.

Neuer, S. (1992). Growth dynamics of marine Synechococcus spp.in the Gulf of Alaska. Marine Ecology Progress Series, 83, 251-262.

Neuer, S., \& Cowles, T. J. (1995). Comparative size-specific grazing rates in field populations of ciliates and dinoflagellates. Marine Ecology Progress Series, 125(1-3), 259-267.

Olli, K., Trikk, O., Klais, R., Ptacnik, R., Andersen, T., Lehtinen, S., \& Tamminen, T. (2013). Harmonizing large data sets reveals novel patterns in the Baltic Sea phytoplankton community structure. Marine Ecology Progress Series, 473, 53-66.

Olson, R. J., Chisholm, S. W., Zettler, E. R., \& Armbrust, E. V. (1990). Pigments, size, and distributions of Synechococcus in the North Atlantic and Pacific Oceans. Limnology and Oceanography, 35(1), 45-58.

Olson, R. J., Shalapyonok, A., \& Sosik, H. M. (2003). An automated submersible flow cytometer for analyzing pico- and nanophytoplankton: FlowCytobot. Deep Sea Research Part I: Oceanographic Research Papers, 50(2), 301-315.

Olson, R. J., \& Sosik, H. M. (2007). A submersible imaging-in-flow instrument to analyze nano- and microplankton : Imaging FlowCytobot. Limnology Oceanography: Methods, 5, 195-203.

Onji, M., Sawabe, T., \& Ezura, Y. (2000). An evaluation of viable staining dyes suitable for marine phytoplankton. Bulletin of the Faculty of Fisheries Hokkaido University, 51, $153-157$.

Paulson, J. N., Stine, O. C., Bravo, H. C., \& Pop, M. (2013). Differential abundance analysis for microbial marker-gene surveys. Nature methods, 10(12), 1200-2.

Pawlowski, J., Lejzerowicz, F., Apotheloz-Perret-Gentil, L., Visco, J., \& Esling, P. (2016). Protist metabarcoding and environmental biomonitoring: Time for change. European Journal of Protistology, 55, Part A, 12-25.

Peperzak, L., \& Brussaard, C. P. D. (2011). Flow cytometric applicability of fluorescent vitality probes on phytoplankton. Journal of Phycology, 47(3), 692-702.

Pierce, R., \& Turner, J. (1992). Ecology of planktonic ciliates in marine food webs. Reviews in Aquatic Science, 6, 139-181. 
Pierce, R. W., \& Turner, J. T. (1994). Plankton studies in Buzzards Bay, Massachusetts, USA. IV. Tintinnids, 1987 to 1988. Marine Ecology Progress Series, 112, 235-240.

Pomeroy, L. R. (1974). The ocean's food web, a changing paradigm. BioScience, 24(9), 499-504.

Porter, K. G. (1988). Phagotrophic phytoflagellates in microbial food webs. Hydrobiologia, $159(1), 89-97$.

Porter, T. M., \& Goldin, B. G. (2011). Are similarity- or phylogeny-based methods more appropriate for classifying internal transcribed spacer (ITS) metagenomic amplicons? New Phytologist, 192(3), 775-782.

Putt, M. (1990a). Abundance, chlorophyll content and photosynthetic rates of ciliates in the Nordic Seas during summer. Deep Sea Research Part A. Oceanographic Research Papers, $37(11), 1713-1731$.

Putt, M. (1990b). Metabolism of photosynthate in the chloroplast- retaining ciliate Laboea strobila. Marine Ecology Progress Series, 60, 271-282.

Quast, C., Pruesse, E., Yilmaz, P., Gerken, J., Schweer, T., Yarza, P., Peplies, J., \& Glöckner, F. O. (2013). The SILVA ribosomal RNA gene database project: improved data processing and web-based tools. Nucleic Acids Research, 41(Database issue), D590-D596.

Rassoulzadegan, F., Sheldon, R. W., \& Valrose, P. (1988). Partitioning of the food ration of marine ciliates between pico- and. $88,75-88$.

Rose, J. M., Caron, D. A., Sieracki, M. E., \& Poulton, N. (2004). Counting heterotrophic nanoplanktonic protists in cultures and aquatic communities by flow cytometry. Aquatic Microbial Ecology, 34, 263-277.

Rychert, K. (2004). The size structure of the Mesodinium rubrum population in the Gdańsk Basin. Oceanologia, 46(3).

Saito, H., Ota, T., Suzuki, K., Nishioka, J., \& Tsuda, A. (2006). Role of heterotrophic dinoflagellate Gyrodinium sp. in the fate of an iron induced diatom bloom. Geophysical Research Letters, 33, 6-9.

Sanders, R. W. (1995). Seasonal distributions of the photosynthesizing ciliates Laboea strobila and Myrionecta rubra (= Mesodinium rubrum) in an estuary of the Gulf of Maine. Aquatic Microbial Ecology, 9, 237-242.

Sanders, R. W., Porter, K. G., Bennett, S. J., \& Debiase, A. E. (1989). Seasonal patterns of bacterivory by flagellates, ciliates, rotifers, and cladocerans in a freshwater planktonic community. Limnology and Oceanography, 34(4), 673-687.

Santoferrara, L. F., Grattepanche, J. D., Katz, L. A., \& Mcmanus, G. B. (2014). Pyrosequencing for assessing diversity of eukaryotic microbes: Analysis of data on marine planktonic ciliates and comparison with traditional methods. Environmental Microbiology, 16(9), 2752-2763.

Santoferrara, L. F., Grattepanche, J.-D., Katz, L. A., \& McManus, G. B. (2016). Patterns and processes in microbial biogeography: do molecules and morphologies give the same answers? The ISME Journal, 10(7), 1779-1790. 
Santoferrara, L. F., McManus, G. B., \& Alder, V. A. (2012). Utility of genetic markers and morphology for species discrimination within the order Tintinnida (Ciliophora, Spirotrichea). Protist, in press, 13.

Santoferrara, L. F., Tian, M., Alder, V. A., \& McManus, G. B. (2015). Discrimination of closely related species in tintinnid ciliates: new insights on crypticity and polymorphism in the genus Helicostomella. Protist, 166(1), 78-92.

Schmoker, C., Hernández-León, S., \& Calbet, A. (2013). Microzooplankton grazing in the oceans: Impacts, data variability, knowledge gaps and future directions. Journal of Plankton Research, 35(4), 691-706.

Schmoker, C., Thor, P., Hernández-León, S., \& Hansen, B. (2011). Feeding, growth and metabolism of the marine heterotrophic dinoflagellate Gyrodinium dominans. Aquatic Microbial Ecology, 65, 65-73.

Sherr, B. F., Sherr, E. B., \& Rassoulzadegan, F. (1988). Rates of digestion of bacteria by marine phagotrophic protozoa: temperature dependence. Applied and Environmental Microbiology, 54 (5), 1091-1095.

Sherr, E. B., Rassoulzadegan, F., \& Sherr, B. F. (1989). Bacterivory by pelagic choreotrichous ciliates in coastal waters of the NW Mediterranean Sea. Marine Ecology Progress Series, 55, 235-240.

Sherr, E. B., \& Sherr, B. F. (1983). Double-staining epifluorescence technique to assess frequency of dividing cells and bacteriovory in natural populations of heterotrophic microprotozoa. Applied and Environmental Microbiology, 46(6), 1388-1393.

Sherr, E. B., \& Sherr, B. F. (1987). High rates of consumption of bacteria by pelagic ciliates. Nature, 325(6106), 710-711.

Sherr, E. B., \& Sherr, B. F. (1994). Bacterivory and herbivory: Key roles of phagotrophic protists in pelagic food webs. Microbial Ecology, 28(2), 223-235.

Sherr, E. B., \& Sherr, B. F. (2007). Heterotrophic dinoflagellates: A significant component of microzooplankton biomass and major grazers of diatoms in the sea. Marine Ecology Progress Series, 352, 187-197.

Sherr, E. B., Sherr, B. F., Fallon, R. D., \& Newell, S. Y. (1986). Small, aloricate ciliates as a major component of the marine heterotrophic nanoplankton. Limnology and Oceanography, 31(1), 177-183.

Sherr, E. B., Sherr, B. F., \& Hartz, A. J. (2009). Microzooplankton grazing impact in the Western Arctic Ocean. Deep Sea Research Part II: Topical Studies in Oceanography, $56(17), 1264-1273$.

Sieracki, M. E., Haas, L. W., Caron, D. A., \& Lessard, E. J. (1987). Effect of fixation on particle retention by microflagellates: underestimation of grazing rates. Marine Ecology Progress Series, 38, 251-258.

Smetacek, V. (1981). The annual cycle of protozooplankton in the Kiel Bight. Marine Biology, 63(1), 1-11. 
Smetacek, V., von Bodungen, B., Knoppers, B., Peinert, R., Pollehne, F., Stegmann, P., \& Zeitzshel, B. (1982). Seasonal stages characterizing the annual cycle of an inshore pelagic system. Reun. Cons. int. Explor. Mer., 183, 126-135.

Smith, W. O., \& Barber, R. T. (1979). A carbon budget for the autotrophic ciliate Mesodinium rubrum. Journal of Phycology, 15(1), 27-33.

Sosik, H. M., \& Futrelle, J. (2012). Informatics solutions for large ocean optics data sets. In Proceedings of Ocean Optics XXI, (pp. 1-7). Glasgow, Scotland. URL http://hdl .handle.net/1912/8011

Sosik, H. M., \& Olson, R. J. (2007). Automated taxonomic classification of phytoplankton sampled with imaging-in-flow cytometry. Oceanography: Methods, (pp. 204-216).

Sosik, H. M., Peacock, E. E., \& Brownlee, E. F. (2015). Annotated plankton images- data set for developing and evaluating classification methods.

URL http://darchive.mblwhoilibrary.org/handle/1912/7341

Stoeck, T., Behnke, A., Christen, R., Amaral-Zettler, L., Rodriguez-Mora, M. J., Chistoserdov, A., Orsi, W., \& Edgcomb, V. P. (2009). Massively parallel tag sequencing reveals the complexity of anaerobic marine protistan communities. BMC Biology, 7, 72.

Stoeck, T., Breiner, H.-W., Filker, S., Ostermaier, V., Kammerlander, B., \& Sonntag, B. (2014). A morphogenetic survey on ciliate plankton from a mountain lake pinpoints the necessity of lineage-specific barcode markers in microbial ecology. Environmental Microbiology, 16(2), 430-444.

Stoecker, D., Johnson, M., DeVargas, C., \& Not, F. (2009). Acquired phototrophy in aquatic protists. Aquatic Microbial Ecology, 57(3), 279-310.

Stoecker, D. K. (1998). Conceptual models of mixotrophy in planktonic protists and some ecological and evolutionary implications. European Journal of Protistology, 34(3), 281290.

Stoecker, D. K., \& Capuzzo, J. M. (1990). Predation on protozoa: Its importance to zooplankton. Journal of Plankton Research, 12(5), 891-908.

Stoecker, D. K., Gifford, D. J., \& Putt, M. (1994). Preservation of marine planktonic ciliates: Losses and cell shrinkage during fixation. Marine Ecology Progress Series, 110, 293-299.

Stoecker, D. K., \& Michaels, A. E. (1991). Respiration, photosynthesis and carbon metabolism in planktonic ciliates. Marine Biology, 108(3), 441-447.

Stoecker, D. K., Michaels, A. E., \& Davis, L. H. (1987). Large proportion of marine planktonic ciliates found to contain functional chloroplasts. Nature, 326, 790-792.

Stoecker, D. K., Silver, M. W., Michaels, A. E., \& Davis, L. H. (1988). Obligate mixotrophy in Laboea strobila, a ciliate which retains chloroplasts. Marine Biology, 99(3), 415-423.

Stoecker, D. K., Silver, M. W., Michaels, A. E., \& Davis, L. H. (1989a). Enslavement of algal chloroplasts by four Strombidium spp. (Ciliophora, Oligotrichida). Marine Microbial Food Webs, 3(2), 79-100. 
Stoecker, D. K., Taniguchi, A., \& Michaels, A. E. (1989b). Abundance of autotrophic, mixotrophic and heterotrophic planktonic ciliates in shelf and slope waters. Marine Ecology Progress Series, 50, 241-254.

Stoupin, D., Kiss, A. K., Arndt, H., Shatilovich, A. V., Gilichinsky, D. A., \& Nitsche, F. (2012). Cryptic diversity within the choanoflagellate morphospecies complex Codosiga botrytis - phylogeny and morphology of ancient and modern isolates. European Journal of Protistology, 48(4), 263-273.

Strom, S. L., Macri, E. L., \& Olson, M. B. (2007). Microzooplankton grazing in the coastal Gulf of Alaska: Variations in top-down control of phytoplankton. Limnology and Oceanography, 52, 1480-1494.

Strom, S. L., \& Morello, T. a. (1998). Comparative growth rates and yelds of ciliates and heterotrophic dinoflagellates. Journal of Plankton Research, 20(3), 571-584.

Takahashi, M. (1978). Winter condition of marine plankton populations in Saanich Inlet, B.C., Canada. II. Mico-zooplankton. Journal of Experimental Marine Biology and Ecology, 32, 27-37.

Tamigneaux, E., Mingelbier, M., Klein, B., \& Legendre, L. (1997). Grazing by protists and seasonal changes in the size structure of protozooplankton and phytoplankton in a temperate nearshore environment (western Gulf of St. Lawrence, Canada). Marine Ecology Progress Series, 146, 231-247.

Taylor, F. J. R., Blackbourn, D. J., \& Blackbourn, J. (1971). The red-water ciliate Mesodinium rubrum and its "incomplete symbionts": A review including new ultrastructural observations. Journal of the Fisheries Research Board of Canada, 28(3), 391-407.

Throndsen, J. (1978). Preservation and storage. In A. Sournia (Ed.) Phytoplankton manual, (pp. 69-74). Paris, France: UNESCO.

Urrutxurtu, I. (2004). Seasonal succession of tintinnids in the Nervión River estuary, Basque Country, Spain. Journal of Plankton Research, 26 (3), 307-314.

Verity, P. G. (1985). Grazing, respiration, excretion, and growth rates of tintinnids. Limnology and Oceanography, 30(6), 1268-1282.

Verity, P. G. (1987). Abundance, community composition, size distribution, and production rates of tintinnids in Narragansett Bay, Rhode Island. Estuarine, Coastal and Shelf Science, 24(5), 671-690.

Verity, P. G. (1991). Measurement and simulation of prey uptake by marine planktonic ciliates fed plastidic and aplastidic nanoplankton. Limnology and Oceanography, 36(4), $729-749$.

Weiner, A., Aurahs, R., Kurasawa, A., Kitazato, H., \& Kucera, M. (2012). Vertical niche partitioning between cryptic sibling species of a cosmopolitan marine planktonic protist. Molecular Ecology, 21(16), 4063-4073.

White, A. W., Sheath, R. G., \& Hellebust, J. A. (1977). A red tide caused by the marine ciliate Mesodinium rubrum in Passamaquoddy Bay, including pigment and ultrastructure 
studies of the endosymbiont. Journal of the Fisheries Research Board of Canada, 34(3), 413-416.

Wiackowski, K., Doniec, A., \& Fyda, J. (1994). an empirical study of the effect of fixation on ciliate cell volume. Marine Microbial Food Webs, (8), 59-69.

Wilkerson, F. P., \& Grunseich, G. (1990). Formation of blooms by the symbiotic ciliate Mesodinium rubrum: the significance of nitrogen uptake. Journal of Plankton Research, 12(5), 973-989.

Zinger, L., Gobet, A., \& Pommier, T. (2012). Two decades of describing the unseen majority of aquatic microbial diversity. Molecular Ecology, 21(8), 1878-1896. 